US Army Corps

of Engineers

Waterways Experiment

Station

\title{
Wave Response of Kahului Harbor, Maui, Hawaii
}

by Edward F. Thompson, Lori L. Hadley, Willie Ann Brandon, David D. McGehee, Jon M. Hubertz

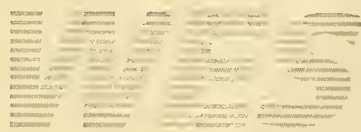

Approved For Public Release; Distribution Is Unlimited

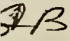

उ乙)

745

EERC-

$-11$

Prepared for U.S. Army Engineer Division, Pacific Ocean 
The contents of this report are not to be used for advertising, publication, or promotional purposes. Citation of trade names does not constitute an official endorsement or approval of the use of such commercial products. 


\section{Wave Response of Kahului Harbor, Maui, Hawaii}

by Edward F. Thompson, Lori L. Hadley, Willie Ann Brandon, David D. McGehee, Jon M. Hubertz

U.S. Army Corps of Engineers

Waterways Experiment Station

3909 Halls Ferry Road

Vicksburg, MS 39180-6199

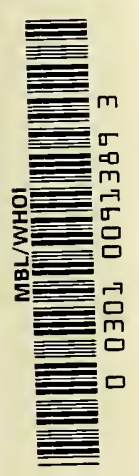

Final report

Approved for public release; distribution is unlimited 


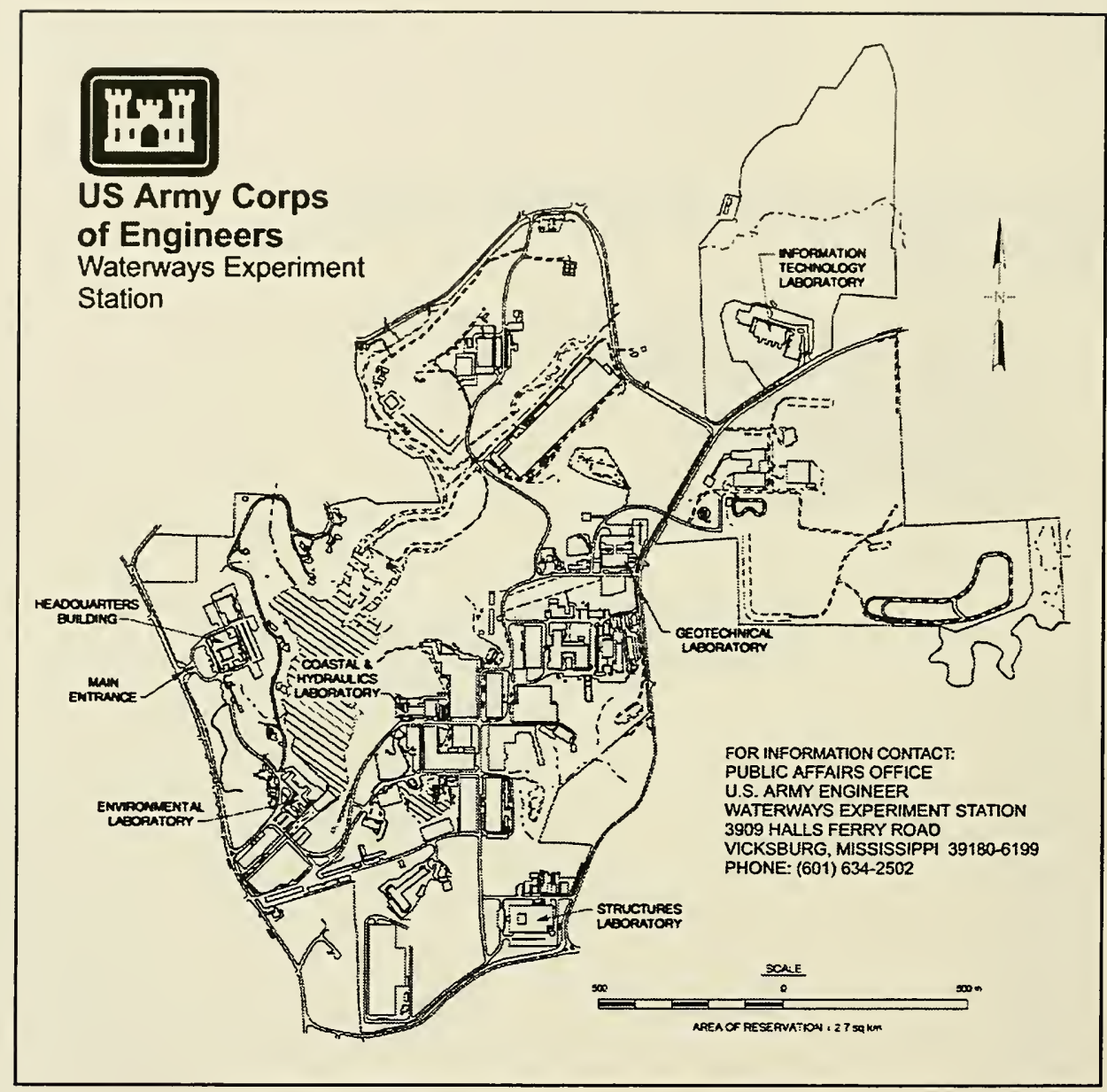

Waterways Experiment Station Cataloging-in-Publication Data

Wave response of Kahului Harbor, Maui, Hawaii / by Edward F.

Thompson ... [et al.] ; prepared for U.S. Army Engineer Division, Pacific Ocean.

224 p. : ill. ; $28 \mathrm{~cm}$. - (Technical report ; CERC-96-11)

Includes bibliographic references.

1. Ocean waves - Hawaii - Kahului. 2. Wind waves - Hawaii - Maui. 3. Harbors - Hydrodynamics - Mathematical models. 4. Harbors Hawaii - Maui. I. Thompson, Edward F. II. United States. Army. Corps of Engineers. Pacific Ocean Division. III. U.S. Army Engineer Waterways Experiment Station. IV. Coastal Engineening Research Center (U.S. Army Engineer Waterways Experiment Station) V. Series: Technical report (U.S. Army Engineer Waterways Experiment Station) ; CERC-96-11.

TA7 W34 no.CERC-96-11 


\section{Contents}

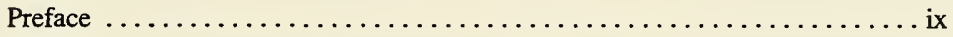

Conversion Factors, Non-SI to SI Units of Measurement $\ldots \ldots \ldots \ldots \ldots \ldots$ xi

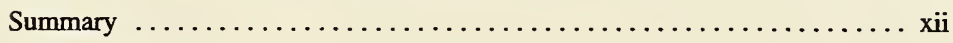

1 -Introduction $\ldots \ldots \ldots \ldots \ldots \ldots \ldots \ldots \ldots \ldots \ldots \ldots \ldots \ldots \ldots \ldots \ldots$

Background $\ldots \ldots \ldots \ldots \ldots \ldots \ldots \ldots \ldots \ldots \ldots \ldots \ldots \ldots, 1$

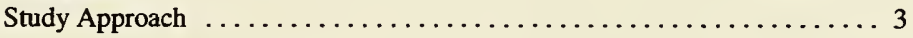

2-Field Wave Measurements $\ldots \ldots \ldots \ldots \ldots \ldots \ldots \ldots \ldots \ldots \ldots$

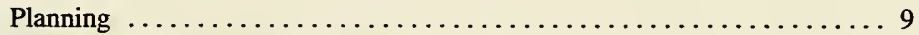

Instrument Type and Site Selection $\ldots \ldots \ldots \ldots \ldots \ldots \ldots \ldots \ldots$

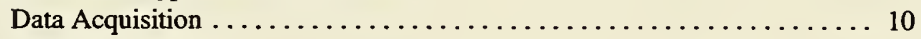

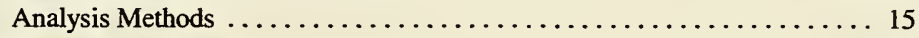

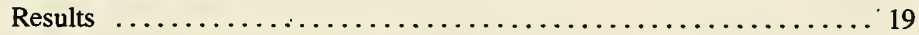

3-Wind Wave and Swell Climate $\ldots \ldots \ldots \ldots \ldots \ldots \ldots \ldots \ldots \ldots \ldots \ldots \ldots$

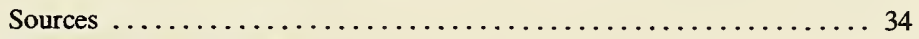

Deepwater Wave Climate ............................ 34

Wave Climate at Kahului Harbor ....................... 37

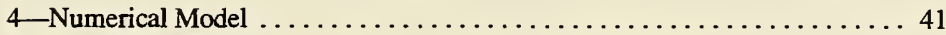

Objectives and Approach $\ldots \ldots \ldots \ldots \ldots \ldots \ldots \ldots \ldots \ldots \ldots \ldots, 41$

Model Description ............................... 42

Test Procedures and Calculations ....................... 61

5-Harbor Response to Wind Waves and Swell $\ldots \ldots \ldots \ldots \ldots \ldots \ldots \ldots$

Amplification Factors . . . . . . . . . . . . . . . . . . . . . . . 69

Evaluation Against Operational Criteria for Wind Waves and Swell .... 71 
6 -Harbor Oscillations $\ldots \ldots \ldots \ldots \ldots \ldots \ldots \ldots \ldots \ldots \ldots \ldots \ldots$

Amplification Factors $\ldots \ldots \ldots \ldots \ldots \ldots \ldots \ldots \ldots \ldots$

Evaluation Against Operational Criteria for Long Waves . . . . . . . 80

7 Conclusions and Recommendations $\ldots \ldots \ldots \ldots \ldots \ldots$

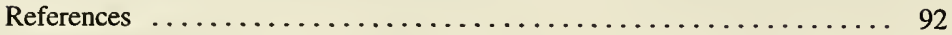

Appendix A: Field Data Summary $\ldots \ldots \ldots \ldots \ldots \ldots \ldots \ldots \ldots \ldots$ A1

Appendix B: Means and Standard Deviations of $A_{\text {amp.s }}$ from Field

Wave Gages ............................... B1

Appendix C: Summary Tables of Extreme Events of $H_{s}$ and $H_{\text {s.long }} \ldots \ldots . \mathrm{C} 1$

Appendix D: Wave Climate Summary $\ldots \ldots \ldots \ldots \ldots \ldots \ldots \ldots \ldots$ D1

Appendix E: Basin Locations for Alternative Plans . . . . . . . . . . E1

Appendix F: Wind Wave and Swell Summaries from Numerical Model ... F F1

Appendix G: Harbor Oscillation Summaries from Numerical Model . . . . G1

Appendix H: Resonant Amplification Factor and Phase Contour Plots,

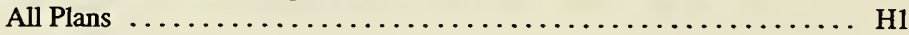

Appendix I: Notation $\ldots \ldots \ldots \ldots \ldots \ldots \ldots \ldots \ldots \ldots \ldots \ldots \ldots \ldots \ldots$

SF 298

\section{List of Figures}

Figure 1. Study location $\ldots \ldots \ldots \ldots \ldots \ldots \ldots \ldots \ldots \ldots \ldots \ldots \ldots$

Figure 2. Kahului Harbor, existing plan $\ldots \ldots \ldots \ldots \ldots \ldots \ldots \ldots \ldots$

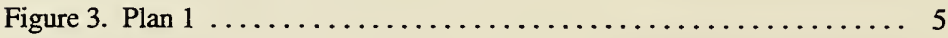

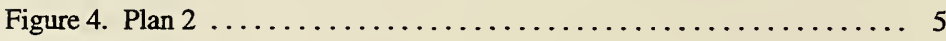

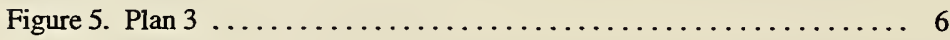

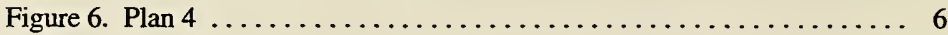

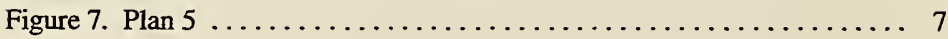




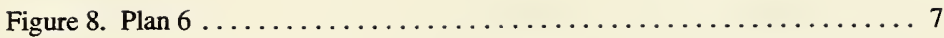

Figure 9. Plan $7 \ldots \ldots \ldots \ldots \ldots \ldots \ldots \ldots \ldots \ldots \ldots \ldots \ldots$

Figure 10. Field gage locations and bathymetry, in feet $\ldots \ldots \ldots \ldots \ldots \ldots$

Figure 11. Wave rose, NDBC buoy 51026, N. Molokai $\ldots \ldots \ldots \ldots \ldots$

Figure 12. Overview of extreme infragravity wave events; only events with $H_{\text {s, long }} \geq 15 \mathrm{~cm}$ are shown (from McGehee (1995)) . . . . . 14

Figure 13. Influence of spectral bandwidth on $T_{p}$, non-overlapping bands;

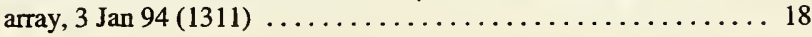

Figure 14. Influence of spectral bandwidth on $T_{p}$, overlapping bands (two-line offset); array, $3 \operatorname{Jan} 94$ (1311) . . . . . . . . . . . . 18

Figure 15. Time-history of $H_{s}$ and $\theta_{m}$ (deg, going toward); array, Jan $94 \ldots 20$

Figure 16. Time history of $H_{s, \text { long }}, H_{s}$, and $\left(T_{p}\right)_{\text {array }}$; harbor gages, Jan $94 \ldots 21$

Figure 17. Time-history of $A_{a m p, s}$ and $A_{a m p, l}$; harbor gages, Jan $94 \ldots \ldots 22$

Figure 18. Probability distribution of $\left(T_{p}\right)_{\text {array }}$; Nov 93-Sep 94,

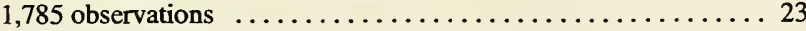

Figure 19. Probability distribution of $\left(\theta_{m}\right)_{\text {array }}$; Nov 93-Sep 94,

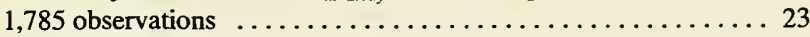

Figure 20. Average and maximum long wave spectra, Jan $94 \ldots \ldots \ldots 26$

Figure 21. Long wave spectra for event on $2 \operatorname{Jan} 94$ (2355) to 3 Jan 94

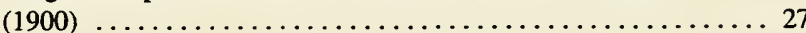

Figure 22. Time-history of amplification of specific resonant

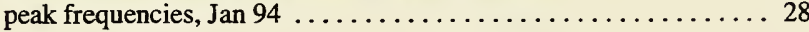

Figure 23. Probability distribution of $\left(H_{s, \text { long }}\right)_{\text {array }}$, Oct 93-Mar 95 (from Merrifield and Okihiro (1996)) ............... 28

Figure 24. Probability distribution of $\left(\theta_{m}\right)_{\text {buoy }}$, from NDBC buoy 51026 , N. Molokai, Oct 93-Mar 95 (from Merrifield and Okihiro (1996)) . 29

Figure 25. Scatter plot of $\left(H_{s, \text { long }}\right)_{\text {array }}$ versus $\left(H_{s}\right)_{\text {buoy }}$ (from Merrifield and Okihiro (1996))

Figure 26. Harbor closing event; array parameters $\ldots \ldots \ldots \ldots \ldots \ldots \ldots$

Figure 27. Harbor closing event; NDBC buoy wave parameters $\ldots \ldots \ldots \ldots 31$ 
Figure 29. Time-history of selected wave parameters, array and NDBC buoy, winter of 1993-4 (from Merrifield and Okihiro (1996)) . . . . . 33

Figure 30 . Location map for wave climate study $\ldots \ldots \ldots \ldots \ldots \ldots$

Figure 31. Deepwater wave climate comparison, $H_{s} \ldots \ldots \ldots \ldots \ldots$

Figure 32. Deepwater wave climate comparison, $T_{p} \ldots \ldots \ldots \ldots \ldots$

Figure 33. Deepwater wave climate comparison, $\theta_{m}$ (deg, coming from) $\ldots .37$

Figure 34. Harbor entrance wave climate comparison, $H_{s} \ldots \ldots \ldots \ldots$

Figure 35. Harbor entrance wave climate comparison, $T_{p} \ldots \ldots \ldots \ldots \ldots$

Figure 36. Harbor entrance wave climate comparison, $\theta_{m}$ (deg, coming from) . 40

Figure 37. Representation of HARBD domain $\ldots \ldots \ldots \ldots \ldots \ldots \ldots$

Figure 38. Grid of existing harbor $\ldots \ldots \ldots \ldots \ldots \ldots \ldots \ldots \ldots \ldots \ldots \ldots$

Figure 39. Bathymetry, existing harbor $\ldots \ldots \ldots \ldots \ldots \ldots \ldots \ldots \ldots$

Figure 40. Wave reflection coefficient values, short waves, existing harbor . . 55

Figure 41. Model short wave calibration to four storm events ........ 57

Figure 42. Model short wave validation to 11 months of gage data ....... 58

Figure 43. Model long wave calibration $\ldots \ldots \ldots \ldots \ldots \ldots \ldots \ldots \ldots$

Figure 44. Long wave comparison of average gage spectra and model ..... 60

Figure 45 . Incident wave directions $\ldots \ldots \ldots \ldots \ldots \ldots \ldots \ldots \ldots \ldots \ldots \ldots \ldots \ldots$

Figure 46. Output basins, existing harbor $\ldots \ldots \ldots \ldots \ldots \ldots \ldots \ldots$

Figure 47. Wilson's threshold of surge damage for moored ships (from Seabergh and Thomas (1995)) ................... 65

Figure 48. Example swell amplification factor contours, existing harbor $\ldots .70$

Figure 49. Comparison of $\left(A_{\text {amp }}\right)_{\text {eff }}$ averaged over periods of $10-20 \mathrm{sec}$ at piers, existing harbor and Plans $4 b, 6$, and 7 (see Figure 46 and

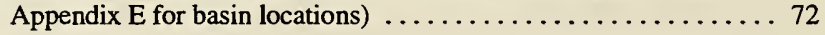

Figure 50. Comparison of $H_{s}$ exceeded 10 percent of the time at piers $\ldots \ldots 75$ 
Figure 51. Comparison of $H_{s}$ exceeded 1 percent of the time at piers $\ldots \ldots 76$

Figure 52. Harbor oscillation definitions $\ldots \ldots \ldots \ldots \ldots \ldots \ldots \ldots$

Figure 53. Long wave response, existing harbor, Piers $1-3 \ldots \ldots \ldots \ldots .79$

Figure 54. Resonant long wave amplification factor contours, existing

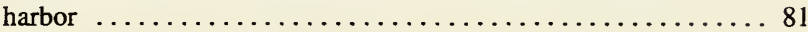

Figure 55. Resonant long wave phase contours, existing harbor $\ldots \ldots \ldots .82$

Figure 56. Long wave RMS amplification factor comparison at piers,

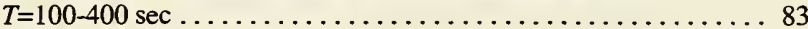

Figure 57. Percent occurrence of $H_{\text {s.long }} \geq 10 \mathrm{~cm}$ at piers, $T=100-400 \mathrm{sec} \ldots . .86$

Figure 58. Percent occurrence of $H_{\text {s,long }} \geq 10 \mathrm{~cm}$ at piers, $T=30-100 \mathrm{sec} \ldots \ldots 87$

\section{List of Tables}

Table 1. Field Wave Gages $\ldots \ldots \ldots \ldots \ldots \ldots \ldots \ldots \ldots \ldots \ldots \ldots \ldots$

Table 2. Summary Statistics, NDBC Buoy 51026, N. Molokai .......... 13

Table 3. Field Wave Parameters $\ldots \ldots \ldots \ldots \ldots \ldots \ldots \ldots \ldots \ldots \ldots \ldots \ldots \ldots \ldots \ldots$

Table 4. Effect of Overlapping Bands on $T_{p}$ Estimates, Array ......... 19

Table 5. Field Wave Gage Parameter Correlation Coefficients, Pier 2,

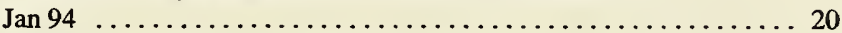

Table 6. Sources of Wave Climate Information $\ldots \ldots \ldots \ldots \ldots \ldots \ldots \ldots$

Table 7. Empirical Relationships Between Deepwater and

Kahului Harbor Entrance $\ldots \ldots \ldots \ldots \ldots \ldots \ldots \ldots \ldots \ldots$

Table 8. Critical HARBD Input Parameters and Ranges of Typical Values ... 47

Table 9. Guidance for Choosing $\gamma \ldots \ldots \ldots \ldots \ldots \ldots \ldots \ldots \ldots \ldots \ldots \ldots \ldots \ldots$

Table 10. Guidance for Choosing $s \ldots \ldots \ldots \ldots \ldots \ldots \ldots \ldots \ldots \ldots \ldots \ldots \ldots \ldots$

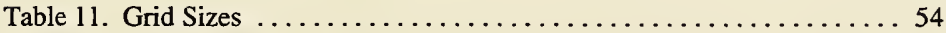

Table 12. Parameter Values Used in HARBD $\ldots \ldots \ldots \ldots \ldots \ldots \ldots \ldots \ldots$

Table 13. Harbor Alternatives for Numerical Modeling $\ldots \ldots \ldots \ldots \ldots$ 
Table 14. Field Cases for Short Wave Model Calibration, Array ....... 57

Table 15. Summary of Incident Short Wave Conditions $\ldots \ldots \ldots \ldots \ldots$...... 61

Table 16. Summary of Incident Long Wave Conditions $\ldots \ldots \ldots \ldots 2$

Table 17. Approximate Relationships Among $T_{p}, \gamma$, and $s \ldots \ldots \ldots \ldots 63$

Table 18. Slope Values Defined by Seabergh and Thomas' (1995) Long Wave Criteria $\ldots \ldots \ldots \ldots \ldots \ldots \ldots \ldots \ldots \ldots \ldots \ldots$

Table 19. Significant Wave Heights Exceeded 10 Percent and 1 Percent of the Time at Field Gages $\ldots \ldots \ldots \ldots \ldots \ldots \ldots \ldots \ldots \ldots$

Table 20. Percent Occurrence of $H_{\text {s,long }} \geq 10 \mathrm{~cm}$ at Field Gages $\ldots \ldots \ldots .84$

Table 21. Plans with $H_{s}>1 \mathrm{ft}$ Less Than 1 Percent of the Time $\ldots \ldots \ldots \ldots 90$

Table 22. Plans with $H_{\text {s.long }} \geq 10 \mathrm{~cm}$ Less Than 16 Percent of the Time, 100 - to 400 -sec Periods $\ldots \ldots \ldots \ldots \ldots \ldots \ldots \ldots \ldots \ldots \ldots$

Table 23. Plans with $H_{\text {s,long }} \geq 10 \mathrm{~cm}$ Less Than 7 Percent of the Time,

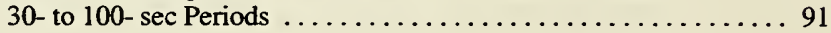




\section{Preface}

A request for field measurement and model investigations of Kahului Harbor, Maui, HI, was initiated by the U.S. Army Engineer Division, Pacific Ocean (POD), in coordination with the Harbors Division, Department of Transportation, State of Hawaii (HDOT). Authorization for the U.S. Army Engineer Waterways Experiment Station (WES), Coastal Engineering Research Center (CERC), to perform the study was subsequently granted by Headquarters, U.S. Army Corps of Engineers. Field measurements were collected during the period September 1993 through March 1995 and numerical model tests were conducted at WES from September 1994 to April 1996. The physical modeling component of the investigation, which is generally used to determine the final recommended design of harbor modifications, was postponed because of budget limitations.

Messrs. Stanley Boc, POD, and Fred Nunes, HDOT, oversaw progress of the study. Meetings at WES at critical points in the study were the mid-study model review conference on 11-12 July 1995 and the wrap-up conference on 28-29 February 1996.

Mr. Dennis G. Markle, Chief, Wave Processes Branch, Wave Dynamics Division, was the principal WES point of contact for the study. Mr. David D. McGehee, Prototype Measurement and Analysis Branch, Engineering Development Division, was responsible for the field measurement program. Ms. Willie Ann Brandon and Dr. Jon M. Hubertz, both of the Coastal Oceanography Branch (COB), Research Division (RD), CERC, conducted the wave climate analysis portion of the study. Dr. Edward F. Thompson and Ms. Lori L. Hadley, both of $\mathrm{COB}$, performed some additional analysis of the field data, conducted the numerical harbor modeling, and assembled this report. Ms. Rebecca L. Russell, $\mathrm{COB}$, assisted with data processing and analysis. Direct supervision was provided by Mr. Markle and Dr. Martin C. Miller, Chief, COB. General supervision was provided by Mr. H. Lee Butler, Chief, RD; Mr. Charles C. Calhoun, Jr., Assistant Director, CERC; and Dr. James R. Houston, Director, CERC.

Special appreciation is extended to Ms. Juliana Thomas and Messrs. David Castel and Joseph Keefe, Center for Coastal Studies, Scripps Institution of Oceanography, for not only providing field wave parameters and spectra but also modifying the methodology for calculating peak wave period to provide more accurate swell estimates. Drs. Mark A. Merrifield and Michele S. Okihiro, 
Department of Ocean Engineering, University of Hawaii at Manoa, investigated the correlation between deep ocean wave buoy measurements and long wave energy incident to Kahului Harbor. Ms. Jennifer Chen, HDOT, provided assistance with harbor plan graphics.

At the time of publication of this report, Dr. Robert W. Whalin was Director of WES. COL Bruce K. Howard, EN, was Commander. 


\section{Conversion Factors, Non-SI to SI Units of Measurement}

Non-SI units of measurement can be converted to SI (metric) units as follows:

\begin{tabular}{||l|l|l|}
\hline Multiply & By & To Obtain \\
\hline \hline degrees (angle) & 0.01745329 & radians \\
\hline feet & 0.3048 & meters \\
\hline miles (U.S. nautical) & 1.852 & kilometers \\
\hline tons (2,000 pounds, mass) & 907.1847 & kilograms \\
\hline
\end{tabular}




\section{Summary}

\section{Introduction}

Because of present and projected commercial activities in Kahului Harbor, the needs and concerns of community, private business, and government have been reviewed under the state of Hawaii planning process. New berths for barge and passenger ship operations are an expected future requirement. Space for related land-based facilities is needed. Deepening of main harbor areas from $35 \mathrm{ft}$ to 38 $\mathrm{ft}$ is also anticipated.

The new facilities would require expansion of harbor operations into areas not presently used, particularly the western part of the harbor. Field wave measurements and numerical (computer) model studies to evaluate the technical feasibility of alternative modifications were conducted from September 1993 to May 1996 by the U.S. Army Corps of Engineers at the U.S. Army Engineer Waterways Experiment Station, Coastal Engineering Research Center, Vicksburg, MS. Eleven alternative harbor plans were studied along with the existing harbor (see table that follows).

\section{Study Results}

\section{Harbor basin}

Wind waves and swell in the harbor are affected by distance from the entrance, directional exposure, and bottom depths. Wave approach directions at the entrance are consistently aimed at the southwest part of the harbor. Facilities in the western harbor and located closer to the entrance (as the extension of Pier 1) are prone to increased wind wave and swell conditions. A stub added to the west breakwater tip in some plans shelters the western harbor from wind waves and swell. Changes in the western harbor have no significant impact on wind waves and swell at existing facilities in the eastern harbor. 


\begin{tabular}{|c|c|c|c|c|c|}
\hline \multicolumn{6}{|c|}{ Summary of Kahului Harbor Plans and Wave Response } \\
\hline $\begin{array}{l}\text { Harbor } \\
\text { Plan }\end{array}$ & Distinctive Features & $\begin{array}{l}\text { Wind Waves } \\
\text { and Swell }\end{array}$ & $\begin{array}{l}\text { Surge } \\
\text { Oscillations }\end{array}$ & Remarks & $\begin{array}{l}\text { See } \\
\text { Figure }\end{array}$ \\
\hline 1 & $\begin{array}{l}\text { Slip cut in coral stockpile; } \\
\text { Concept C for barge pier }\end{array}$ & 2 & 3 & $\begin{array}{l}\text { Large oscillations at } \\
\text { passenger pier }\end{array}$ & 3 \\
\hline 2 & $\begin{array}{l}\text { Slip cut in coral stockpile; } \\
\text { Concept } 12 \text { for barge pier }\end{array}$ & 2 & 3 & $\begin{array}{l}\text { Large oscillations at } \\
\text { passenger pier }\end{array}$ & 4 \\
\hline $3 a$ & $\begin{array}{l}\text { Notch cut in coral stockpile; } \\
\text { No breakwater stub }\end{array}$ & 2 & 2 & & 5 \\
\hline $3 b$ & $\begin{array}{l}\text { Notch cut in coral stockpile; } \\
600 \text {-ft breakwater stub }\end{array}$ & 1 & 1 & & 5 \\
\hline $3 c$ & $\begin{array}{l}\text { Notch cut in coral stockpile; } \\
1,000 \text {-ft breakwater stub }\end{array}$ & 1 & 1 & & 5 \\
\hline $4 a$ & $\begin{array}{l}\text { Adjacent to coral stockpile; } \\
\text { No breakwater stub }\end{array}$ & 3 & 1 & High wind waves and swell & 6 \\
\hline $4 b$ & $\begin{array}{l}\text { Adjacent to coral stockpile; } \\
600 \text {-ft breakwater stub }\end{array}$ & 2 & 1 & & 6 \\
\hline $4 c$ & $\begin{array}{l}\text { Adjacent to coral stockpile; } \\
1,000 \text {-ft breakwater stub }\end{array}$ & 1 & 1 & & 6 \\
\hline 5 & Fill area in SW harbor & 2 & 2 & $\begin{array}{l}\text { Large oscillations at barge } \\
\text { and passenger piers }\end{array}$ & 7 \\
\hline 6 & Same as $4 \mathrm{~b}$ but with $38-\mathrm{ft}$ depth & 2 & 1 & & 8 \\
\hline 7 & $\begin{array}{l}\text { Fully utilized harbor } \\
\text { (combination of } 4 \mathrm{~b} \text { and } 5 \text { ) }\end{array}$ & 2 & 2 & $\begin{array}{l}\text { Large oscillations at barge } \\
\text { and passenger piers }\end{array}$ & 9 \\
\hline \multicolumn{6}{|c|}{$\begin{aligned} \text { 'General indicator of plan performance: } 1 & =\text { equal or better than existing facilities } \\
2 & =\text { somewhat worse than existing facilities } \\
3 & =\text { much worse than existing facilities }\end{aligned}$} \\
\hline
\end{tabular}

All of the proposed harbor plans have comparable or increased surge (or oscillation) activity relative to the existing harbor. The dredged access areas, straight piers, and corners added in the alternative plans tend to increase surge motions. Changes in the western harbor can potentially worsen surge conditions at the existing commercial piers.

\section{Ship surge response}

Kahului Harbor experiences natural resonance modes, which cause standing waves in the harbor. These waves are commonly present in the harbor, but their height varies considerably according to incident wave conditions. High standing waves can cause operational difficulties such as excessive ship motion and high mooring line forces. Areas of greatest horizontal motion (nodal areas) are most likely to experience problems. Possible actions to remedy effects of the surge include proper ballasting as ships are offloaded, adjustment to mooring line tensions, and modifications to mooring line configuration. 


\section{Piers 1-3}

Wind wave and swell activity at existing Piers 1-3 is not appreciably changed in any of the alternative plans. The proposed Pier l extension will experience an increase in wave heights with closer proximity to the entrance. Surge level is increased in some plans. A nodal area between the seaward end of Pier 2 and the middle of Pier 1 is visible in all plans, including the existing harbor. The Pier 1 extension will likely be in the nodal area for the 176- to 178 -sec resonant oscillation.

\section{Barge facility}

Wind waves and swell at the recommended Concept 12 configuration along the southwest side of Pier 2 are similar to the more seaward parts of existing Piers 1 and 2. Surge activity is substantially lower than at existing facilities except in plans which include a landfill in the southwest harbor.

\section{Passenger ship pier}

Wind wave and swell protection varies greatly between plans, ranging from better than any existing facilities to much worse. Surge activity is similar to or higher than the present Pier 1.

\section{Boat ramp}

Most plans have the added benefit of helping to shelter the boat ramp from wind waves and swell. Overall surge levels are generally similar to the existing harbor except in Plan 5.

\section{Model performance}

The final numerical model behaved realistically when compared to field observations at Kahului Harbor. There is a high level of confidence in the predictions made by the model, especially those involving comparisons between harbor alternatives.

\section{Limitations}

No instances of operational problems inside the harbor were reported during the measurement studies, although they are known to have occurred in the past. (One episode of hazardous waves at the entrance, resulting in harbor closing, was recorded.) Such events would have been very helpful in identifying more clearly the processes and threshold wave heights which deter specific operations in the harbor. They would also have aided the evaluation of alternative plans. There are inherent limits on the numerical model representations of the harbor response. Wave climate information used to evaluate each plan was based mainly on 11 months of field data. Ship and mooring system responses, the ultimate operational concern, were not explicitly studied. 


\section{Recommendations}

Recommended modifications to Kahului Harbor include a 200-ft extension to Pier 1, dredging and a new T-pier for fuel barges between Piers 1 and 3, a new barge facility along the south side of Pier 2, and a new passenger ship pier located in the western harbor. Variations to the alternative plans studied may include design changes for improved performance. For example, the passenger ship facility in Plans 5 and 7 could be pile-supported rather than solid to reduce resonances.

Results of this study should be combined with operational experience at existing facilities to define a most-promising general plan. A final optimized plan should be determined with the aid of a physical model. The numerical model should be validated against the physical model studies to ensure that the final plan is free of problem surge response in existing pier areas and new facilities. Effects of future modifications to the harbor should be evaluated using the validated numerical model. 



\section{Introduction}

\section{Background}

Kahului Harbor is the only deep-draft harbor on the Island of Maui and the busiest port in Hawaii outside of the Island of Oahu. The harbor is approximately 94 miles $^{1}$ southeast of Honolulu and is conveniently located on Maui's north shore (Figure 1).

The harbor is exposed to wind and waves from the north and northeast. The northwest end of Maui shelters the harbor from waves arriving from the northwest. The harbor is protected by two large breakwaters. High energy waves generated by intense winter storms in the north Pacific Ocean routinely attack the breakwaters. Hurricanes can also create large waves incident to the harbor. The breakwaters have a long history of construction and repair (Markle and Boc 1994; Sargent, Markle, and Grace 1988). Breakwaters are armored with molded concrete units of up to 35 tons on the trunk and 50 tons on the head. The harbor entrance is a 660-ft opening between the breakwaters.

Commercial piers are located in the southeast part of the harbor. Piers are used by a variety of vessels including barges, container ships, passenger cruise ships, and fishing vessels. Pier 1 accommodates the larger overseas vessels and barges. Water depth in the Federal entrance channel, harbor basin, and commercial pier areas is $35 \mathrm{ft}$.

Two canoe clubs are located along the shore immediately southwest of Pier 2. A large coral stockpile has been placed inside the harbor, adjacent to the west breakwater. This area, under the jurisdiction of the County of Maui, is being considered for park development. A public boat ramp is located near the landward end of the stockpile (Figure 2). The southern shore of the harbor, between the boat ramp and canoe clubs, includes a revetment along Kahului Beach Road and several rock groins further east.

Because of Kahului Harbor's size and importance (both recreational and commercial), the Harbors Division, Department of Transportation, State of

\footnotetext{
1 A table of factors for converting non-SI units of measurement to SI units is presented on page xi.
} 


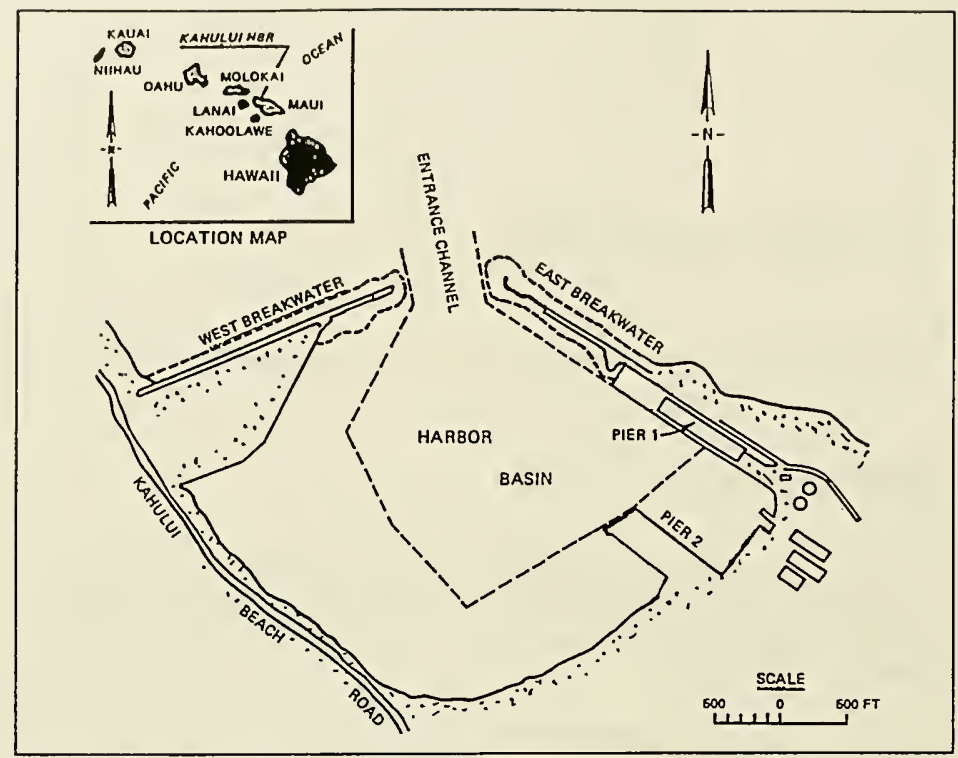

Figure 1. Study location

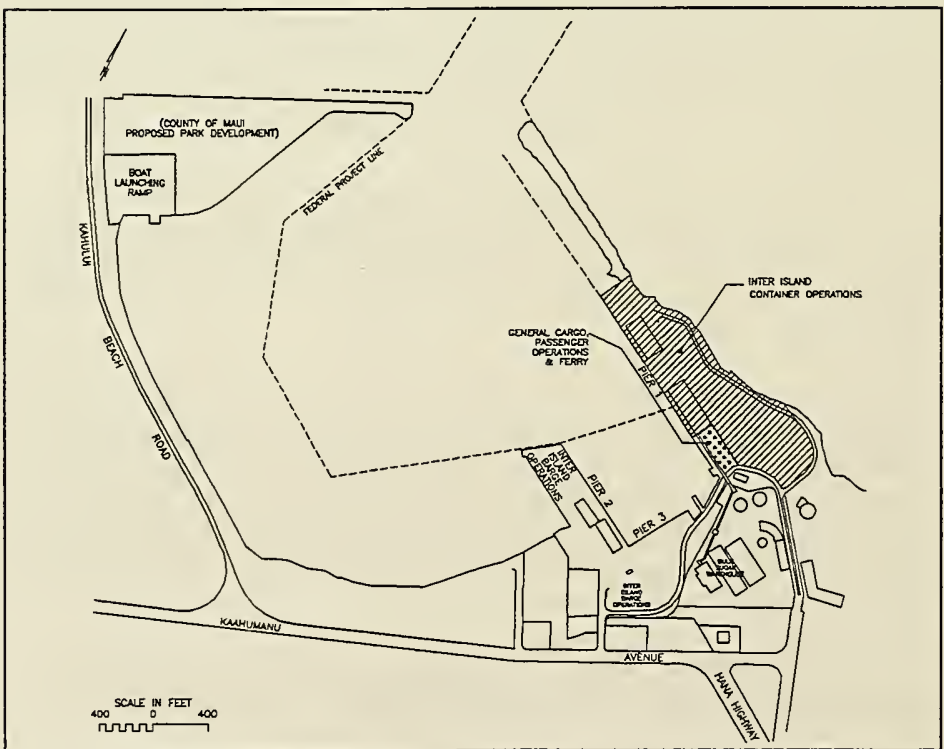

Figure 2. Kahului Harbor, existing plan 
Hawaii (HDOT), has devoted special care to long-range planning. Plans and concerns are described in the 2010 Master Plan for Kahului Harbor produced by the State of Hawaii in 1994. A key concern is the possibility for expansion of the harbor in concert with projected increases in population and economic activity. Wave activity at the existing piers during heavy northerly swells is also a concern.

\section{Study Approach}

The study described in this report was performed by the U.S. Army Engineer Waterways Experiment Station (WES), Coastal Engineering Research Center (CERC), in support of the 2010 Master Plan for Kahului Harbor. The approach consisted of the following components:

a. Collect and analyze field wave data.

b. Relate field data to long-term wave climate.

c. Use field data to calibrate and validate a numerical wave model.

$d$. Use the numerical model to investigate alternative harbor modification plans.

Field wave gages were installed outside the harbor and at four locations inside the harbor. Locations for the harbor gages were selected with the aid of a preliminary numerical model study of harbor oscillations (Okihiro et al. 1994). Two events of special interest occurred during the measurement program. Intense wave activity causing closure of the harbor occurred on 14-15 March 1994. A sizeable (but not damaging) tsunami event due to an earthquake off the coast of Japan occurred on 4 October 1994. The field wave measurement portion of the study is described in Chapter 2.

Long-term wind wave and swell climate was investigated primarily with numerical hindcast information covering a period of 20 years. Statistics from the gage outside the harbor were evaluated relative to the long-term climate. The wave climate study is presented in Chapter 3.

A numerical wave model was set up to cover the entire harbor and the area outside the harbor extending to the wave gage. The model was tested, calibrated, and validated, mainly using the field data. Nine altemative harbor plans were defined as part of the mid-study model review conference, with provisions for two additional plans to be specified after evaluating the initial plans. Thus the study included a total of eleven plans and the existing harbor. All plans included the following features:

a. A 200-ft extension of Pier 1 toward the harbor entrance.

b. A dredged area between Piers 1 and 3 to $35-\mathrm{ft}$ depth to accommodate fuel barges. 
Each plan includes provisions for a new passenger vessel area on the west side of the harbor and a new barge facility on the south side of Pier 2. Appropriate dredging is incorporated into the plans to provide 35 - $\mathrm{ft}$ depth for passenger vessels and 25-ft depth for barges. Special features of each plan are:

a. Plan 1 (Figure 3). Slip cut into coral stockpile to accommodate passenger ships; fill south of Pier 2 to provide barge pier oriented nearly north/south (referred to as Concept $C$ in HDOT planning documents).

b. Plan 2 (Figure 4). Slip cut into coral stockpile to accommodate passenger ships; fill south of Pier 2 to provide barge pier parallel to Pier 2 (referred to as Concept 12 in HDOT planning documents).

c. Plans $3 a, 3 b$, and $3 c$ (Figure 5). Notch cut into coral stockpile to accommodate passenger ships; protective stub aligned with entrance channel added to end of west breakwater in Plans $3 b$ and $3 c$ with length of $600 \mathrm{ft}$ (Plan 3b), and 1,000 ft (Plan 3c); fill south of Pier 2 to provide barge pier parallel to Pier 2.

d. Plans 4a, 4b, and 4c (Figure 6). Passenger ship pier located adjacent to existing coral stockpile; protective stub added to end of west breakwater in Plans $4 \mathrm{~b}$ and $4 \mathrm{c}$ with length of $600 \mathrm{ft}$ (Plan 4b), and 1,000 ft (Plan 4c); fill south of Pier 2 to provide barge pier parallel to Pier 2 .

e. Plan 5 (Figure 7). 800 - $\mathrm{ft}$ by 800 - $\mathrm{ft}$ fill area added in southwest area of harbor to accommodate passenger ships; fill south of Pier 2 to provide barge pier parallel to Pier 2.

f. Plan 6 (Figure 8). Identical to Plan 4b except 35-ft project depths dredged to $38 \mathrm{ft}$.

g. Plan 7 (Figure 9). Combination of Plans $4 \mathrm{~b}$ and 5 with $35-\mathrm{ft}$ project depth areas dredged to $38 \mathrm{ft}$ and realignment of passenger ship pier along southeast side of fill area. This plan represents a fully utilized harbor.

Development of the numerical model and test procedures is described in Chapter 4.

Response of the existing harbor to waves was studied using field data and numerical model results. Response of the alternative harbor plans was investigated with only numerical model results. Harbor response to wind waves and swell (short waves) is presented in Chapter 5 . Harbor oscillation characteristics (response to long waves) are presented in Chapter 6. For both short and long waves, the harbor response is related to wave climate and to relevant operational criteria at commercial piers.

Conclusions and recommendations are given in Chapter 7. This chapter is followed by references and appendices with detailed information supporting the main report and notation definitions. 


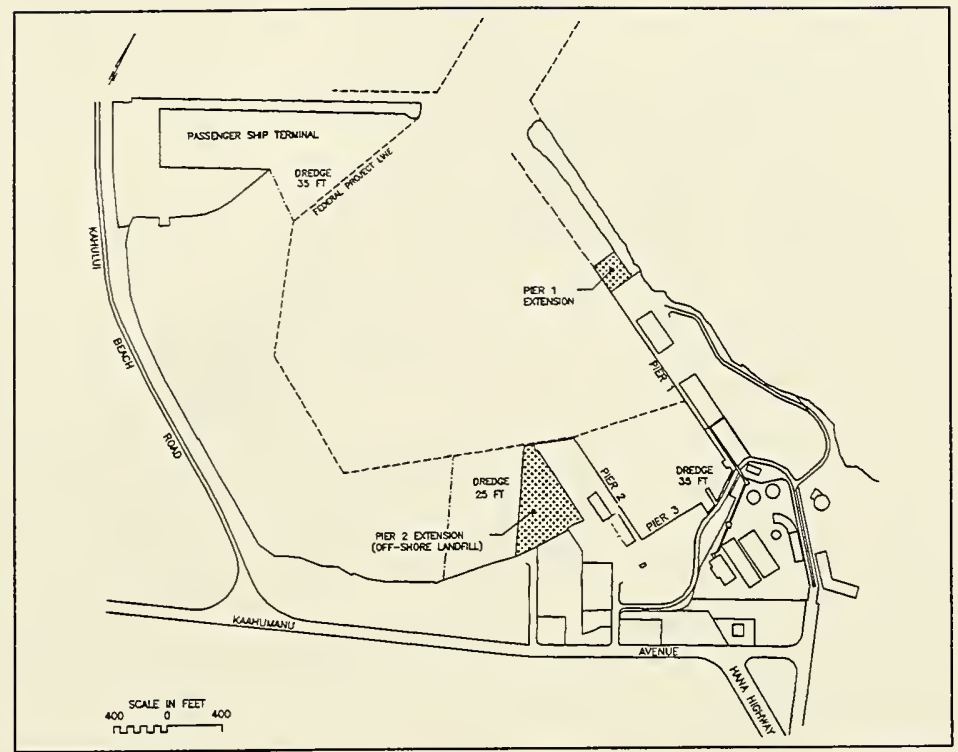

Figure 3. Plan 1

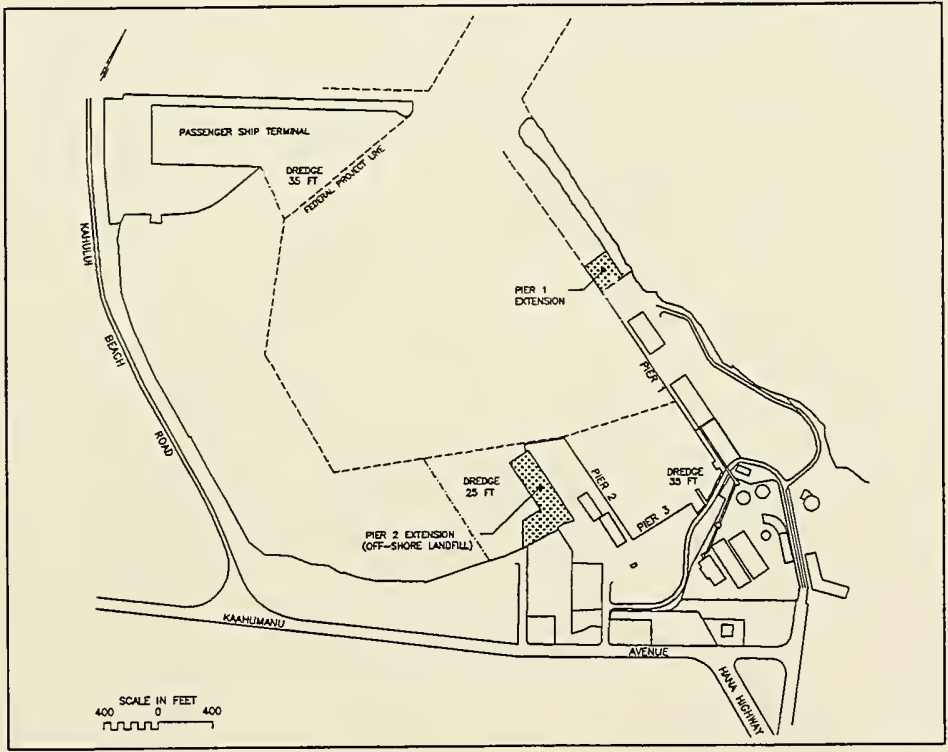

Figure 4. Plan 2 


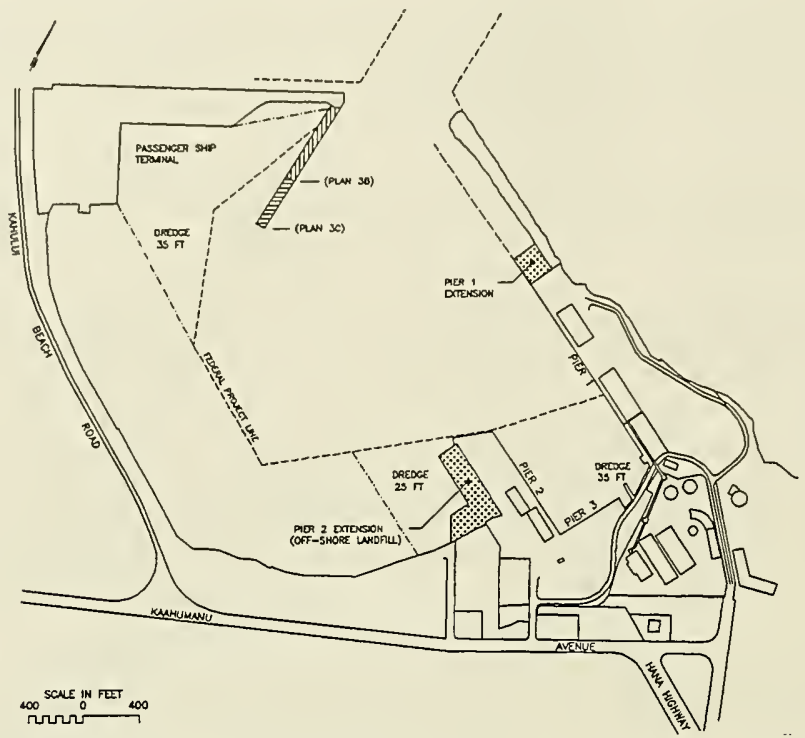

Figure 5. Plan 3

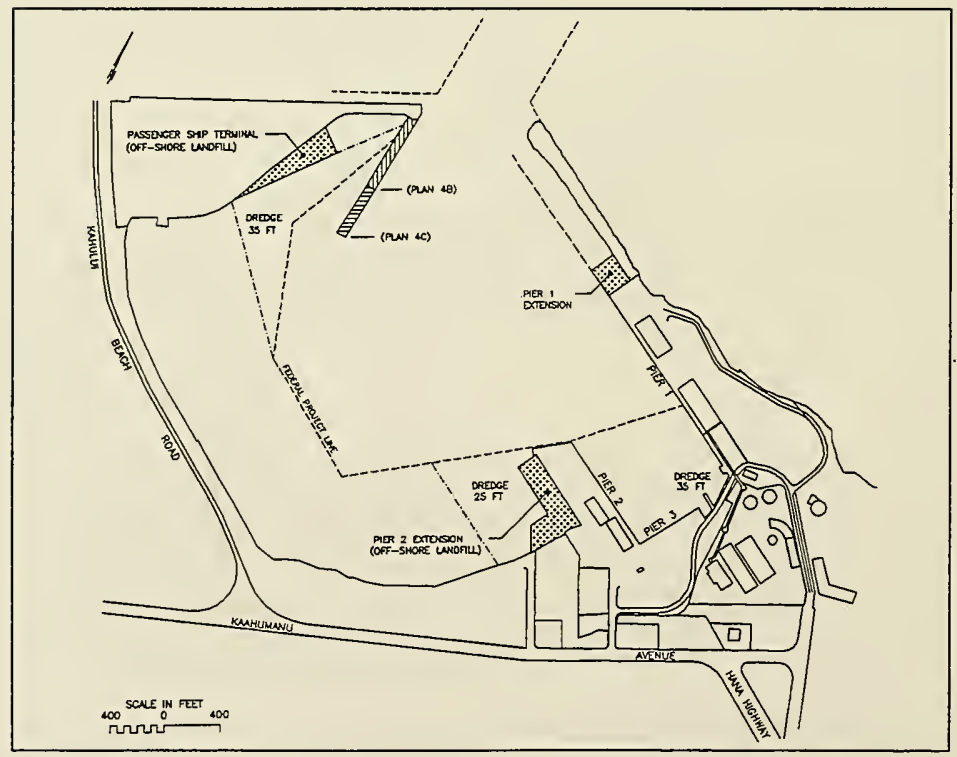

Figure 6. Plan 4 


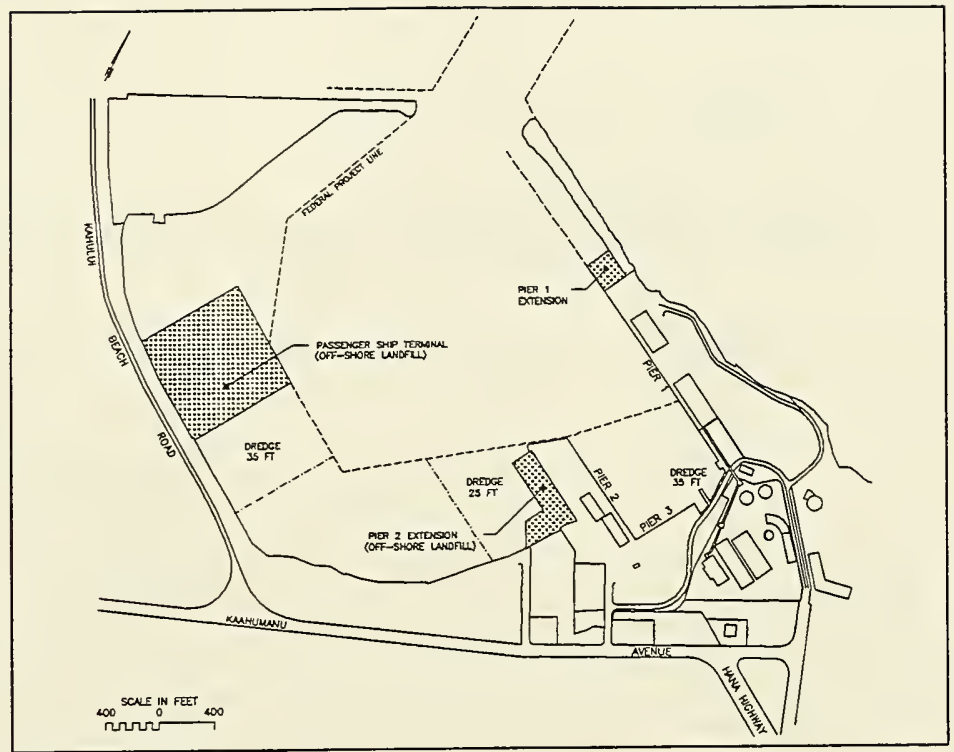

Figure 7. Plan 5

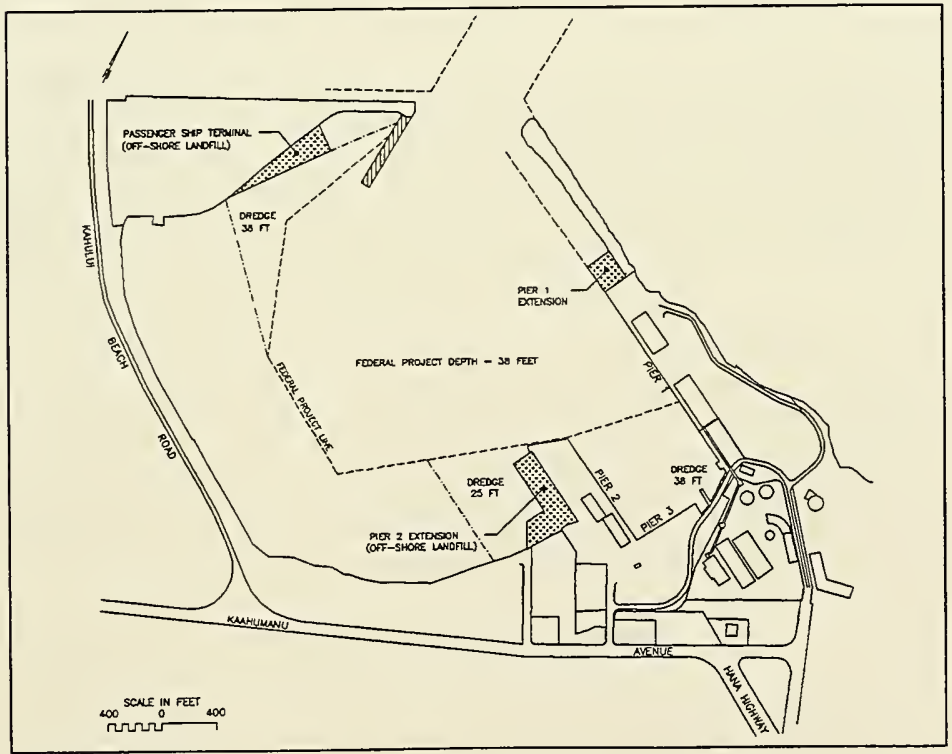

Figure 8. Plan 6 


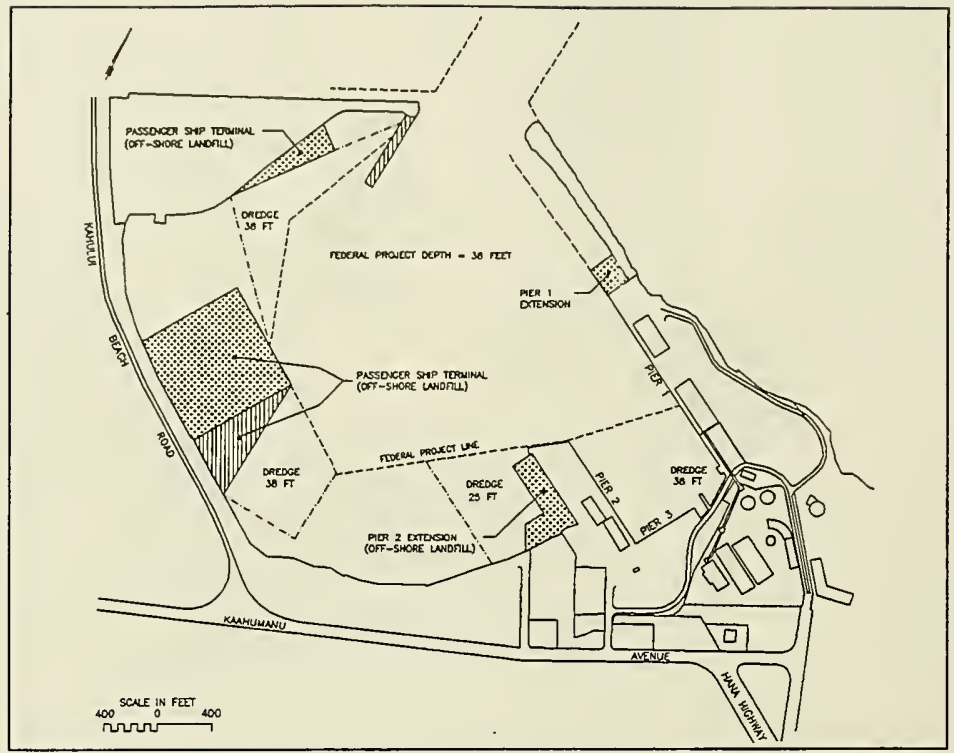

Figure 9. Plan 7 


\section{Field Wave Measurements}

\section{Planning}

Wave data were required at Kahului Harbor to document present conditions and provide data to validate numerical and physical models of harbor response to incident wind waves and long waves, also called seiche, or infragravity waves (typically, waves with frequencies lower than $0.03 \mathrm{~Hz}$ or wave periods longer than $33 \mathrm{sec}$ ). Tidal response was not included. The numerical model calculates the amplitude of the response at each grid point to an incident wave of a particular height, frequency, and approach angle. For each frequency and direction, validation involves driving the model with measured data of known energy and comparing the model's output to the measured energy at one or more sites within the harbor.

Planning the measurement program requires specifying the location, duration, and type of data collected. Ideally, incident measurements coincide with the outer boundary of the model, and there are sufficient interior measurements to define spatial variability within the harbor. Finally, the types of data (wave energy, wave direction, currents, etc.) and the range of frequencies measured should equal or exceed the requirements of the model. Fiscal, logistic, and schedule limits always constrain the ideal measurement plan.

Due to the random nature of waves, it is always difficult to schedule the duration of a wave study in advance based solely on engineering considerations. It is desirable to continue measurements long enough to obtain a broad range of incident conditions - up to or exceeding design conditions - but study schedules and budgets usually override this issue. The plan for Kahului was an initial deployment of one year. A decision to continue measurements would be based on the amount and type of measurements obtained by the end of that year.

\section{Instrument Type and Site Selection}

Incident waves in deep water are used to define the wave field before it is affected by local shallow water. For ocean swell with a period of $25 \mathrm{sec}$, deep water is considered greater than about $500 \mathrm{~m}$. Surface-following buoys are typically used to measure waves in deep water, but the accelerometer-based 
sensors have a low frequency cutoff near $0.05 \mathrm{~Hz}(20 \mathrm{sec})$, or about at the infragravity band, so only wind waves are measured. In January 1993, a 3-m discus buoy, station number 51026 , was installed at latitude $21.37^{\circ} \mathrm{N}$, longitude $156.96^{\circ} \mathrm{W}$ - about $20 \mathrm{n}$. m. north of Molokai in 7,618 ft $(2,322 \mathrm{~m})$ of water. While not directly offshore of the study site, the difference in the deep-ocean conditions over distances less than $100 \mathrm{n}$. m. was considered small. The wave climate portion of this study (Chapter 3 ) helped confirm this judgement. The buoy, which measures directional wave energy and meteorological data, is operated by the National Weather Service (NWS) National Data Buoy Center (NDBC). The station was installed prior to, and maintained after, the Kahului Harbor study by the Corps of Engineers' Field Wave Gaging Program. During the scheduled Kahului field data collection period, the station was funded by HDOT.

The range of frequencies of interest for wave energy inside the harbor extends from approximately $0.001 \mathrm{~Hz}$ to $0.2 \mathrm{~Hz}$. Experience has shown bottom-mounted pressure sensors provide the desired frequency response, flexibility of placement, reliability, and survivability in the coastal environment. Due to the attenuation of wave-induced pressure fluctuations with depth, measurement of the higher frequency wind waves limits the allowable water depth of the bottom-mounted sensors to around $10 \mathrm{~m}$. (This constraint indirectly affected the offshore extent of the numerical model grid boundary.) Directional information was needed for incident energy at the model boundary. Three or more pressure sensors in an array provide a two-dimensional (energy and direction) spectrum. Only nondirectional wave energy, provided by a single pressure sensor at each site, is required inside the model domain. Design, installation, and operation of the shallow water gaging system was provided by the Coastal Data Information Program (CDIP), a joint effort of the Corps and the California Department of Boating and Waterways. The CDIP is a network of wave gages operated by the Scripps Institution of Oceanography (SIO). Gages in the network are linked by radio and/or telephone to a central computing facility in La Jolla, CA, where data are collected, analyzed, qualified, and stored.

Given the size and complexity of the harbor, a minimum of three interior sites, in addition to the incident, or boundary site, were planned. Usually, these sites are selected based on engineering judgement and logistics (Basco and McGehee 1990). For this study, the numerical model itself was used to optimize the measurement sites (Okihiro et al. 1994). Four interior sites were used in this study. Gage locations are summarized in Figure 10 and Table 1.

\section{Data Acquisition}

The NDBC buoy measures directional energy with a pitch-roll-heave sensor and magnetometer. The superstructure supports dual anemometers and barometers for wind velocity and atmospheric pressure. Thermistors measure nearsurface sea and air temperature. Signals from the sensors are time averaged or spectrally analyzed with on-board computers. Reduced parameters are 


\begin{tabular}{|c|c|c|c|c|c|c|c|}
\hline \multicolumn{8}{|c|}{$\begin{array}{l}\text { Table } 1 \\
\text { Field Wave Gages }\end{array}$} \\
\hline \multirow[b]{2}{*}{ Name } & \multirow[b]{2}{*}{ No. } & \multirow[b]{2}{*}{ Type } & \multicolumn{2}{|c|}{ Coordinates } & \multirow{2}{*}{$\begin{array}{l}\text { Depth } \\
\text { MSL } \\
\text { (ft) }\end{array}$} & \multirow{2}{*}{$\begin{array}{l}\text { Sampling } \\
\text { Freq. } \\
\text { (Hiz) }\end{array}$} & \multirow{2}{*}{$\begin{array}{l}\text { Record Length } \\
\text { (sec) }\end{array}$} \\
\hline & & & N. Lat. & w. Long. & & & \\
\hline N. Molokai & 51026 & NDBC buoy & $21^{\circ} 22.2^{\prime}$ & $156^{\circ} 57.6^{\prime}$ & 7,618 & 1.7 & 1,200 \\
\hline Array & $\pi$ & CDIP array & $20^{\circ} 54.2^{\prime}$ & $156^{\circ} 28.2^{\prime}$ & 47.6 & 1 & 8,192 \\
\hline Pier 2 & $79-1$ & CDIP single pt. & $20^{\circ} 53.7^{\prime}$ & $156^{\circ} 28.0^{\prime}$ & 45.3 & 1 & 8,192 \\
\hline Canoe Club & $79-2$ & CDIP single pt. & $20^{\circ} 53.7^{\prime}$ & $156^{\circ} 28.1^{\prime}$ & 9.5 & 2 & 8,192 \\
\hline Back Basin & $79-3$ & CDIP single pt. & $20^{\circ} 53.6^{\prime}$ & $156^{\circ} 28.3^{\prime}$ & 12.1 & 1 & 8.192 \\
\hline $\begin{array}{l}\text { Channel } \\
\text { Entrance }\end{array}$ & $79-4$ & CDIP single pt. & $20^{\circ} 53.9^{\prime}$ & $156^{\circ} 28.5^{\prime}$ & 30.5 & $i$ & 8,192 \\
\hline
\end{tabular}

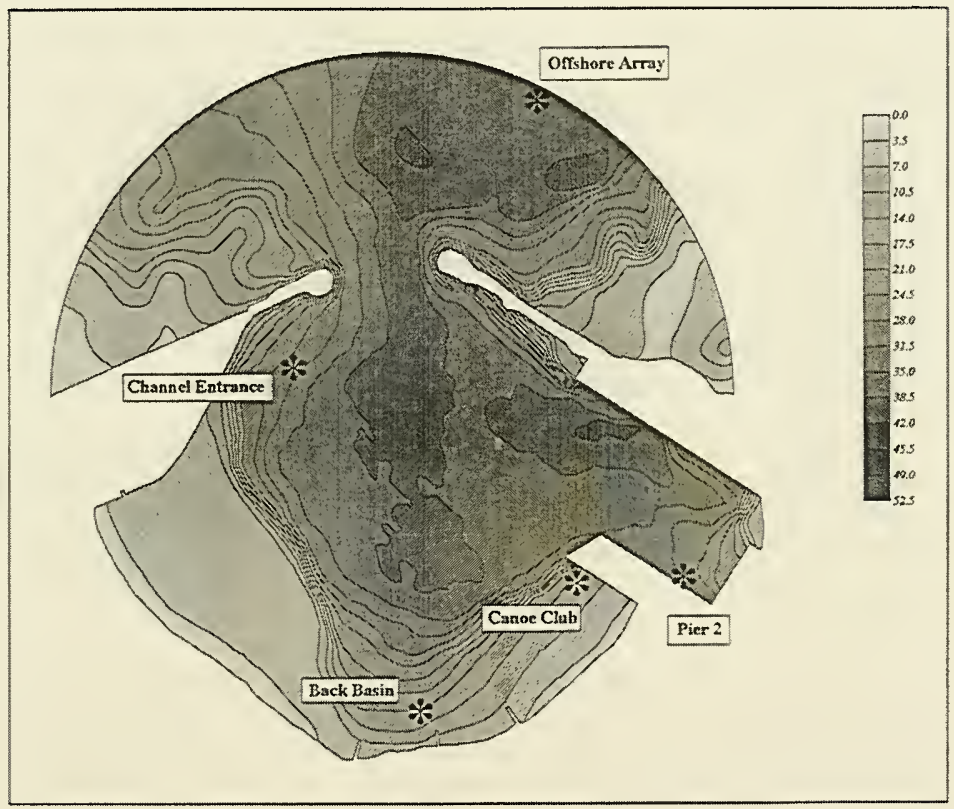

Figure 10. Field gage locations and bathymetry, in feet

transmitted hourly to the NWS gateway via Geostationary Operational Environmental Satellite (GOES) for additional analysis, qualification, and distribution. Edited data are provided monthly to CERC. Details of the measurement, transmission, and analysis process can be found in Steele and Mettlach (1993). 
The CDIP system was operated as a "hardwired" system. Signals from the pressure sensors are sampled at 1-2 $\mathrm{Hz}$ (Table 1) via submarine cables from an onshore field data logging station. The field station was designed to operate independently, under locally resident program control, as a software-driven, autonomous, data acquisition system. Its primary function is to locally acquire, $\log$, and, in response to a call from a host computer, upload the stored data. The data are received through a phase lock loop, electronically conditioned and optimally compacted, according to the header block instructions, and stored locally in $16 \mathrm{~K}$-bytes of RAM. Storage is based on the "first in, first out" principle, with the oldest word overwritten by the latest word as the storage buffer is filled. Two-way communication between the field station and the central station in La Jolla is accomplished via modem connections, through normal phone service. In response to a phone query from the central station, typically every $3 \mathrm{hr}$, the field station uploads the latest data buffer. Since each record is over $2 \mathrm{hr}$ long, this allows for nearly continuous sampling (gaps of several minutes occur during downloading). The central station data collection computer, a Sun workstation, superficially examines the incoming data for obvious defects, such as incomplete transmissions and failed phone connections. A detected fault will trigger a retry call to the field station. After additional quality control, final data are transferred monthly to CERC via Internet. Additional details of the CDIP operation are given by Seymour et al. (1993).

Data collection commenced for the NDBC buoy in January 1993, was interrupted briefly in May 1993, and continued through May 1994. Repairs were effected in September 1994, and the buoy continued operation through 1995. Table 2 provides summary statistics for the deployment with 20 -year hindcast statistics for comparison (Corson et al. 1986). ${ }^{1}$ Figure 11 is a rose plot of the mean significant wave height and occurrence by direction (convention is direction waves are coming from, with respect to true north).

The CDIP system was installed in October 1994 and operated without interruption through the duration of the study. As planned, the adequacy of the measurements was assessed after the first year of operation (McGehee 1995). The principal issues were the range of different types of incident conditions measured by the buoy, and the level of infragravity energy measured by the harbor gages.

While a reasonable variety of incident wave directions and frequencies was captured, it was not a particularly energetic year. One event sufficient to affect harbor operations occurred, on 14-15 March 1994, reportedly due to wind wave conditions in the entrance. Figure 12 expresses the total measured infragravity energy for each record (high-energy cases only) at each site as an equivalent wave height during the first 8 months of record. Infragravity wave heights experienced in mid-March were exceeded in other months without reported problems. It is not clear whether the lack of reported impacts on operations in

${ }^{1}$ For convenience, mathematical symbols used in Table 2 and throughout this report are listed in the notation 


\section{Table 2}

Summary Statistics, NDBC Buoy 51026, N. Molokai

\begin{tabular}{||l|l|l||}
\hline Statistical Parameter & NDBC Buoy 51026' & WIS Station 31 \\
\hline \hline Mean $H_{s}$ (ft) & 8.5 & 8.2 \\
\hline Standard deviation of $H_{s}(\mathrm{ft})$ & 2.6 & 3.0 \\
\hline Mean $T_{p}$ (sec) & 10.7 & 9.3 \\
\hline Standard deviation of $T_{\rho}$ (sec) & 2.9 & 2.6 \\
\hline Most frequent direction (deg coming from) & 90 & 45 \\
\hline Maximum $H_{s}$ (ft) & 23.9 & 23.3 \\
Associated $T_{p}$ (sec) & 16.7 & 10.0 \\
Associated direction (deg coming from) & 344 & 196 \\
\hline Percent occurrence, period $>18.2$ sec & 1.2 & 0.0 \\
\hline Percent occurrence, period $>15.4$ sec & 7.7 & 0.4 \\
\hline \hline ' Data from Jan 93 through Feb 96 & & \\
\hline
\end{tabular}

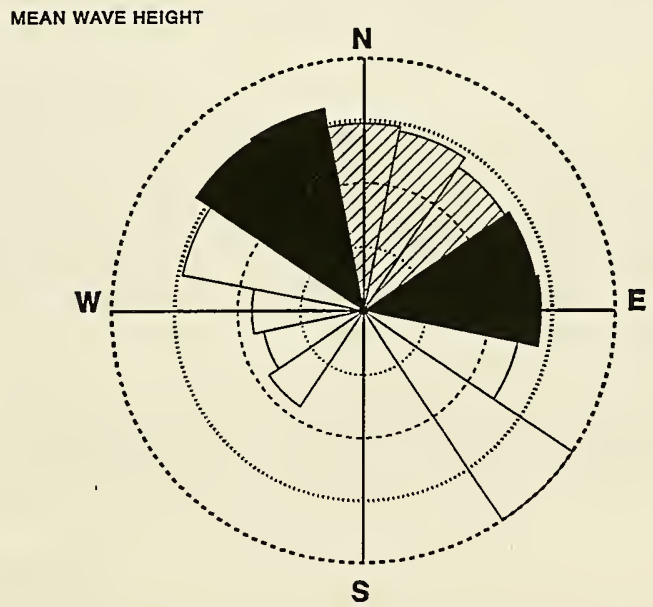

Figure 11. Wave rose, NDBC buoy 51026, N. Molokai

the harbor at those other times results from lack of problems, or failure of problems to be observed/documented. Thus, a simple, quantifiable threshold for allowable infragravity energy was not determined. Additional measurements 
were recommended to attempt the capture of a high infragravity event concurrently with noticeable impacts on harbor operations.

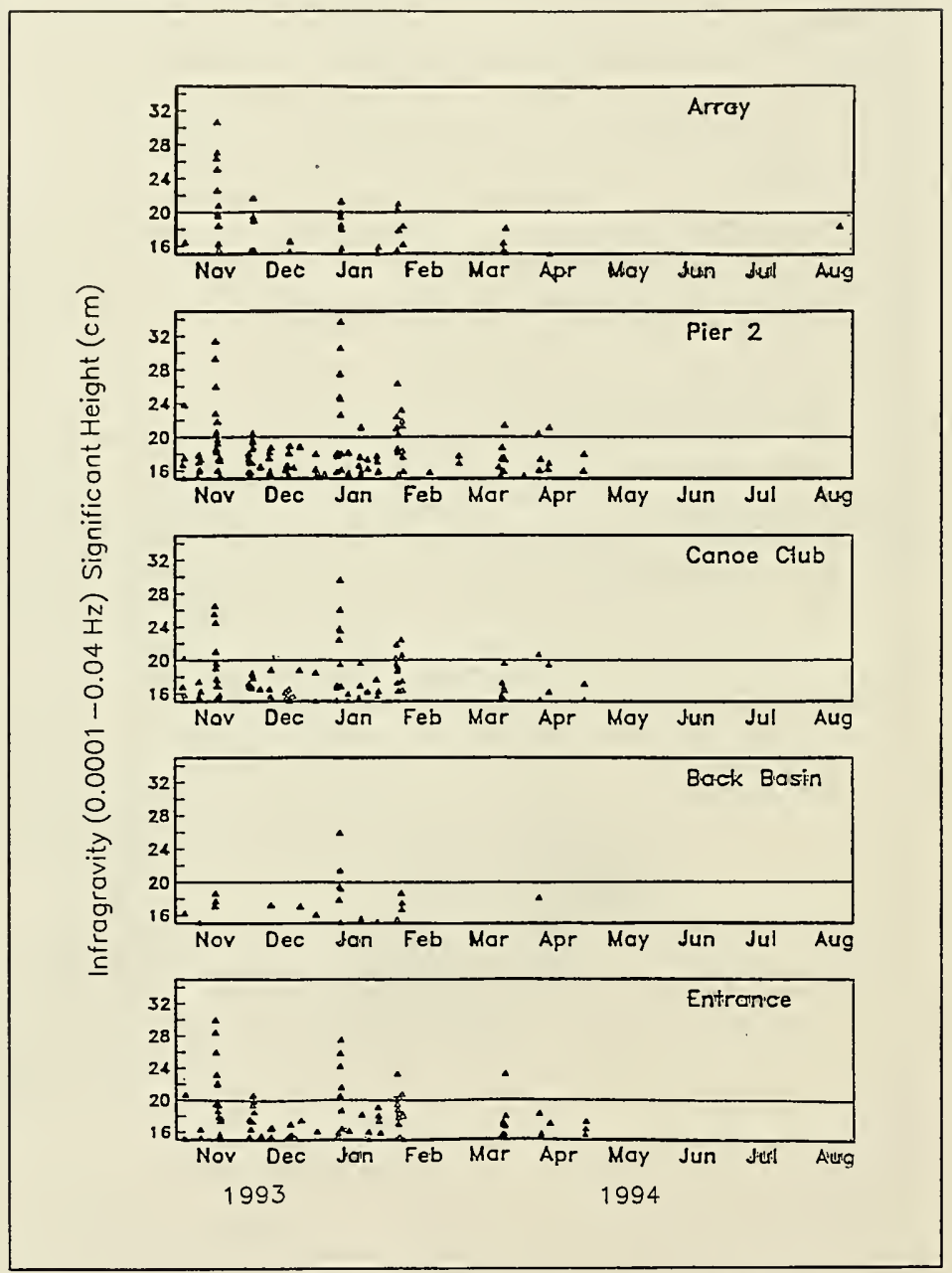

Figure 12. Overview of extreme infragravity wave events; only events with $H_{\text {s,long }} \geq 15 \mathrm{~cm}$ are shown (from McGehee (1995))

The memorandum (McGehee 1995) also supported a statistical correlation study to test the ability to predict the amplitude of observed infragravity energy in shallow water with the characteristic wind wave parameters measured offshore. Preliminary analysis showed weak correlation. A longer data set was recommended for statistical reliability of the correlation study. The recommen- 
dation was followed, and the gages were funded for an additional winter season, through March 1995.

\section{Analysis Methods}

The CDIP nearshore wave gage data were processed to give two types of output for each record: spectra and parameters. These outputs, which were customized to meet needs of the Kahului Harbor study, are briefly described here. NDBC buoy data were analyzed with standard NDBC procedures.

SIO provided customized spectra and parameters covering the time period Nov 93 - Sep 94. Subsequent wave climate studies indicated that this data set gives a reasonable representation of the wind wave and swell climate. Wind wave and swell data from the winter of 1994-5 are comparable to the winter of 1993-4. Fewer extreme infragravity (long) wave events occurred in the winter of 1994-5 than in the winter of 1993-4. There were eight events with significant wave heights for long (infragravity) waves $H_{\text {s.long }}>15 \mathrm{~cm}$ in 1993-4 and only three such events in 1994-5 (Merrifield and Okihiro 1996). Also there were no reported operational problems in the harbor during the winter of 1994-5. Because of these considerations, harbor data from Nov 93 - Sep 94 were considered sufficiently representative of the full measurement period for validation of the numerical model and for relating numerical model results to operational concerns.

\section{Spectra}

Time series from the CDIP gages were subjected to SIO's standard spectral analysis for long records. The 8,192-sec records gave a spectral resolution of $0.000122 \mathrm{~Hz}$. Spectral output files were created with energy values for the first 286 spectral frequencies, or spectral lines (up to a frequency of $0.0349 \mathrm{~Hz}$, corresponding to a wave period of $28.6 \mathrm{sec}$ ), followed by energy values for higher frequencies (shorter wave periods) grouped into bands of width $0.01 \mathrm{~Hz}$. A total of 32 frequency bands were included, with central frequencies ranging from $0.04 \mathrm{~Hz}(25 \mathrm{sec})$ to $0.35 \mathrm{~Hz}(2.9 \mathrm{sec})$. Thus the analysis system produced a high-resolution spectrum for infragravity waves and a conventional resolution spectrum for wind waves and swell. The wind wave and swell spectrum is estimated with an unusually high level of confidence (high number of degrees of freedom) because of the exceptionally long records.

\section{Parameters}

Spectral results were also condensed into a small number of parameters for output (Table 3). Significant wave height and peak spectral period for long waves were computed from the infragravity portion of the spectrum using the same procedures traditionally used for wind waves and swell (short waves). The Back Basin gage, used for water depth measurement, had a higher quality pressure transducer than the other gages, and was more stable over long time periods. 
The last three parameters in the table were added at CERC to the basic parameter files provided by SIO. The number of major peaks in the short wave spectrum was computed by a procedure similar to that of Thompson (1980). Peaks were considered major if their energy density differed from that of the intervening low point by at least 3 percent of the total energy. Amplification factors for long and short waves were defined as

$$
A_{\text {amp }, 1}=\frac{\left(H_{\text {slong }}\right)_{\text {harbor gage }}}{\left(H_{s, \text { long }}\right)_{\text {array }}} ; \quad A_{\text {amp }, s}=\frac{\left(H_{s}\right)_{\text {harbor gage }}}{\left(H_{s}\right)_{\text {array }}}
$$

\begin{tabular}{||l|l||}
\hline Table 3 \\
Field Wave Parameters & Symbol \\
\hline \hline Description & \\
\hline \hline Year, month, day, hour, minute & $H_{\text {stong }}$ \\
\hline Significant wave height, long waves & $T_{p, \text { tong }}$ \\
\hline Peak wave period, long waves (greater than 29 sec) & $H_{s}$ \\
\hline Significant wave height, short waves & $T_{p}$ \\
\hline Peak wave period, short waves (3-25 sec) & $\theta_{m}$ \\
\hline Incident wave direction, short waves & \\
\hline Long-term average depth at Back Basin & $\bar{\eta}$ \\
\hline Mean depth over record length at Back Basin & $N_{p}$ \\
\hline Number of major peaks in short wave spectrum & $A_{\text {anp, }}$ \\
\hline Amplification factor, long waves & $A_{\text {amp,s }}$ \\
\hline Amplification factor, short waves & \\
\hline \hline
\end{tabular}

\section{Estimation of $T_{p}$}

The traditional procedure for estimating $T_{p}$ for wind waves and swell was modified in this study to obtain better resolution in the swell periods. Peak period is normally calculated as the reciprocal of the frequency at the midpoint of the highest energy spectral band. This is a standard, widely accepted procedure. The resolution with standard $0.01-\mathrm{Hz}$ spectral bands is sufficient to give a good estimate of peak period over most of the possible frequency range, but it is rather coarse for the longer swell periods. The standard procedure imposes some limitations on the Kahului Harbor study for the following two reasons:

a. Much of the wave energy at Kahului Harbor, including cases of greatest interest, is long period, low frequency swell. 
b. The range of possible wave period variation within a single lowfrequency band translates into significantly different harbor responses in the numerical model and, presumably, the field.

The most straightforward change is to use a finer spectral bandwidth, though finer bands have the undesirable consequence of lower confidence levels. SIO provided CERC with one month (January 1994) of detailed line spectral coefficients to explore alternatives (Thompson 1995). The effect of bandwidth on the $T_{p}$ estimate is illustrated in Figure 13 using data from the array (line spectra from all four sensors averaged together). This record was selected because there was an exceptional level of long wave energy in the harbor. Bandwidth is expressed in the figure in terms of the number of spectral lines. The standard SIO procedure for the Kahului Harbor gages gives 82 lines per band. Peak period estimates are quite variable. For this particular case, $T_{p}$ estimated by the standard procedure is $14.29 \mathrm{sec}$ while the "true" peak period (middle of the scatter) appears to be around $15 \mathrm{sec}$. The sawtooth shape of the plotted data arises because the main energy concentration slowly marches toward shorter period as bandwidth increases. Eventually, the band preceding the main energy extends far enough to encompass that energy, and peak period abruptly shifts to the center of that band.

The artificial variability induced by bandwidth can be reduced by using overlapping bands to identify a $T_{p}$. The approach is to select a bandwidth and identify $T_{p}$. Then the bands (keeping the same bandwidth) are shifted a fixed number of lines toward higher frequency (shorter period) and $T_{p}$ is again estimated. The bands are shifted repeatedly and the final estimate of $T_{p}$ is based on whichever band gives the very highest energy. The whole process can be repeated with different choices of bandwidth to examine this effect as well. Results with a two-line shift show a significantly reduced scatter relative to the nonoverlapping approach (Figure 14). Thus the overlapping bands allow a more refined estimate of $T_{p}$.

Two other cases in January 1994 corresponding to high levels of long wave energy in the harbor were examined using the same overlapping band approach. Peak period for 20 Jan 94 (1314) appears to be well-estimated by both the overlapping approach and the standard approach (Table 4). However, this case has a relatively short $T_{p}$ and broad energy spectrum. The $T_{p}$ for $31 \mathrm{Jan} 94(0719)$ is around $18 \mathrm{sec}$ by the overlapping approach and $20 \mathrm{sec}$ by the standard approach. The standard analysis is not sufficiently discriminating for this case. 


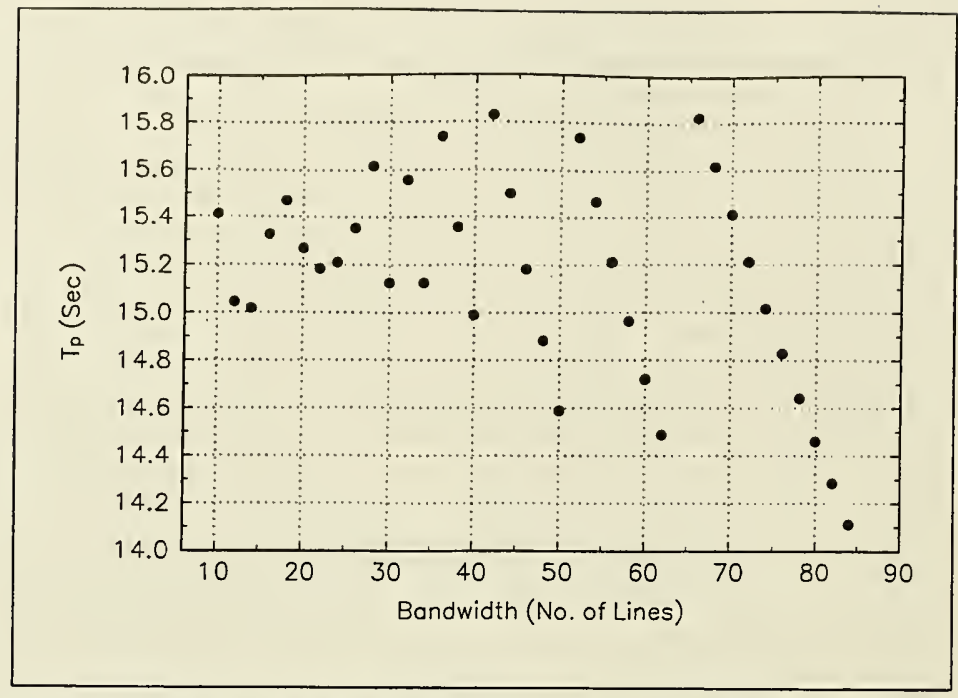

Figure 13. Influence of spectral bandwidth on $T_{p}$, non-overlapping bands; array, 3 Jan 94 (1311)

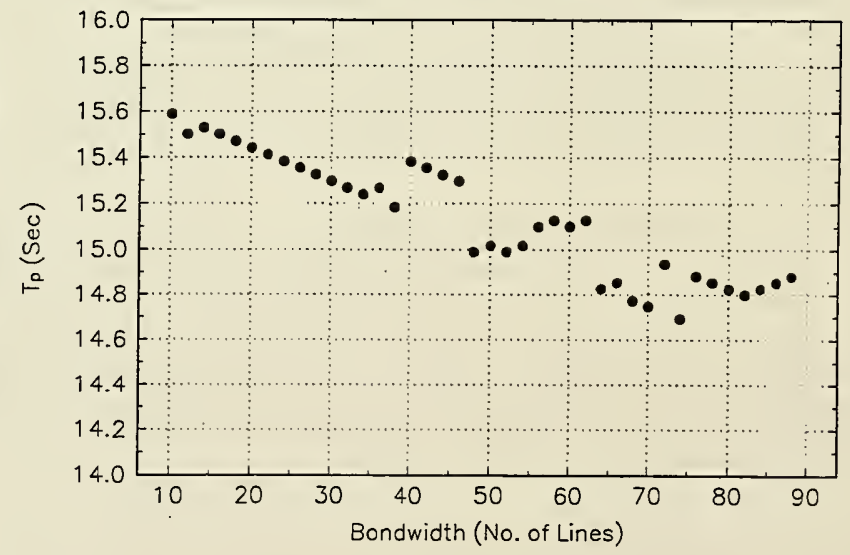

Figure 14. Influence of spectral bandwidth on $T_{p}$, overlapping bands (two-line offset); array, 3 Jan 94 (1311) 


\begin{tabular}{|l|l|l||}
\hline \multicolumn{2}{||l|}{$\begin{array}{l}\text { Table } 4 \\
\text { Effect of Overlapping Bands on } T_{p} \text { Estimates, Array }\end{array}$} \\
\hline \hline \multirow{2}{*}{ Date } & $T_{p}$ (sec) & \multicolumn{2}{|l|}{} \\
\cline { 2 - 3 } & Standard Analysis & $\begin{array}{l}\text { Overlapping Bands, Two-Line } \\
\text { Offset }\end{array}$ \\
\hline \hline 131103 Jan 94 & 14.3 & 14.8 \\
\hline 131420 Jan 94 & 10.0 & 10.1 \\
\hline 071931 Jan 94 & 20.0 & 18.0 \\
\hline
\end{tabular}

Because of these considerations, the SIO procedure for estimating $T_{p}$ values for wind waves and swell in this study was modified to an overlapping approach with a one-line overlap. Thus the reported $T_{p}$ corresponds to the midpoint of the 82 consecutive spectral lines which collectively have the highest energy in the spectrum.

\section{Results}

Parameters and spectra from the CDIP array and harbor gages were studied and evaluated in various ways to better understand harbor behavior and to prepare results in a form useful for validating the numerical model. Summaries are included in Appendix A of this report and in monthly compendia (e.g., Coastal Engineering Research Center (1996)). Complementary studies by Okihiro and Guza (1996) have also contributed to understanding of the harbor.

\section{Parameters}

Parameter time-histories were plotted by month, as illustrated in Figures 15-17. The plots are useful for reviewing the variety of conditions recorded and for identifying relationships between parameters. As an example, Figure 16 shows a strong tendency for high values of $H_{s}$ and $H_{s, \text { long }}$ to occur together. Correlation coefficient statistics were computed between selected parameters, as illustrated in Table 5 for Pier 2. The correlation coefficient for $H_{s}$ and $H_{\text {s,long }}$ is fairly high, 0.81 at Pier 2 . That correlation was also high at other gages (not shown): 0.74 at the array and between 0.61 and 0.72 at the other harbor gages. Other parameters showed lower correlations, but evidence of some other tendencies, such as a weak correlation between $H_{\text {s.long }}$ in the harbor and $\left(H_{s}\right)_{\text {array }}$

The variation of $A_{a m p, s}$ and $A_{a m p, l}$ with various long and short wave parameters is an important concern. These parameters are actually quite consistent at any given location. For example at Pier 2, $A_{\text {amp,s }}$ is around 0.1 and $A_{\text {amp, },}$ is generally between 1.2 and 1.8. Peaks in $A_{\text {amp,s }}$ tend to coincide with long period swell events (high values of $T_{p}$ ). The smallest values of $A_{\text {amp,l }}$ generally occur with high energy events (high values of $H_{s}$ and $H_{s, \text { long }}$ ). 
Parameter summaries are especially useful for numerical modeling of short waves. The range and distribution of measured $T_{p}$ and $\theta_{m}$ values at the array help determine wave conditions to be modeled (Figures 18 and 19). Since the numerical model produces amplification factors as a function of incident short wave period and direction, similar results from the field data are needed for validation. Values of $A_{\text {amp.s }}$ from field gage records were grouped according to 1-sec bins of $T_{p}$ and 10-deg bins of $\theta_{m}$. A mean and standard deviation were computed from values of $A_{\text {amp,s }}$ in each bin (Appendix B).

The parameter $N_{p}$ (number of spectral peaks) at the array was found to be one in almost every case. Thus short wave conditions at Kahului Harbor are generally well-represented by $T_{p^{*}}$. More than one major wave event (e.g. sea and swell) occurring simultaneously is unusual.

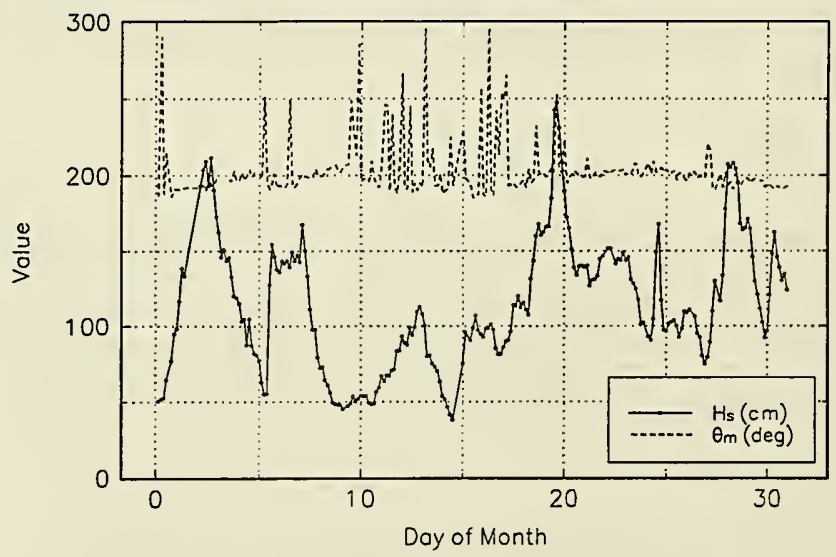

Figure 15. Time-history of $H_{s}$ and $\theta_{m}$ (deg, going toward); array, Jan 94

\section{Table 5}

Field Wave Gage Parameter Correlation Coefficients, Pier 2, Jan 94

\begin{tabular}{|c|c|c|c|c|c|c|c|c|c|}
\hline \multirow{2}{*}{$\begin{array}{l}\text { Para- } \\
\text { meter }\end{array}$} & \multicolumn{9}{|c|}{ Parameter } \\
\hline & $T_{p \text { pong }}$ & $\mathrm{H}_{s}$ & $T_{p}$ & $\theta_{m}$ & $\bar{n}$ & $A_{\text {amp,s }}$ & $A_{\text {mmps }}$ & $\left(H_{2}\right)_{\text {erray }}$ & $\left(T_{p}\right)_{\text {array }}$ \\
\hline$H_{\text {s,ong }}$ & 0.49 & 0.81 & 0.42 & 0.03 & 0.06 & & 0.10 & 0.47 & 0.12 \\
\hline$H_{s}$ & & 1.00 & 0.33 & 0.03 & 0.10 & 0.44 & & & 0.24 \\
\hline$T_{p}$ & & & 1.00 & 0.05 & & 0.54 & & & \\
\hline$\theta_{m}$ & & & & 1.00 & 0.01 & 0.10 & & & \\
\hline$A_{\text {emp,s }}$ & & & & & & 1.00 & & & 0.66 \\
\hline
\end{tabular}




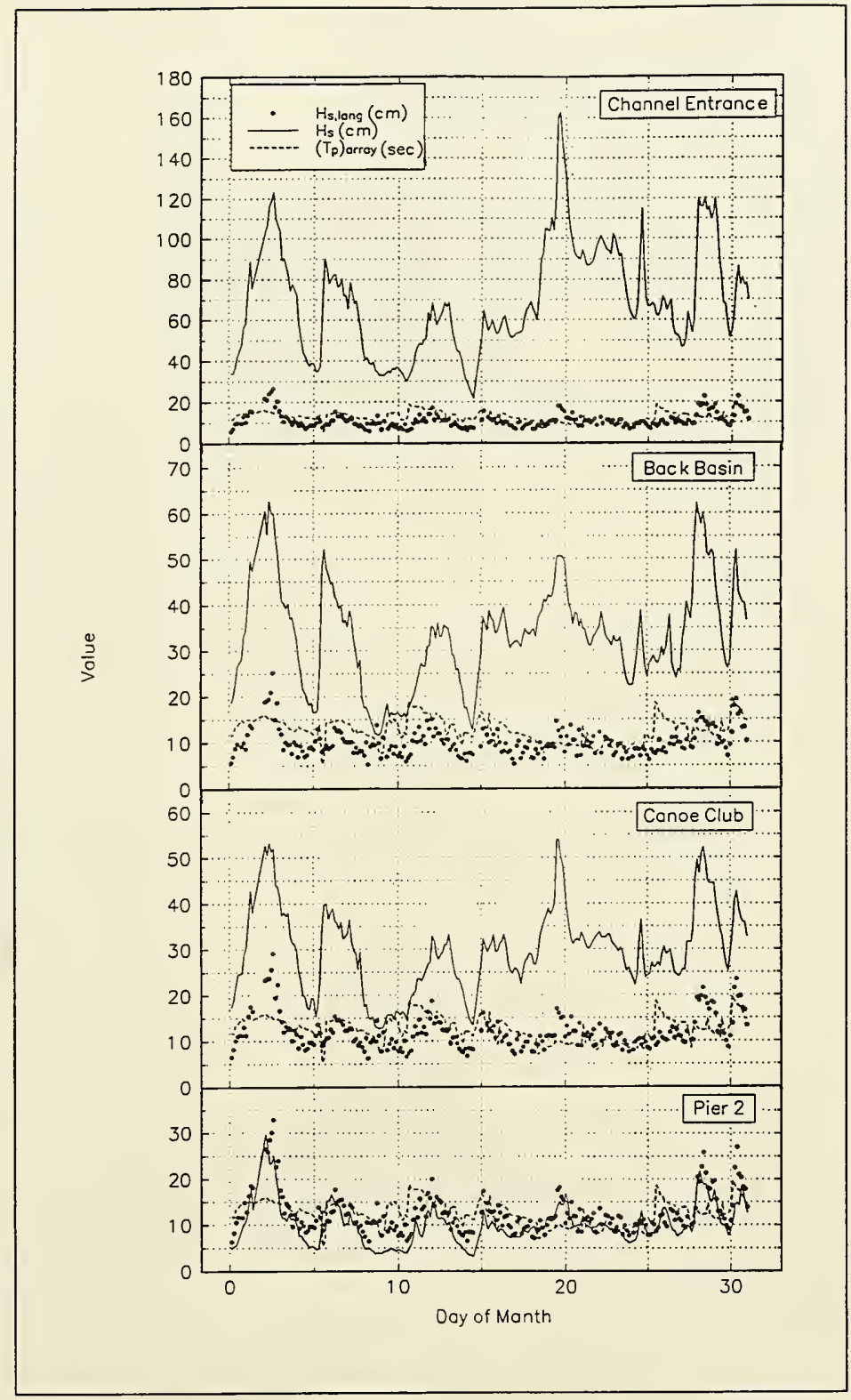

Figure 16. Time-history of $H_{s, \text { long }}, H_{s}$, and $\left(T_{p}\right)_{a r r a y}$; harbor gages, Jan 94 


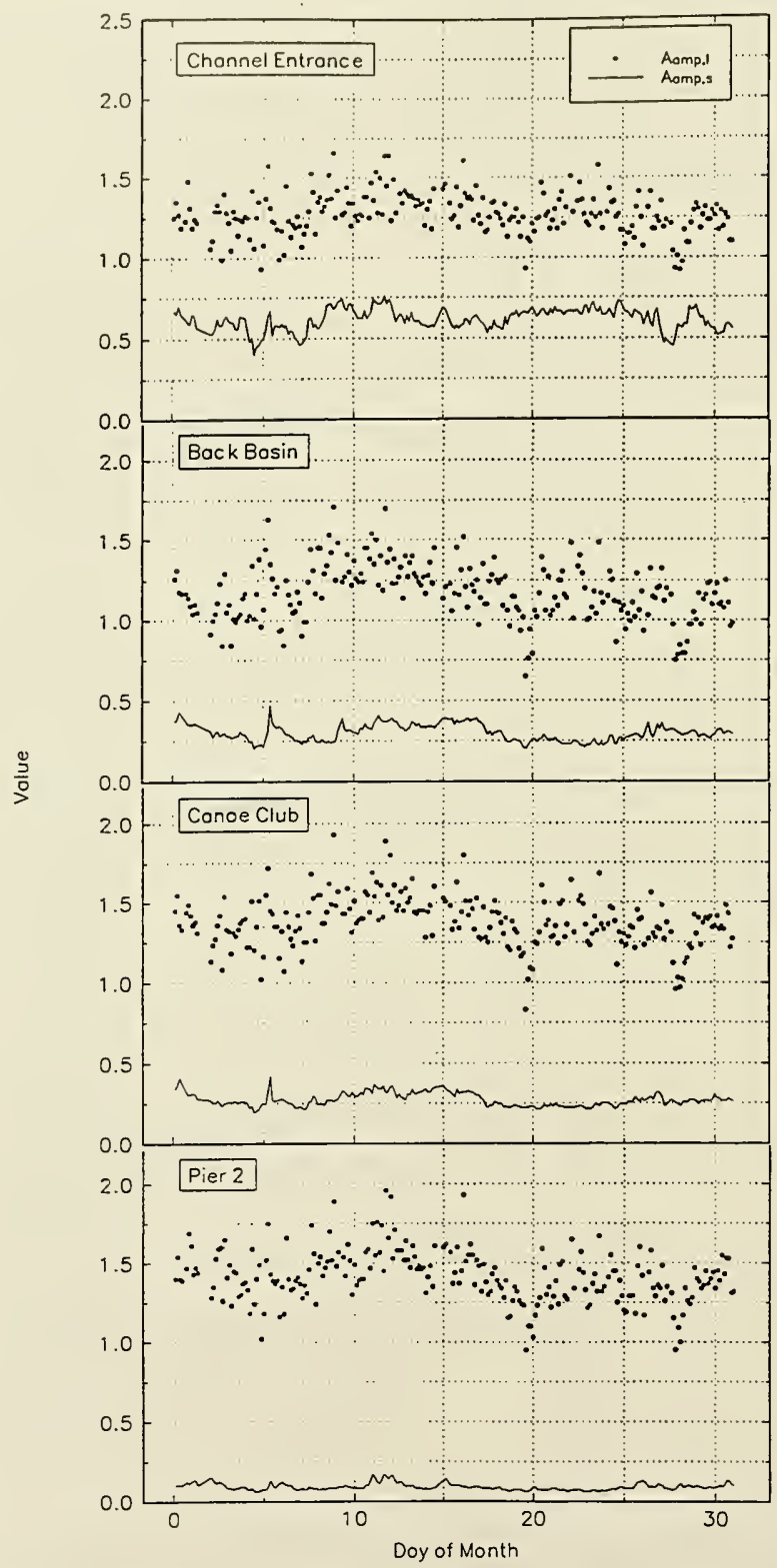

Figure 17. Time-history of $A_{a m p, s}$ and $A_{a m p, l} ;$ harbor gages, Jan 94 


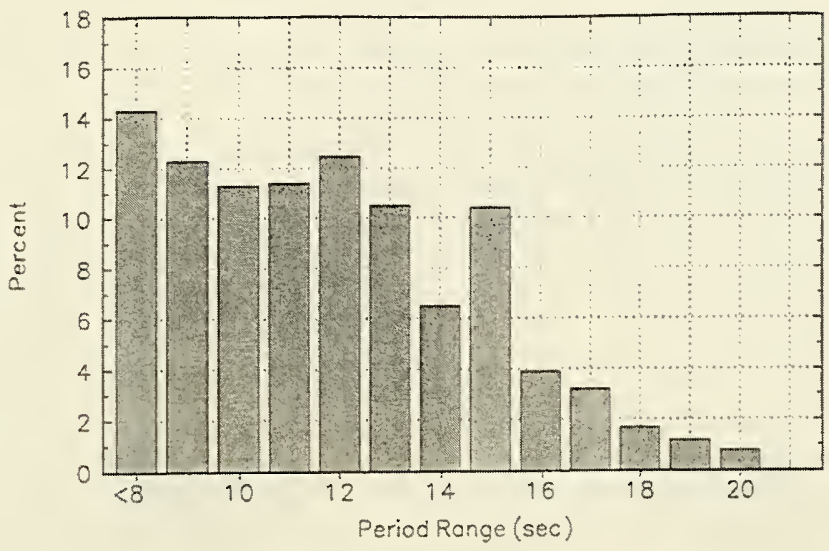

Figure 18. Probability distribution of $\left(T_{p}\right)_{\text {array }}$; Nov 93-Sep 94, 1,785 observations

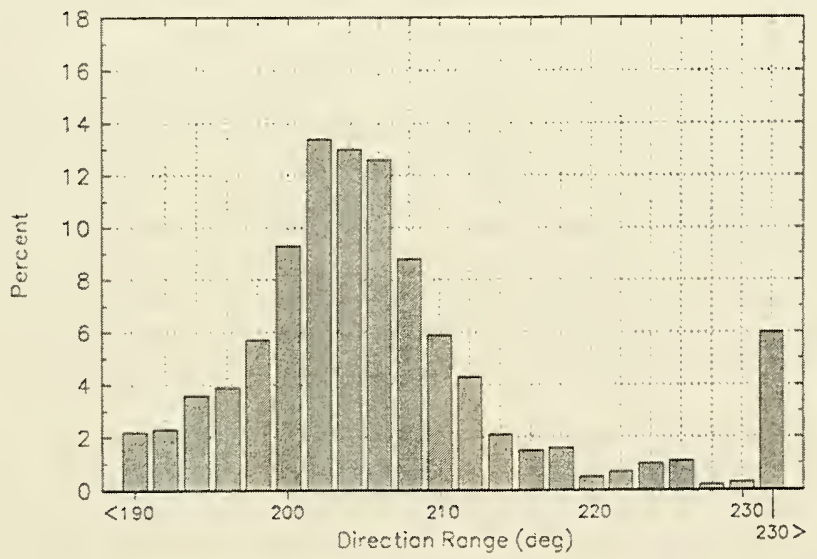

Figure 19. Probability distribution of $\left(\theta_{m}\right)_{a r a y}$; Nov 93-Sep $94,1,785$ observations 


\section{Spectra}

Short wave spectra were required to compute $N_{p}$ It is also helpful to examine spectra for specific events of interest to identify any presence of multiple wave systems or to confirm that $H_{s}$ and $T_{p}$ adequately characterize the sea state.

Spectra are especially useful in relation to long waves. Average long wave spectra were computed by month for each gage to reveal general structure in the long wave response of the harbor. A maximum energy density value (over all records during the month) at each spectral frequency was also identified. The results for January 1994 are typical (Figure 20). Average spectra are surprisingly similar from month to month. Maxima are typically an order of magnitude higher than the average, but they define a shape very similar to the average spectra. The maxima clearly show more statistical variability than the averages, as would be expected.

Long wave spectra were examined in more detail to better understand harbor response during high energy long wave events. Spectra for one such event are shown in Figure 21. Averages of the event spectra are also shown. Individual spectral values fluctuate over a very wide range. Averages follow the characteristic shape of monthly averages, suggesting that each area of the harbor tends toward a signature response curve which varies in energy level according to incident wave variations but not in shape. The energy level across all frequencies of the extreme event average spectra is considerably higher than that of the monthly average spectra (Figure 20). Mean water level variations during the event had no clear impact on energy level of the spectral peaks at Pier 2, but they did appear to cause very small shifts in the frequency at which the peaks occurred.

To explore whether high energy long wave events consistently excite the main resonant peaks of the signature response curve, the time-history of energy level at specific resonant frequencies was plotted. Figure 22 shows results for a dominant resonant frequency at Pier 2 . Two adjacent frequencies are shown because varying conditions, such as tidal water level, caused the peak frequency to vary over this very small range. By comparing with Figure 16 , it is clear that high values of $H_{\text {s.long }}$ are accompanied by high energy in this resonant peak. Other resonant peaks show similar correspondence, indicating that when $H_{s, \text { long }}$ is high, all of the characteristic resonant frequencies have high energy levels.

\section{Correlations for predicting incident infragravity wave energy}

A special study was conducted to relate incident infragravity (long) wave energy to offshore wave conditions, for which long-term information is available. The purpose of the correlation study was to determine the ability to predict infragravity energy levels incident to the harbor from deepwater, wind wave parameters (Merrifield and Okihiro 1996). Correlations and linear regressions were calculated between observed infragravity energy (converted to an $H_{\text {s.long }}$ ) in the frequency range $0.002-0.040 \mathrm{~Hz}(500$ to $25 \mathrm{sec})$ at the array just outside of the harbor and reduced parameters $\left(H_{s} T_{p}\right.$, and $\left.\theta_{m}\right)$ measured at the offshore 
NDBC buoy. The distribution of $H_{\text {s,ong }}$ at the array and $\theta_{m}$ at the buoy over the two-winter analysis period is shown in Figures 23 and 24 .

In general, the correlations were weak. A correction for the reduction in wind wave energy at the array based on the direction of the deepwater waves provided some improvement, but predictions of infragravity energy levels based on offshore wind wave height still vary by a factor of five or more (Figure 25). The study concluded that detailed inspection of the deepwater spectra, perhaps in combination with a refraction-diffraction transformation model, would be needed to significantly improve the predictions.

\section{Special events, harbor closing}

The only reported operational problem during the period of harbor wave measurement was a closing of the harbor on 14-15 Mar 94. Figures 26-28 summarize CDIP array and NDBC buoy wave and meteorological measurements during the event. Figure 29 helps put the event in perspective relative to the full winter of 1993-4. The steepness parameter in the figure is the ratio of $\left(H_{j}\right)_{\text {buoy }}$ to deepwater wavelength based on $\left(T_{p}\right)_{\text {buoy }}$ Although $(H)_{\text {array }}\left(H_{s, \text { long }}\right)_{\text {array }}$ and $\left(H_{s}\right)_{\text {buoy }}$ are all high during the closure, they are not sufficiently high to distinguish the event as more extreme than other recorded events. The exceptional condition during closure appears to be a combination of high winds, high wave steepness, and long duration. Thus the harbor was apparently closed by a hazardous short wave condition (steep, energetic waves with likely wind-induced breaking).

\section{Special events, tsunami}

While tsunamis were not considered in the design of this study, the continuance of the gages beyond the first year resulted in a fortuitous measurement of the Shikotan tsunami on 4 October 1994 (McGehee and McKinney 1996). The measurement represents one of the few large (approximately $1-\mathrm{m}$ wave height) tsunami time series sampled continuously at high frequency $(1 \mathrm{~Hz})$. The tsunami wave period was approximately $30-35 \mathrm{~min}$, or about $0.0005 \mathrm{~Hz}$. Aside from the scientific value, this data set provided an opportunity to examine the response of the harbor to one instance of large-amplitude infragravity energy.

\section{Special events, extreme event parameters}

A more detailed documentation of extreme events recorded by the CDIP gages is given in Appendix C. Included are tabular summaries of parameters for observations with $\left(H_{s}\right)_{\text {array }} \geq 200 \mathrm{~cm}$ for short wave extremes and $H_{s, \text { long }} \geq 20 \mathrm{~cm}$ at the array or Pier 2 for long wave extremes. 


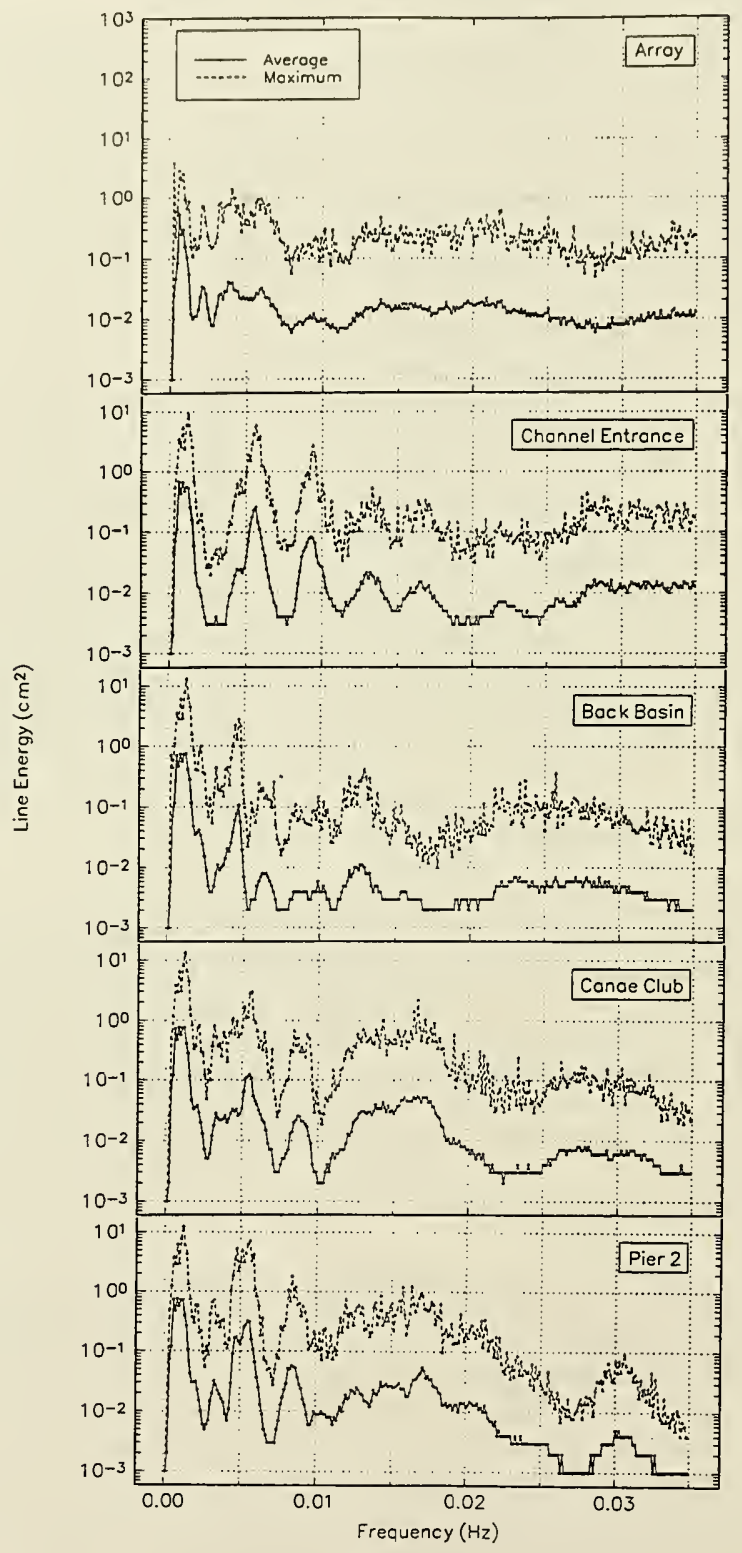

Figure 20. Average and maximum long wave spectra, Jan 94 


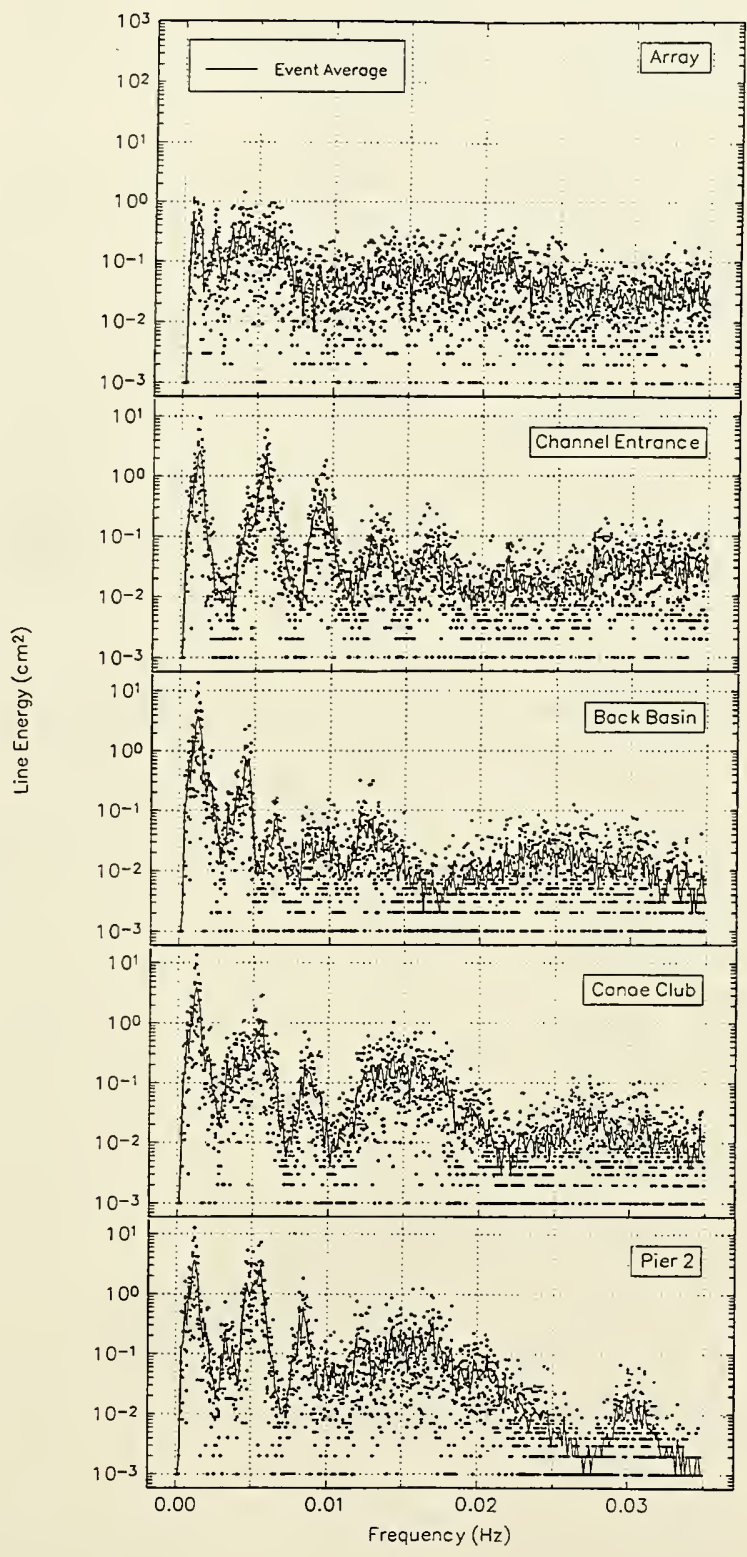

Figure 21. Long wave spectra for event on 2 Jan 94 (2355) to 3 Jan 94 (1900) 


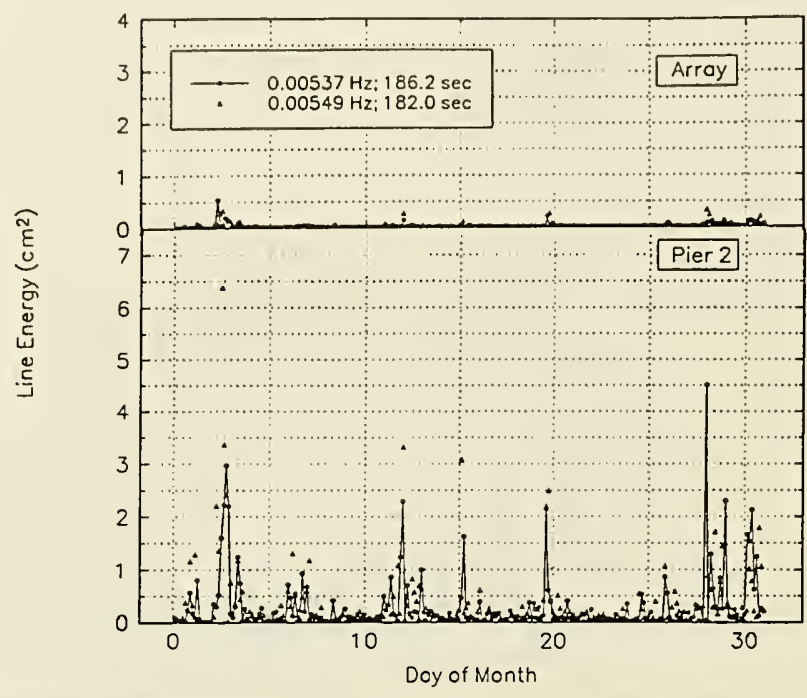

Figure 22. Time-history of amplification of specific resonant peak frequencies, Jan 94

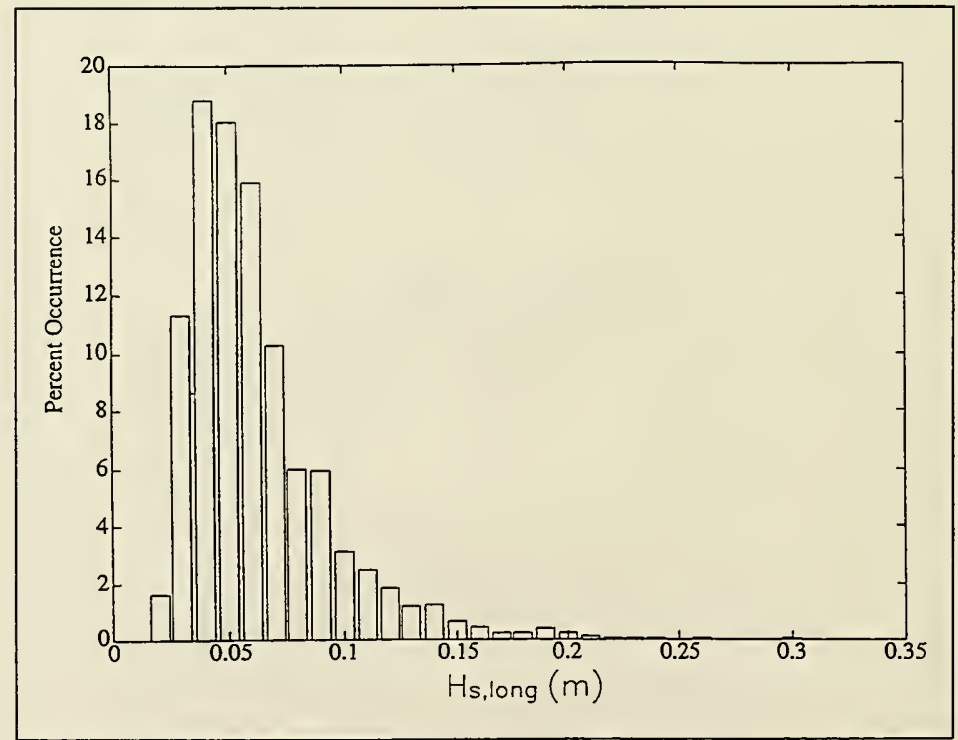

Figure 23. Probability distribution of ( $\left.H_{s, \text { long }}\right)_{\text {array }}$, Oct 93-Mar 95 (from Merrifield and Okihiro (1996)) 


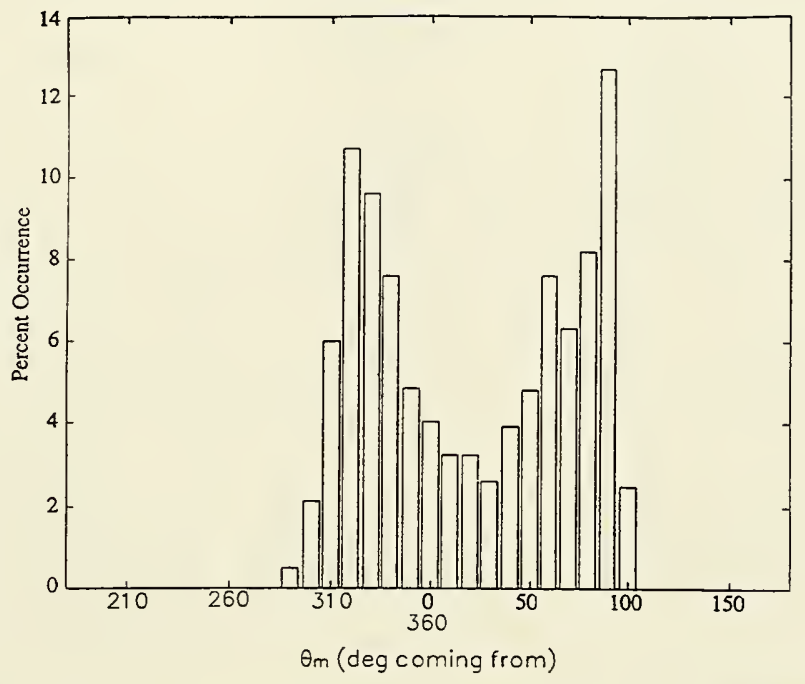

Figure 24. Probability distribution of $\left(\theta_{m}\right)_{b u o y}$, from NDBC buoy 51026, N. Molokai, Oct 93-Mar 95 (from Merrifield and Okihiro (1996))

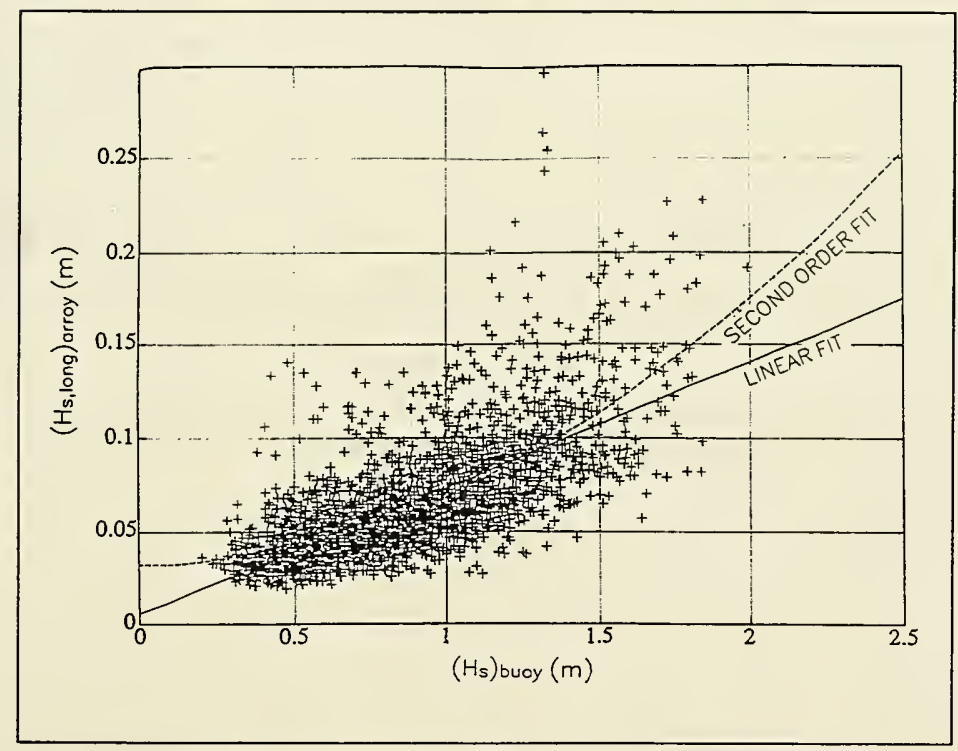

Figure 25. Scatter plot of $\left(H_{s, \text { long }}\right)_{\text {array }}$ versus $\left(H_{s}\right)_{\text {buoy }}$ (from Merrifield and Okihiro 1996) 

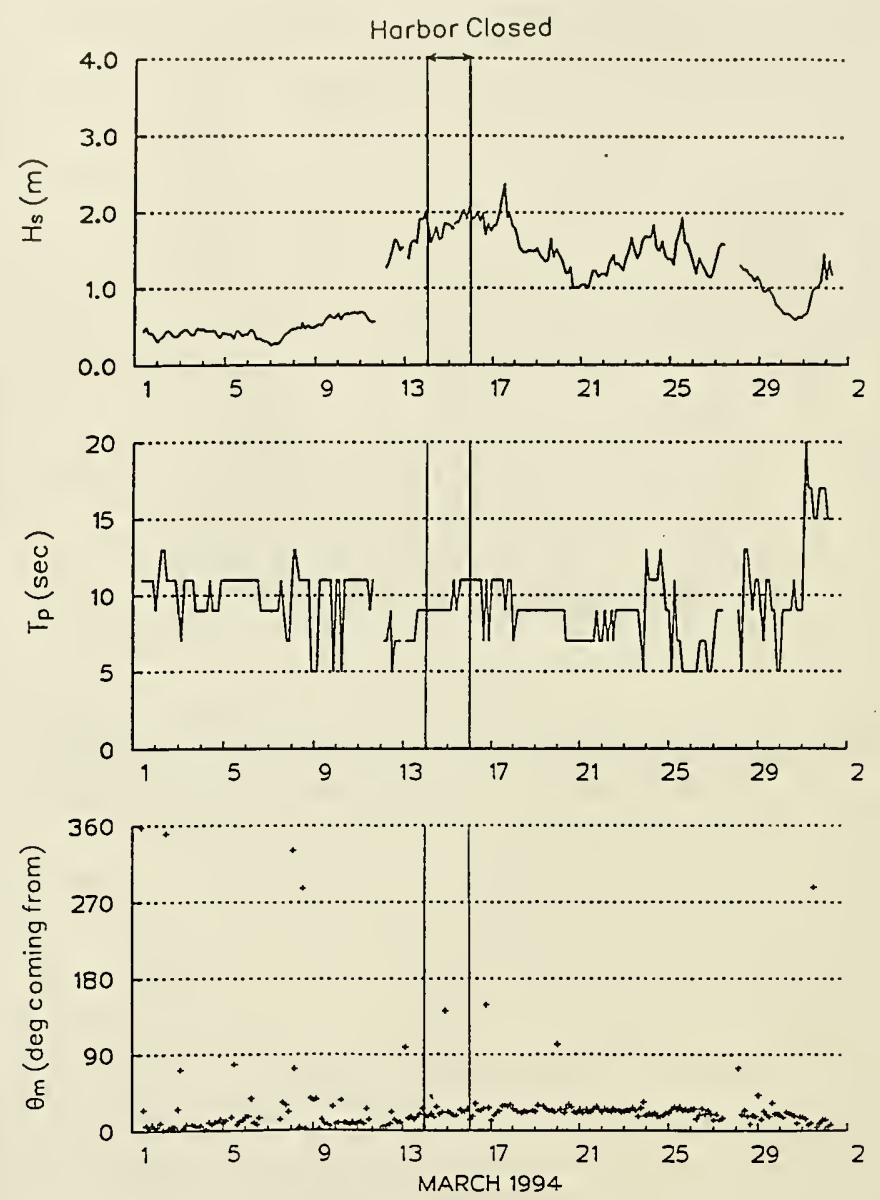

Figure 26. Harbor closing event; array parameters 


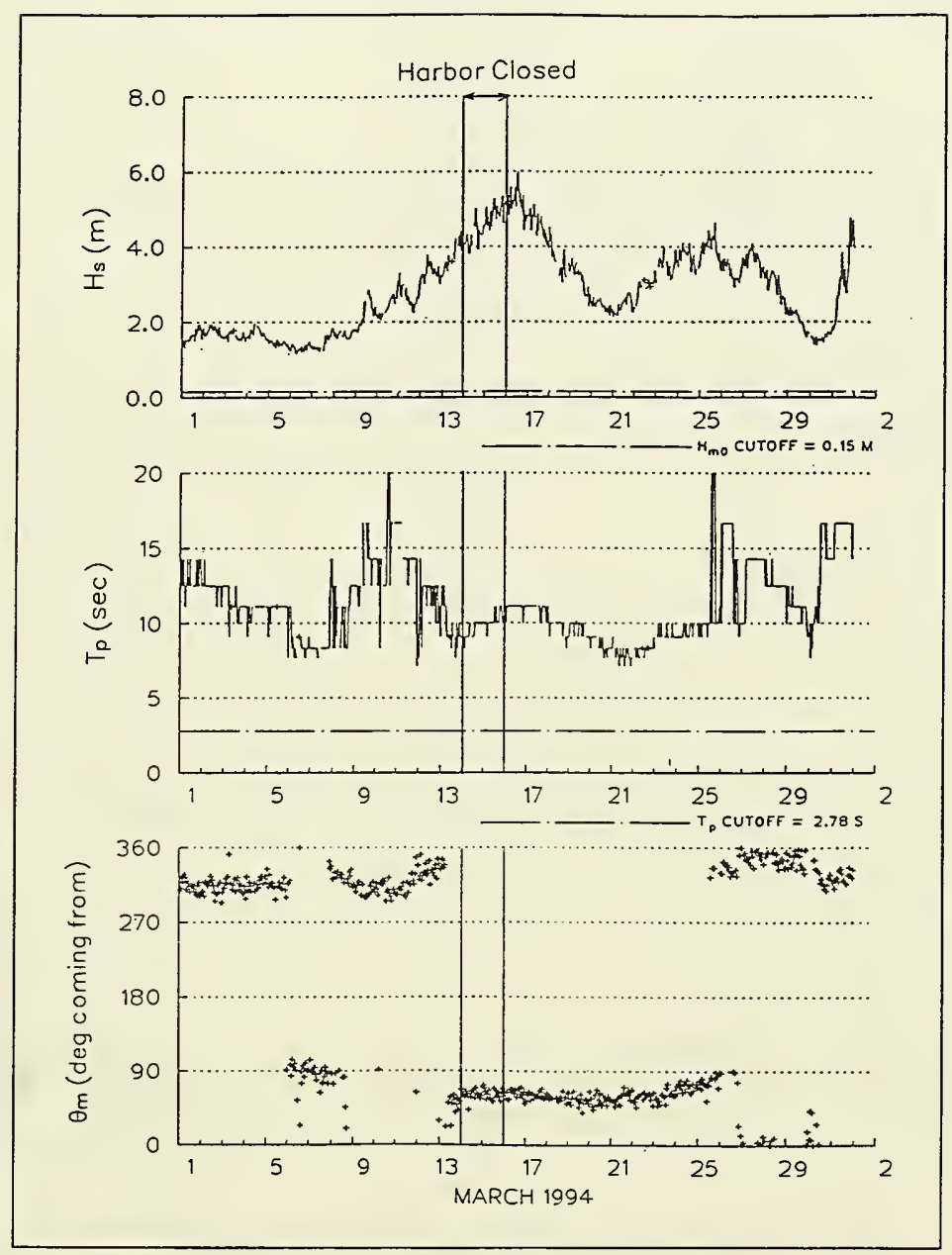

Figure 27. Harbor closing event; NDBC buoy wave parameters 


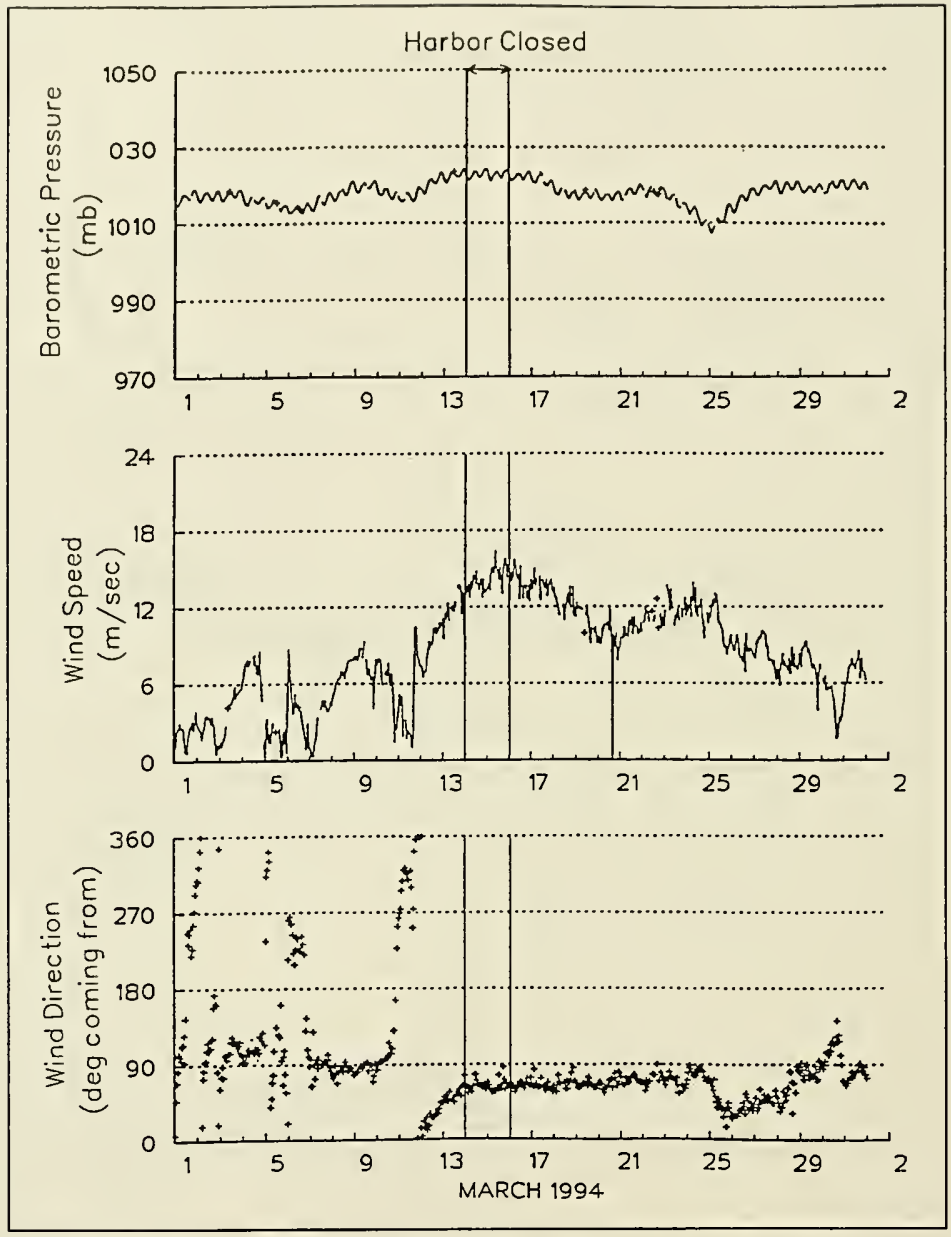

Figure 28. Harbor closing event; NDBC buoy meteorological parameters 

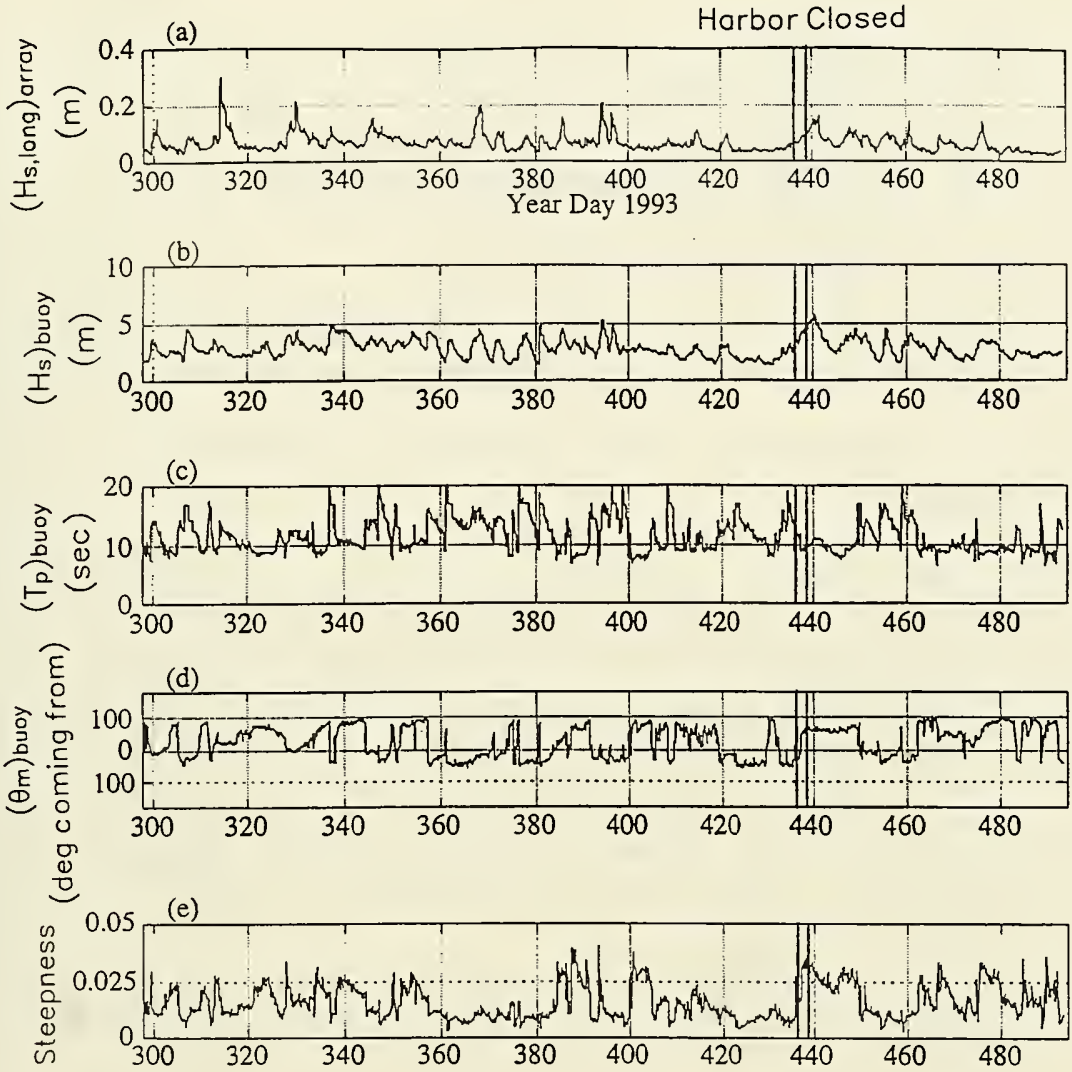

Figure 29. Time-history of selected wave parameters, array and NDBC buoy, winter of 1993-4 (from Merrifield and Okihiro (1996)) 


\section{Wind Wave and Swell Climate}

\section{Sources}

Three sources of wind wave and swell information were available to develop wave climate outside the harbor entrance (Table 6 and Figure 30). The first was the directional array gage in the 47.6-ft $(14.5-\mathrm{m})$ depth just outside the harbor entrance (CDIP gage 77). Data from November 1993 through December 1994 were used. The second was the directional buoy north of Molokai (NDBC buoy 51026) with data from October 1993 through May 1994 and September through December 1994. These gages are discussed in Chapter 2. The time intervals used were intended to be reasonably representative of the seasons of the year so that the gage data could be compared to long-term climate. Inclusion of the additional three months of available array data (Jan-Mar 95) would have distorted the distribution toward winter conditions (high wave beights).

The third source was the Wave Information Studies (WIS). WIS has hindcast waves over the North Pacific Ocean and saved information at selected deepwater stations around the Hawaiian Islands (Corson et al. 1986). Station 31, north of Maui, from the main 20-year hindcast, was considered in this study. The study also included two stations from a specially prepared 1-year WIS update coincident with the measurement time period. Stations of interest in the special update, which used a different grid, are shown in Figure 30 (Stations 3 and 5). Results from Station 5 were compared to data from the NDBC buoy to validate the special hindcast. Sample validation plots and wave summaries are given in Appendix D.

\section{Deepwater Wave Climate}

Although an NDBC buoy and three WIS stations are available in deep water offshore from Kahului Harbor, only WIS Station 31 provides long-term climate information. It is important to evaluate whether the locations and time period of measurement and special hindcast are representative of the long-term 


\begin{tabular}{|c|c|c|c|}
\hline \multicolumn{4}{|c|}{$\begin{array}{l}\text { Table } 6 \\
\text { Sources of Wave Climate Information }\end{array}$} \\
\hline Source & Years & Latitude (deg N) & Longitude (deg $W$ ) \\
\hline CDIP Gage 77 (Kahului array) & 1993-94 & 20.90 & 156.47 \\
\hline NDBC Buoy 51026 (N. Molokai) & $1993-94$ & 21.37 & 156.96 \\
\hline WIS Station 31 & $1956-75$ & 21.94 & 155.69 \\
\hline WIS Station 3 & 1994 & 22.20 & 155.63 \\
\hline WIS Station 5 & 1994 & 21.26 & 156.56 \\
\hline
\end{tabular}

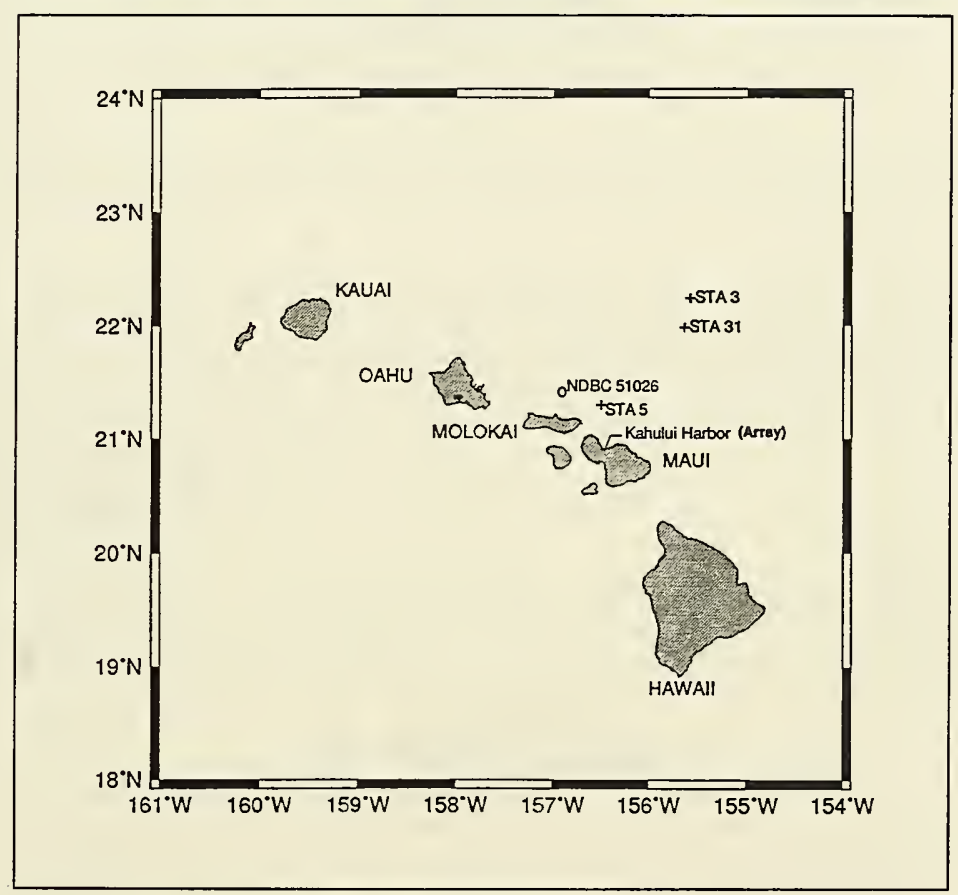

Figure 30 . Location map for wave climate study

climate incident to the north coast of Maui. Wave parameter summaries for the deepwater sources are compared in Figures 31-33.

Peak wave direction was not available for the 20 -year hindcast, only the mean wave direction. Wave components for sea (component 1) and swell (component 2) were available for this data set and consisted of height, period, and direction for each component. To get a representation of peak directions for comparison, a direction was chosen from either the sea or swell. If the overall 


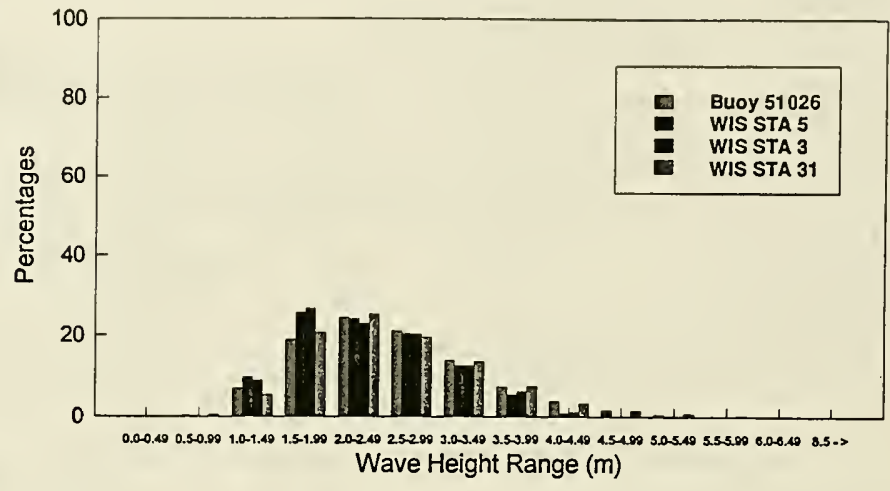

Figure 31. Deepwater wave climate comparison, $H_{s}$

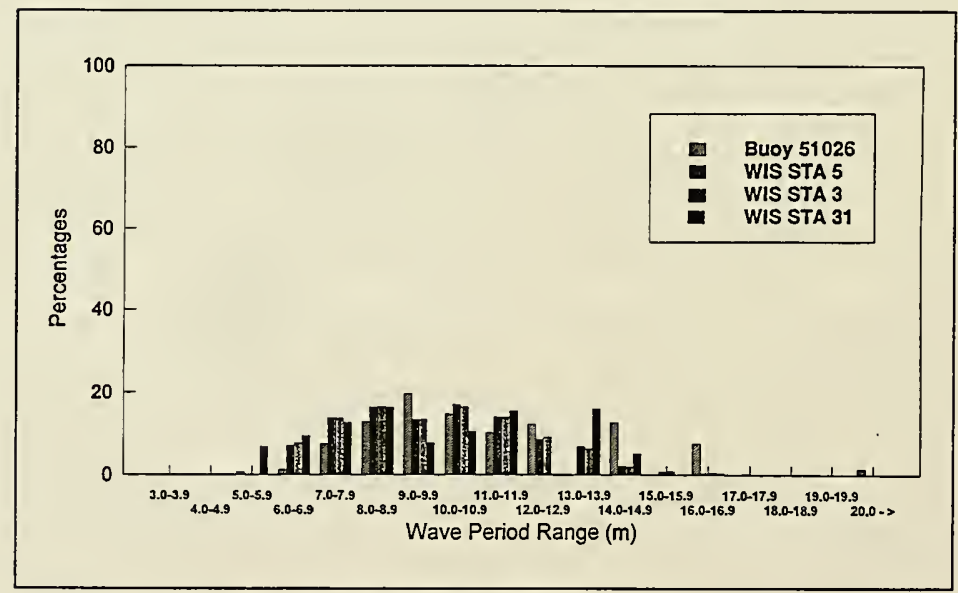

Figure 32. Deepwater wave climate comparison, $T_{p}$

peak period was close to the sea period, the direction associated with the sea was chosen as the peak direction. If the peak period was close to the swell peak, the direction associated with the swell was used.

Summaries shown in the figures are generally similar. Wave height and period distributions indicate virtually the same climate from all sources, although the buoy shows a tendency for a greater occurrence of swell periods above $14 \mathrm{sec}$. Wave direction distributions for the buoy and Station 31 both show 


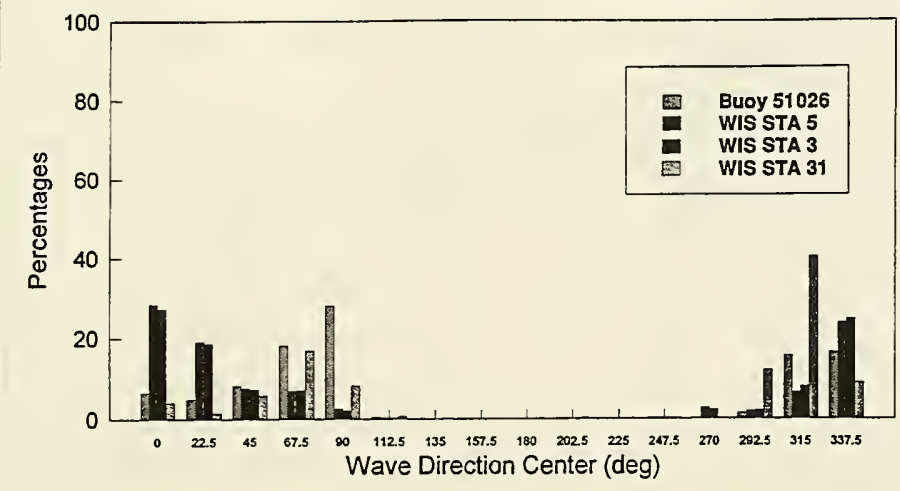

Figure 33. Deepwater wave climate comparison, $\theta_{m}$ (deg, coming from)

preferences for waves from the east, east-northeast, and northwest. Stations 3 and 5 also show a concentration of waves from northerly directions but the main concentration is centered on north. Despite these differences, it is concluded that the deepwater wave climate offshore from Maui's north coast is adequately represented by the available buoy measurements and long-term WIS station.

\section{Wave Climate at Kahului Harbor}

The deepwater wave climate analysis suggests that data from the array, which covers a time period comparable to the NDBC buoy and special hindcast sources, would reasonably characterize the wave climate immediately incident to Kahului Harbor. The array measurements incorporate local effects of sheltering and bathymetry.

To further validate the use of array data as the incident wave climate, an approximate procedure was used to relate the 20-year WIS hindcast to Kahului Harbor entrance. The procedure was to develop an empirical transformation between NDBC buoy and array measurement sites and then apply the transformation to the 20-year deepwater climate.

Wave heights and peak periods in the NDBC buoy and array data sets were segregated by direction bands, based on direction measured at the buoy. Linear regression equations were calculated for bands with more than 100 cases (Table 7). The regression equations were applied to the 20 years of WIS Station 31 information to estimate long-term climate at the Kahului gage. The transformed Station 31 (WIS 31T) and array gage summaries are very similar, especially considering the approximations involved in the transformation (Figures 34-36). 


\begin{tabular}{|c|c|c|c|}
\hline \multicolumn{4}{|c|}{$\begin{array}{l}\text { Table } 7 \\
\text { Empirical Relationships Between Deepwater and Kahului } \\
\text { Harbor Entrance }\end{array}$} \\
\hline Parameter & $\begin{array}{l}\text { NDBC Buoy Direction } \\
\text { (deg. coming from) }\end{array}$ & Empirical Transformation' & Correlation \\
\hline \multirow{6}{*}{$\begin{array}{l}\text { Significant } \\
\text { Wave Height } \\
\text { (m) }\end{array}$} & & $H_{s}=-0.21+0.64 H_{s o}$ & 0.77 \\
\hline & $45-90$ & $H_{s}=0.06+0.34 H_{s o}$ & 0.77 \\
\hline & $90-135$ & $H_{s}=0.06+0.27 H_{s o}$ & 0.71 \\
\hline & $270-315$ & $H_{s}=0.18+0.21 H_{s o}$ & 0.71 \\
\hline & $315-360$ & $H_{s}=0.05+0.36 H_{s o}$ & 0.71 \\
\hline & $0-360$ & $H_{s}=0.07+0.35 H_{s o}$ & 0.71 \\
\hline \multirow{6}{*}{$\begin{array}{l}\text { Peak Wave } \\
\text { Period (s) }\end{array}$} & $0-45$ & $T_{p}=-2.5+0.77 T_{p o}$ & 0.62 \\
\hline & $45-90$ & $T_{p}=8.1+0.23 T_{p o}$ & 0.10 \\
\hline & $90-135$ & $T_{p}=5.9+0.53 T_{p o}$ & 0.17 \\
\hline & $270-315$ & $T_{p}=3.4+0.65 T_{p o}$ & 0.42 \\
\hline & $315-360$ & $T_{p}=4.1+0.65 T_{p o}$ & 0.58 \\
\hline & $0-360$ & $T_{p}=5.0+0.58 T_{p \infty}$ & 0.55 \\
\hline \multirow{6}{*}{$\begin{array}{l}\text { Wave Direction } \\
\text { (deg, coming } \\
\text { from) }\end{array}$} & $0-45$ & $\theta_{p}=22+0.20 \theta_{p 0}$ & 0.14 \\
\hline & $45-90$ & $\theta_{p}=33-0.05 \theta_{p 0}$ & -0.04 \\
\hline & $90-135$ & $\theta_{p}=45-0.17 \theta_{p o}$ & -0.06 \\
\hline & $270-315$ & $\theta_{p}=-153+0.60 \theta_{\rho o}$ & 0.10 \\
\hline & $315-360$ & $\theta_{p}=95-0.19 \theta_{p o}$ & -0.08 \\
\hline & $0-360$ & $\theta_{p}=29+0.01 \theta_{\rho 0}$ & 0.10 \\
\hline
\end{tabular}

In conclusion, the time period of available measurements at the array gage appears to give a good representation of the overall wind wave and swell climate immediately incident to Kahului Harbor. It is recommended that the array data be used as the primary source of wave information for driving numerical and physical models of the harbor. 


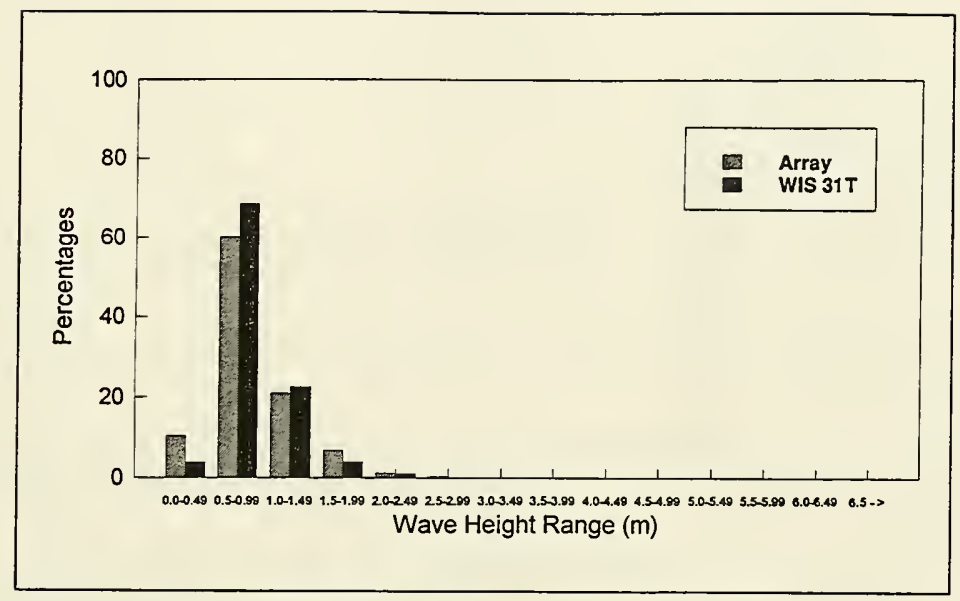

Figure 34. Harbor entrance wave climate comparison, $H_{s}$

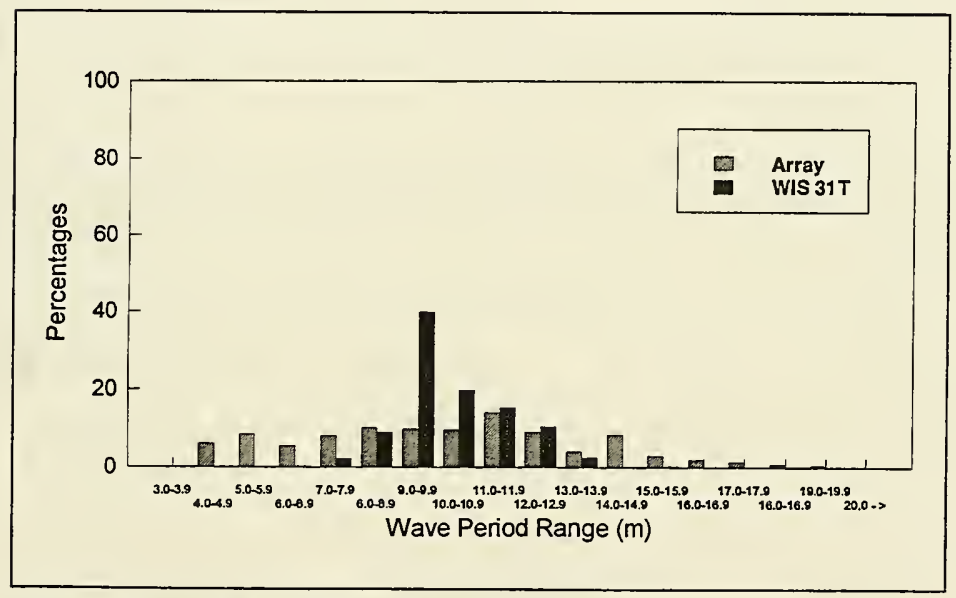

Figure 35. Harbor entrance wave climate comparison, $T_{p}$ 


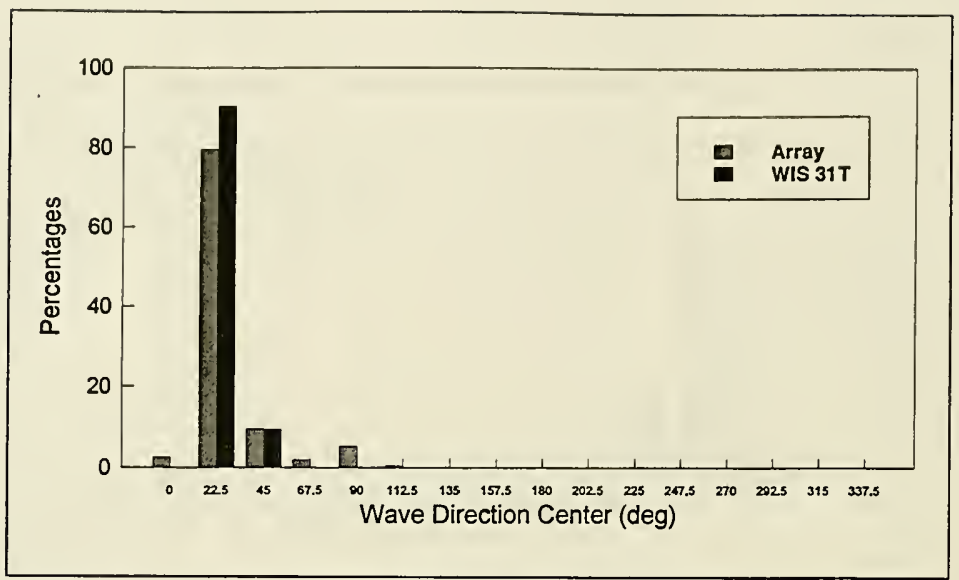

Figure 36. Harbor entrance wave climate comparison, $\theta_{m}$ (deg, coming from) 


\section{Numerical Model}

\section{Objectives and Approach}

The numerical model studies have three main objectives:

a. Calibrate and validate the numerical model with field data.

$b$. Advance understanding of the existing harbor wave response.

c. Evaluate the effect of proposed harbor modifications on harbor wave response.

The numerical model used for the studies, HARBD, is the standard WES tool for numerical harbor wave investigations. The model includes the following assumptions:

$a$. No wave transmission through the breakwaters.

$b$. No wave overtopping of structures.

c. Structure crest elevations above the water surface cannot be tested or optimized.

d. Currents in the channel cannot be evaluated.

$e$. Wave breaking effects in the entrance and harbor cannot be considered.

f. No nonlinear effects are considered.

g. Diffraction around structure ends is represented by diffraction around a blunt vertical wall with specified reflection coefficient.

Despite limitations imposed by the above assumptions, HARBD is considered suitable for meeting the numerical modeling objectives of the Kahului Harbor study. 
The harbor wave response model is presented in the following section, including a general description of the HARBD model and implementation of the model at Kahului Harbor. Validation was accomplished with a combination of storm wave events selected from available field data and with statistical summaries of a wide range of field cases. The final section of this chapter describes the test procedures and calculations. Procedures for evaluating operational performance at a pier are discussed.

As part of the test procedures, a suite of incident wave conditions must be specified at the seaward boundary of the area covered by HARBD. Incident short waves are determined by consideration of measurements outside the harbor. Incident long waves are specified over a broad range of frequencies but only a normally incident direction to identify possible harbor resonant responses.

The existing harbor and 11 proposed modifications were studied. Results for wind waves and swell are presented in Chapter 5. Harbor oscillation results are presented in Chapter 6. The presentation focuses on wave conditions in the vicinity of existing or proposed piers, but results over the full harbor area are also given.

\section{Model Description}

\section{Model formulation}

The numerical wave model HARBD is a steady-state hybrid element model used in the calculation of linear wave response in harbors of varying size and depth (Chen 1986, Chen and Houston 1987, Lillycrop and Thompson 1996). Originally developed for use with long-period waves (Chen and Mei 1974), HARBD has since been adapted to include capabilities for modeling wind waves and swell (Houston 1981), bottom friction, and partially reflective boundaries (Chen 1986). The model is based on a linearized mild slope equation. An overview of the model and its applications is given by Thompson and Hadley (1995).

The HARBD model has been shown to perform satisfactorily in comparison to analytic solutions and laboratory data for a variety of wind wave and swell cases (Houston 1981; Crawford and Chen 1988; Thompson, Chen, and Hadley 1996) and long wave cases (Chen 1986; Chen and Houston 1987; Houston 1981; Thompson, Chen, and Hadley 1993). As a result, it has been used with confidence in both long wave and short wave studies. Studies encompassing both long (harbor oscillations) and short waves are Harkins et al. (1996) and Thompson and Hadley (1994b). Additional long wave studies have included harbor oscillations (Briggs et al. 1994; Briggs, Lillycrop, and McGehee 1992; Mesa 1992; Sargent 1989; Weishar and Aubrey 1986; Houston 1976) and tsunamis (Farrar and Houston 1982, Houston and Garcia 1978, Houston 1978). Additional wind wave and swell studies include Thompson and Hadley (1994a); Lillycrop et al. (1993); Lillycrop and Boc (1992); Lillycrop, Bratos, and 
Thompson (1990); Kaihatu, Lillycrop, and Thompson (1989); Farrar and Chen (1987); Clausner and Abel (1986); and Bottin, Sargent, and Mize (1985).

The HARBD model covers in detail a domain including the harbor and a portion of the adjacent nearshore area (Figure 37). This domain is bounded by a 180-deg semicircle in the water region seaward of the harbor entrance $(\partial A$ in Figure 37) and the land-water interface along the shoreline and harbor $(\partial C$ in Figure 37). The region defined by these boundaries is denoted Region $A$. If possible, the semicircle radius should be at least twice the wavelength of the longest incident wave to be modeled (using a typical water depth within the semicircle). Also, the semicircle should encompass any complex offshore bathymetry which strongly influences waves entering the harbor. In general, the semicircle should be as large as practical constraints on grid size and resolution will allow.

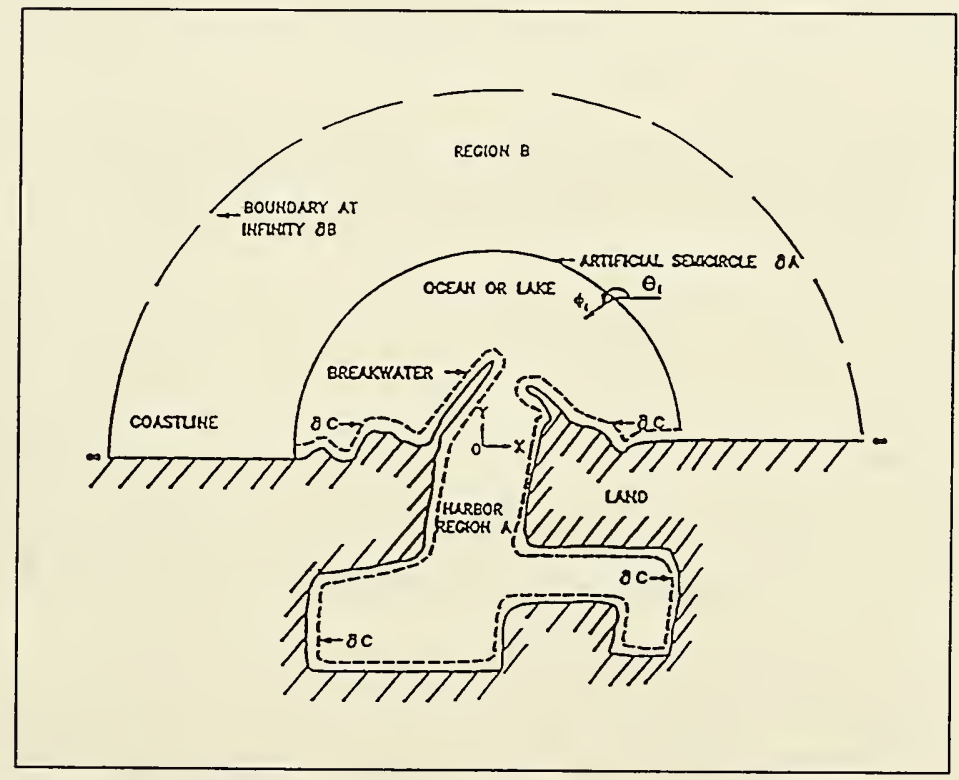

Figure 37. Representation of HARBD domain

The area outside the semicircle is treated as a semi-infinite region which extends from a straight coastline seaward to infinity (Region $B$ ). This region is assumed to have a constant water depth and no bottom friction.

Assuming linear, regular waves propagating over mild slope in arbitrary water depth, Chen (1986) derived the governing equation as 


$$
\nabla \cdot\left(\lambda c c_{g} \nabla \phi\right)+\frac{\omega^{2} c_{g}}{c} \phi=0
$$

where

$$
\begin{aligned}
& \nabla=\text { horizontal gradient operator } \\
& \lambda=\text { complex bottom friction factor } \\
& c=\text { wave phase speed } \\
& c_{g}=\text { wave group speed } \\
& \phi=\text { velocity potential } \\
& \omega=\text { angular frequency }
\end{aligned}
$$

This equation is identical to Berkhoff's (1972) equation except for addition of the bottom friction factor $\lambda$. The factor $\lambda$, which is a complex number with magnitude greater than zero and less than or equal to one, is specified as

$$
\lambda=\frac{1}{1+\frac{i \beta a_{i}}{d \sinh \kappa d} e^{i \gamma}}
$$

where

$$
\begin{aligned}
& i=(-1)^{1 / 2} \\
& \beta=\text { dimensionless bottom friction coefficient that can vary in space } \\
& a_{i}=\text { incident wave amplitude } \\
& d=\text { water depth } \\
& \kappa=\text { wave number } \\
& \gamma=\text { phase shift between stress and flow velocity }
\end{aligned}
$$

The bottom friction factor is a factor tending to reduce local velocities proportionately through the relationships 


$$
\begin{aligned}
& u=\lambda \frac{\partial \phi}{\partial x} \\
& v=\lambda \frac{\partial \phi}{\partial y}
\end{aligned}
$$

where

$$
\begin{aligned}
& u, v=\text { local horizontal velocity components } \\
& x, y=\text { horizontal coordinates }
\end{aligned}
$$

Boundary conditions are specified in Regions $A$ and $B$. At the solid boundary $\partial C$, a reflection/absorption boundary condition is used similar to the impedance condition in acoustics. The condition is specified as

$$
\frac{\partial \phi}{\partial n}-\alpha \phi=0
$$

with

$$
\alpha=i \kappa \frac{1-K_{r}}{1+K_{r}}
$$

where

$$
\begin{aligned}
& n=\text { unit normal vector directed into the solid region } \\
& K_{r}=\text { reflection coefficient of the boundary }
\end{aligned}
$$

Values of $K_{r}$ for wind waves and swell are normally chosen based on the boundary material and shape. General guidelines for $K_{r}$ can be assembled from laboratory and field data (Thompson, Chen, and Hadley 1996). In wind wave and swell studies, $K_{r}$ is generally chosen to be consistent with this guidance. Effects such as slope, permeability, relative depth, wave period, breaking, and overtopping can be considered in selecting values within these fairly wide ranges. For long wave studies, $K_{r}$ is generally set equal to 1.0 , representing full reflection.

The second boundary condition is imposed in the far region (Region $B$ ) at infinity. It requires that the scattered wave, defined as the difference between the total wave and incident wave, behave as a classical outgoing wave at infinity. This radiation condition may be expressed as 


$$
\lim _{r \rightarrow \infty} \sqrt{r}\left(\frac{\partial}{\partial r}-i \kappa\right) \phi^{s}=0
$$

where

$r \quad$ radial polar coordinate

$\phi^{s}=$ velocity potential of the scattered wave

The complete boundary value problem is specified by Equations 2, 5, and 7 . A hybrid element method is employed to solve the boundary value problem. A conventional finite element grid is developed and solved in Region $A$. The triangular elements allow detailed representation of harbor features and bathymetry within Region $A$. An analytical solution with unknown coefficients in a Hankel function series is used to describe Region $B$. For a given grid, short wave period tests (relatively large values of $\kappa$ ) require more terms than long period tests to adequately represent the series. A variational principle with a proper functional is established such that matching conditions are satisfied along $\partial A$. Details are given by Chen (1986) and Lillycrop and Thompson (1996).

Experience with the model has indicated that the element size $\Delta x$ and local wavelength $L$ should be related by

$$
\Delta x \leq \frac{L}{6}
$$

Typically, harbor domains include some shallow areas in which many elements would be needed to satisfy the constraint in Equation 8 . In practice, Equation 8 is at least satisfied in the harbor channel and basin depths. If additional elements can be accomodated, it is generally preferred to extend the semicircle further seaward rather than to greatly refine shallow harbor regions.

Input information for HARBD must be carefully assembled. In addition to developing the finite element grid to suit HARBD requirements, a number of parameters must be specified. Critical input parameters and ranges of typical values are summarized in Table 8.

The principal output information available from HARBD consists of amplification factor and phase at each node. These are defined as

$$
\begin{aligned}
A_{\text {amp }} & =\left|\frac{a}{a_{i}}\right|=\left|\frac{H}{H_{i}}\right|=|\phi| \\
\theta & =\tan ^{-1}\left[\frac{\operatorname{Im}\{\phi\}}{\operatorname{Re}\{\phi\}}\right]
\end{aligned}
$$




\begin{tabular}{|c|c|c|c|}
\hline \multicolumn{4}{|c|}{$\begin{array}{l}\text { Table } 8 \\
\text { Critical HARBD Input Parameters and Ranges of Typical Values }\end{array}$} \\
\hline \multirow[b]{2}{*}{ Parameter } & \multirow{2}{*}{ Where Specified } & \multicolumn{2}{|l|}{ Typical Values } \\
\hline & & Short Waves & Long Waves \\
\hline Bottom friction, $\beta$ & Every element & 0.0 & $0.0-0.1$ \\
\hline Boundary reflection, $K_{r}$ & $\begin{array}{l}\text { Every element on solid } \\
\text { boundary }\end{array}$ & $0.0-1.0$ & 1.0 \\
\hline Coastline reftection, $K_{r, \text { cosst }}$ & Single value & 1.0 & 1.0 \\
\hline $\begin{array}{l}\text { Depth in infinite region, } \\
d_{t a r}\end{array}$ & Single value & \multicolumn{2}{|c|}{ Between avg. \& max. on semicircle } \\
\hline $\begin{array}{l}\text { Number of terms in } \\
\text { Hankel function series }\end{array}$ & Single value & $8-100^{\prime}$ & 8 \\
\hline
\end{tabular}

where

$$
\begin{aligned}
A_{\text {amp }} & =\text { amplification factor } \\
a, a_{i} & =\text { local and incident wave amplitudes } \\
H, H_{i} & =\text { local and incident wave heights } \\
\theta & =\text { phase relative to the incident wave } \\
\operatorname{Im}\{\phi\} & =\text { imaginary part of } \phi \\
\operatorname{Re}\{\phi\} & =\text { real part of } \phi
\end{aligned}
$$

Amplification factors are easily interpreted. Phases are helpful in viewing wind wave and swell propagation characteristics and in interpreting standing wave patterns. In long wave applications, phases prove useful for determining relative phase differences within the harbor, interpreting harbor oscillation patterns, and identifying potentially troublesome nodal areas.

\section{Spectral adaptation}

HARBD computes harbor response to specified wave period and direction combinations. However, the model is often used to approximate irregular wind wave and swell behavior, as in physical model tests with irregular waves and all field cases. More realistic numerical model simulations can be obtained by linearly combining HARBD results from a range of regular wave frequencies and directions in the irregular wave spectrum. With proper weighting, regular wave results represent a desired spectral distribution of energy. 
Spectral adaptation of the HARBD model is done as a post-processing step using the standard, regular wave output from the model. For a given set of incident wave directions representing the range of possible approach directions, HARBD is run for a number of wave periods spread between the shortest period satisfying the grid resolution constraint of Equation 8 and the longest swell period of interest.

Spectral post-processing is based on the assumption that a consistent spectral form can be applied at every node. This major assumption provides the basis for a workable, reasonable spectral weighting which improves on the traditional regular wave approach. The spectrum is represented as the product of two functions:

$$
S(f, \theta)=S(f) D(f, \theta)
$$

where

$$
\begin{aligned}
S(f, \theta) & =\text { directional spectral energy density function } \\
S(f) & =\text { spectral energy density function } \\
D(f, \theta) & =\text { angular spreading function }
\end{aligned}
$$

The JONSWAP spectral form was chosen for $S(f)$ (Hasselmann et al. 1973). The JONSWAP spectrum is specified as (U.S. Army Corps of Engineers 1989)

$$
S\left(f_{i}\right)=\frac{\alpha g^{2}}{(2 \pi)^{4} f_{i}^{5}} e^{a} \gamma^{b}
$$

where $S\left(f_{i}\right)=$ spectral energy density at frequency $f_{i}$ -

The parameters $a$ and $b$ are given by the following relationships:

$$
\begin{aligned}
a & =\frac{-1.25}{f_{i} T_{p}^{4}} \\
b & =e^{\frac{-1}{2 \sigma^{2}}\left(f_{i} T_{p}-1\right)^{2}} \\
\sigma & =0.07 \quad \text { for } f_{i} \leq f_{p} \\
& =0.09 \text { for } f_{i} \geq f_{p}
\end{aligned}
$$


where

$$
\begin{aligned}
T_{p} & =\text { peak spectral period } \\
f_{p} & =\text { peak spectral frequency }=\frac{1}{T_{p}}
\end{aligned}
$$

Parameters $\alpha$ and $\gamma$ are calculated as

$$
\begin{aligned}
& \alpha=157.9 \epsilon^{2} \\
& \gamma=6614 \epsilon^{1.59} \\
& \epsilon=\frac{H_{s}}{4 L_{p}}
\end{aligned}
$$

where

$$
\begin{aligned}
& H_{s}=\text { significant wave height } \\
& L_{p}=\text { wavelength for waves at peak frequency }
\end{aligned}
$$

The parameter $\epsilon$ is a significant wave steepness. The parameter $\gamma$, called the peak enhancement factor, controls the sharpness of the spectral peak.

Although the JONSWAP spectrum was developed primarily for actively growing wind waves, it can be used with appropriate choice of $\gamma$ to approximate any single-peaked spectrum, including old swell which has travelled a great distance from the generation area (e.g. Goda 1985) (Table 9).

\begin{tabular}{|l|l|}
\hline $\begin{array}{l}\text { Table } 9 \\
\text { Guidance for } \\
\text { Choosing } \mathrm{Y}\end{array}$ \\
\hline Wave Condition & $\mathrm{Y}$ \\
\hline \hline Growing sea & 3.3 \\
\hline Old swell & $8-10$ \\
\hline
\end{tabular}

The angular spreading function in Equation 10 is described by the commonly used expression

$$
D(\theta)=G(s) \cos ^{2 s}\left(\frac{\theta-\theta_{0}}{2}\right)
$$

where

$$
\begin{aligned}
G(s) & =\text { normalizing function } \\
s & =\text { constant-valued spreading parameter }
\end{aligned}
$$


$\theta_{0}=$ primary wave direction

$\theta-\theta_{0}=$ wave direction difference, ranging from $-\pi / 2$ to $+\pi / 2$

The spreading parameter $s$ controls the magnitude of directional spread. As the value of $s$ increases, directional spread narrows. Wind waves are typically represented by broad spreads and swell by narrow spreads. Recommended representative values for each are given in Table 10 (Goda 1985).

\begin{tabular}{|l|l|}
\hline $\begin{array}{l}\text { Table } 10 \\
\text { Guidance for Choosing s }\end{array}$ \\
\hline Wave Condition & $s$ \\
\hline \hline Wind waves & 10 \\
\hline Swell & $25-75$ \\
\hline
\end{tabular}

Spectral post-processing begins

with specification of the desired $H_{s}, T_{p}, \gamma$, and $s$ and the arrays of HARBD amplification factors. A refined JONSWAP spectrum is computed with 1,000 points, where the $f_{i}$ 's in Equation 11 are

$$
f_{1}=0.5 * f_{p}, f_{2}=0.502 * f_{p}, f_{3}=0.504 * f_{p}, \ldots, f_{1000}=2.498 * f_{p}
$$

The number of wave periods computed with HARBD is always much smaller than 1,000 , typically less than 20 . These periods, converted to frequency (reciprocal of period), can be used to define bands in the JONSWAP spectrum. Bands are bounded by the midpoints between HARBD computational frequencies. The highest and lowest frequency bands are assumed to be centered on the highest and lowest HARBD computational frequencies, respectively. A weighting factor for each HARBD-defined band is computed by summing values from the refined JONSWAP spectrum which fall within the band and normalizing by the total spectral energy.

$$
w_{k}=\frac{\sum_{i=N_{k 1}}^{N_{k 2}} S\left(f_{i}\right)}{\sum_{i=1}^{1,000} S\left(f_{i}\right)}
$$

where

$$
\begin{aligned}
& w_{k}=\text { weighting factor for } k \text { 'th HARBD computational frequency } \\
& N_{k l}=\text { index of lowest JONSWAP frequency } f_{i} \text { satisfying } f_{i}>\frac{f_{k-1}+f_{k}}{2} \\
& N_{k 2}=\text { index of highest JONSWAP frequency } f_{i} \text { satisfying } f_{i}<\frac{f_{k}+f_{k+1}}{2}
\end{aligned}
$$


$f_{k-1}, f_{k} f_{k+1}=(k-1)$ 'th, $k$ 'th, and $(k+1)^{\prime}$ th HARBD computational frequencies, with $f_{k-1}<f_{k}<f_{k+1}$

Though not shown in the equation, the weighting factor also includes fractional energy interpolated across JONSWAP frequencies bracketing the two end points of each HARBD band.

Directional spread is also calculated over 1,000 points, covering a range of $-\pi / 2$ to $+\pi / 2$. The midpoints between HARBD wave directions are used to define directional bands. The weighting factor for each HARBD-defined directional band becomes:

$$
w_{n}=\frac{\sum_{i=N_{n 1}}^{N_{n 2}} D\left(\theta_{i}\right)}{\sum_{i=1}^{1.000} D\left(\theta_{i}\right)}
$$

where

$w_{n}=$ weighting factor for $n$ 'th HARBD computational direction

$N_{n I}=$ index of lowest spreading direction $\theta_{i}$ satisfying $\theta_{i}>\frac{\theta_{n-1}+\theta_{n}}{2}$

$N_{n 2}=$ index of highest spreading direction $\theta_{i}$ satisfying $\theta_{i}<\frac{\theta_{n}+\theta_{n+1}}{2}$

$\theta_{n-1}, \theta_{n}, \theta_{n+1}=(n-1)^{\prime}$ th, $n^{\prime}$ th, $(n+1)^{\prime}$ th HARBD computational directions, with $\theta_{n-1}<\theta_{n}<\theta_{n+1}$

The width of the lowest HARBD-defined directional band is assumed to be twice the difference between the HARBD direction and the first midpoint. The width of the highest HARBD-defined directional band is defined similarly.

The effective amplification factor at each node can then be computed as

$$
\left(A_{\text {amp }}\right)_{\text {eff }}=\sqrt{\sum_{k=1}^{N_{T}} \sum_{n=1}^{N_{D}} w_{n} w_{k} A_{a m p}^{2}\left(f_{k}, \theta_{n}\right)}
$$

where

$$
\left(A_{\text {amp }}\right)_{\text {eff }}=\text { effective, or spectral, amplification factor at a node }
$$




$$
\begin{aligned}
A_{\text {amp }}\left(f_{b} \theta_{n}\right) & =\text { nodal amplification factor for HARBD computational } \\
& \text { frequency } f_{k} \text { and direction } \theta_{n} \\
N_{T} & =\text { number of HARBD computational wave periods } \\
N_{D} & =\text { number of HARBD computational wave directions }
\end{aligned}
$$

\section{Finite element grids}

The finite element numerical grid depicting existing conditions at Kahului Harbor was created using WES's finite element grid development software (Turner and Baptista 1993) (Figure 38). The grid covers the entire Kahului Harbor area and extends somewhat seaward into Kahului Bay. The land boundary was digitized from an aerial photograph. Grid element size is based on the criterion of 6 elements per wavelength (the minimum recommended resolution with HARBD) for a 10 -sec wave in $15-\mathrm{ft}$ water depth. Depths for virtually all areas of interest exceed $15 \mathrm{ft}$. For the longer period waves, the grid gives a high degree of resolution. Grid characteristics are summarized in Table 11.

The radius of the seaward semicircle is $2,307 \mathrm{ft}$. This is equivalent to 2.9 and 9.7 wavelengths for the longest and shortest short wave periods considered, assuming a representative water depth of $35 \mathrm{ft}$. The semicircle size and location were chosen to include both breakwaters and the immediate nearshore area. The semicircle extends sufficiently far seaward to cover the most important nearshore bathymetry while maintaining a reasonable number of grid elements.

Bathymetric data were obtained from National Oceanic and Atmospheric Administration hydrographic chart 19342 and WES bathymetric survey data. Digitized depths were transferred onto the finite element grid using the WES grid software package. A contour plot of bathymetry is given in Figure 39.

Reflection coefficients $K_{r}$ are needed for all solid boundaries. For the short wave tests, $K_{r}$ values were estimated from existing Corps of Engineers guidance, photos, and field notes from a recent site visit by WES personnel, and past experience. The solid boundary was divided into 13 zones and a reflection coefficient was estimated for each zone (Figure 40). Reflection coefficients ranged from 0.2 for the shallow sandy beach along the southwest shore of the existing harbor to 0.5 for all pier areas and 0.9 for the grouted revetment along the western side of Pier 2. Additional parameter values used in the numerical model are summarized in Table 12.

Different parameters are used for the long wave tests. The reflection coefficient was set to 1.0 for all boundaries, since long waves generally reflect very well from a coastal boundary. Long waves are more affected by bottom friction than short waves, so a value of $\beta$ greater than zero is appropriate. The value of $\beta$ is best determined by calibration with field data, as discussed in the following section. A value of $\beta=0.032$ was selected. This and other parameters are summarized in Table 12. 


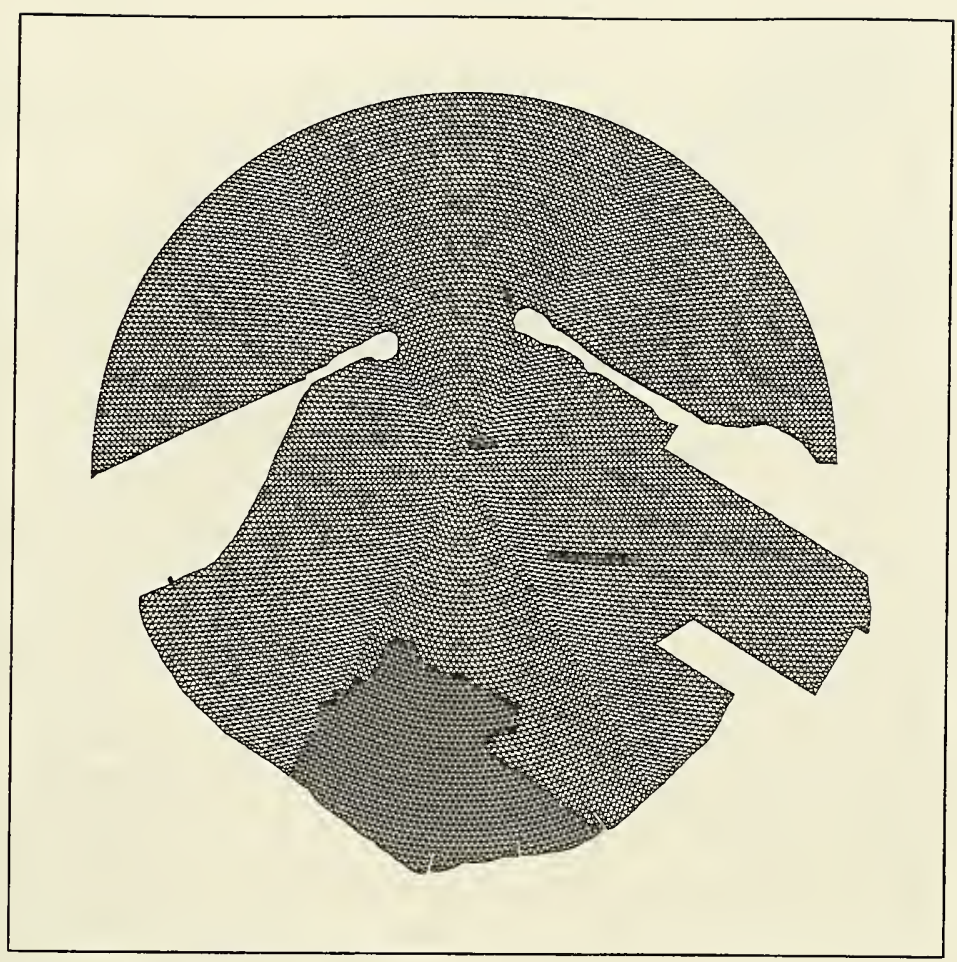

Figure 38. Grid of existing harbor

In addition to existing conditions, 11 harbor modification plans were specified for evaluation, as discussed in Chapter 1 and summarized in Table 13. The existing harbor grid was modified to represent each alternative configuration. Grid characteristics for each configuration are included in Table 11. Short wave reflection coefficients were modified as appropriate for the plan grids. General guidelines were $K_{r}=0.5$ along piers (mainly due to steep, partially revetted slopes under piers) and $K_{r}=0.35$ along breakwater extensions. 


\begin{tabular}{|c|c|c|c|c|c|}
\hline \multicolumn{6}{|c|}{$\begin{array}{l}\text { Table } 11 \\
\text { Grid Sizes }\end{array}$} \\
\hline \multirow[b]{2}{*}{$\begin{array}{l}\text { Harbor } \\
\text { Plan }\end{array}$} & \multicolumn{4}{|c|}{ Number of: } & \multirow[b]{2}{*}{$\begin{array}{l}\text { Length } \\
\text { of Typical } \\
\text { Element ( } \mathrm{t} \text { ) }\end{array}$} \\
\hline & Elements & Nodes & $\begin{array}{l}\text { Solid } \\
\text { Boundary } \\
\text { Nodes }\end{array}$ & $\begin{array}{l}\text { Semicircle } \\
\text { Boundary } \\
\text { Nodes }\end{array}$ & \\
\hline Existing & 22908 & 11801 & 497 & 196 & 35.5 \\
\hline Plan 1 & 23351 & 12045 & 542 & 196 & 35.5 \\
\hline Plan 2 & 23468 & 12106 & 547 & 196 & 35.5 \\
\hline Plan 3a & 23393 & 12053 & 516 & 196 & 35.5 \\
\hline Plan 3b & 23331 & 12036 & 544 & 196 & 35.5 \\
\hline Plan $3 c$ & 23286 & 12024 & 565 & 196 & 35.5 \\
\hline Plan 4a & 22562 & 11627 & 495 & 196 & 35.5 \\
\hline Plan 4b & 22500 & 11610 & 523 & 196 & 35.5 \\
\hline Plan $4 c$ & 22455 & 11598 & 544 & 196 & 35.5 \\
\hline Plan 5 & 21696 & 11216 & 539 & 196 & 35.5 \\
\hline$P \operatorname{lan} 6$ & 22500 & 11610 & 523 & 196 & 35.5 \\
\hline Plan 7 & 21239 & 10998 & 560 & 196 & 35.5 \\
\hline
\end{tabular}




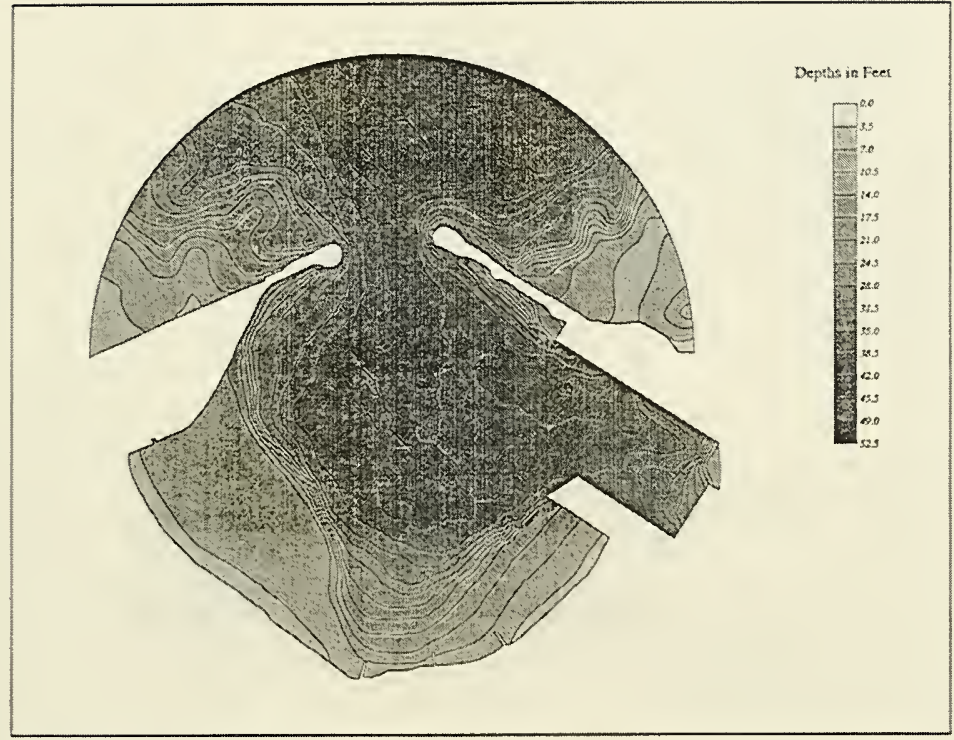

Figure 39. Bathymetry, existing harbor

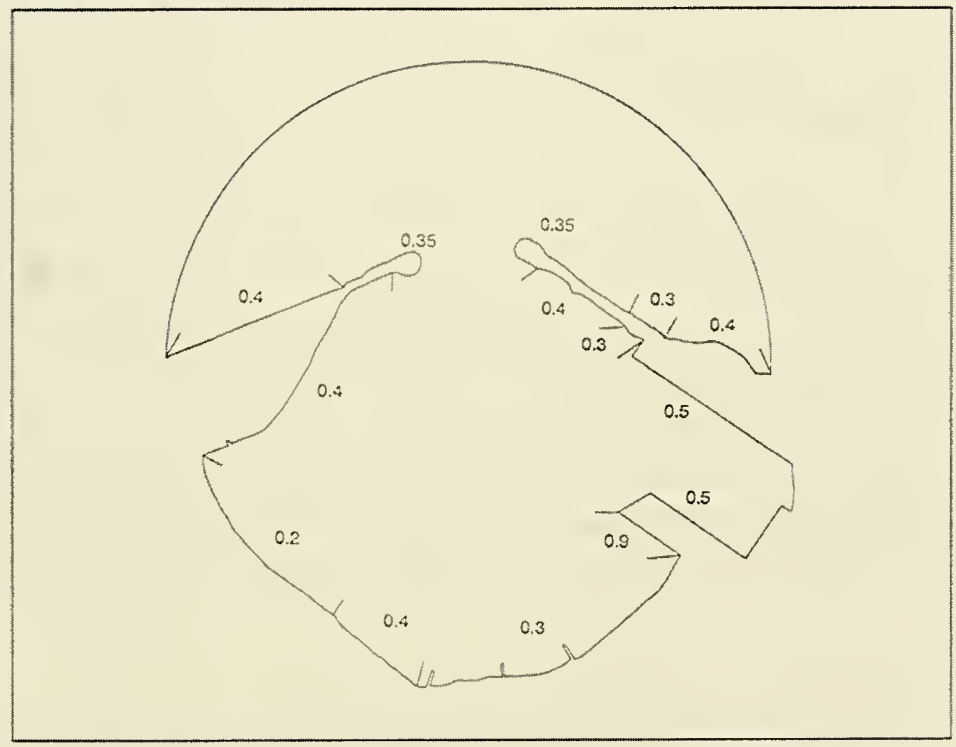

Figure 40 . Wave reflection coefficient values, short waves, existing harbor 


\begin{tabular}{|c|c|c|}
\hline \multicolumn{3}{|c|}{$\begin{array}{l}\text { Table } 12 \\
\text { Parameter Values Used in HARBD }\end{array}$} \\
\hline \multirow[b]{2}{*}{ Parameter } & \multicolumn{2}{|l|}{ Value } \\
\hline & Short Waves & Long Waves \\
\hline Bottom friction, $\beta$ & 0.0 & 0.032 \\
\hline Coastline reflection, $K_{r, \text { coaser }}$ & 1.0 & 1.0 \\
\hline Depth in infinite region, $d_{t x t}$ & $45.5 \mathrm{ft}$ & $45.5 \mathrm{ft}$ \\
\hline
\end{tabular}

\begin{tabular}{|c|c|c|c|c|c|c|c|}
\hline \multicolumn{8}{|c|}{$\begin{array}{l}\text { Table } 13 \\
\text { Harbor Alternatives for Numerical Modeling }\end{array}$} \\
\hline \multirow[b]{2}{*}{ Features } & \multicolumn{7}{|c|}{ Alternative Plan } \\
\hline & 1 & 2 & 3 & 4 & 5 & 6 & 7 \\
\hline \multicolumn{8}{|l|}{ Passenger Ship Pier } \\
\hline Slip cut into existing fill & $x$ & $x$ & & & & & \\
\hline Notch cut into existing fill & & & $x$ & & & & \\
\hline Pier adjacent to existing fill & & & & $x$ & & $x$ & $\underline{x}$ \\
\hline New fill area in SW area of harbor & & & & & $x$ & & $\underline{x}$ \\
\hline $\begin{array}{l}\text { Protective Stub Added to End of West Breakwater } \\
\text { (test lengths of } 0,600,1,000 \mathrm{ft} \text { ) }\end{array}$ & & & $x$ & $x$ & & $x^{2}$ & $x^{9}$ \\
\hline \multicolumn{8}{|l|}{ Barge Pier in Canoe Club Area } \\
\hline Aligned northisouth (Concept C) & $x$ & & & & & & \\
\hline Parallel to Pier 2 (Concept 12) & & $x$ & $\underline{x}$ & $\underline{x}$ & $x$ & $x$ & $\underline{x}$ \\
\hline Pier 1 Extension & $x$ & $x$ & $x$ & $x$ & $x$ & $\underline{x}$ & $\underline{x}$ \\
\hline $\begin{array}{l}\text { T-Pier for Fuel Barges } \\
\text { (dredge \& revet between Piers } 1 \text { \& } 3 \text { ) }\end{array}$ & $x$ & $x$ & $x$ & $x$ & $x$ & $x$ & $x$ \\
\hline $\begin{array}{l}\text { Areas with 35-it Project Depth Dredged to 38-ft } \\
\text { Depth }\end{array}$ & & & & & & $x$ & $x$ \\
\hline Selected Combination of Features & & & & & & & $x$ \\
\hline
\end{tabular}

\section{Calibration and validation}

The availability of extensive field data at Kahului Harbor allowed a detailed calibration and validation of the numerical harbor response model. Both short and long wave responses were considered. Data from the time period Nov 93 Sep 94 were used for calibration and validation, as discussed in Chapter 2. 
Short waves. Four high wave events during January and March 1994 were selected for short wave calibration (Table 14). HARBD was run for the incident wave periods and directions described in the following section and the output was post-processed to give spectral estimates of the four events. Reflection coefficients were adjusted within reasonable ranges to achieve a good fit between field data and model results (Figure 41). The principal adjustment was the reflection coefficient used along the piers. As-built plans for the commercial piers and laboratory studies of a similar configuration of pile-supported pier with underlying slope (Allsop 1990) were used to determine reasonable ranges for reflection coefficient. Only the 192-, 203-, and 214-deg incident wave directions were used during the calibration and validation phase of the study. The remaining two directions were added later to more completely represent

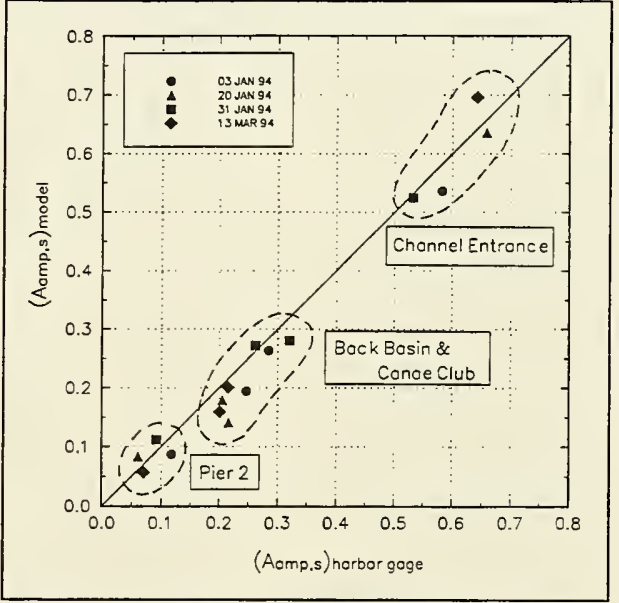

Figure 41. Model short wave calibration to four storm events the range of diffraction

possibilities for alternatives involving the western portion of the harbor.

\section{Table 14}

Field Cases for Short Wave Model Calibration, Array

\begin{tabular}{||l|l|l|l|l||}
\hline \hline Date & Hour & $\begin{array}{l}H_{s} \\
\mathrm{~cm}\end{array}$ & $\begin{array}{l}T_{p} \\
\text { sec }\end{array}$ & $\begin{array}{l}\theta_{m} \\
\text { deg }\end{array}$ \\
\hline \hline 3 Jan 94 & 1300 & 212 & 14.8 & 194 \\
\hline 20 Jan 94 & 1300 & 247 & 10.1 & 202 \\
\hline 31 Jan 94 & 0700 & 162 & 17.9 & 191 \\
\hline 13 Mar 94 & 1300 & 195 & 8.9 & 205 \\
\hline
\end{tabular}

A comparison of HARBD results and field data with published diffraction patterns through a breakwater gap, done as part of the calibration process, showed the dominance of diffraction between the entrance and interior harbor locations. Goda (1985) gives diffraction of a directional spectrum through a gap between two straight, colinear breakwaters in uniform depth. Bowers and Welsby (1982) report on laboratory tests of several other breakwater gap 
configurations, including one similar to the Kahului breakwaters. Their tests, as well as others by Blue and Johnson (1949), show that the relative rotation of the breakwaters makes little difference in the diffraction pattern for wave periods of concern here. However, the presence of rubble on the inside of the breakwaters causes significant absorption and dissipation relative to the classical vertical wall breakwater. Appropriate adjustment factors taken from Bowers and Welsby (1982) were applied to the spectral diffraction results of Goda (1985) for comparison to two of the field calibration events.

The calibrated short wave model was run in a spectral mode for the $T_{p}$ and $\theta_{m}$ combinations represented in the field data summaries of Appendix B. Comparing the model results to field data validates the numerical model against an 11month summary of gage data (Figure 42). The validation comparison is generally comparable to the calibration results. The agreement at Pier 2 is excellent. The model shows a persistent tendency to underestimate the amplification factor at the other gages.

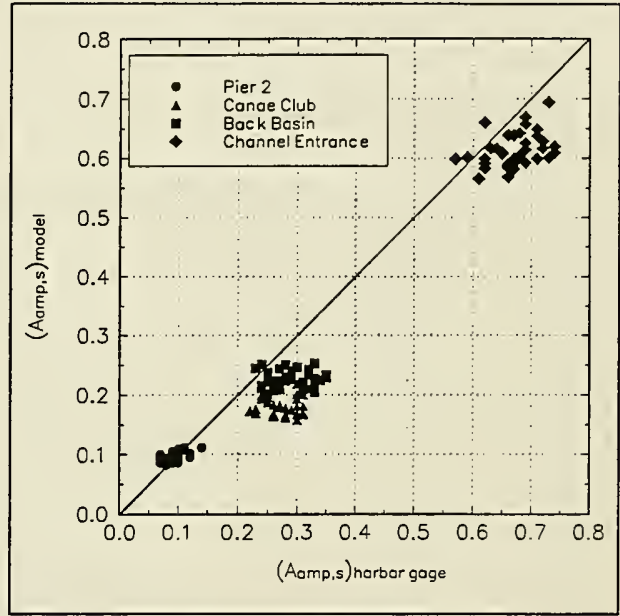

Figure 42. Model short wave validation to 11 months of gage data

The tendency is more

evident than in the initial storm calibration, particularly at Canoe Club and Back Basin. In most cases, it is greater than one standard deviation of the field data. The possibility of incorrect reflection coefficients and/or bathymetry in these shallow areas was explored within reasonable ranges, but the general level of agreement could not be improved.

Long waves. Long wave calibration was aimed at adjusting bottom friction $\beta$ to approximately match amplification factors between model and data. The reflection coefficient $K_{r}$ was set to 1.0 . Only the lower frequencies $(0.003$ $0.010 \mathrm{~Hz}$ or 100 - to 333 -sec period) were considered because most prominent resonant peaks are in this range and $K_{r}=1.0$ is more strictly correct at low frequencies. Only resonant peaks were considered in calibration because they are the features of greatest interest and are most sensitive to the choice of $\beta$. A value of $\beta=0.032$ was found to give a reasonably good match at all peaks in the selected frequency range and at all harbor gages, as illustrated in Figure 43. 


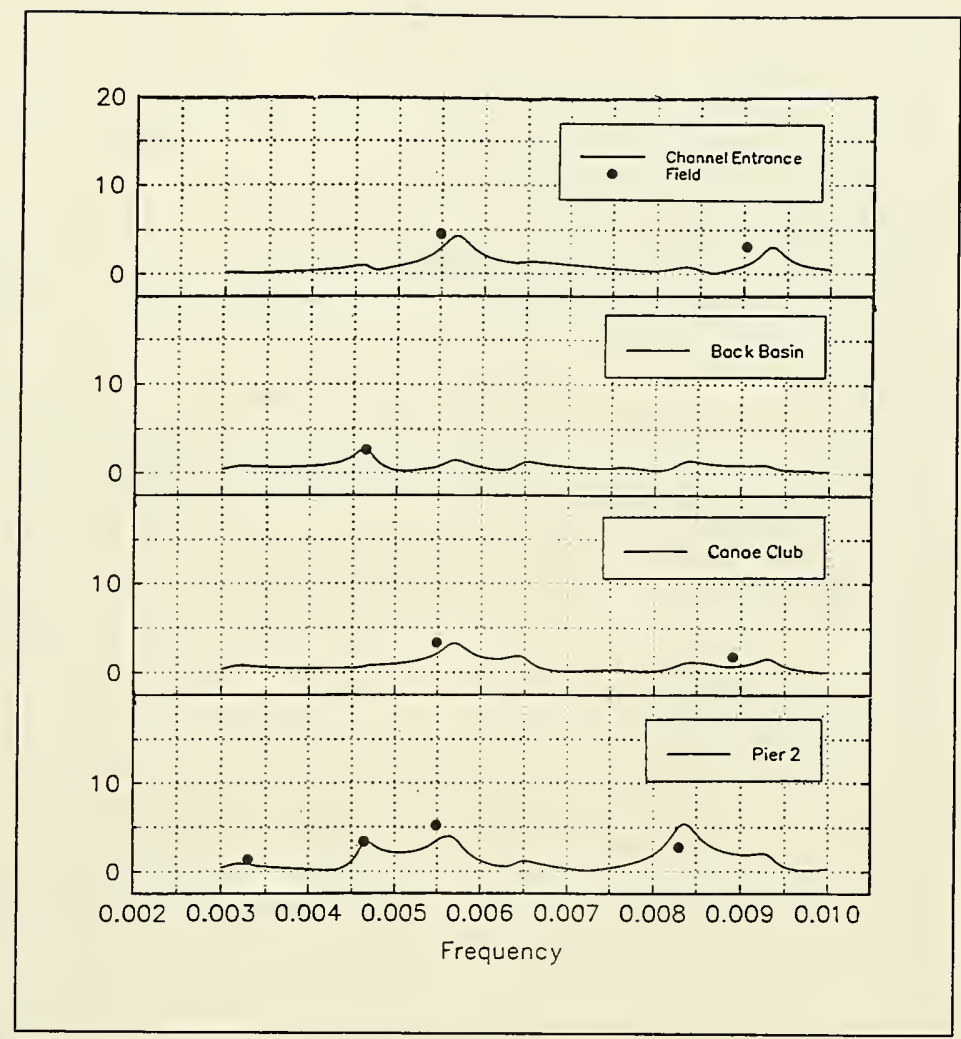

Figure 43. Model long wave calibration

Field and model amplification factors over the full range of long wave frequencies are compared in Figure 44. The general agreement is reasonable. The model shows several overly large peaks, especially at frequencies higher than the $0.01-\mathrm{Hz}$ limit considered in calibration. 


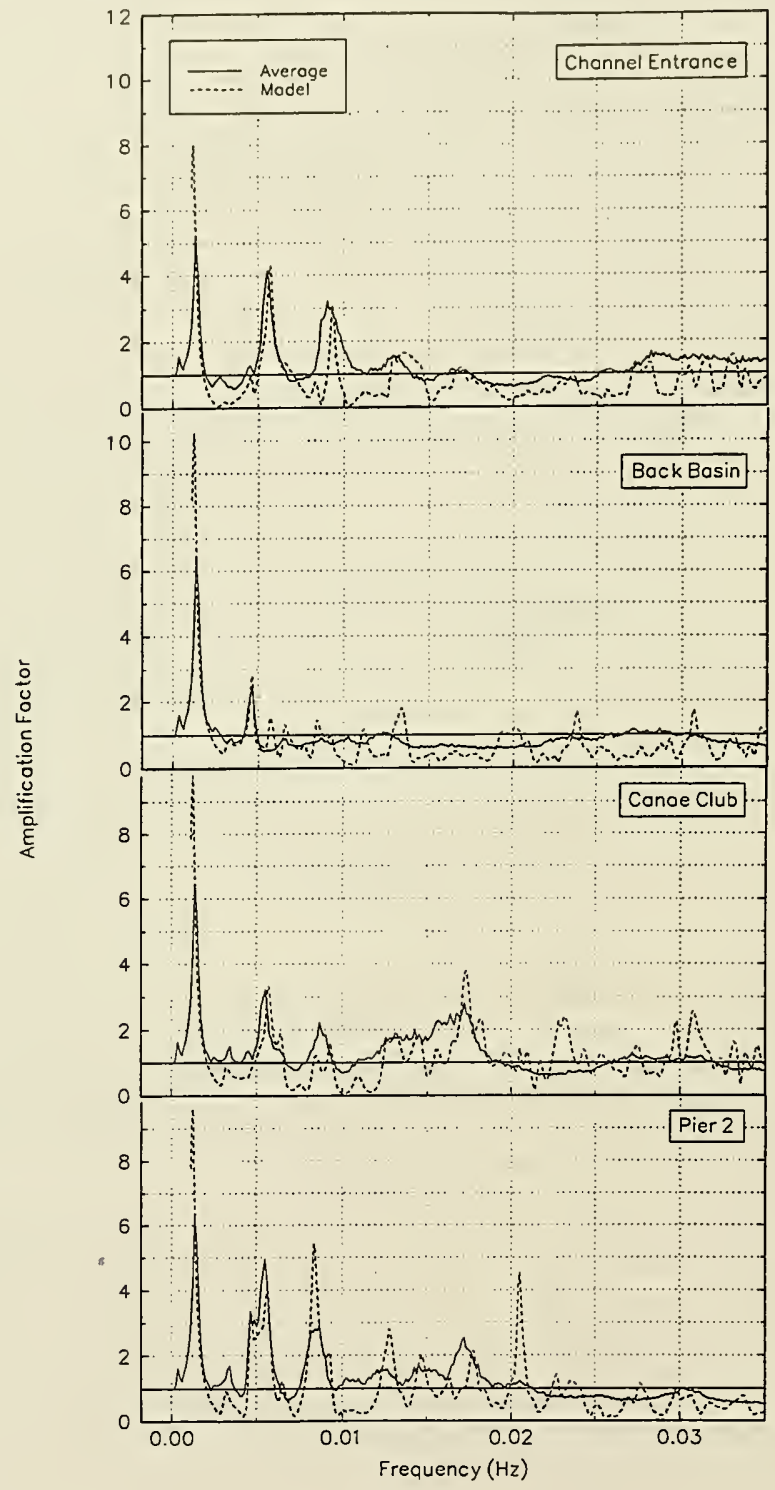

Figure 44. Long wave comparison of average gage spectra and model 


\section{Test Procedures and Calculations}

\section{Incident wave conditions}

A range of short and long wave conditions incident to Kahului Harbor was considered. A representative range of wave periods and directions which could cause damaging waves inside the harbor was included, based on field measurements.

The short wave periods and approach directions considered are given in Table 15. These conditions provide reasonable coverage of the field measurements summarized in Figures 18 and 19. The shortest wave period, representative of strong local storms, is $2 \mathrm{sec}$ shorter than the grid design period. Past experience has shown that the model still provides adequate results for small increments below the grid design period. The longest period represents a very long swell condition. Directions were chosen to include likely approach directions to the harbor entrance and to give adequate representation of the directional spectrum in post-processing. They were also chosen after review of directional response sensitivity runs at a selected

\begin{tabular}{|c|c|c|}
\hline \multicolumn{3}{|c|}{$\begin{array}{l}\text { Table } 15 \\
\text { Summary of Incident Short } \\
\text { Wave Conditions }\end{array}$} \\
\hline \multicolumn{2}{|c|}{$\begin{array}{l}\text { Wave Period } \\
\text { (sec) }\end{array}$} & $\begin{array}{l}\text { Wave Direction } \\
\text { (deg, going toward) }\end{array}$ \\
\hline 8 & 17 & 192 \\
\hline 9 & 18 & 203 \\
\hline 10 & 19 & 214 \\
\hline 11 & 20 & 225 \\
\hline 12 & 21 & 236 \\
\hline 13 & 22 & \\
\hline 14 & 23 & \\
\hline 15 & 24 & \\
\hline 16 & & \\
\hline
\end{tabular}
swell period. Test directions were reckoned in 11-deg increments beginning with $192 \mathrm{deg}$ (coming from, relative to true north). Incident wave directions and the angular orientation of the seaward semicircular model boundary are illustrated in Figure 45.

For the study of existing harbor conditions and comparison of alternatives, HARBD was run with the full set of short wave periods and directions in all possible combinations. Model results were then evaluated for directional spectra with $T_{p}$ and $\theta_{m}$ values equivalent to the period and direction values used in the initial HARBD runs (Table 15). 
Incident long wave conditions considered are given in Table 16. A fine resolution in wave frequency was used over the full range of possible resonant conditions to ensure that all important peaks were identified. A total of 468 periods were considered. Only one approach direction is included, since past studies have indicated that harbor response is relatively insensitive to incident long wave direction. This direction represents a wave directly approaching the harbor entrance from deep water.

One water level was tested. The tide range at Kahului Harbor is relatively small, with a mean range of $1.9 \mathrm{ft}$. Harbor wave response is unlikely to vary much with water level over this tidal range. The water level was selected as mean lower low water, the reference datum for bathymetric data.

\begin{tabular}{|l|l|}
\hline $\begin{array}{l}\text { Table } 16 \\
\text { Summary of } \\
\text { Incident Long Wave } \\
\text { Conditions }\end{array}$ \\
\hline $\begin{array}{l}\text { Wave } \\
\text { Period } \\
\text { (sec) }\end{array}$ & $\begin{array}{l}\text { Wave Direction } \\
\text { (deg, going } \\
\text { toward) }\end{array}$ \\
\hline 25.00 & 180 \\
\hline 25.06 & \\
\hline 25.13 & \\
\hline$\ldots$
\end{tabular}

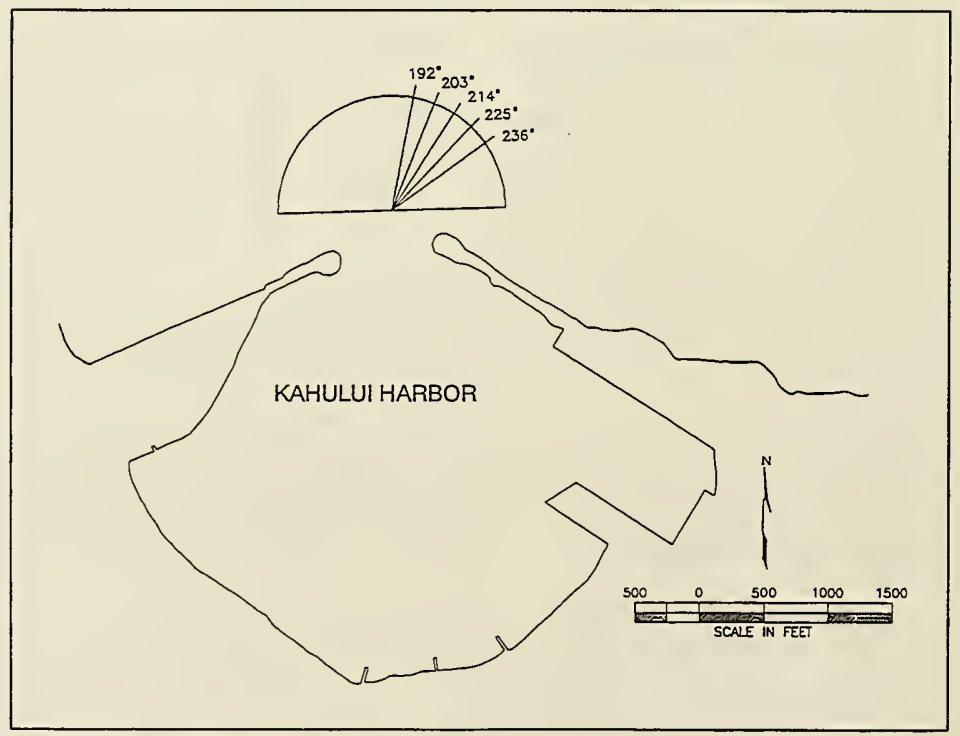

Figure 45. Incident wave directions 


\section{Calculation of spectra}

Numerical model test results for short waves in Kahului Harbor are all based on spectral post-processing of the initial HARBD runs. Hence, short wave amplification factors are all in the form of $\left(A_{\text {amp }}\right)_{\text {eff }}$ in Equation 17. This approach requires, first, that HARBD be run with the range of wave periods and directions to be considered in the spectral calculations. Second, values of peak wave period $T_{p}$ corresponding to the peak spectral frequency, wave approach direction $\theta_{m}$, spectral peak enhancement factor $\gamma$, and directional spreading factor $s$ must be specified. The $T_{p}$ and $\theta_{m}$ values were chosen to represent wind wave and swell conditions at the harbor, as discussed in the section "Incident wave conditions" (pages 61 and 62).

Values for $\gamma$ and $s$ were approximated by relating the guidance in Tables 9 and 10 to $T_{p}$ values. High energy waves, of concern for harbor design, with $T_{p}$ up to $10 \mathrm{sec}$ were assumed to be growing seas. Parameters $\gamma$ and $s$ were set to 3.3 and 10, respectively. Waves with $T_{p}$ greater than $10 \mathrm{sec}$ were treated as swell. As swell $T_{p}$ increases, the swell is expected to have an increasingly peaked frequency spectrum and narrow directional spread. To represent the spectrum for the range of swell considered, values of $\gamma$ and $s$ were scaled to fall between the values for growing seas and maximum values established for old swell (Table 17).

\section{Output basins}

In order to get special coverage of areas where harbor traffic would most likely be affected by wave conditions, 38 possible output locations or "basins" were selected to cover all harbor layouts. A basin is a small cluster of elements over which the HARBD response is averaged to give a more representative output. Whenever possible, basins were positioned to coincide with basins of other plans, particularly those of the existing harbor (Figure 46). Basin locations for alternative plans are given in Appendix E. In general, primary output basins define five areas of interest: Pier 1 (Basins 2-6), Piers 2 and 3 (Basins 7-10), recreational boat ramp (Basin 21), modified barge pier, and proposed passenger pier. Locations

\begin{tabular}{|c|c|c|}
\hline \multicolumn{3}{|c|}{$\begin{array}{l}\text { Table } 17 \\
\text { Approximate } \\
\text { Relationships Among } \\
T_{p, Y}, \text { and } s\end{array}$} \\
\hline $\begin{array}{l}T_{p} \\
(\mathrm{sec}) \\
\end{array}$ & $Y$ & $s$ \\
\hline 8 & 3.3 & 10 \\
\hline 9 & 3.3 & 10 \\
\hline 10 & 3.3 & 10 \\
\hline 11 & 4 & 15 \\
\hline 12 & 4 & 20 \\
\hline 13 & 5 & 25 \\
\hline 14 & 5 & 30 \\
\hline 15 & 6 & 35 \\
\hline 16 & 6 & 40 \\
\hline 17 & 7 & 45 \\
\hline 18 & 7 & 50 \\
\hline 19 & 8 & 55 \\
\hline 20 & 8 & 60 \\
\hline 21 & 9 & 65 \\
\hline 22 & 9 & 70 \\
\hline 23 & 10 & 75 \\
\hline 24 & 10 & 75 \\
\hline
\end{tabular}


and defining basins of barge and passenger piers vary with plan. Each basin in this study contains 22-28 elements. HARBD output information was saved at each of these locations in addition to the detailed output at nodes.

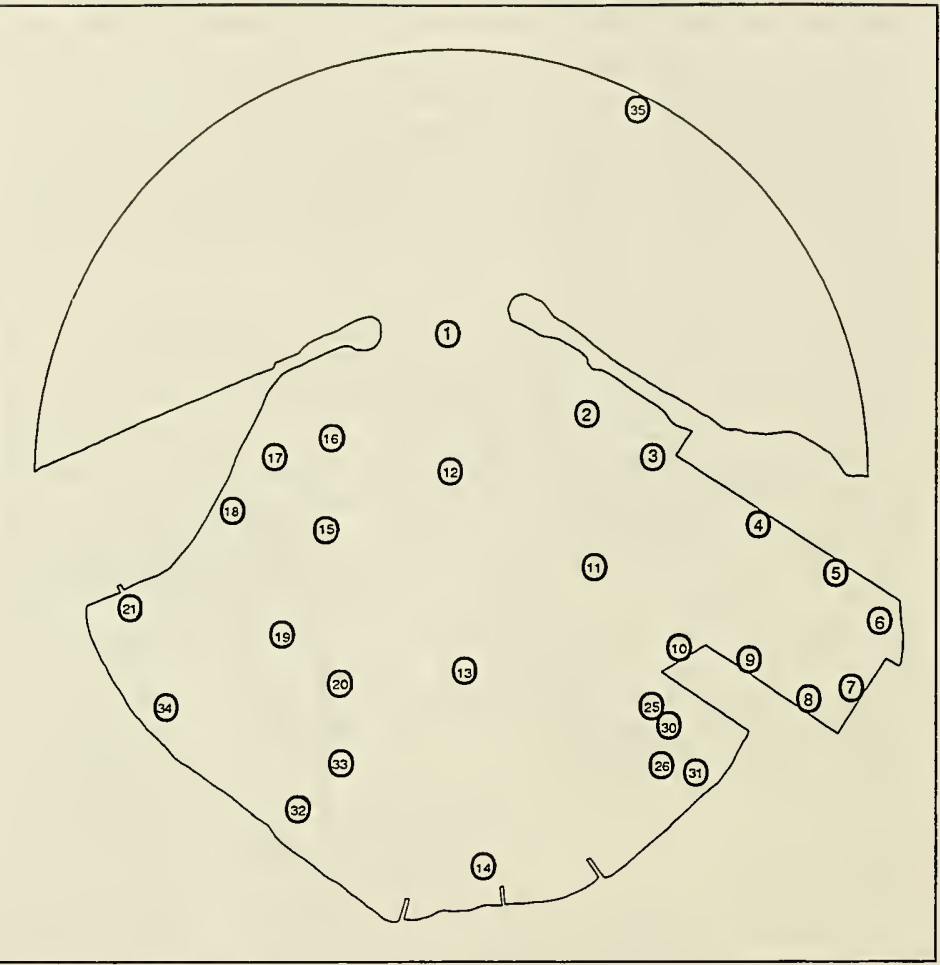

Figure 46. Output basins, existing harbor

\section{Procedures for evaluating operational performance at a pier}

One objective of this study was to develop and implement a more quantitative procedure for comparing the operational acceptability of different harbor plans subjected to long waves using HARBD. The procedures are described in the following paragraphs.

Existing criteria. The following criteria are relevant to operational performance at a pier:

1. Wilson (1967) suggests that a wharf will be operationally acceptable if 


$$
\begin{aligned}
& \frac{H}{T}<0.0038 \mathrm{ft} / \mathrm{sec} \\
& \frac{H}{T}<0.0012 \mathrm{~m} / \mathrm{s}
\end{aligned}
$$

where $H$ and $T$ are long wave height and period measured in an adjacent corner. He refers to this as a slope criterion since it was derived from $H / L$ for a shallow-water wave. The $H$ and $T$ combinations for threshold damage are shown in Figure 47.

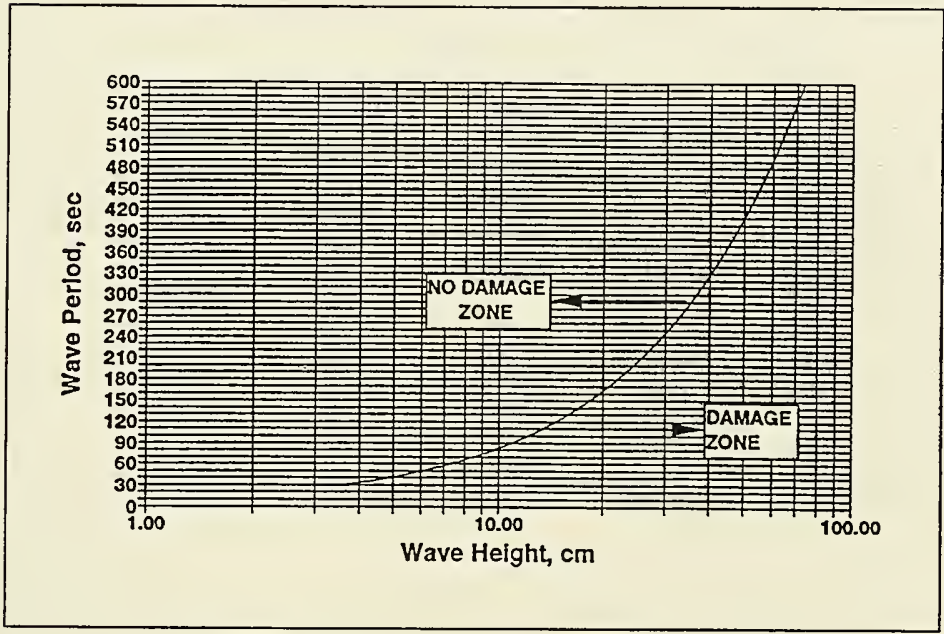

Figure 47. Wilson's threshold of surge damage for moored ships (from Seabergh and Thomas (1995))

2. Seabergh and Thomas (1995) reference unpublished long-wave significant height criteria suggested by Walker and Szwetlot $\left(H_{\text {s.long }}<5-10 \mathrm{~cm}\right.$ for 100 percent operational efficiency with man-made fiber mooring lines; $H_{\text {s.long }}<10-15 \mathrm{~cm}$ with steel wire mooring lines) and Burke for the Los Angeles Long Beach Harbor complex. Based on these and Wilson's (1967) published criterion, Seabergh and Thomas use the following criteria as indicators of successful operational conditions:

$$
\begin{array}{ll}
H_{\text {s,long }}<5 \mathrm{~cm} & \text { for } T=41-205 \mathrm{sec} \\
H_{\text {s,long }}<10 \mathrm{~cm} & \text { for } T=205-1,024 \mathrm{sec}
\end{array}
$$

3. The Permanent International Association of Navigation Congresses (PIANC) (1995) gives criteria for each degree of freedom of a moored ship (surge, sway, heave, etc.). The criteria for horizontal translational motions 
are given in terms of distance and velocity. Since horizontal motions are highly constrained by mooring lines, the velocity criteria seem more useful for present purposes (though they are stated to be applicable only for fishing vessels, coasters, freighters, ferries, and Ro-Ro vessels). Velocity criteria vary with size of ship, but they are as follows:

$$
\begin{aligned}
& u_{\max }<0.3-0.6 \mathrm{~m} / \mathrm{s} \\
& u_{\max }<1.0-2.0 \mathrm{ft} / \mathrm{sec}
\end{aligned}
$$

4. Damage at a wharf presumably occurs when forces (in mooring lines, against fenders, against ship hull, etc.) are too great. Since force is equal to mass times acceleration, it seems that an operational criterion based on long wave accelerations would be most relevant to the physical problem.

Intercomparison of existing criteria. It is useful to consider how consistent the above four criteria are with each other. Slope, velocity, and acceleration criteria can be inter-related by using equations for an idealized two-dimensional standing wave. Velocity can be expressed as (Sorensen 1993)

$$
u=\frac{H c}{d} \sin k x \sin \sigma t
$$

where

$$
\begin{aligned}
& k=\text { wave number },=\frac{2 \pi}{L} \\
& x=\text { horizontal coordinate } \\
& \sigma=\text { frequency } \\
& t=\text { time }
\end{aligned}
$$

Differentiating with respect to time gives an expression for acceleration, $a$

$$
\begin{aligned}
a=\frac{d u}{d t} & =\frac{H c}{d} \sigma \sin k x \cos \sigma t \\
& =\frac{2 \pi H c}{T d} \sin k x \cos \sigma t \\
& =\left(2 \pi \sqrt{\frac{g}{d}}\right) \frac{H}{T} \sin k x \cos \sigma t
\end{aligned}
$$

The term in parentheses is relatively constant (assuming that $d$ is relatively constant). The key variable is $H / T$. Thus it is clear that Wilson's slope criterion 
is basically an acceleration criterion as well. Maximum acceleration can also be written as

$$
a_{\max }=\frac{H c}{d} \frac{2 \pi}{T}=2 \pi \frac{u_{\max }}{T}
$$

Thus the acceleration criterion is similar to the velocity criterion with the addition of a scaling by the wave period $T$. A critical threshold acceleration for harbor operations can be defined from Wilson's slope criterion as

$$
a_{c r i t}=2 \pi \sqrt{\frac{g}{d}}\left(\frac{H}{T}\right)_{c r i t}=2 \pi \sqrt{\frac{g}{d}} \times(0.0038 \mathrm{ft} / \mathrm{sec})
$$

Now the velocity criterion (No. 3 ) is examined. Maximum velocity in a standing wave (from Equation 21) is

$$
u_{\max }=\frac{H c}{d}=\frac{H \sqrt{g d}}{d}=H \sqrt{\frac{g}{d}}
$$

or, rearranging terms,

$$
H=u_{\max } \sqrt{\frac{d}{g}}
$$

Putting this expression for $H$ into Wilson's criterion gives

$$
\frac{u_{\max }}{T} \sqrt{\frac{d}{g}}<0.0038 \mathrm{ft} / \mathrm{sec}
$$

or

$$
u_{\max }<0.0038 T \sqrt{\frac{g}{d}}, \quad u_{\max } \text { in } \mathrm{ft} / \mathrm{sec}
$$

If representative values for $T$ and $d$ are taken, this expression can be evaluated and compared to PIANC's criterion. Assume $d=32 \mathrm{ft}$ and $\sqrt{\frac{g}{d}}=1$, and $T$ ranges from $40 \mathrm{sec}$ to $400 \mathrm{sec}$. Then 
which is reasonably consistent with the PIANC criterion in Equation 20 (though the threshold velocity for damage at the shorter periods is much lower than the PIANC values).

Seabergh and Thomas' criteria (No. 2) can be compared directly with Wilson's criterion (No. 1) (Table 18). Slope values at the high end of the range defined by Seabergh and Thomas' criteria are reasonably comparable to Wilson's criterion.

In conclusion, the four criteria are reasonably consistent. Considering the major simplifications in the overall problem (particularly the lack of explicit consideration of the type of

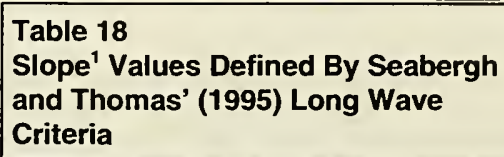

\begin{tabular}{||l||l|l|l|}
\hline \hline \multirow{2}{*}{$\begin{array}{l}H_{\text {stong }} \\
(\mathrm{cm})\end{array}$} & \multicolumn{3}{|l|}{ Wave Period, $T(\mathrm{sec})$} \\
\cline { 2 - 5 } & 41 & 205 & 1,024 \\
\hline 5 & 0.0040 & 0.0008 & \\
\hline 10 & & 0.0016 & 0.0003 \\
\hline \hline
\end{tabular}

'Slope values are defined as $H_{\text {slong }} \pi$, in $\mathrm{ft} / \mathrm{sec}$ for comparison with Wilson's criterion of $H / T<0.0038 \mathrm{ft} / \mathrm{sec}$ vessel and mooring system), differences between criteria seem relatively minor.

Adaptation of HARBD output for comparing harbor plans to operational criteria. None of the criteria seems ideally suited to the physical problem and HARBD's capabilities, but HARBD output can be adapted to give quantitative insight relative to the criteria. More importantly, the criteria provide a convenient yardstick for comparing operational performance of alternative plans to the existing harbor. Thus operational experience at existing piers can be applied to piers in the alternative plans. The Wilson and Seabergh and Thomas criteria (Nos. 1 and 2) were used in this study because they are best suited to the standard HARBD output. 


\section{Harbor Response to Wind Waves and Swell}

Numerical model studies of the harbor response to wind waves and swell were directed primarily toward assessing the operational performance of alternative harbor modifications. Results, especially at existing and proposed new pier areas, are summarized in this chapter. Amplification factors are presented in the following section. The final section gives $H_{s}$ values exceeded 10 percent and 1 percent of the time, a result more directly applicable to operational performance. The $H_{s}$ values are derived from a combination of amplification factors from the numerical model and wave measurements at the directional array outside the harbor. They are compared to operational criteria for wind waves and swell.

\section{Amplification Factors}

Amplification factors, representing directionally spread short wave spectra in the form of $\left(A_{\text {amp }}\right)_{\text {eff }}$ in Equation 17, were calculated for a variety of wind wave and swell conditions. Figure 48 shows examples of a short period swell and a long period swell coming from two different directions. Tables of $\left(A_{\text {amp }}\right)$ eff in the existing harbor for various incident peak wave periods and directions $\left(T_{p}\right.$ and $\left.\theta_{m}\right)$ are given in Appendix F.

For a more concise comparison between the existing harbor and alternative plans, average values of $\left(A_{\text {amp }}\right)_{\text {eff }}$ were computed for each basin across wave periods ranging from $10 \mathrm{sec}$ through $20 \mathrm{sec}$. Figure 49 shows results for the existing harbor and three plans. The $\left(A_{\text {amp }}\right)$ eff changes progressively as incident wave direction changes. As would be expected, amplification tends to be greater for directions of more direct approach to the basins. Also it is evident that the proposed new passenger pier locations in these particular plans have an exposure to wind waves and swell which is significantly greater than that at the existing Pier 1 (Basins 4-6).

As illustrated in Figure 49, the average amplification factor changes between plans only if there are significant changes in basin location (as in the passenger 


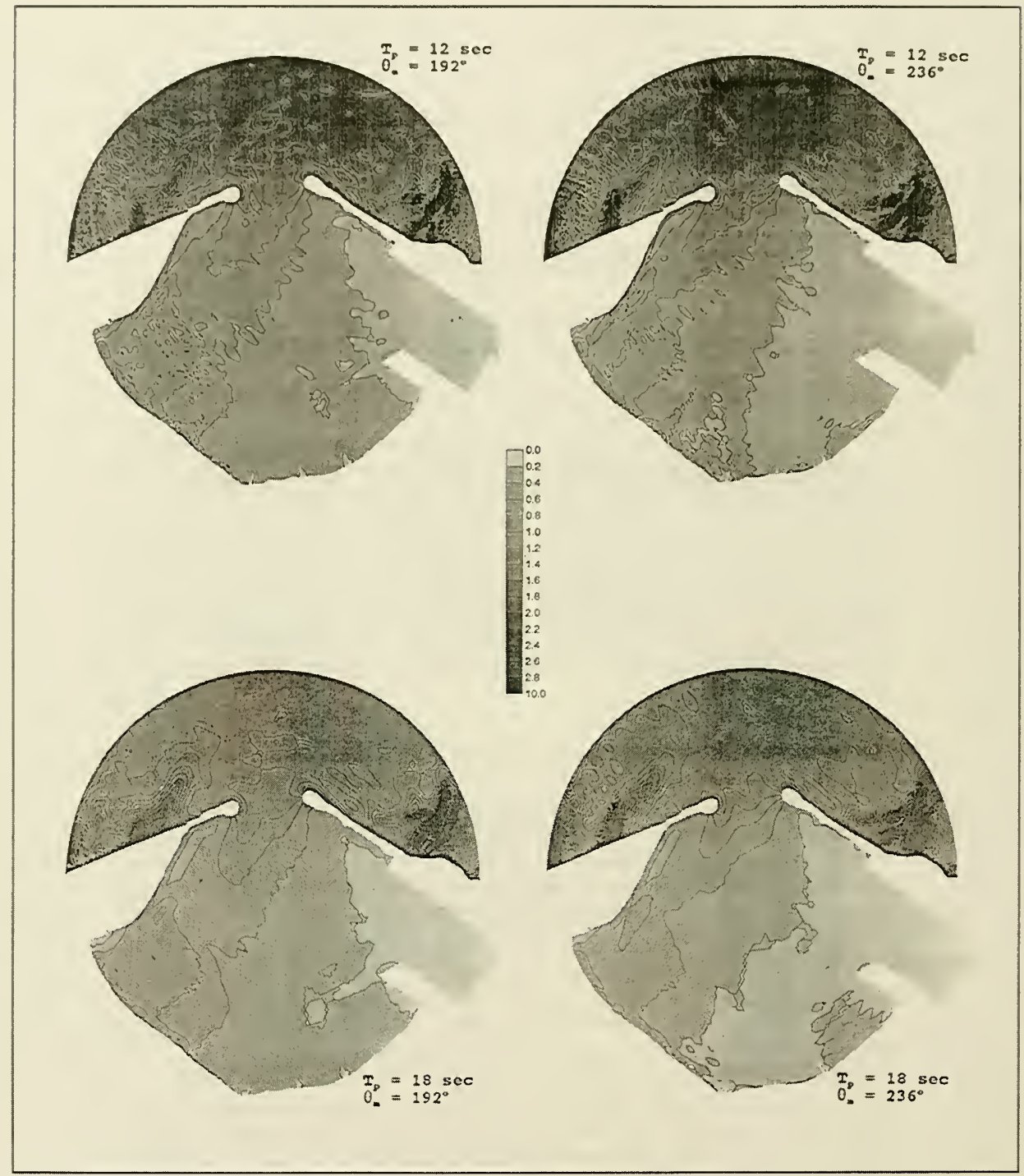

Figure 48. Example swell amplification factor contours, existing harbor

pier moving to different locations) or sheltering by the breakwater extension.

Piers 1-3 behave similarly in the various plans. The wind wave and swell response in the harbor is basically a result of diffraction through the breakwater gap. Boundary reflection characteristics have a localized effect on the waves, but 
changes in the western half of the harbor have virtually no effect on the existing pier areas.

An even more concise description of $\left(A_{\text {amp }}\right)_{\text {eff }}$ at each basin can be obtained by considering wave climate as well. A climate-based amplification factor is calculated for each basin as

$$
\left(A_{\text {amp }}\right)_{\text {climate }}=\sum_{j=1}^{N_{T}} \sum_{k=1}^{N_{D}}\left(\left(A_{\text {amp }}\right)_{\text {eff }}\right)_{j k} \frac{N_{j k}}{N_{\text {total }}}
$$

where

$$
\begin{aligned}
j k= & \text { indices denoting the } j^{\text {th }} \text { period interval and } k^{\text {th }} \text { direction interval, } \\
& \text { where the intervals are based on the incident wave conditions in } \\
& \text { Table } 15
\end{aligned}
$$

$$
\begin{aligned}
\left(\left(A_{\text {amp }}\right)_{e f f}\right)_{j k}= & \text { spectral amplification factor for the } j^{\text {th }} \text { period and } k^{\text {th }} \text { direction } \\
N_{j k}= & \begin{array}{l}
\text { number of array records with } T_{p} \text { and } \theta_{m} \text { in the } j^{\text {th }} \text { and } k^{\text {th }} \text { period } \\
\text { and direction intervals }
\end{array} \\
N_{\text {total }}= & \text { total number of records from the array gage }
\end{aligned}
$$

This climate-based amplification factor is given in Appendix F for every basin and harbor plan. Array data used in the calculation were from Nov 93 - Sep 94, as discussed in Chapter 2.

One complication which arose during the wind wave and swell studies was inconsistent results at the boat ramp (Basin 21) between some of the plans. After investigation, it was discovered that bottom friction has a signficant effect at this location because of the expanse of very shallow water approaching it. Rough correction factors were developed from a small number of runs with $\beta=0.032$ and applied to Basin 21 for all plans. Results presented here include that correction.

\section{Evaluation Against Operational Criteria for Wind Waves and Swell}

Standard operational criteria used by the U.S. Army Corps of Engineers (USACE) for wind waves and swell in shallow draft harbors are:

a. Wave height in berthing areas will not exceed $1 \mathrm{ft}$ more than 10 percent of the time.

b. Wave height in entrance and access channels and turning basins will not exceed $2 \mathrm{ft}$ more than 10 percent of the time. 


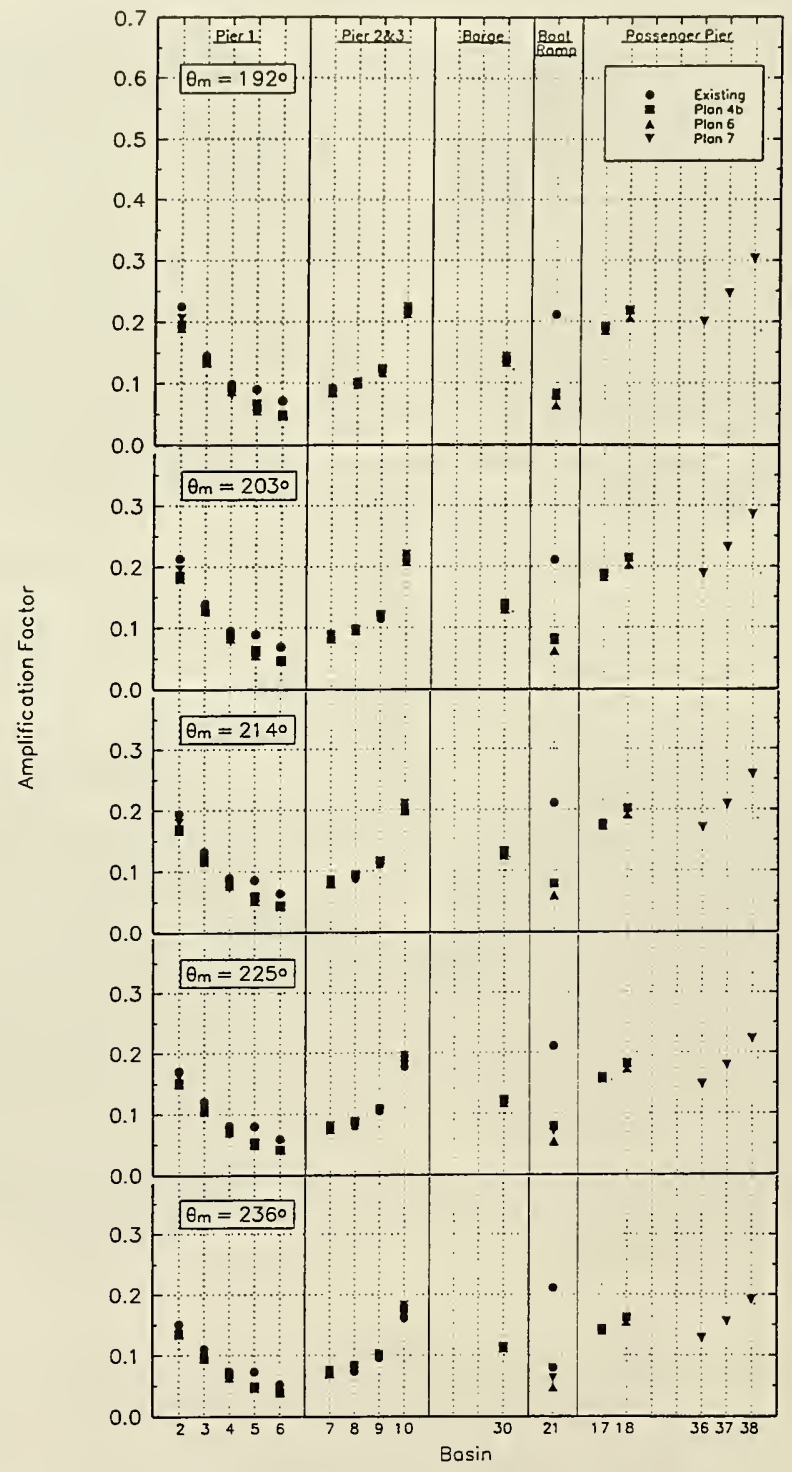

Figure 49. Comparison of $\left(A_{\text {amp }}\right)_{\text {eff }}$ averaged over periods of $10-20 \mathrm{sec}$ at piers, existing harbor and Plans 4b, 6, and 7 (see Figure 46 and Appendix $E$ for basin locations) 
Standard criteria for wind waves and swell in deep draft harbors, such as Kahului Harbor, are not so well established. However, the criteria for shallow draft harbors can provide a useful basis for comparing alternative plans at Kahului Harbor.

Another, perhaps more valuable, criterion for evaluating proposed new pier areas is to conduct comparisons with existing piers. Many years of practical experience at Piers 1 and 2 can then be approximately transferred to new plans.

Wave heights for assessing the USACE criteria were computed by combining the time-history of array gage parameters over the time period November 1993 through September 1994 with numerical model results to create a time-history of wave heights at each harbor basin. For each array record, the corresponding wave height at a harbor basin is

$$
\left(H_{s}\right)_{\text {harbor }}=\left(A_{\text {amp }}\right)_{\text {eff }} \times\left(H_{s}\right)_{\text {array }}
$$

where

$\left(H_{s}\right)_{h a r b o r}=$ significant wave height at a harbor basin

$\left(A_{\text {amp }}\right)_{\text {eff }}=$ spectral amplification factor interpolated between values for periods and directions in Table 15 to represent $T_{p}$ and $\theta_{m}$ at the array

$\left(H_{s}\right)_{a r r a y}=$ significant wave height at the array

The 11-month time-history of $\left(H_{s}\right)_{\text {harbor }}$ at each basin was sorted into descending order and the value of $H_{s}$ which was exceeded 10 percent of the time was identified. The $H_{s}$ value exceeded 1 percent of the time was also identified. The $H_{s}$ with 1 percent exceedance relates to a more demanding operational condition, which may be more applicable to large commercial vessels.

Significant wave heights exceeded 10 percent of the time are less than $1 \mathrm{ft}$ at all existing and most proposed pier areas (Figure 50). The existing harbor is included in each panel of the figure to give a common reference. Existing Piers 1-3 extend approximately between Basins 3-9. Basin 3, which is centered on the proposed extension of Pier 1 , has higher wave conditions than any basins along existing piers. Basin 2, the location of a possible future extension of Pier 1 , has wave heights approximately twice as high as the main existing Pier 1 (Basins 4 and 5). Wave heights at the exposed end of Pier 2 (Basin 10) also approach this level. The significant wave height exceeded 10 percent of the time computed directly from Pier 2 wave gage results is $0.39 \mathrm{ft}$, which compares well with corresponding numerical model results at Basin 8 in the existing harbor and helps to validate the model wave heights (Table 19). 
Except for Plan 2, wave heights at the proposed new barge pier (Basins 25, 26 , and 30) range between those near the center of Pier 2 (Basin 9) to the exposed end of Pier 2 (Basin 10), depending on the harbor plan. The boat ramp is considerably more protected in most plans relative to the existing harbor. Proposed passenger pier locations in the alternative plans have a wide range of protection. The best protected alternatives give wave conditions similar to the existing Pier 1. The most exposed alternative (Plan 4a) gives waves signficantly higher than Table 19
Significant Wave Heights Exceeded
10 Percent and 1 Percent of the Time at
Field Gages at any existing pier locations.

\begin{tabular}{||l|l|l||}
\hline \hline Gage & $\begin{array}{l}H_{\text {s with 10\% }} \\
\text { Exceedance (ft) }\end{array}$ & $\begin{array}{l}H_{\text {, with 1\% }} \\
\text { Exceedance (ft) }\end{array}$ \\
\hline \hline Pier 2 & 0.39 & 0.63 \\
\hline Canoe Club & 1.15 & 1.65 \\
\hline Back Basin & 1.26 & 1.99 \\
\hline $\begin{array}{l}\text { Channel } \\
\text { Entrance }\end{array}$ & 3.10 & 4.63 \\
\hline
\end{tabular}

The $H_{s}$ values exceeded 1 percent of the time are considerably higher than those exceeded 10 percent of the time, but show similar relative trends (Figure 51). Existing pier areas still fall below the 1-ft wave height threshold, with the exception of the exposed end of Pier 2 (Basin 10) and, possibly, the northwest end of Pier 1. Proposed new barge and passenger piers are below the threshold in some plans and above in others. 


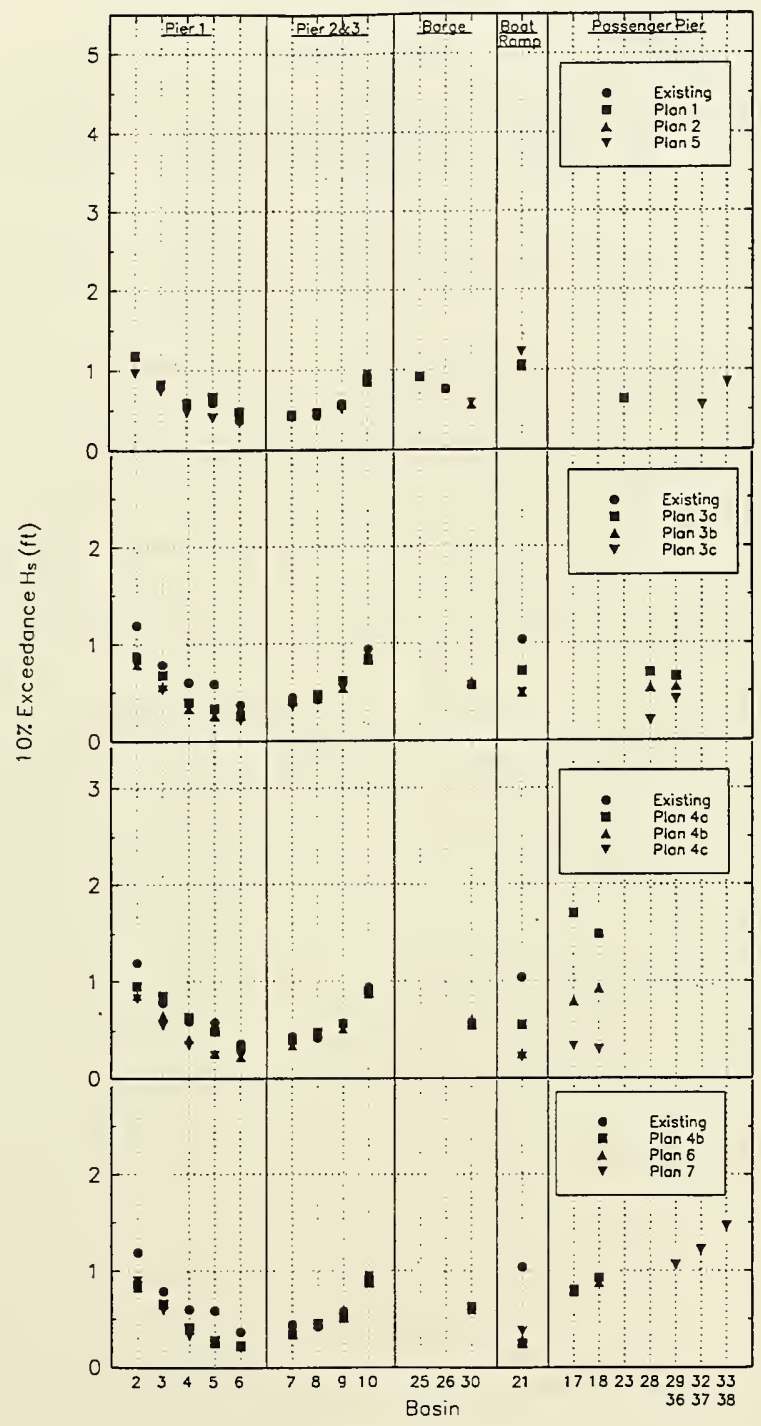

Figure 50. Comparison of $H_{s}$ exceeded 10 percent of the time at piers 


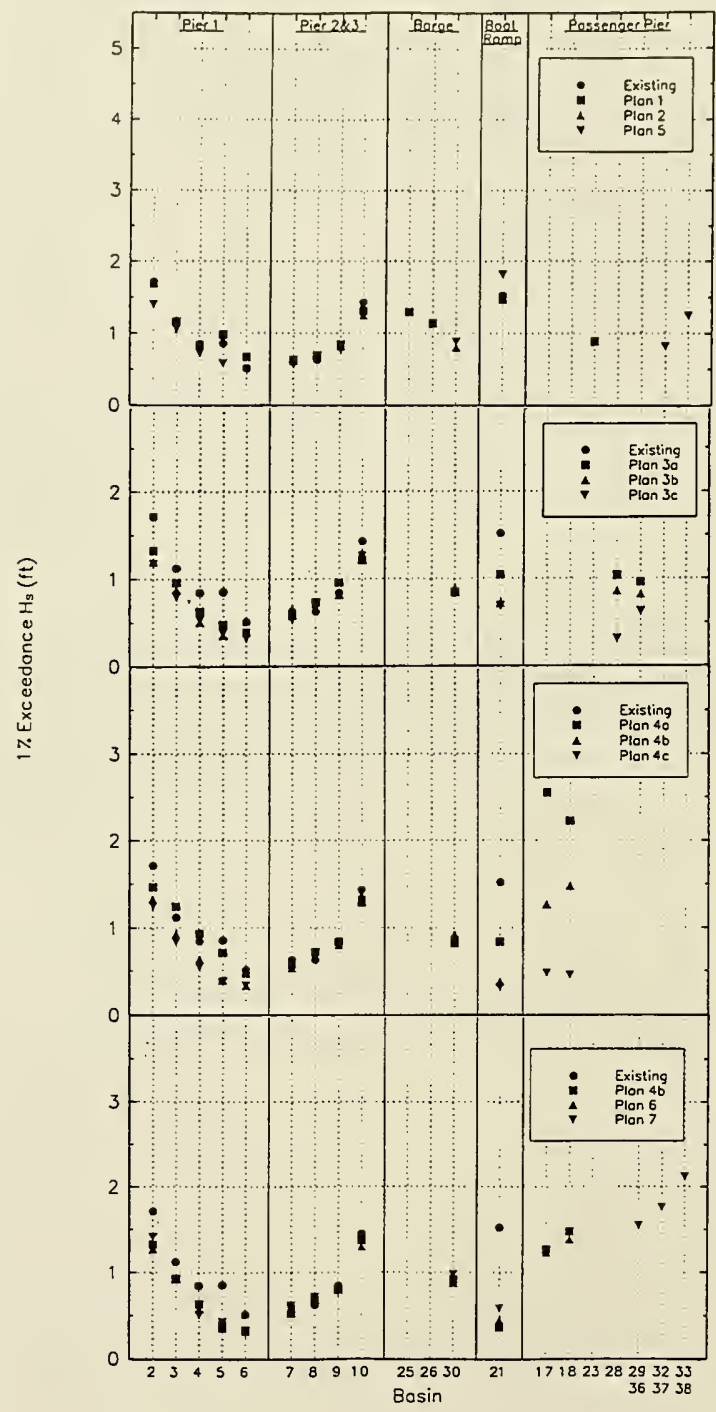

Figure 51. Comparison of $H_{s}$ exceeded 1 percent of the time at piers 


\section{Harbor Oscillations}

To evaluate harbor resonance characteristics, the HARBD numerical model was run for the existing harbor and all alternative plans. Incident long wave periods ranged from $25 \mathrm{sec}$ to $1,000 \mathrm{sec}$ in very fine increments, as discussed in Chapter 4. These evaluations were included because oscillations are an important part of interpreting the existing harbor wave response (as evidenced by gage data in the harbor), and modifications to the harbor can potentially lead to increased operational problems due to harbor oscillations. Amplification factor results are presented in the following section. Additional results more closely related to operational performance criteria are given in the final section.

\section{Amplification Factors}

Amplification factors for the long waves involved in harbor oscillation behave differently than those for wind waves and swell. Long waves, because of their length relative to harbor dimensions and their reflectivity from harbor boundaries, form standing wave patterns in the harbor. Standing wave behavior in a simple closed basin of uniform depth is illustrated in Figure 52. In the fundamental mode of oscillation, antinodes occur at both basin walls and a node midway between walls. Second and third modes of oscillation are also illustrated. Antinodes always occur at the walls. Additional antinodes and nodes occur at regular

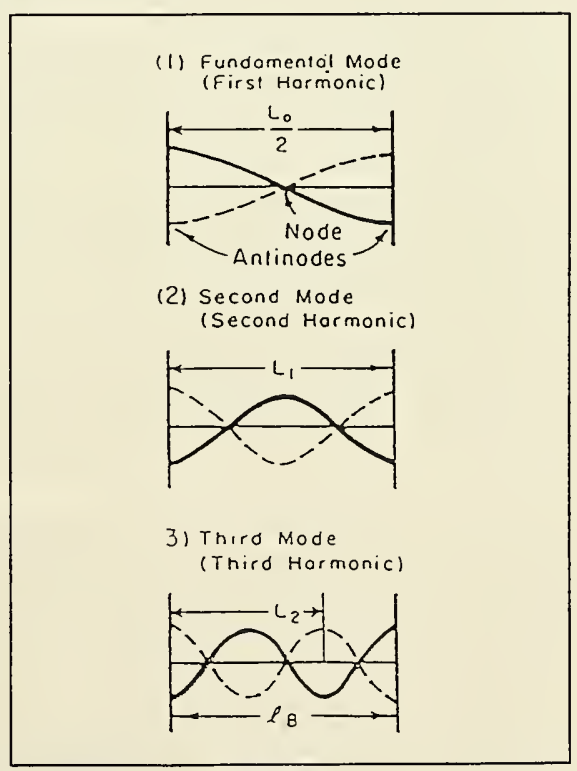

Figure 52. Harbor oscillation definitions 
intervals between walls, with the number of antinodes and nodes dependent on the mode of oscillation.

The water surface in a standing wave has its greatest vertical motion at antinodes. There is no vertical movement at an ideal node, but horizontal velocities reach a maximum there. In terms of amplification factors, this behavior gives large values of $A_{\text {ampl, }}$ at antinodes and small values around nodes. Contrary to wind waves and swell, small values of $A_{\text {amp.l }}$ are not necessarily indicative of a tranquil harbor area.

Phases in a standing wave also behave differently than for typical wind waves and swell. For example, the water surface in the fundamental mode of oscillation in Figure 52 simultaneously reaches a maximum at every point to the left of the node. These points are all in phase. At the same time, every point to the right of the node reaches a minimum value. These points are also in phase with each other but exactly out of phase with the points to the left of the node. Thus phases in a simple standing wave are constant between an antinode and node. They quickly change by $180 \mathrm{deg}$ (or $\pi$ radians) across the node and remain constant up to the next node or boundary.

Amplification factors for pier areas in the existing harbor are shown as a function of wave frequency in Figure 53. Some frequencies produce a strong resonant amplification, with peak amplification factors between about 2 and 10 . Many of the same resonant frequencies appear at all basins, though the strength of amplification can vary considerably between basins. A large peak at very low frequency $(0.0007 \mathrm{~Hz}$ or 1,500 -sec period) shows at every basin and plan. This peak represents the Helmholtz (or grave) mode of oscillation, in which the entire harbor rises and falls in unison. Phase is constant over the whole harbor. This peak also dominates long wave spectra at the array (Figure 20).

Amplification factor and phase contour plots for the four highest resonant peaks (excluding Helmholtz resonance) show oscillation patterns in the existing harbor. In the amplification factor plots, areas of high amplification are evident as darker shades of gray (Figure 54). Corresponding phase contours are shown in Figure 55. Areas in which phase contours are tightly bunched indicate nodal areas. As would be expected for standing waves, nodal lines in Figure 55 coincide with low amplification factors in Figure 54. The phase plots also indicate areas of the harbor which rise and fall together during the resonant condition (same gray shade). Thus the oscillation patterns can be interpreted.

The 212.77-sec resonant period, peak $A$, shown in Figure 54 represents a relatively simple rocking oscillation between Piers 1-3, the south end of the harbor, and the boat ramp area. A single nodal line runs across the harbor in a generally east-west direction. The 176.99 -sec resonance, peak $B$, is primarily a rocking between Piers 1-3 and the coral stockpile along the west breakwater. The shorter period oscillations are more complex patterns, though they generally indicate a strong nodal area at or near Pier 1 and the seaward end of Pier 2 . The peak $D$ resonance is an interesting pattern between the comers of Pier 1 and Pier 2. 


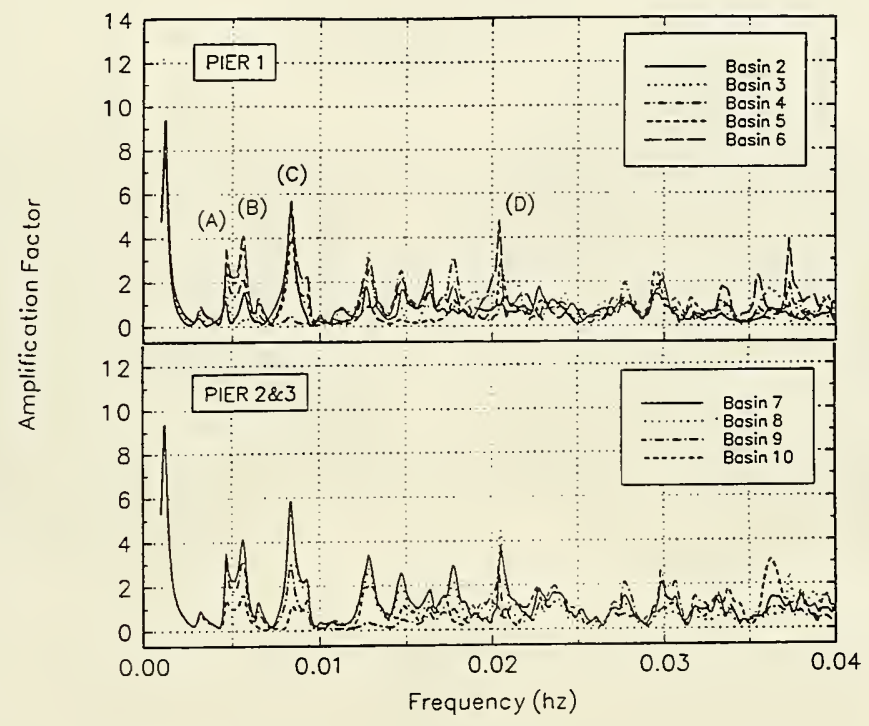

Figure 53. Long wave response, existing harbor, Piers 1-3

The long wave amplification factors shown here may be overestimated for resonant peaks at periods less than about $100 \mathrm{sec}$. The wave reflection coefficient at all solid boundaries was set to 1.0 for all long wave runs, but Figure 44 shows some evidence that peaks at the shorter long wave periods tend to be overestimated. The peak $D$ case is particularly evident. Some reduction in reflection coefficient as wave period decreases could be expected physically. This case was rerun with $K_{r}=0.95$ along all boundaries. The height of peak $D$ was reduced from 4.5 to near 1.0. Additional tests with $K_{r}=0.95$ helped confirm that this choice would improve the long wave calibration at periods between $25 \mathrm{sec}$ and $100 \mathrm{sec}$. It was not practical to refine $K_{r}$ values and revise long wave runs for all plans, and the initial runs with $K_{r}=1.0$ are considered adequate for evaluating alternative plans.

Amplification factor plots for alternative plans are given in Appendices $G$ and H. Plots of $A_{\text {amp, },}$ versus frequency (Appendix G) are grouped so that the existing and proposed harbor plans can be easily compared at each pier area. Amplification factor and phase contour plots for the main resonant frequencies are given in Appendix $\mathrm{H}$.

A more quantitative comparison between the existing harbor and alternative plans can be obtained by averaging amplification factors across a range of long wave frequencies. The root-mean-square (RMS) amplification factor was 
computed for each plan (Figure 56). The RMS is used because squared amplification factors are indicative of wave energy, a more relevant basis for comparison than wave height. In computing the RMS, frequencies lower than $0.0025 \mathrm{~Hz}(400 \mathrm{sec})$ were not included to avoid domination by the Helmholtz peak common to all plans.

The existing harbor and all plans show minimum values of the RMS amplification factor around the middle of Pier 1 and end of Pier 2 (Basins 4 and 10). Thus, these tend to be nodal areas. Another notable feature of the figure is the exceptionally high amplifications at the proposed passenger pier in Plans 1 and 2. Basin 30, representing the proposed barge pier for most plans, was inadvertently omitted in Plan 2 long wave runs. Basin 31, which was very similar to Basin 30 in other long wave runs, is used in its place in the long wave summaries in this report.

\section{Evaluation Against Operational Criteria for Long Waves}

Procedures for evaluating the operational acceptability of different harbor plans subjected to long waves are reviewed in Chapter 4. This study used a variation of the most direct procedure (Seabergh and Thomas 1995). The percent of observations with $H_{\text {s,long }}$ greater than $10 \mathrm{~cm}$ was computed for each basin and plan. However, the range of long wave frequencies was divided into two segments having periods ranging from $30-100 \mathrm{sec}$ and $100-400 \mathrm{sec}$. The choice of $100 \mathrm{sec}$ as the dividing point was based on an expected sensitivity of barges to periods in the shorter period range and a lower confidence in that range because of the concern that $K_{r}$ may be slightly high. $H_{s, \text { long }}$ is calculated as

$$
H_{s, \text { long }}=4 \sqrt{\sum_{i=N_{1}}^{N_{2}}\left[\frac{\left(A_{\text {amp }}\right)_{\text {harbor }}}{\left(A_{\text {amp }}\right)_{\text {array }}}\right]_{i} \times E_{\text {array }}\left(f_{i}\right)}
$$

where

$$
\begin{aligned}
N_{l}, N_{2}= & \begin{array}{l}
\text { spectral line numbers in model corresponding to the } \\
\text { period range being considered }(30-100 \mathrm{sec} \text { or } 100- \\
\\
400 \mathrm{sec})
\end{array} \\
\left(A_{\text {amp }}\right)_{\text {harbor }}\left(A_{\text {amp }}\right)_{\text {array }}= & \text { amplification factors for } i^{\text {th }} \text { spectral line in model } \\
E_{\text {array }}\left(f_{i}\right)= & \begin{array}{l}
\text { spectral energy at array for } i^{\text {th }} \text { spectral line in model } \\
\text { (interpolated from gage data), in units of } \mathrm{cm}^{2}
\end{array}
\end{aligned}
$$

Amplification factor at the array is needed as a divisor because long waves can easily reflect back to the array. Spectral energy at the array cannot be considered 


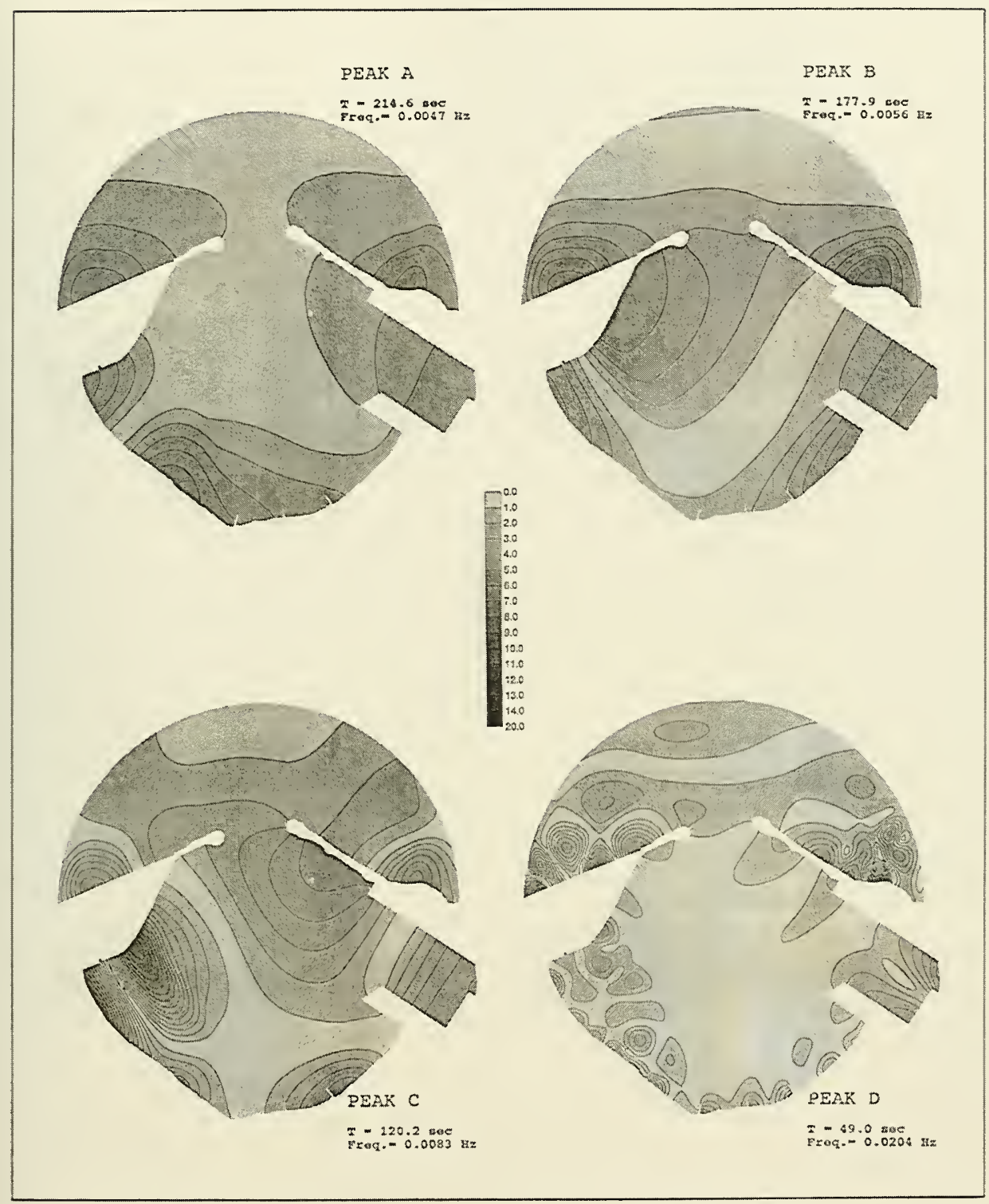

Figure 54. Resonant long wave amplification factor contours, existing harbor 


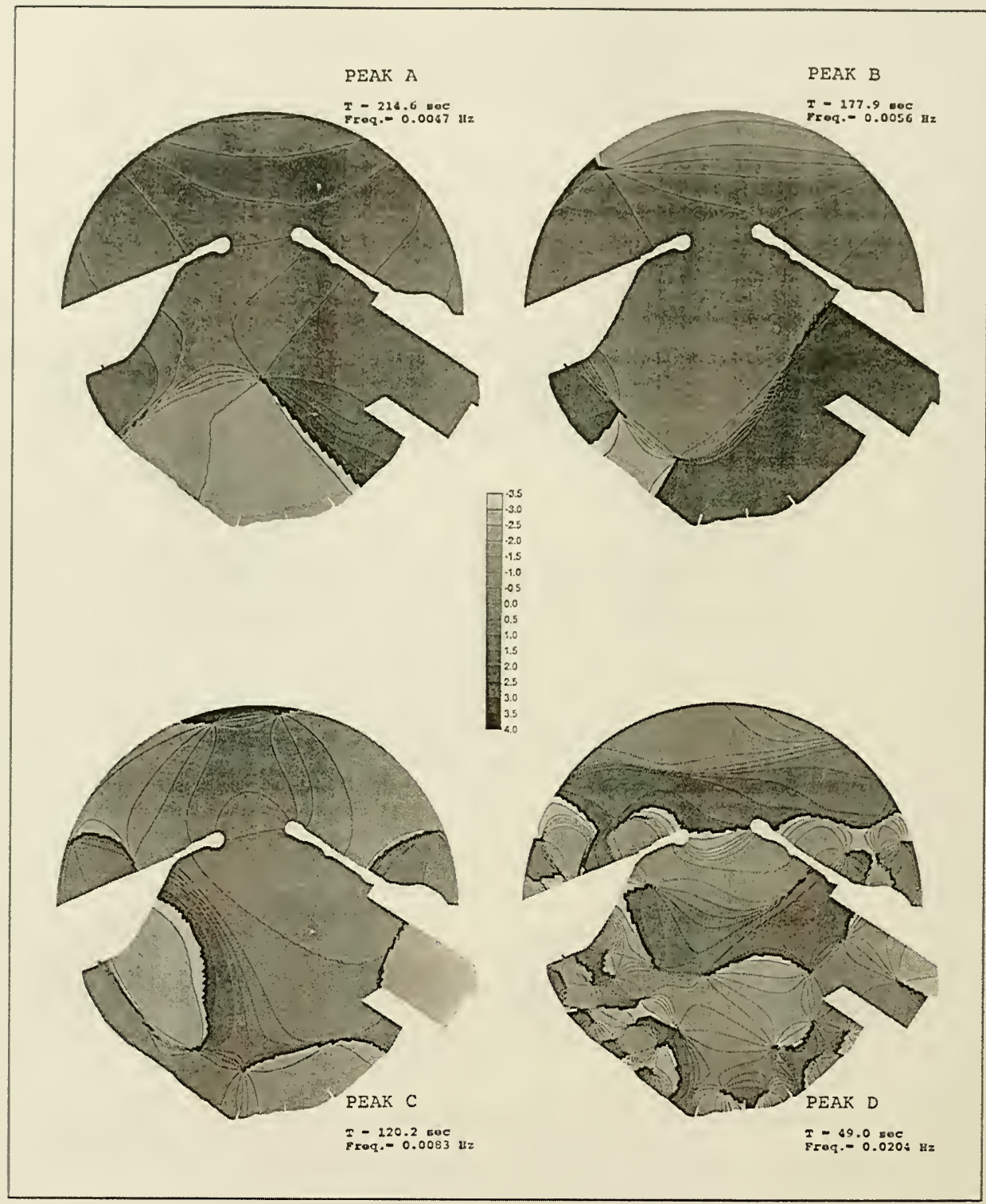

Figure 55. Resonant long wave phase contours, existing harbor 


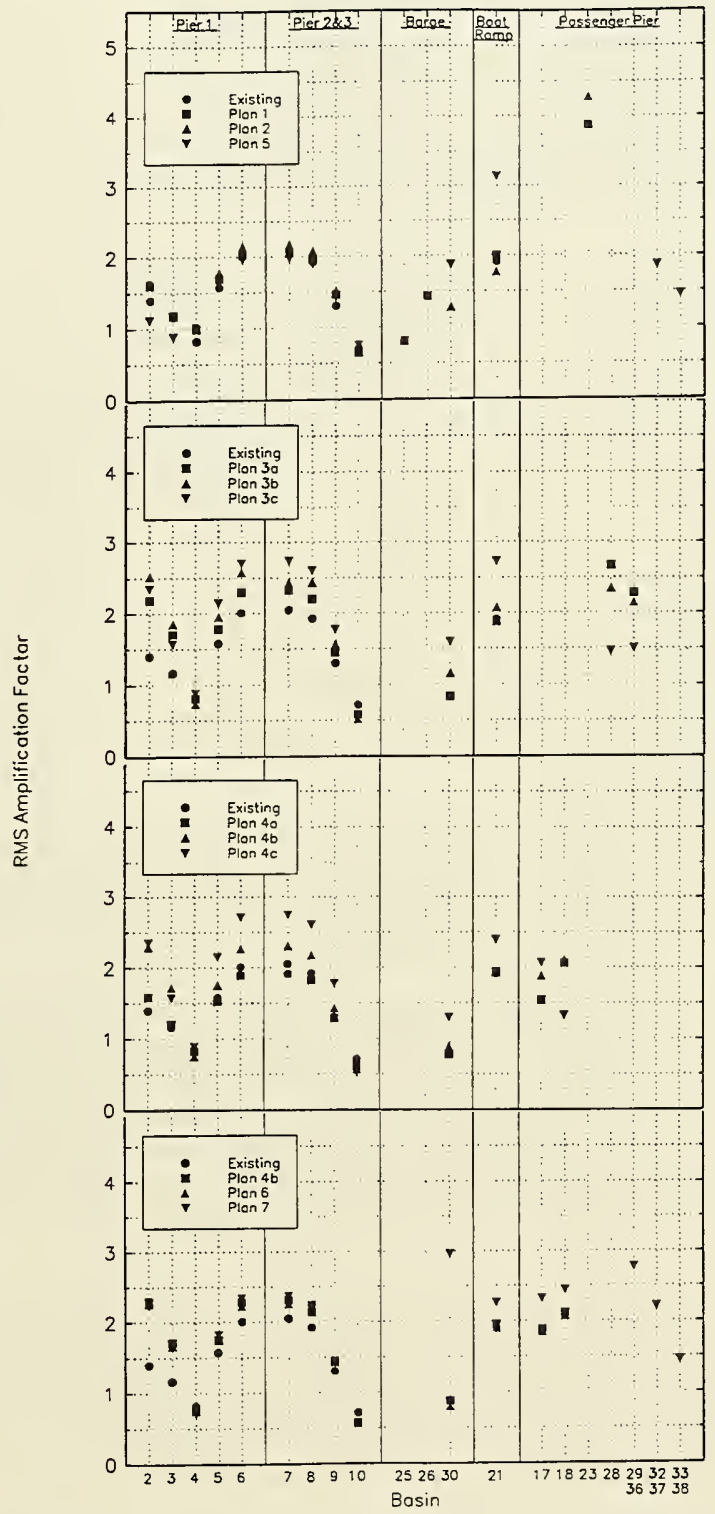

Figure 56. Long wave RMS amplification factor comparison at piers, $T=100-400$ $\mathrm{sec}$ 
as purely incident energy. $\left(A_{\text {amp }}\right)_{\text {array }}$ was constrained to be greater than or equal to 1.0 in this calculation.

Using Equation 32 and the 11-month field data set, the percent of observations with $H_{\text {s, bong }} \geq 10 \mathrm{~cm}$ was calculated. Results for the $100-\mathrm{sec}$ to 400 -sec range are similar to the RMS amplification factor results (Figure 57). Results for the 30 -sec to $100-\mathrm{sec}$ range are more scattered (Figure 58). Corresponding information from the field gages is given in Table 20 for comparison.

A slope criterion as suggested by Wilson (1967) was also evaluated. Wave height for the criterion was an $H_{\text {s.long }}$ as in Equation 32, with the summation taken over nine successive model frequencies. The number nine was chosen because nine successive frequencies encompass a broad enough band to include most or all of any peak in the model spectral

\begin{tabular}{|l|l|l||}
\hline \multicolumn{2}{|l|}{$\begin{array}{l}\text { Table } 20 \\
\text { Percent Occurrence of } H_{s, l o n g} \geq 10 \mathrm{~cm} \text { at } \\
\text { Field Gages }\end{array}$} \\
\hline \hline \multirow{2}{*}{ Gage } & \multicolumn{2}{|l|}{ Wave Period Range (sec) } \\
\cline { 2 - 4 } & $100-400$ & $30-100$ \\
\hline \hline Pier 2 & 3.8 & 1.4 \\
\hline Canoe Club & 0.8 & 2.1 \\
\hline Back Basin & 0.1 & 0.2 \\
\hline Channel Entrance & 2.2 & 1.6 \\
\hline Array & 0.4 & 3.0 \\
\hline \hline
\end{tabular}
response. The $H_{\text {s.long }}$ was multiplied by the center frequency to give a slope. If any combination of nine successive frequencies gave a slope exceeding Wilson's criterion, the record was counted as having exceeded the threshold. Period ranges of $30-100 \mathrm{sec}$ and $100-400 \mathrm{sec}$ were evaluated separately as before. Results are given in Appendix G.

An additional operational guideline is based on the value of $A_{\text {ampl, }}$ for the higher resonant peaks. Experience with Los Angeles and Long Beach Harbors has indicated that if $A_{\text {amp, },}$ is greater than about 5, some operational difficulties may be encountered. If $A_{\text {amp, },}$ is greater than 10, major operational problems can be expected. ${ }^{1}$ This guideline may be applied to the plots in Appendix $G$. If the very low frequency Helmholtz peak is excluded, Plans 1, 2, 5, and 7 all appear to be operationally unacceptable as presently formulated. They all have basins at which $A_{\text {amp }, l}$ exceeds 10.

Results are best judged by comparison to the existing piers. Plans 1 and 2 clearly have potential problems at the passenger pier (Basin 23) in the 100- to $400-\mathrm{sec}$ range. The magnitude of response in a range which affects ships of this size is large enough that this facility would likely be unacceptable. Plans 5 and 7 also tend toward elevated responses.

${ }^{1}$ Personal Communication, William C. Seabergh, Research Hydraulic Engineer, U.S. Army Engineer Waterways Experiment Station, Vicksburg, MS. 
Most plans indicate improved conditions at the new barge facility on the south side of Pier 2 relative to existing piers. The 30 - to 100 -sec period range is considered especially important for barge response. Most plans show improved conditions for passenger vessels, too. The 100 - to 400 -sec range is probably more critical for these vessels. 


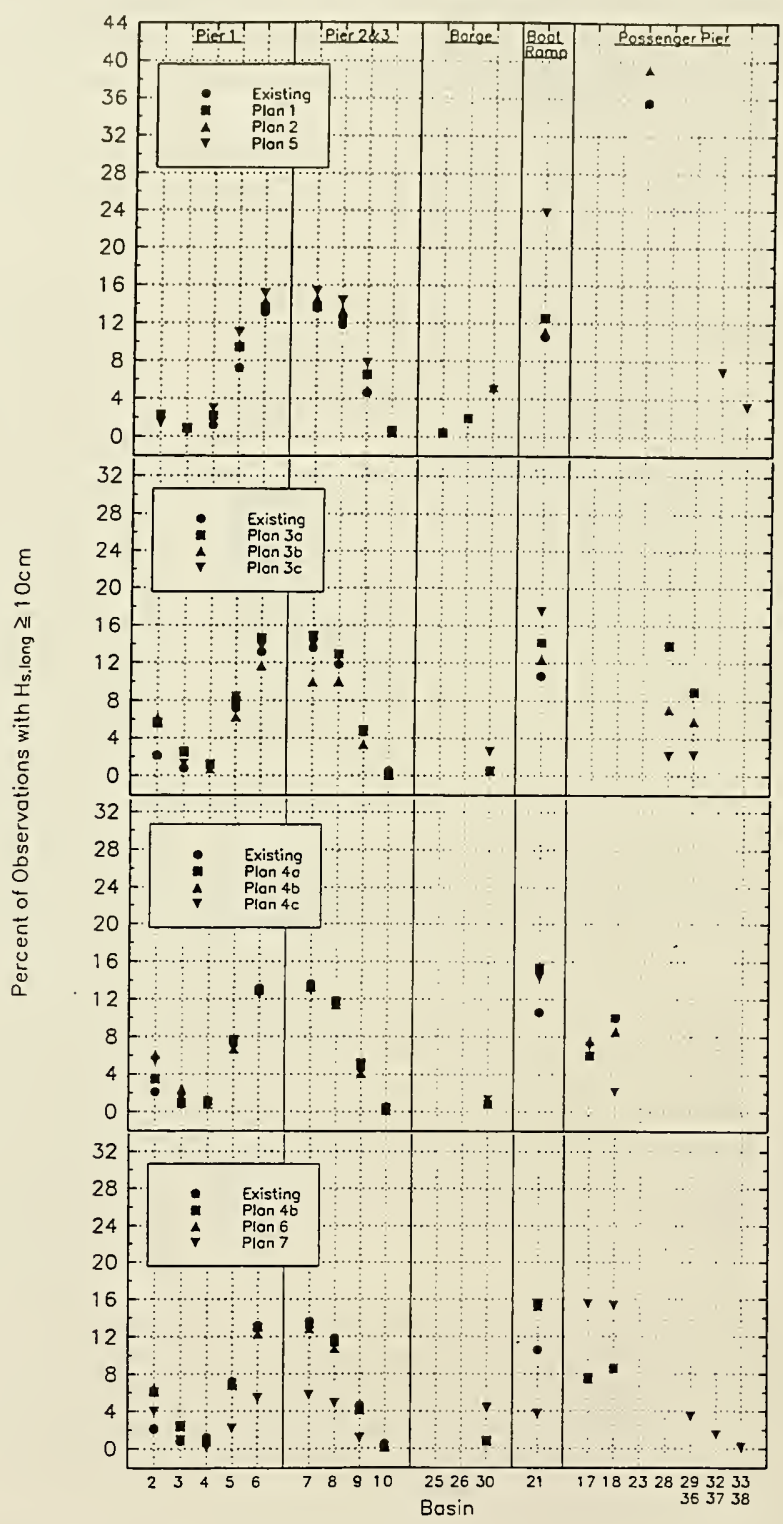

Figure 57. Percent occurrence of $H_{\text {s, long }} \geq 10 \mathrm{~cm}$ at piers, $T=100-400 \mathrm{sec}$ 


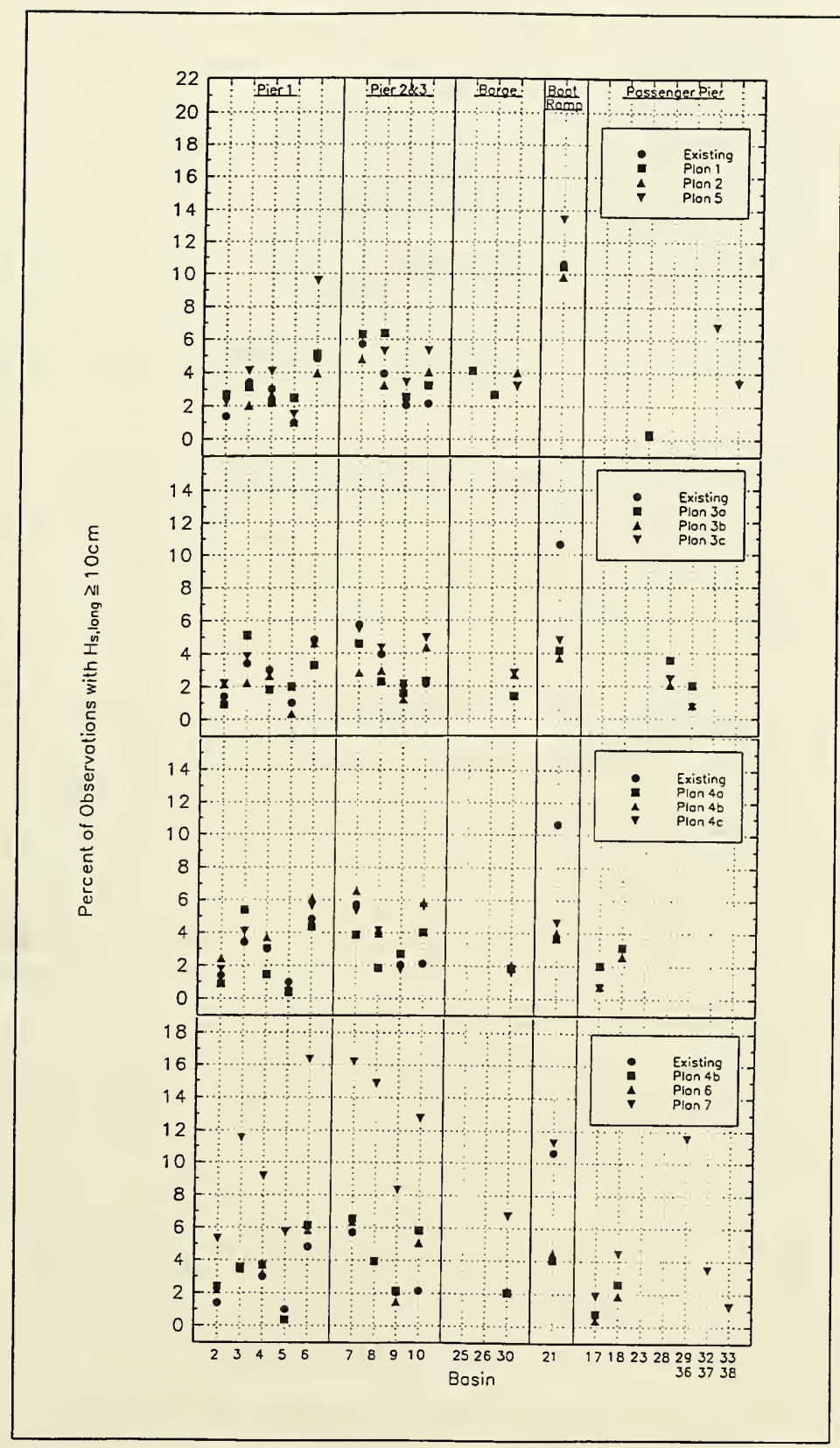

Figure 58. Percent occurrence of $H_{s, \text { long }} \geq 10 \mathrm{~cm}$ at piers, $T=30-100 \mathrm{sec}$ 


\section{Conclusions and Recommendations}

Studies of the wave response of Kahului Harbor have produced valuable information about the existing harbor and possible modifications. Field measurements taken over a period of 18 months at a deepwater directional buoy, a directional array outside the harbor, and four gages inside the harbor were extremely helpful in understanding present harbor behavior. Numerical modeling of the existing harbor also helped to explain the response to short and long waves.

The numerical model was used to simulate the behavior of 11 alternative modifications to the harbor. Model results are compared with criteria for operational acceptability and with experience in the existing harbor to the extent possible. The effectiveness of proposed new harbor areas for wind wave and swell protection often has little relationship to protection from oscillations. These two aspects of pier operability must both be considered in judging success of the alternative plans.

An overview of performance of the alternative plans is given by their success relative to a simple, meaningful criterion. For wind waves and swell, success was defined as having $H_{>}>1 \mathrm{ft}$ less than 1 percent of the time at all basins along the pier (Table 21). The 1 percent level was chosen because the existing Piers 1 and 2 (which are considered successful) meet this criterion but the seaward ends of Piers 1 and 2 (which are believed to be marginal) slightly exceed the criterion. Thus successful piers in Table 21 should be comparable or better than the existing facilities for wind waves and swell.

A similar overview of plan performance for harbor oscillations is given in Tables 22 and 23. The criteria are expressed in terms of percent exceedances of $H_{\text {s,long }}=10 \mathrm{~cm}$. The threshold percent values were selected to be slightly higher than the existing harbor facilities.

Specific conclusions and recommendations are as follows:

a. Plan 1. Not recommended because of large long wave amplifications at proposed passenger pier. 
b. Plan 2. Not recommended because of large long wave amplifications at proposed passenger pier.

c. Plan $3 a$. Generally acceptable for both short and long waves. The long wave amplification factor at one resonance is quite high at Piers 1-3 and the proposed passenger pier.

d. Plan $3 b$. Generally acceptable.

e. Plan 3c. Generally acceptable.

f. Plan $4 a$. Not recommended because of large wind waves and swell at the proposed passenger pier.

g. Plan $4 b$. Generally acceptable. Fairly large wind waves and swell can be expected at the proposed passenger pier.

h. Plan 4c. Generally acceptable.

i. Plan 5. Not recommended because of large long wave amplifications at proposed barge and passenger piers.

j. Plan 6. Generally acceptable. Fairly large wind waves and swell can be expected at the proposed passenger pier.

k. Plan 7. Not recommended because of large long wave amplifications at proposed barge and passenger piers.

All of the plans, including those designated as acceptable, include some long wave resonant peaks which are larger than in the existing harbor. These seem to be a likely consequence of creating new pier areas. It is assumed that peaks with amplification factors well under 10 will not cause any major operational difficulties.

Some of the limitations in the plans tested may be overcome by prudent design. For example, the fill area in the southwest area of the harbor created strong oscillations. However, the same facility could be designed as a pilesupported structure and the strong oscillations would be avoided. The breakwater extension present in some of the plans might be designed without a core, allowing it to block wind waves and swell but remain transparent to long waves.

A physical model study to refine and validate the preferred plan(s) is strongly recommended as a final phase of the studies. The physical modeling component was part of the originally proposed WES study. 


\begin{tabular}{|c|c|c|c|c|c|}
\hline \multicolumn{6}{|c|}{$\begin{array}{l}\text { Table } 21 \\
\text { Plans with } H_{s}>1 \text { ft Less Than } 1 \text { Percent of the Time }\end{array}$} \\
\hline \multirow[t]{2}{*}{ Plan } & \multicolumn{5}{|l|}{ Area } \\
\hline & Pier 1 & Piers 2 \& 3 & Barge & Boat Ramp & Passenger Pier \\
\hline Existing & $x$ & $x$ & & & \\
\hline 1 & & $x$ & & & $x$ \\
\hline 2 & & $x$ & $x$ & & $x$ \\
\hline $3 a$ & $x$ & $x$ & $x$ & & \\
\hline $3 b$ & $x$ & $x$ & $x$ & $x$ & $x$ \\
\hline $3 c$ & $x$ & $x$ & $x$ & $x$ & $x$ \\
\hline $4 a$ & & $x$ & $x$ & $x$ & \\
\hline $4 b$ & $x$ & $x$ & $x$ & $x$ & \\
\hline $4 c$ & $x$ & $x$ & $x$ & $x$ & $x$ \\
\hline 5 & & $x$ & $x$ & & \\
\hline 6 & $x$ & $x$ & $x$ & $x$ & \\
\hline 7 & $x$ & $x$ & $x$ & $x$ & \\
\hline
\end{tabular}

\begin{tabular}{|c|c|c|c|c|c|}
\hline \multicolumn{6}{|c|}{$\begin{array}{l}\text { Table } 22 \\
\text { Plans with } H_{\text {s,long }} \geq 10 \mathrm{~cm} \text { Less Than } 16 \text { Percent of the Time, 100- to } \\
\text { 400-sec Periods }\end{array}$} \\
\hline \multirow[t]{2}{*}{ Plan } & \multicolumn{5}{|l|}{ Area } \\
\hline & Pier 1 & Piers $2 \& 3$ & Barge & Boat Ramp & Passenger Pier \\
\hline Existing & $x$ & $x$ & & $x$ & \\
\hline 1 & $x$ & $x$ & $x$ & $x$ & \\
\hline 2 & $x$ & $x$ & $x$ & $x$ & \\
\hline 3а & $x$ & $x$ & $x$ & $x$ & $x$ \\
\hline $3 b$ & $x$ & $x$ & $x$ & $x$ & $\mathbf{x}$ \\
\hline $3 c$ & $x$ & $x$ & $x$ & & $x$ \\
\hline $4 a$ & $x$ & $x$ & $x$ & $x$ & $x$ \\
\hline $4 b$ & $x$ & $x$ & $x$ & $x$ & $x$ \\
\hline $4 c$ & $x$ & $x$ & $x$ & $x$ & $x$ \\
\hline 5 & $x$ & $x$ & $x$ & & $x$ \\
\hline 6 & $x$ & $x$ & $x$ & $x$ & $x$ \\
\hline 7 & $x$ & $x$ & $x$ & $\underline{x}$ & $x$ \\
\hline
\end{tabular}




\begin{tabular}{|c|c|c|c|c|c|}
\hline \multicolumn{6}{|c|}{$\begin{array}{l}\text { Table } 23 \\
\text { Plans with } H_{\text {s,long }} \geq 10 \mathrm{~cm} \text { Less Than } 7 \text { Percent of the Time, } 30 \text { - to } \\
\text { 100-sec Periods }\end{array}$} \\
\hline \multirow[t]{2}{*}{ Plan } & \multicolumn{5}{|l|}{ Area } \\
\hline & Pier 1 & Piers 2 \& 3 & Barge & Boat Ramp & Passenger Pier \\
\hline Existing & $x$ & $x$ & & & \\
\hline 1 & $x$ & $x$ & $x$ & & $x$ \\
\hline 2 & $x$ & $x$ & $x$ & & $x$ \\
\hline $3 a$ & $x$ & $x$ & $x$ & $x$ & $x$ \\
\hline $3 b$ & $x$ & $x$ & $x$ & $x$ & $x$ \\
\hline $3 c$ & $x$ & $x$ & $x$ & $x$ & $x$ \\
\hline $4 a$ & $x$ & $x$ & $x$ & $x$ & $x$ \\
\hline $4 b$ & $x$ & $x$ & $x$ & $x$ & $x$ \\
\hline $4 c$ & $x$ & $x$ & $x$ & $x$ & $x$ \\
\hline 5 & & $x$ & $x$ & & $x$ \\
\hline 6 & $x$ & $x$ & $x$ & $x$ & $x$ \\
\hline 7 & & & $x$ & & \\
\hline
\end{tabular}




\section{References}

Allsop, N. W. H. (1990). "Reflection performance of rock armoured slopes in random waves." Proceedings of the 22nd International Conference on Coastal Engineering. American Society of Civil Engineers, Vol 2, 1460 1472.

Basco, D. R., and McGehee, D. D. (1990). "A methodology to select nearshore wave gauge sites: The Virginia wave gauge study," Report No. 90-1, Coastal Engineering Institute, Old Dominion University, Norfolk, VA.

Berkhoff, J. C. W. (1972). "Computation of combined refraction-diffraction." Proceedings of the 13th International Conference on Coastal Engineering. American Society of Civil Engineers, Vol 1, 471-490.

Blue, F. L., and Johnson, J. W. (1949). "Diffraction of water waves passing through a breakwater gap." Transactions, American Geophysical Union. Vol 30, No. 5, 705-718.

Bottin, R. R., Jr., Sargent, F. E., and Mize, M. G. (1985). 'Fisherman's Wharf area, San Francisco Bay, California, design for wave protection: Physical and numerical model investigation," Technical Report CERC-86-7, U.S. Army Engineer Waterways Experiment Station, Vicksburg, MS.

Bowers, E. C., and Welsby, J. (1982). "Experimental study of diffraction through a breakwater gap," Report No. IT 229, Hydraulics Research Station, Wallingford, England.

Briggs, M. J., Lillycrop, L. S., and McGehee, D. D. (1992). "Comparison of model and field results for Barbers Point Harbor." Proceedings, Coastal Engineering Practice. American Society of Civil Engineers, 387-99.

Briggs, M. J., Lillycrop, L. S., Harkins, G. R., Thompson, E. F., and Green, D. R. (1994). "Physical and numerical model studies of Barbers Point Harbor, Oahu, Hawaii," Technical Report CERC-94-14, U.S. Army Engineer Waterways Experiment Station, Vicksburg, MS. 
Chen, H. S. (1986). "Effects of bottom friction and boundary absorption on water wave scattering," Applied Ocean Research 8 (2), 99-104.

Chen, H. S., and Houston, J. R. (1987). "Calculation of water oscillation in coastal harbors: HARBS and HARBD user's manual," Instruction Report CERC-87-2, U.S. Army Engineer Waterways Experiment Station, Vicksburg, MS.

Chen, H. S., and Mei, C. C. (1974). "Oscillations and wave forces in an offshore harbor," Report No. 190, Department of Civil Engineering, Massachusetts Institute of Technology, Cambridge, MA.

Clausner, J. E., and Abel, C. E. (1986). “Contained aquatic disposal: Site location and cap material investigations for Outer Indiana Harbor, $\mathbb{I N}$, and Southern Lake Michigan," Technical Report EL-87-9, Vol II, Appendix J, U.S. Army Engineer Waterways Experiment Station, Vicksburg, MS.

Coastal Engineering Research Center. (1996). "Compendium of U.S. wave data, summary statistics, January 1996," U.S. Army Engineer Waterways Experiment Station and U.S. Department of Commerce, National Oceanic and Atmospheric Administration. To obtain copies, contact U.S. Army Engineer Waterways Experiment Station, CD-P, 3909 Halls Ferry Road, Vicksburg, MS 39180.

Corson, W. D., Abel, C. E., Brooks, R. M., Farrar, P. D., Groves, B. J., Jensen, R. E., Payne, J. B., Ragsdale, D. S., and Tracy, B. A. (1986). "Pacific Coast hindcast deepwater wave information," WIS Report 14, U.S. Army Engineer Waterways Experiment Station, Vicksburg, MS.

Crawford, P. L., and Chen, H. S. (1988). "Comparison of numerical and physical models of wave response in a harbor," Miscellaneous Paper CERC88-11, U.S. Army Engineer Waterways Experiment Station, Vicksburg, MS.

Farrar, P. D., and Chen, H. S. (1987). "Wave response of the proposed harbor at Agat, Guam: Numerical model investigation," Technical Report CERC87-4, U.S. Army Engineer Waterways Experiment Station, Vicksburg, MS.

Farrar, P. D., and Houston, J. R. (1982). "Tsunami response of Barbers Point Harbor, Hawaii," Miscellaneous Paper HL-82-1, U.S. Army Engineer Waterways Experiment Station, Vicksburg, MS.

Goda, Y. (1985). Random seas and design of maritime structures. University of Tokyo Press, Tokyo, Japan.

Harkins, G., Smith, E., McGehee, D., Thompson, E., and Hadley, L. (1996). "Wave response of Kaumalapau Harbor, Lanai, Hawaii," in preparation, U.S. Army Engineer Waterways Experiment Station, Vicksburg, MS. 
Hasselmann, K., Barnett, T. P., Bouws, E., Carlson, H., Cartwright, D. E., Enke, K., Ewing, J. A., Gienapp, H., Hasselmann, D. E., Kruseman, D., Meerburg, A., Muller, D., Olberg, D. J., Richter, K., Sell, W., and Walden, H. (1973). "Measurements of wind wave growth and swell decay during the Joint North Sea Wave Project (JONSWAP)," Deutsches Hydrographisches Institut, Hamburg, Germany.

Houston, J. R. (1976). "Long Beach Harbor numerical analysis of harbor oscillation; Report 1, Existing conditions and proposed improvements," Miscellaneous Paper H-76-20, U.S. Army Engineer Waterways Experiment Station, Vicksburg, MS.

. (1978). "Interaction of tsunamis with the Hawaiian Islands calculated by a finite-element numerical model," Journal of Physical Oceanography 8 (1), 93-101.

. (1981). "Combined refraction and diffraction of short waves using the finite element method," Applied Ocean Research 3 (4), 163-170.

Houston, J. R., and Garcia, A. W. (1978). "Type 16 flood insurance study: Tsunami predictions for the west coast of the continental United States," Technical Report H-78-26, U.S. Army Engineer Waterways Experiment Station, Vicksburg, MS.

Kaihatu, J. M., Lillycrop, L. S., and Thompson, E. F. (1989). "Effects of entrance channel dredging at Morro Bay, California," Miscellaneous Paper CERC-89-3, U.S. Army Engineer Waterways Experiment Station, Vicksburg, MS.

Lillycrop, L. S., and Boc, S. J. (1992). "Numerical modeling of proposed Kawaihae Harbor, HI." Proceedings, Coastal Engineering Practice. American Society of Civil Engineers, 412-24.

Lillycrop, L. S., and Thompson, E. F. (1996). "Harbor wave oscillation model (HARBD) theory and program documentation," Coastal Modeling System (CMS) User's Manual, Instruction Report CERC-91-1, M. A. Cialone, ed., U.S. Army Engineer Waterways Experiment Station, Vicksburg, MS.

Lillycrop, L. S., Bratos, S. M., and Thompson, E. F. (1990). "Wave response of proposed improvements to the shallow-draft harbor at Kawaihae, Hawaii," Miscellaneous Paper CERC-90-8, U.S. Army Engineer Waterways Experiment Station, Vicksburg, MS.

Lillycrop, L. S., Bratos, S. M., Thompson, E. F., and Rivers, P. (1993). "Wave response of proposed improvements to the small boat harbor at Maalaea, Maui, Hawaii," Miscellaneous Paper CERC-93-4, U.S. Army Engineer Waterways Experiment Station, Vicksburg, MS. 
Markle, D. G., and Boc, S. J. (1994). "Periodic inspections of Kahului and Laupahoehoe Breakwaters, Hawaii; Report 1, base conditions," Technical Report CERC-94-12, U.S. Army Engineer Waterways Experiment Station, Vicksburg, MS.

McGehee, D. D. (1995). "Requirement for FY95 wave measurements in Kahului Harbor," Memorandum for Record, U.S. Army Engineer Waterways Experiment Station, Vicksburg, MS.

McGehee, D. D., and McKinney, J. P. "Tsunami detection and warning capability using nearshore submerged pressure transducers; Case study of the 4 October 1994 Shikotan tsunami." Proceedings, IUGG Tsunami Symposium. In preparation, Boulder, CO.

Merrifield, M. A., and Okihiro, M. S. "Correlations between infragravity energy at Kahului Harbor and deep ocean wave buoy measurements," in preparation, U.S. Army Engineer Waterways Experiment Station, Vicksburg, MS.

Mesa, C. (1992). “A dual approach to low frequency energy definition in a small craft harbor." Proceedings, Coastal Engineering Practice. American Society of Civil Engineers, 400-11.

Okihiro, M. S., and Guza, R. T. (1996). "Observations of seiche forcing and amplification in three small harbors," J. Waterway, Port, Coastal and Ocean Engineering 122 (5), 232-238, American Society of Civil Engineers.

Okihiro, M. S., Guza, R. T., O'Reilly, W. C., and McGehee, D. D. (1994). "Selecting wave gauge sites for monitoring harbor oscillations: A case study for Kahului Harbor, Hawaii," Miscellaneous Paper CERC-94-10, U.S. Army Engineer Waterways Experiment Station, Vicksburg, MS.

Permanent International Association of Navigation Congresses. (1995). "Criteria for movements of moored ships in harbours, a practical guide," Report of Working Group No. 24, Supplement to Bulletin No. 88, Brussels, Belgium.

Sargent, F. E. (1989). "Los Angeles - Long Beach Harbor Complex 2020 Plan harbor resonance analysis: Numerical model investigation," Technical Report CERC-89-16, U.S. Army Engineer Waterways Experiment Station, Vicksburg, MS.

Sargent, F. E., Markle, D. G., and Grace, P. J. (1988). "Case histories of Corps breakwater and jetty structures; Report 4, Pacific Ocean Division," Technical Report REMR-CO-3, U.S. Army Engineer Waterways Experiment Station, Vicksburg, MS.

Seabergh, W. C., and Thomas, L. J. (1995). "Los Angeles Harbor Pier 400 harbor resonance model study," Technical Report CERC-95-8, U.S. Army Engineer Waterways Experiment Station, Vicksburg, MS. 
Seymour, R., Castel, D., McGehee, D., Thomas, J., and O'Reilly, W. (1993).

"New technology in coastal wave monitoring." Proceedings of the 2 nd International Symposuim on Ocean Wave Measurement and Analysis. American Society of Civil Engineers, 105-123.

Sorensen, R. M. (1993). Basic wave mechanics for coastal and ocean engineers. Wiley, New York.

Steele, K. E., and Mettlach, T. (1993). "NDBC wave data - current and planned." Proceedings of the 2nd International Symposium on Ocean Wave Measurement and Analysis. American Society of Civil Engineers, 198-207.

Thompson, E. F. (1980). "Energy spectra in shallow U.S. coastal waters," Technical Paper 80-2, U.S. Army Engineer Waterways Experiment Station, Vicksburg, MS.

. (1995). "Estimation of peak period in wave data from Kahului Harbor," Memorandum for Record, U.S. Army Engineer Waterways Experiment Station, Vicksburg, MS.

Thompson, E. F., and Hadley, L. L. (1994a). "Wave response of Port Allen Harbor, Kauai, Hawaii” Miscellaneous Paper CERC-94-9, U.S. Army Engineer Waterways Experiment Station, Vicksburg, MS.

(1994b). "Wave response of proposed improvement plan 6 to the small boat harbor at Maalaea, Maui, Hawaii" Miscellaneous Paper CERC-9417, U.S. Army Engineer Waterways Experiment Station, Vicksburg, MS.

. (1995). "Numerical modeling of harbor response to waves,"

J. Coastal Research 11(3), 744-753.

Thompson, E. F., Chen, H. S., and Hadley, L. L. (1993). "Numerical modeling of waves in harbors," Proceedings, WAVES 93. American Society of Civil Engineers, 590-601.

(1996). "Validation of a numerical model for wind waves and swell in harbors," J. Waterway, Port, Coastal and Ocean Engineering 122 (5), 245-257, American Society of Civil Engineers.

Turner, P. J., and Baptista, A. M. (1993). "ACE/gredit User's Manual," Center for Coastal and Land-Margin Research, Oregon Graduate Institute of Science and Technology, Beaverton, OR.

U.S. Army Corps of Engineers. (1989). "Water levels and wave heights for coastal engineering design," Engineer Manual 1110-2-1414, Washington, DC. 
Weishar, L. L., and Aubrey, D. G. (1986). "A study of inlet hydraulics at Green Harbor, Marshfield, Mass.," Miscellaneous Paper CERC 88-10, U.S. Army Engineer Waterways Experiment Station, Vicksburg, MS.

Wilson, B. W. (1967). "The threshold of surge damage for moored ships." Proceedings of the Institute of Civil Engineers. London, Vol. 38, 107-132. 



\section{Appendix A \\ Field Data Summary}




\begin{tabular}{|c|c|c|c|c|c|c|c|c|c|c|c|c|}
\hline \multirow{2}{*}{$\begin{array}{l}T_{p} \\
\text { (sec) }\end{array}$} & \multicolumn{12}{|c|}{$\theta_{m}$ (deg azimuth) } \\
\hline & $<190$ & 190. & 192- & 194. & 196 & 198- & 200 & 202- & 204- & $206-$ & 208- & 210 \\
\hline$<8$ & 0 & 2 & 1 & 7 & 4 & 3 & 10 & 36 & 43 & 49 & 32 & 33 \\
\hline 8- & 0 & 0 & 1 & 2 & 1 & 10 & 21 & 39 & 42 & 39 & 33 & 14 \\
\hline 9 & 3 & 1 & 0 & 2 & 7 & 16 & 46 & 22 & 35 & 25 & 13 & 6 \\
\hline 10- & 2 & 1 & 3 & 3 & 9 & 19 & 37 & 42 & 36 & 15 & 8 & 4 \\
\hline 11- & 13 & 5 & 12 & 14 & 18 & 27 & 33 & 29 & 26 & 7 & 4 & 2 \\
\hline 12- & 6 & 9 & 3 & 8 & 20 & 24 & 27 & 29 & 17 & 8 & 2 & $\underline{0}$ \\
\hline 13. & 5 & 5 & 3 & 5 & 14 & 12 & 24 & 8 & 8 & 1 & 0 & 8 \\
\hline 14. & 3 & 10 & 25 & 11 & 15 & 19 & 20 & 16 & 4 & 11 & 11 & 2 \\
\hline 15- & 5 & 3 & 5 & 6 & 7 & 7 & 4 & 6 & 7 & 2 & 0 & 6 \\
\hline $16-$ & 3 & 2 & 3 & 2 & 1 & 16 & 7 & 2 & 5 & 1 & 1 & 0 \\
\hline 17. & 0 & 3 & 7 & 2 & 1 & 1 & 5 & 1 & 2 & 0 & 1 & 0 \\
\hline 18. & 0 & 0 & 2 & 6 & 2 & 5 & 2 & 1 & 1 & 0 & 1 & 1 \\
\hline $19-$ & 0 & 0 & 0 & 2 & 2 & 7 & 3 & 1 & 0 & 0 & 0 & 0 \\
\hline 220 & 0 & 0 & 0 & 0 & 0 & 0 & 0 & 0 & 0 & 0 & 0 & 0 \\
\hline Tot & 40 & 41 & 65 & 70 & 101 & 166 & 239 & 232 & 226 & 158 & 106 & 76 \\
\hline$\%$ & 2.2 & 2.3 & 3.6 & 3.9 & 5.7 & 9.3 & 13.4 & 13.0 & 12.6 & 8.8 & 5.9 & 4.3 \\
\hline
\end{tabular}




\begin{tabular}{|c|c|c|c|c|c|c|c|c|c|c|c|c|}
\hline \multirow{2}{*}{$\begin{array}{l}T_{\rho} \\
\text { (sec) }\end{array}$} & \multicolumn{10}{|c|}{$\theta_{m}$ (deg azimuth) } & \multicolumn{2}{|l|}{ Total } \\
\hline & 212- & 214 & 216- & 218- & $220-$ & 222- & $224-$ & 226- & $228-$ & 2230 & No. & $\%$ \\
\hline$<8$ & 11 & 5 & 3 & 1 & 2 & 2 & 1 & 0 & 1 & 10 & 256 & 14.3 \\
\hline 8- & 4 & 3 & 5 & 0 & 0 & 1 & 1 & 0 & 0 & 3 & 219 & 12.3 \\
\hline 9 & 5 & 3 & 4 & 2 & 0 & 1 & 3 & 0 & 0 & 7 & 201 & 11.3 \\
\hline 10 & 3 & 4 & 2 & 3 & 1 & 3 & 4 & 0 & 1 & 4 & 204 & 11.4 \\
\hline $11-$ & 2 & 0 & 4 & 2 & 0 & 3 & 1 & 1 & 1 & 19 & 223 & 12.5 \\
\hline 12- & 4 & 4 & 1 & 1 & 2 & 4 & 1 & 1 & 2 & 14 & 187 & 10.5 \\
\hline 13- & 0 & 3 & 6 & 0 & 1 & 0 & 2 & 0 & 0 & 11 & 116 & 6.5 \\
\hline $14-$ & 0 & 4 & 1 & 0 & 4 & 2 & 6 & 1 & 0 & 22 & 187 & 10.4 \\
\hline 15- & 2 & 0 & 1 & 0 & 1 & 0 & 1 & 0 & 1 & 6 & 70 & 3.9 \\
\hline 16 & 1 & 0 & 1 & 0 & 1 & 1 & 0 & 1 & 0 & 9 & 57 & 3.2 \\
\hline 17. & 5 & 1 & 0 & 0 & 0 & 0 & 0 & 0 & 0 & 2 & 31 & 1.7 \\
\hline 18 & 0 & 0 & 0 & 0 & 0 & 0 & 0 & 0 & 0 & 0 & 21 & 1.2 \\
\hline 19 & 0 & 0 & 0 & 0 & 0 & 0 & 0 & 0 & 0 & 0 & 15 & 0.8 \\
\hline$\geq 20$ & 0 & 0 & 0 & 0 & 0 & 0 & 0 & 0 & 0 & 0 & 0 & 0 \\
\hline Tot & 37 & 27 & 28 & 9 & 12 & 17 & 20 & 4 & 6 & 107 & 1787 & \\
\hline$\%$ & 2.1 & 1.5 & 1.6 & 0.5 & 0.7 & 1.0 & 1.1 & 0.2 & 0.3 & 6.0 & & 100.0 \\
\hline
\end{tabular}


NUMBER OF RECORDS WITH HMO BY MONTH EOR 1993 - 1996

\begin{tabular}{|c|c|c|c|c|c|c|c|c|c|c|c|c|c|}
\hline YEAR & JAN & FEB & MAR & APR & MAY & JUN & JUL & $A D G$ & SEP & $\infty \mathrm{CT}$ & NOV & DEC & TOTAL \\
\hline 1993 & 331 & 574 & 681 & 485 & 0 & 151 & 700 & 686 & 677 & 708 & 700 & 701 & 6394 \\
\hline 1994 & 701 & 591 & 697 & 712 & 172 & 0 & 0 & 0 & 325 & 727 & 701 & 486 & 5112 \\
\hline 1995 & 137 & 646 & 727 & 701 & 733 & 707 & 728 & 727 & 709 & 729 & 703 & 715 & 7962 \\
\hline 1996 & 716 & 680 & 0 & 0 & 0 & 0 & 0 & 0 & 0 & 0 & 0 & 0 & 1396 \\
\hline
\end{tabular}

NUMBER OF RECORDS WITH HMO AND TP BY MONTH FOR 1993 - 1996

YEAR JAN FEB MAR APR MAY JON JUL AUG SEP OCT NOV DEC TOTAL

\begin{tabular}{|c|c|c|c|c|c|c|c|c|c|c|c|c|c|}
\hline 1993 & 331 & 574 & 681 & 485 & 0 & 151 & 700 & 686 & 677 & 708 & 700 & 701 & 6394 \\
\hline 1994 & 701 & 591 & 697 & 712 & 172 & 0 & 0 & 0 & 325 & 727 & 701 & 486 & 5112 \\
\hline 1995 & 137 & 646 & 727 & 701 & 733 & 707 & 728 & 727 & 709 & 729 & 703 & 715 & 7962 \\
\hline 1996 & 716 & 680 & 0 & 0 & 0 & 0 & 0 & 0 & 0 & 0 & 0 & 0 & 1396 \\
\hline
\end{tabular}

NUMBER OF RECORDS WITH HMO, TP, AND DP BY MONTH FOR 1993 - 1996

YEAR JAN FEB MAR APR MAY JUN JUL AUG SEP OCT NOV DEC TOTAL

\begin{tabular}{|c|c|c|c|c|c|c|c|c|c|c|c|c|c|}
\hline 1993 & 331 & 574 & 681 & 485 & 0 & 151 & 700 & 686 & 677 & 708 & 700 & 701 & 6394 \\
\hline 1994 & 701 & 591 & 697 & 712 & 172 & 0 & 0 & 0 & 325 & 727 & 701 & 486 & 5112 \\
\hline 1995 & 137 & 646 & 727 & 701 & 733 & 707 & 728 & 727 & 709 & 729 & 703 & 715 & 7962 \\
\hline 996 & 716 & 680 & 0 & 0 & 0 & 0 & 0 & 0 & 0 & 0 & 0 & 0 & 1396 \\
\hline
\end{tabular}


MEAN HMO (METRES) BY MONTH AND YEAR

NDBC BUOY $51026(21.37 \mathrm{~N}, 156.96$ W)

MONTH
JAN FEB MAR APR MAY JUN JUL AUG SEP OCT NOV DEC

YEAR

1993

$\begin{array}{llll}2.0 & 2.9 & 2.6 & 2.7\end{array}$

$2.7 \quad 1.7 \quad 1.9$

$\begin{array}{lllll}2.0 & 1.4 & 2.1 & 2.8 & 3.2\end{array}$

MEAN

1994

$\begin{array}{llllllllllllll}2.9 & 2.4 & 2.9 & 2.5 & 2.1 & . & . & . & 1.6 & 2.0 & 2.8 & 3.1\end{array}$

2.3

1995

$\begin{array}{llllllllllll}2.3 & 2.2 & 2.3 & 2.4 & 1.8 & 1.6 & 1.8 & 1.9 & 1.7 & 2.0 & 2.3 & 2.5\end{array}$

2.5

1996

2.43.

MEAN

$\begin{array}{llllllllllll}2.5 & 2.7 & 2.6 & 2.5 & 1.9 & 1.6 & 1.9 & 1.9 & 1.6 & 2.0 & 2.6 & 2.9\end{array}$

LARGEST HMO (METRES) BY MONTH AND YEAR

NDBC BUOY $51026(21.37 \mathrm{~N}, 156.96 \mathrm{~W})$

MONTH

JAN FEB MAR APR MAY JUN JUL AUG SEP OCT NOV DEC

YEAR

1993

$\begin{array}{llllllllllll}3.5 & 6.8 & 5.0 & 4.4 & . & 2.3 & 4.0 & 4.7 & 2.6 & 3.9 & 4.8 & 5.0\end{array}$

$\begin{array}{lllllllllllllll}1994 & 5.6 & 4.6 & 6.0 & 4.5 & 2.6 & . & . & . & 2.4 & 3.7 & 4.8 & 5.0\end{array}$

$\begin{array}{lllllllllllll}1995 & 4.5 & 5.5 & 4.6 & 4.8 & 3.4 & 2.5 & 2.9 & 2.8 & 3.9 & 3.4 & 7.3 & 5.0\end{array}$

1996

$5.0 \quad 5.9$

4 YR. STATISTICS FOR NDBC BUOY 51026 (21.37 N, $156.96 \mathrm{~W})$

THE MEAN SIGNIFICANT WAVE HEIGHT (METRES)=

2.3

THE MEAN PEAK WAVE PERIOD (SECONDS)=

10.7

THE MOST FREQUENT 22.5 (CENTER) DIRECTION BAND (DEGREES) $=$

90.0

THE STANDARD DEVIATION OF HMO (ME'TRES)=

0.8

THE STANDARD DEVIATION OF TP (SECONDS)=

2.9

THE LARGEST HMO (METRES) =

7.3

THE TP (SECONDS) ASSOC. WITH THE LARGEST HMO=

16.7

THE PEAK DIRECTION (DEGREES) ASSOC. WITH THE LARGEST HMO=

344.0

THE DATE OE LARGEST HMO OCCURRENCE IS

95114350 
BUOY STATION $5102621.37 \mathrm{~N}, 156.96 \mathrm{~W}$ AZIMUTH (DEGREES) $=0.0$ PERCENT OCCURRENCE (X1000) OF HEIGHT AND PERIOD BY DIRECTION

HE IGHT (METRES)

PEAK PERIOD (SECONDS)

TOTAL

$$
\begin{aligned}
& <6.96 .9-8.1-8.8-9.6-10.6-11.8-13.4-15.4-18.2-
\end{aligned}
$$

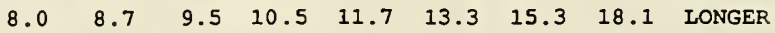

$0.0-0.9$

1. $0-1.9$

2. $0-2.9$

3. $0-3.9$

4. $0-4.9$

5. $0-5.9$

$6.0-6.9$

$7.0-7.9$

$8.0-8.9$

9. $0-9.9$

$10.0+$

TOTAI

$\begin{array}{rrrrrrrrrrr}. & 14 & 23 & 28 & 4 & 14 & . & . & . & . \\ 4 & 43 & 186 & 493 & 1064 & 929 & 464 & 110 & 14 & 4 \\ 9 & 28 & 86 & 153 & 301 & 867 & 1020 & 220 & 71 & 9 \\ . & . & 9 & 23 & 105 & 162 & 522 & 412 & 119 & . \\ . & . & . & . & 9 & 4 & 86 & 115 & 81 & 4 \\ . & . & . & . & . & . & . & . & 28 & 9 \\ . & . & . & . & . & . & . & . & 9 & 4 \\ . & . & . & . & . & . & . & . & . & . \\ 13 & 85 & 304 & 697 & 1483 & 1976 & 2092 & 857 & 322 & 30\end{array}$

BUOY STATION $5102621.37 \mathrm{~N}, 156.96 \mathrm{~W}$ AZIMUTH (DEGREES) $=22.5$ PERCENT OCCURRENCE $(X 1000)$ OF HEIGHT AND PERIOD BY DIRECTION

HEIGHT (METRES)

PEAK PERIOD (SECONDS)

TOTAL

$$
\begin{aligned}
& <6.96 .9-8.1-8.8-9.6-10.6-11.8-13.4-15.4-18.2- \\
& \begin{array}{lllllllll}
8.0 & 8.7 & 9.5 & 10.5 & 11.7 & 13.3 & 15.3 & 18.1 & \text { IONGER }
\end{array}
\end{aligned}
$$

$0.0-0.9$

1. $0-1.9$

2. 0-2.9

3. $0-3.9$

4. $0-4.9$

5. $0-5.9$

6. $0-6.9$

7. $0-7.9$

8. $0-8.9$

9. $0-9.9$

10. $0+$

TOTAL

$\begin{array}{rrrrr}. & 23 & 38 & 14 & 38 \\ 4 & 76 & 268 & 680 & 824 \\ 19 & 138 & 167 & 186 & 258 \\ 4 & 9 & 43 & 206 & 162 \\ . & . & . & . & 28 \\ . & . & . & . & . \\ . & . & . & . & . \\ . & . & . & . & . \\ . & . & . & . & . \\ . & . & . & . & . \\ . & . & . & . & . \\ 27 & 246 & 516 & 1086 & 1310\end{array}$

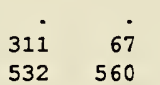

110

560

158

$$
\begin{array}{rrr}
110 & 158 & 158 \\
. & . & 33 \\
. & . &
\end{array}
$$

.

MEAN HMO (M)

27

$5.8 \operatorname{MEAN} \operatorname{TP}(\mathrm{SEC})=10.5$ NO. OF CASES=

1115. 
BUOY STATION $5102621.37 \mathrm{~N}, 156.96 \mathrm{~W}$ AZIMUTH (DEGREES) $=45.0$ PERCENT OCCURRENCE (X1000) OF HEIGHT AND PERIOD BY DIRECTION

HEIGHT (METRES)

PEAK PERIOD (SECONDS)

TOTAL

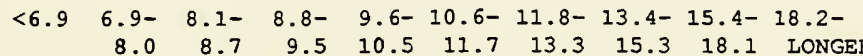

0. 0-0.9

1. $0-1.9$

2. $0-2.9$

3. $0-3.9$

4. $0-4.9$

5. 0-5.9

6. $0-6.9$

7. $0-7.9$

8. $0-8.9$

9.0-9.9

$10.0+$

TOTAL

$\begin{array}{rrrrrrrrrr}. & 38 & 86 & 100 & 23 & . & . & . & . & . \\ 95 & 690 & 666 & 949 & 642 & 162 & 9 & 9 & 9 & . \\ 67 & 474 & 517 & 661 & 522 & 340 & 67 & 71 & 14 & . \\ 4 & 71 & 148 & 268 & 258 & 19 & 4 & . & . & . \\ . & 4 & . & 23 & 19 & 38 & 4 & 23 & . & . \\ . & . & . & . & 9 & 23 & . & . & . & . \\ . & . & . & . & . & . & . & . & . & . \\ . & . & . & . & . & . & . & . & . & . \\ 166 & 1277 & 1417 & 2001 & 1473 & 582 & 84 & 103 & 23 & .\end{array}$

$\operatorname{MEAN} \operatorname{HmO}(M)=2.1$ LARGEST $\operatorname{HmO}(M)=5.2 \operatorname{MEAN} \operatorname{TP}(\mathrm{SEC})=9.1$ NO. OF CASES $=1491$.

BUOY STATION $5102621.37 \mathrm{~N}, 156.96 \mathrm{~W}$ AZTMUTH(DEGREES) $=67.5$ PERCENT OCCURRENCE (X1000) OF HEIGHT AND PERIOD BY DIRECTION

HEIGHT (METRES)

PEAK PERIOD (SECONDS)

TOTAL

$$
\begin{aligned}
& <6.96 .9-8.1-8.8-9.6-10.6-11.8-13.4-15.4-18.2-
\end{aligned}
$$

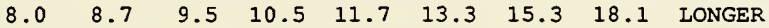

\begin{tabular}{|c|c|c|c|c|c|c|c|c|c|c|c|}
\hline $0.0-0.9$ & 23 & 76 & 71 & 33 & 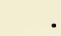 & & 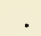 & . & . & . & 203 \\
\hline $1.0-1.9$ & 1318 & 3168 & 2367 & 1433 & 450 & 210 & 4 & . & . & . & 8950 \\
\hline $2.0-2.9$ & 416 & 1787 & 2276 & 1974 & 637 & 100 & 33 & 4 & . & . & 7227 \\
\hline $3.0-3.9$ & . & 134 & 273 & 632 & 508 & 67 & 23 & 9 & . & . & 1646 \\
\hline $4.0-4.9$ & . & . & 14 & 105 & 287 & 292 & 33 & 19 & . & . & 750 \\
\hline $5.0-5.9$ & . & . & . & 4 & 33 & 76 & . & . & . & . & 113 \\
\hline $6.0-6.9$ & . & . & . & . & . & . & . & . & - & . & 0 \\
\hline $7.0-7.9$ & . & . & - & . & . & . & - & . & - & . & 0 \\
\hline $8.0-8.9$ & . & . & . & . & . & . & . & . & . & . & 0 \\
\hline $9.0-9.9$ & . & . & . & . & . & . & . & . & . & . & 0 \\
\hline $10.0+$ & . & . & . & . & . & . & . & . & . & . & 0 \\
\hline TOTAL & 1757 & 5165 & 5001 & 1010 & $107-$ & 70 & & & & & \\
\hline
\end{tabular}

MEAN HMO $(M)=2.2$ LARGEST HMO $(M)=6.0$ MEAN TP $(S E C)=8.4$ NO. OF CASES $=3945$. 
BUOY STATION $5102621.37 \mathrm{~N}, 156.96 \mathrm{~W}$ AZIMUTH (DEGREES) $=90.0$ PERCENT OCCURRENCE $(X 1000)$ OF HEIGHT AND PERIOD BY DIRECTION

HEIGHT (METRES)

PEAK PERIOD (SECONDS)

TOTAL

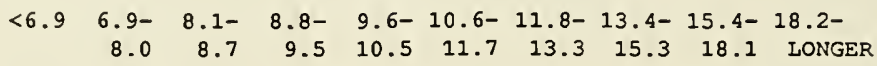

$0.0-0.9$

$\begin{array}{rrrrrrrrrr}81 & 81 & 105 & 28 & . & 4 & . & . & . & . \\ 1615 & 3091 & 3589 & 2175 & 282 & 402 & 206 & 4 & . & . \\ 493 & 1615 & 2324 & 3311 & 1926 & 287 & 9 & 9 & 28 & . \\ 4 & 81 & 263 & 661 & 1231 & 579 & 38 & 91 & 47 & . \\ . & . & 4 & 14 & 244 & 369 & 19 & 28 & . & . \\ . & . & . & . & . & . & . & . & . & . \\ . & . & . & . & . & . & . & . & . & . \\ . & . & . & . & . & . & . & . & . & . \\ . & . & . & . & . & . & . & . & . & . \\ 2193 & 4868 & 6285 & 6189 & 3683 & 1641 & 272 & 132 & 75 & 0\end{array}$

299

$1.0-1.9$

2. $0-2.9$

3. $0-3.9$

$4.0-4.9$

$5.0-5.9$

$6.0-6.9$

$7.0-7.9$

$8.0-8.9$

$9.0-9.9$

$10.0+$

TOTAL

2.2

4.9 MEAN TP $(S E C)=8.7$ NO. OF CASES $=$

5291.

BUOY STATION $5102621.37 \mathrm{~N}, 156.96 \mathrm{~W}$ AZIMUTH (DEGREES) $=112.5$ PERCENT OCCURRENCE $(X 1000)$ OF HEIGHT AND PERIOD BY DIRECTION

HEIGHT (METRES)

PEAK PERIOD (SECONDS)

TOTAL

$$
\begin{aligned}
& <6.96 .9-8.1-8.8-9.6-10.6-11.8-13.4-15.4-18.2- \\
& \begin{array}{lllllllll}
8.0 & 8.7 & 9.5 & 10.5 & 11.7 & 13.3 & 15.3 & 18.1 & \text { LONGER }
\end{array}
\end{aligned}
$$

$0.0-0.9$

1. $0-1.9$

2. $0-2.9$

3. $0-3.9$

$4.0-4.9$

$5.0-5.9$

$6.0-6.9$

$7.0-7.9$

$8.0-8.9$

9.0-9.9

$10.0+$

TOTAL

$\begin{array}{rrrrrrrrrr}47 & 28 & 23 & 38 & 4 & 4 & 43 & . & . & . \\ . & 19 & 4 & 62 & 62 & 19 & . & . & . & . \\ . & . & . & . & 9 & . & . & . & . & . \\ . & . & . & . & . & . & . & . & . & . \\ . & . & . & . & . & . & . & . & . & . \\ . & . & . & . & . & . & . & . & . & . \\ . & . & . & . & . & . & . & . & . & . \\ 47 & 47 & 27 & 100 & 75 & 27 & 43 & 0 & 0 & 0\end{array}$

MEAN HmO $(M)=2.0$ LARGEST HMO $(M)=3.6$ MEAN TP $(S E C)=9.1$ NO. OF CASES=

78. 
BUOY STATION $5102621.37 \mathrm{~N}, 156.96 \mathrm{~W}$ AZIMUTH (DEGREES) $=135.0$ PERCENT OCCURRENCE $(\times 1000)$ OF HEIGHT AND PERIOD BY DIRECTION

HEIGHT (METRES)

PEAK PERIOD (SECONDS)

TOTAL

$<6.96 .9-8.1-8.8-9.6-10.6-11.8-13.4-15.4-18.2-$

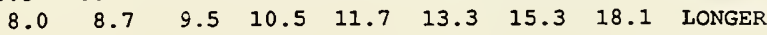

$0.0-0.9$

1. 0-1.9

2. $0-2.9$

$3.0-3.9$

4.0-4.9

$5.0-5.9$

6. $0-6.9$

$7.0-7.9$

8. 0-8. 9

9.0-9.9

$10.0+$

TOTAI

MEAN HMO $(M)=3.1$ LARGEST HmO $(M)=3.5 \operatorname{MEAN} T P(S E C)=22.5$ NO. OF CASES=

BUOY STATION $5102621.37 \mathrm{~N}, 156.96 \mathrm{~W}$ AZIMUTH (DEGREES) $=157.5$ PERCENT OCCURRENCE $(\mathrm{X} 1000)$ OF HEIGHT AND PERIOD BY DIRECTION

HEIGHT (METRES)

PEAK PERIOD (SECONDS)

TOTAL

$$
\begin{array}{rrrrrrrrrr}
<6.9 & 6.9- & 8.1- & 8.8- & 9.6- & 10.6- & 11.8- & 13.4- & 15.4- & 18.2- \\
8.0 & 8.7 & 9.5 & 10.5 & 11.7 & 13.3 & 15.3 & 18.1 & \text { LONGER }
\end{array}
$$

$0.0-0.9$

1. 0-1.9

2. $0-2.9$

3. $0-3.9$

4. $0-4.9$

$5.0-5.9$

6. $0-6.9$

$7.0-7.9$

8. $0-8.9$

9.0-9.9

$10.0+$

TOTAL

MEAN $\operatorname{HmO}(M)=0.0$ LARGEST $\operatorname{HmO}(M)=0.0$ MEAN TP $(S E C)=0.0$ NO. OE CASES $=$

0 . 
BUOY STATION $5102621.37 \mathrm{~N}, 156.96 \mathrm{~W}$ AZIMUTH (DEGREES) $=180.0$ PERCENT OCCURRENCE (X1000) OF HEIGHT AND PERIOD BY DIRECTION

HEIGHT (METRES)

PEAK PERIOD(SECONDS)

TOTAL

$$
\begin{array}{rrrrrrrrrr}
6.9 & 6.9- & 8.1- & 8.8- & 9.6- & 10.6- & 11.8- & 13.4- & 15.4- & 18.2- \\
& 8.0 & 8.7 & 9.5 & 10.5 & 11.7 & 13.3 & 15.3 & 18.1 & \text { LONGER }
\end{array}
$$

$0.0-0.9$

$1.0-1.9$

2. $0-2.9$

$3.0-3.9$

$4.0-4.9$

$5.0-5.9$

$6.0-6.9$

$7.0-7.9$

$8.0-8.9$

$9.0-9.9$

$10.0+$

TOTAL

MEAN HMO $(M)=0.0$ LARGEST HmO (M)

0.0 MEAN TP $(S E C)=0.0$ NO. OF CASES $=$

0 .

BUOY STATION $5102621.37 \mathrm{~N}, 156.96 \mathrm{~W}$ AZIMUTH (DEGREES) $=202.5$

PERCENT OCCURRENCE (X1000) OF HEIGHT AND PERIOD BY DIRECTION

HEIGHT (METRES)

PEAK PERIOD (SECONDS)

TOTAL

$$
\begin{aligned}
& <6.96 .9-8.1-8.8-9.6-10.6-11.8-13.4-15.4-18.2-
\end{aligned}
$$

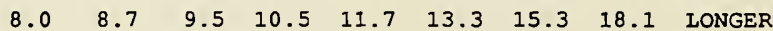

$0.0-0.9$

$1.0-1.9$

$2.0-2.9$

$3.0-3.9$

$4.0-4.9$

$5.0-5.9$

$6.0-6.9$

$7.0-7.9$

8. $0-8.9$

9.0-9.9

$10.0+$

TOTAI

$\operatorname{MEAN} \mathrm{HmO}(\mathrm{M})=0.0$ LARGEST HMO $(M)=0.0$ MEAN TP $(\mathrm{SEC})=0.0$ NO. OF CASES= 
BUOY STATION $5102621.37 \mathrm{~N}, 156.96 \mathrm{~W}$ AZIMUTH (DEGREES) $=225.0$ PERCENT OCCURRENCE $(X 1000)$ OF HEIGHT AND PERIOD BY DIRECTION

HEIGHT (METRES)

PEAK PERIOD (SECONDS)

TOTAL

<6.9 6.9- 8.1- 8.8- 9.6- $10.6-11.8-13.4-15.4-18.2-$

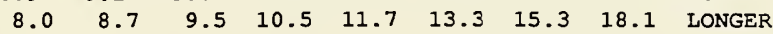

$0.0-0.9$

$1.0-1.9$

2. 0-2. 9

3. $0-3.9$

4. $0-4.9$

$5.0-5.9$

$6.0-6.9$

$7.0-7.9$

$8.0-8.9$

9.0-9.9

$10.0+$

TOTAL

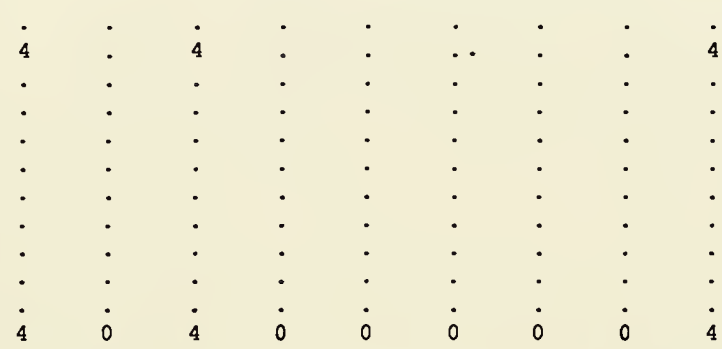

$\operatorname{MEAN} \operatorname{HMO}(M)=1.4$ LARGEST $\operatorname{HMO}(M)=1.7 \operatorname{MEAN} \operatorname{TP}(\mathrm{SEC})=12.1$ NO. OF $\mathrm{CASES}=$

BUOY STATION $5102621.37 \mathrm{~N}, 156.96 \mathrm{~W}$ AZIMUTH (DEGREES) $=247.5$ PERCENT OCCURRENCE (X1000) OF HEIGHT AND PERIOD BY DIRECTION

HEIGHT (METRES)

PEAK PERIOD (SECONDS)

TOTAL

$$
\begin{array}{rrrrrrrrrr}
<6.9 & 6.9- & 8.1- & 8.8- & 9.6- & 10.6- & 11.8- & 13.4- & 15.4- & 18.2- \\
& 8.0 & 8.7 & 9.5 & 10.5 & 11.7 & 13.3 & 15.3 & 18.1 & \text { LONGER }
\end{array}
$$
$0.0-0.9$
1. 0-1.9
2. $0-2.9$
3. $0-3.9$
$4.0-4.9$
$5.0-5.9$
$6.0-6.9$
7. 0-7.9
8. 0-8. 9
9. $0-9.9$
$10.0+$

TOTAL

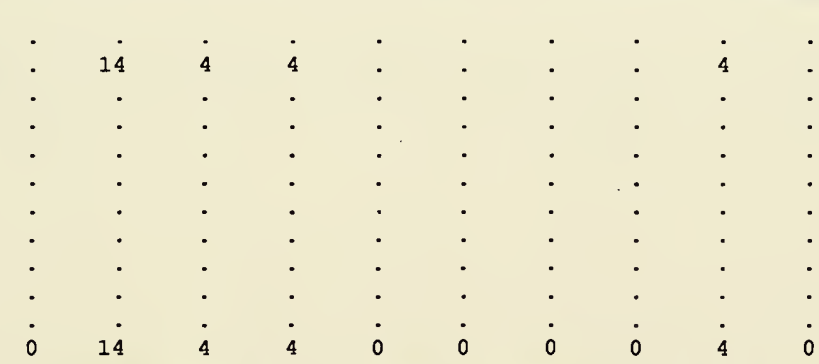
0
26
0
0
0
0
0
0
0
0
0

MEAN HIO $(M)=1.3$ LARGEST HmO $(M)=1.9 \operatorname{MEAN} T P(S E C)=9.4$ NO. OF CASES=

6. 
BUOY STATION $5102621.37 \mathrm{~N}, 156.96 \mathrm{~W}$ AZIMUTH (DEGREES) $=270.0$ PERCENT OCCURRENCE (X1000) OE HEIGHT AND PERIOD BY DIRECTION

HEIGHT (METRES)

PEAK PERIOD (SECONDS)

TOTAL

$$
\begin{array}{rrrrrrrrrr}
<6.9 & 6.9- & 8.1- & 8.8- & 9.6- & 10.6- & 11.8- & 13.4- & 15.4- & 18.2- \\
8.0 & 8.7 & 9.5 & 10.5 & 11.7 & 13.3 & 15.3 & 18.1 & \text { LONGER }
\end{array}
$$

$0.0-0.9$

1. $0-1.9$

2. $0-2.9$

3. $0-3.9$

$4.0-4.9$

5. $0-5.9$

6. $0-6.9$

$7.0-7.9$

8.0-8.9

9.0-9.9

$10.0+$

TOTAL

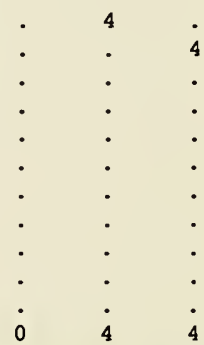

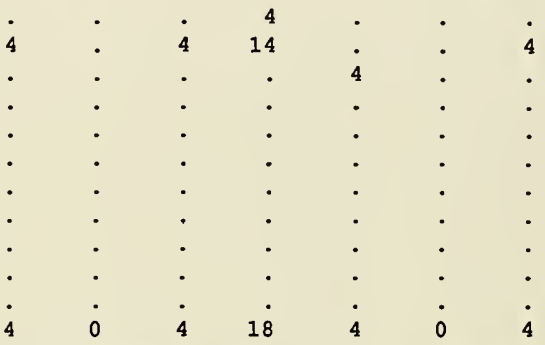

$\operatorname{MEAN} \operatorname{HMO}(M)=1.4$ LARGEST HMO $(M)=2.9$ MEAN TP $(S E C)=12.5$ NO. OF CASES=

BUOY STATION $5102621.37 \mathrm{~N}, 156.96 \mathrm{~W}$ AZIMUTH (DEGREES) $=292.5$ PERCENT OCCURRENCE $(X 1000)$ OF HEIGHT AND PERIOD BY DIRECTION

HEIGHT (METRES)

\author{
PEAK PERIOD (SECONDS)
}

\begin{tabular}{|c|c|c|c|c|c|c|c|c|c|c|c|}
\hline $0.0-0.9$ & . & - & - & : & 9 & 9 & 9 & 9 & • & & 36 \\
\hline $1.0-1.9$ & . & - & - & . & 38 & 86 & 282 & 225 & 86 & 38 & 755 \\
\hline $2.0-2.9$ & . & - & . & . & 19 & 91 & 138 & 273 & 254 & 76 & 851 \\
\hline $3.0-3.9$ & . & . & . & . & . & . & 19 & 105 & 124 & 28 & 276 \\
\hline $4.0-4.9$ & . & - & - & . & . & - & . & - & 62 & 9 & 71 \\
\hline $5.0-5.9$ & - & - & - & . & - & - & . & - & - & - & 0 \\
\hline $6.0-6.9$ & . & - & . & - & - & . & . & . & - & - & 0 \\
\hline $7.0-7.9$ & . & . & . & - & . & - & - & - & - & - & 0 \\
\hline $8 \cdot 0-8 \cdot 9$ & . & - & - & - & . & - & - & . & - & - & 0 \\
\hline $9.0-9.9$ & . & . & . & - & . & . & . & . & . & . & 0 \\
\hline $10.0+$ & - & . & - & . & $\therefore$ & - & - & • & . & . & 0 \\
\hline TOTAL & 0 & 0 & 0 & 0 & 66 & 186 & 448 & 612 & 526 & 151 & \\
\hline
\end{tabular}

TOTAL

$$
\begin{aligned}
& <6.96 .9-8.1-8.8-9.6-10.6-11.8-13.4-15.4-18.2- \\
& \begin{array}{lllllllll}
8.0 & 8.7 & 9.5 & 10.5 & 11.7 & 13.3 & 15.3 & 18.1 & \text { LONGER }
\end{array}
\end{aligned}
$$

$\operatorname{MEAN} \operatorname{HmO}(M)=2.3$ LARGEST $\mathrm{HmO}(M)=4.9 \mathrm{MEAN} \operatorname{TP}(\mathrm{SEC})=14.5$ NO. OF CASES $=417$. 
BUOY STATION $5102621.37 \mathrm{~N}, 156.96 \mathrm{~W}$ AZIMUTH (DEGREES) $=315.0$ PERCENT OCCURRENCE $(X 1000)$ OF HEIGHT AND PERIOD BY DIRECTION

HEIGHT (METRES)

PEAK PERIOD (SECONDS)

TOTAL

$<6.96 .9-8.1-8.8-9.6-10.6-11.8-13.4-15.4-18.2-$

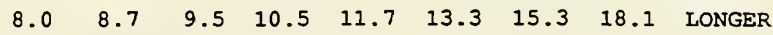

$0.0-0.9$

1.0-1.9

2.0-2.9

$3.0-3.9$

$4.0-4.9$

$5.0-5.9$

$6.0-6.9$

$7.0-7.9$

8. $0-8.9$

$9.0-9.9$

$10.0+$

TOTAL

\section{4}

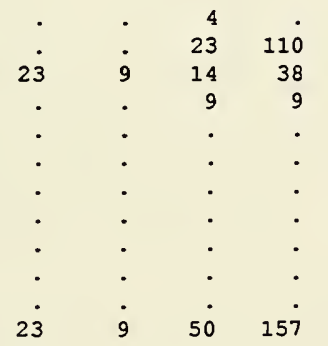

$\begin{array}{rrrrrr}28 & 38 & 14 & . & . & . \\ 273 & 1073 & 1744 & 1068 & 349 & 86 \\ 100 & 388 & 1816 & 2664 & 1380 & 306 \\ 28 & 76 & 325 & 1289 & 1279 & 292 \\ . & . & 57 & 215 & 532 & 23 \\ . & . & . & 9 & 43 & . \\ . & . & . & . & . & . \\ . & . & . & . & . & . \\ . & . & . & . & . & . \\ . & . & . & . & . & . \\ . & . & . & . & . & . \\ 429 & 1575 & 3956 & 5245 & 3583 & 707\end{array}$

$\operatorname{MEAN} \operatorname{HMO}(M)=2.5$ LARGEST $\mathrm{HMO}(M)=5.5 \mathrm{MEAN}$ TP $(S E C)=14.1$ NO. OF CASES=

3287.

BUOY STATION $5102621.37 \mathrm{~N}, 156.96 \mathrm{~W}$ AZIMUTH (DEGREES) $=337.5$ PERCENT OCCURRENCE $(X 1000)$ OF HEIGHT AND PERIOD BY DIRECTION

HEIGHT (METRES)

PEAK PERIOD (SECONDS)

TOTAL

$$
\begin{aligned}
& <6.9 \text { 6.9- 8.1- 8.8- 9.6- } 10.6-11.8-13.4-15.4-18.2-
\end{aligned}
$$

\begin{tabular}{|c|c|c|c|c|c|c|c|c|c|c|c|}
\hline $0.0-0.9$ & - & 14 & • & 4 & 43 & 9 & 4 & • & - & . & 74 \\
\hline $1.0-1.9$ & . & • & 23 & 364 & 925 & 1878 & 1653 & 354 & 95 & 28 & 5320 \\
\hline $2.0-2.9$ & 4 & 43 & 43 & 71 & 182 & 977 & 2856 & 2008 & 555 & 129 & 6868 \\
\hline $3.0-3.9$ & . & 9 & 4 & 23 & 62 & 277 & 819 & 1759 & 642 & 95 & 3690 \\
\hline $4.0-4.9$ & . & . & . & . & • & 28 & 158 & 369 & 349 & 9 & 913 \\
\hline $5.0-5.9$ & . & . & . & . & . & 4 & 28 & 28 & 81 & 4 & 145 \\
\hline $6.0-6.9$ & . & . & - & . & . & . & • & - & 86 & 4 & 90 \\
\hline $7.0-7.9$ & - & . & - & . & - & . & . & . & 9 & . & 9 \\
\hline $8.0-8.9$ & . & - & - & - & - & - & - & - & . & . & 0 \\
\hline $9.0-9.9$ & . & . & . & . & . & . & . & . & . & . & 0 \\
\hline $10.0+$ & . & . & • & • & • & • & • & . & . & . & 0 \\
\hline TOTAL & 4 & 66 & 70 & 462 & 1212 & 3173 & 5518 & 4518 & 1817 & 269 & \\
\hline
\end{tabular}

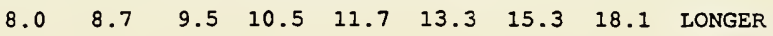

MEAN HIMO $(M)=2.5$ LARGEST HmO $(M)=7.3$ MEAN TP $(S E C)=13.0$ NO. OF CASES= 3575 . 
BUOY STATION $5102621.37 \mathrm{~N}, 156.96 \mathrm{~W}$ FOR ALL DIRECTIONS PERCENT OCCURRENCE $(\mathrm{X} 1000)$ OE HEIGHT AND PERIOD

HEIGHT (METRES)

PEAK PERIOD (SECONDS)

TOTAL

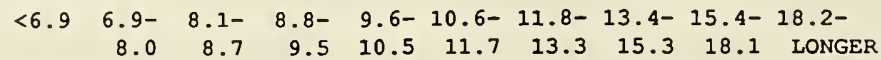

$0.0-0.9$

$$
8.0 .8
$$

$\begin{array}{rrrrrrrrrrr}105 & 249 & 335 & 210 & 148 & 81 & 33 & 9 & . & . & 1170 \\ 3086 & 7117 & 7155 & 6259 & 4505 & 5066 & 4490 & 1773 & 560 & 167 & 40178 \\ 1035 & 4117 & 5435 & 6460 & 4011 & 3604 & 6504 & 5334 & 2319 & 527 & 39346 \\ 14 & 306 & 752 & 1826 & 2367 & 1294 & 1912 & 3824 & 2238 & 421 & 14954 \\ . & 4 & 19 & 143 & 589 & 733 & 359 & 805 & 1092 & 47 & 3791 \\ . & . & . & 4 & 43 & 105 & 28 & 38 & 172 & 28 & 418 \\ . & . & . & . & . & . & . & . & 95 & 9 & 104 \\ . & . & . & . & . & . & . & . & 9 & . & 9 \\ . & . & . & . & . & . & . & . & . & . & 0 \\ . & . & . & . & . & . & . & . & . & . & 0 \\ 4240 & 11793 & 13696 & 14902 & 11663 & 10883 & 13326 & 11783 & 6485 & 1199 & 0\end{array}$

$\operatorname{MEAN} \operatorname{HIO}(M)=2.3$ LARGEST HMO $(M)=7.3$ MEAN TP $(S E C)=10.7 \quad$ TOTAL CASES $=20864$. 


\section{Appendix B Means and Standard Deviations of $\boldsymbol{A}_{\text {amp,s }}$ from Field Wave Gages}




\begin{tabular}{|c|c|c|c|c|c|c|}
\hline \multicolumn{7}{|c|}{$\begin{array}{l}\text { Table B1 } \\
\text { Mean } \boldsymbol{A}_{\text {amp,s, }} \text { Nov 93-Sep 94, Pier } 2 \text { (Only Cases with } 8 \text { or More } \\
\text { Observations are Shown) }\end{array}$} \\
\hline \multirow{2}{*}{$\begin{array}{l}r_{p} \\
\text { (sec) }\end{array}$} & \multicolumn{6}{|c|}{$\theta_{m}$ (deg going toward, referenced to true north) } \\
\hline & $<195$ & 195-205 & 205-215 & $215-225$ & 225-235 & 235-245 \\
\hline$<8$ & & 0.07 & 0.08 & 0.09 & & \\
\hline $8-9$ & & 0.07 & 0.07 & 0.07 & & \\
\hline $9-10$ & 0.12 & 0.10 & 0.10 & & & \\
\hline $10-11$ & 0.10 & 0.09 & 0.09 & 0.08 & & 0.10 \\
\hline 11-12 & 0.09 & 0.09 & 0.09 & 0.10 & & \\
\hline $12-13$ & 0.09 & 0.08 & 0.08 & 0.10 & 0.10 & \\
\hline 13-14 & 0.09 & 0.08 & 0.08 & 0.08 & & \\
\hline 14-15 & 0.09 & 0.07 & 0.07 & 0.08 & & \\
\hline $15-16$ & & 0.07 & 0.07 & 0.07 & & \\
\hline 16-17 & 0.14 & 0.11 & 0.12 & & & \\
\hline $17-18$ & 0.11 & 0.10 & & & & \\
\hline $18-19$ & & 0.09 & & & & \\
\hline $19-20$ & & 0.09 & & & & \\
\hline $20-21$ & & & & & & \\
\hline$>21$ & & & & & & \\
\hline
\end{tabular}




\begin{tabular}{|c|c|c|c|c|c|c|}
\hline \multicolumn{7}{|c|}{$\begin{array}{l}\text { Table } \mathbf{B 2} \\
\text { Mean } \boldsymbol{A}_{\text {amp,s }} \text { Nov 93-Sep 94, Canoe Club (Only Cases with } 8 \text { or } \\
\text { More Observations are Shown) }\end{array}$} \\
\hline \multirow{2}{*}{$\begin{array}{l}T_{p} \\
\text { (sec) }\end{array}$} & \multicolumn{6}{|c|}{$\theta_{m}$ (deg going toward, referenced to true north) } \\
\hline & $<195$ & 195-205 & 205-215 & 215-225 & 225-235 & 235-245 \\
\hline$<8$ & & 0.23 & 0.23 & 0.24 & & \\
\hline $8-9$ & & 0.23 & 0.22 & 0.23 & & \\
\hline $9-10$ & 0.30 & 0.26 & 0.28 & & & \\
\hline 10-11 & 0.30 & 0.26 & 0.28 & 0.26 & & 0.30 \\
\hline $11-12$ & 0.31 & 0.27 & 0.29 & 0.31 & & \\
\hline $12-13$ & 0.30 & 0.25 & 0.26 & 0.28 & 0.31 & \\
\hline 13-14 & 0.31 & 0.24 & 0.25 & 0.30 & & \\
\hline $14-15$ & 0.31 & 0.25 & 0.25 & 0.27 & & \\
\hline 15-16 & & 0.24 & 0.24 & 0.25 & & \\
\hline $16-17$ & 0.32 & 0.26 & 0.25 & & & \\
\hline 17-18 & 0.31 & 0.26 & & & & \\
\hline 18-19 & & 0.30 & & & & \\
\hline $19-20$ & & 0.30 & & & & \\
\hline $20-21$ & & & & & & \\
\hline$>21$ & & & & & & \\
\hline
\end{tabular}




\begin{tabular}{|c|c|c|c|c|c|c|}
\hline \multicolumn{7}{|c|}{$\begin{array}{l}\text { Table B3 } \\
\text { Mean } \boldsymbol{A}_{\text {amp,s, Nov 93-Sep 94, Back Basin (Only Cases with } 8 \text { or }} \\
\text { More Observations are Shown) }\end{array}$} \\
\hline \multirow{2}{*}{$\begin{array}{l}T_{\rho} \\
\text { (sec) }\end{array}$} & \multicolumn{6}{|c|}{$\theta_{m}$ (deg going toward, referenced to true north) } \\
\hline & $<195$ & 195-205 & $205-215$ & $215-225$ & 225-235 & 235-245 \\
\hline$<8$ & & 0.26 & 0.25 & 0.25 & & \\
\hline $8-9$ & & 0.24 & 0.23 & 0.25 & & \\
\hline $9-10$ & 0.33 & 0.28 & 0.27 & & & \\
\hline 10-11 & 0.32 & 0.28 & 0.28 & 0.28 & & 0.31 \\
\hline $11-12$ & 0.35 & 0.29 & 0.31 & 0.33 & & \\
\hline 12-13 & 0.33 & 0.27 & 0.26 & 0.31 & 0.33 & \\
\hline 13-14 & 0.34 & 0.26 & 0.26 & 0.33 & & \\
\hline 14-15 & 0.33 & 0.25 & 0.24 & 0.27 & & \\
\hline 15-16 & & 0.25 & 0.24 & 0.25 & & \\
\hline $16-17$ & 0.35 & 0.26 & 0.26 & & & \\
\hline $17-18$ & 0.32 & 0.29 & & & & \\
\hline $18-19$ & & 0.29 & & & & \\
\hline $19-20$ & & 0.30 & & & & \\
\hline $20-21$ & & & & & & \\
\hline$>21$ & & & & & & \\
\hline
\end{tabular}




\begin{tabular}{|c|c|c|c|c|c|c|}
\hline \multicolumn{7}{|c|}{$\begin{array}{l}\text { Table } \mathbf{B 4} \\
\text { Mean } \boldsymbol{A}_{\text {amp,s, }} \text { Nov 93-Sep 94, Channel Entrance (Only Cases with } \\
8 \text { or More Observations are Shown) }\end{array}$} \\
\hline \multirow{2}{*}{$\begin{array}{l}T_{p} \\
\text { (sec) }\end{array}$} & \multicolumn{6}{|c|}{$\theta_{m}$ (deg going toward, referenced to true north) } \\
\hline & $<195$ & $195-205$ & 205-215 & 215-225 & 225-235 & 235-245 \\
\hline$<8$ & & 0.68 & 0.76 & 0.78 & & \\
\hline 8-9 & & 0.66 & 0.71 & 0.65 & & \\
\hline $9-10$ & 0.66 & 0.69 & 0.73 & & & \\
\hline 10-11 & 0.62 & 0.67 & 0.74 & 0.74 & & 0.69 \\
\hline $11-12$ & 0.57 & 0.65 & 0.69 & 0.68 & & \\
\hline 12-13 & 0.59 & 0.63 & 0.71 & 0.69 & 0.73 & \\
\hline 13-14 & 0.62 & 0.64 & 0.66 & 0.62 & & \\
\hline 14-15 & 0.66 & 0.68 & 0.72 & 0.71 & & \\
\hline $15-16$ & & 0.67 & 0.72 & 0.67 & & \\
\hline $16-17$ & 0.66 & 0.66 & 0.69 & & & \\
\hline $17-18$ & 0.61 & 0.66 & & & & \\
\hline 18-19 & & 0.62 & & & & \\
\hline $19-20$ & & 0.67 & & & & \\
\hline $20-21$ & & & & & & \\
\hline$>21$ & & & & & & \\
\hline
\end{tabular}




\begin{tabular}{|c|c|c|c|c|c|c|}
\hline \multicolumn{7}{|c|}{$\begin{array}{l}\text { Table B5 } \\
\text { Standard Deviation of } A_{a m p, s} \text { Nov 93-Sep 94, Pier } 2 \text { (Only Cases } \\
\text { with } 8 \text { or More Observations are Shown) }\end{array}$} \\
\hline \multirow{2}{*}{$\begin{array}{l}T_{p} \\
\text { (sec) }\end{array}$} & \multicolumn{6}{|c|}{$\theta_{m}$ (deg going toward, referenced to true north) } \\
\hline & $<195$ & 195-205 & 205-215 & 215-225 & 225-235 & 235-245 \\
\hline$<8$ & & 0.01 & 0.01 & 0.01 & & \\
\hline $8-9$ & & 0.01 & 0.01 & 0.00 & & \\
\hline $9-10$ & 0.01 & 0.02 & 0.01 & & & \\
\hline $10-11$ & 0.02 & 0.01 & 0.02 & 0.01 & & 0.01 \\
\hline 11-12 & 0.01 & 0.01 & 0.01 & 0.01 & & \\
\hline $12-13$ & 0.01 & 0.01 & 0.01 & 0.01 & 0.01 & \\
\hline 13-14 & 0.01 & 0.01 & 0.01 & 0.01 & & \\
\hline 14-15 & 0.00 & 0.01 & 0.01 & 0.01 & & \\
\hline 15-16 & & 0.01 & 0.01 & 0.01 & & \\
\hline $16-17$ & 0.02 & 0.02 & 0.02 & & & \\
\hline $17-18$ & 0.02 & 0.01 & & & & \\
\hline 18-19 & & 0.01 & & & & \\
\hline $19-20$ & & 0.01 & & & & \\
\hline $20-21$ & & & & & & \\
\hline$>21$ & & & & & & \\
\hline
\end{tabular}




\begin{tabular}{|c|c|c|c|c|c|c|}
\hline \multicolumn{7}{|c|}{$\begin{array}{l}\text { Table B6 } \\
\text { Standard Deviation of } \boldsymbol{A}_{\text {amp,s }} \text { Nov 93-Sep 94, Canoe Club (Only } \\
\text { Cases with } 8 \text { or More Observations are Shown) }\end{array}$} \\
\hline \multirow{2}{*}{$\begin{array}{l}T_{p} \\
\text { (sec) }\end{array}$} & \multicolumn{6}{|c|}{$\theta_{\mathrm{m}}$ (deg going toward, referenced to true north) } \\
\hline & $<195$ & 195-205 & 205-215 & 215-225 & 225-235 & 235-245 \\
\hline$<8$ & & 0.02 & 0.02 & 0.02 & & \\
\hline $8-9$ & & 0.02 & 0.02 & 0.02 & & \\
\hline $9-10$ & 0.02 & 0.03 & 0.04 & & & \\
\hline 10-11 & 0.04 & 0.03 & 0.05 & 0.02 & & 0.02 \\
\hline $11-12$ & 0.04 & 0.04 & 0.05 & 0.04 & & \\
\hline $12-13$ & 0.04 & 0.03 & 0.04 & 0.05 & 0.05 & \\
\hline 13-14 & 0.05 & 0.03 & 0.03 & 0.06 & & \\
\hline $14-15$ & 0.04 & 0.02 & 0.02 & 0.04 & & \\
\hline 15-16 & & 0.02 & 0.02 & 0.02 & & \\
\hline $16-17$ & 0.03 & 0.04 & 0.04 & & & \\
\hline $17-18$ & 0.04 & 0.01 & & & & \\
\hline 18-19 & & 0.05 & & & & \\
\hline $19-20$ & & 0.04 & & & & \\
\hline $20-21$ & & & & & & \\
\hline$>21$ & & & & & & \\
\hline
\end{tabular}




\begin{tabular}{|c|c|c|c|c|c|c|}
\hline \multicolumn{7}{|c|}{$\begin{array}{l}\text { Table B7 } \\
\text { Standard Deviation of } \boldsymbol{A}_{\text {amp,s, Nov } 93-S e p ~ 94, \text { Back Basin (Only }} \\
\text { Cases with } 8 \text { or More Observations are Shown) }\end{array}$} \\
\hline \multirow{2}{*}{$\begin{array}{l}T_{p} \\
\text { (sec) }\end{array}$} & \multicolumn{6}{|c|}{$\theta_{m}$ (deg going toward, referenced to true north) } \\
\hline & $<195$ & 195-205 & 205-215 & 215-225 & 225-235 & 235-245 \\
\hline$<8$ & & 0.03 & 0.08 & 0.02 & & \\
\hline $8-9$ & & 0.02 & 0.02 & 0.03 & & \\
\hline $9-10$ & 0.03 & 0.03 & 0.04 & & & \\
\hline 10-11 & 0.04 & 0.04 & 0.05 & 0.04 & & 0.04 \\
\hline $11-12$ & 0.04 & 0.04 & 0.05 & 0.03 & & \\
\hline 12-13 & 0.03 & 0.04 & 0.04 & 0.05 & 0.04 & \\
\hline 13-14 & 0.04 & 0.03 & 0.04 & 0.06 & & \\
\hline 14-15 & 0.02 & 0.03 & 0.03 & 0.04 & & \\
\hline 15-16 & & 0.03 & 0.02 & 0.02 & & \\
\hline $16-17$ & 0.03 & 0.04 & 0.06 & & & \\
\hline $17-18$ & 0.03 & 0.01 & & & & \\
\hline 18-19 & & 0.03 & & & & \\
\hline $19-20$ & & 0.02 & & & & \\
\hline $20-21$ & & & & & & \\
\hline$>21$ & & & & & & \\
\hline
\end{tabular}




\begin{tabular}{|c|c|c|c|c|c|c|}
\hline \multicolumn{7}{|c|}{$\begin{array}{l}\text { Table B8 } \\
\text { Standard Deviation of } A_{\text {amp,s }} \text { Nov 93-Sep 94, Channel Entrance } \\
\text { (Only Cases with } 8 \text { or More Observations are Shown) }\end{array}$} \\
\hline \multirow{2}{*}{$\begin{array}{l}T_{\rho} \\
\text { (sec) }\end{array}$} & \multicolumn{6}{|c|}{$\theta_{m}$ (deg going toward, referenced to true north) } \\
\hline & $<195$ & 195-205 & 205-215 & 215-225 & 225-235 & 235-245 \\
\hline$<8$ & & 0.06 & 0.07 & 0.05 & & \\
\hline $8-9$ & & 0.05 & 0.05 & 0.06 & & \\
\hline $9-10$ & 0.08 & 0.06 & 0.07 & & & \\
\hline 10-11 & 0.06 & 0.08 & 0.06 & 0.04 & & 0.05 \\
\hline $11-12$ & 0.07 & 0.08 & 0.06 & 0.10 & & \\
\hline $12-13$ & 0.04 & 0.07 & 0.05 & 0.09 & 0.08 & \\
\hline 13-14 & 0.07 & 0.05 & 0.07 & 0.05 & & \\
\hline 14-15 & 0.08 & 0.05 & 0.05 & 0.05 & & \\
\hline $15-16$ & & 0.05 & 0.04 & 0.03 & & \\
\hline $16-17$ & 0.08 & 0.03 & 0.01 & & & \\
\hline $17-18$ & 0.05 & 0.02 & & & & \\
\hline 18-19 & & 0.03 & & & & \\
\hline $19-20$ & & 0.05 & & & & \\
\hline $20-21$ & & & & & & \\
\hline$>21$ & & & & & & \\
\hline
\end{tabular}





\section{Appendix C Summary Tables of Extreme Events of $\boldsymbol{H}_{s}$ and $\boldsymbol{H}_{\text {s,long }}$}




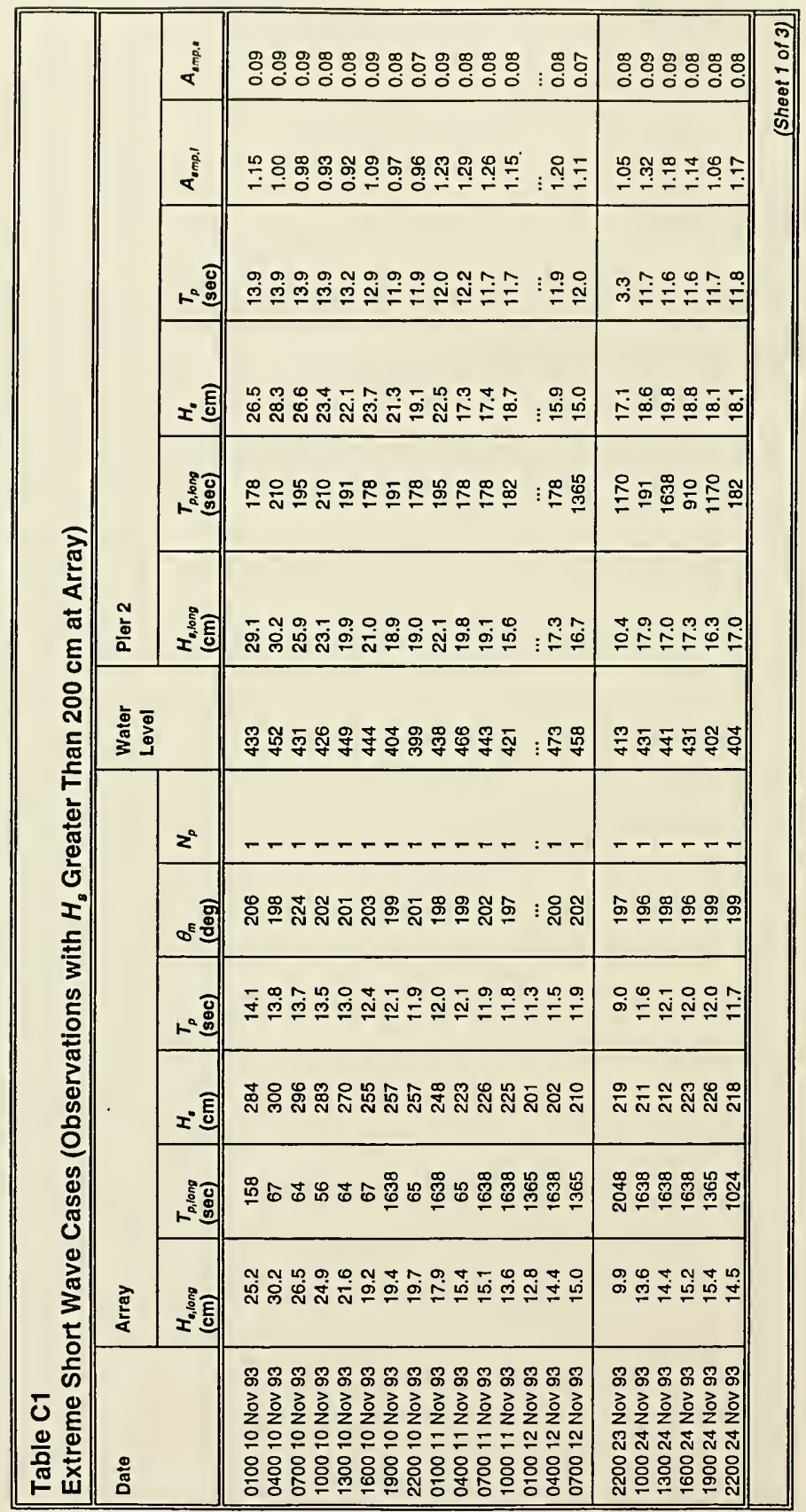




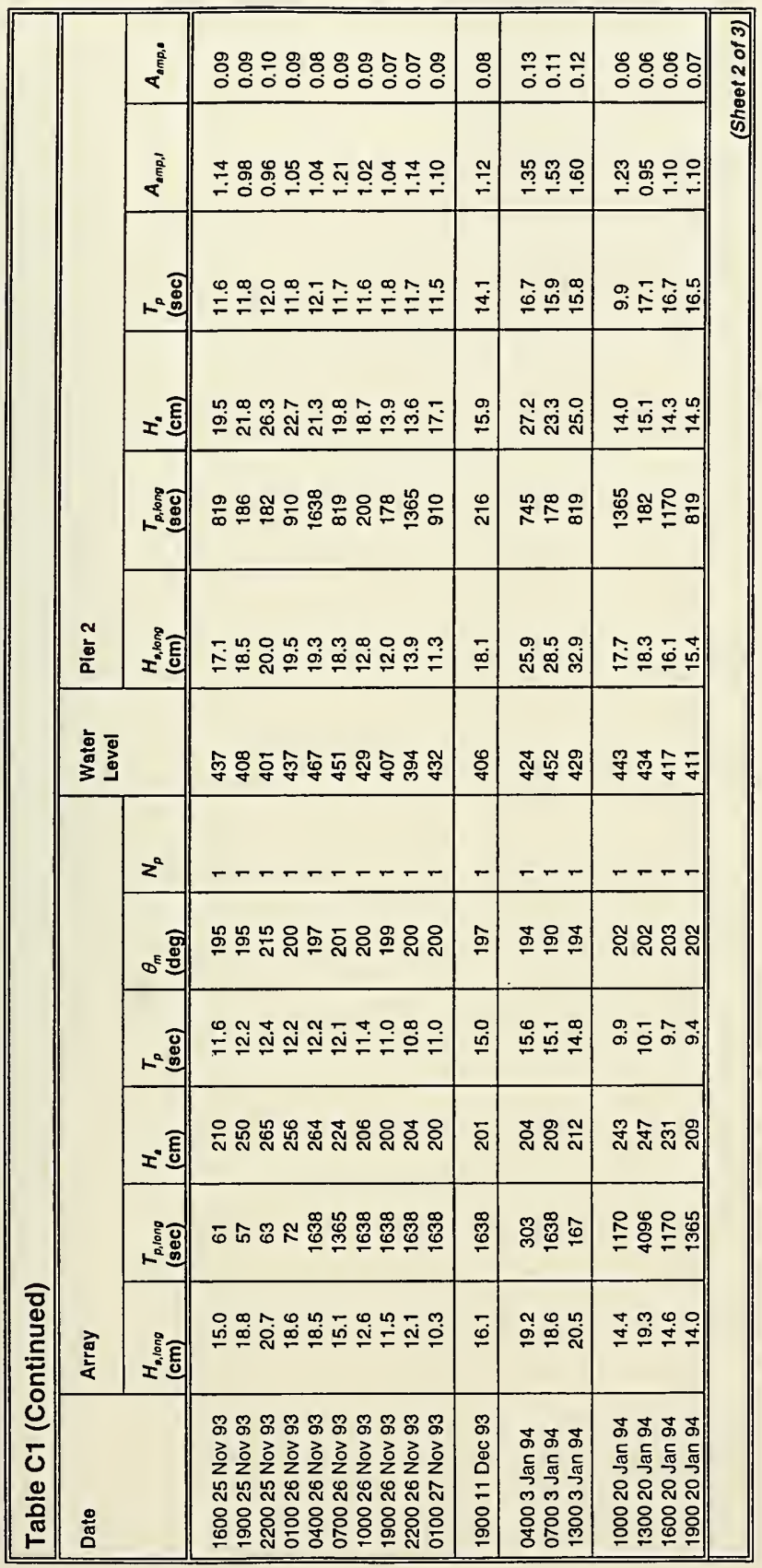




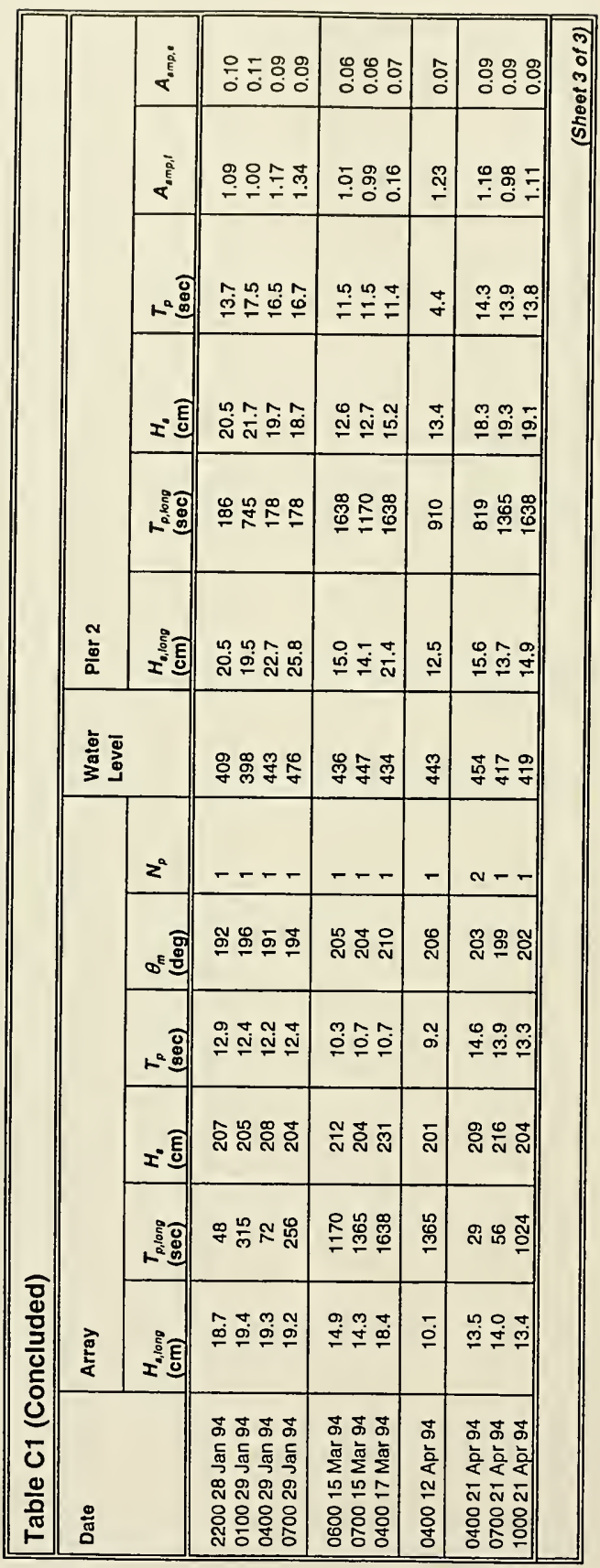




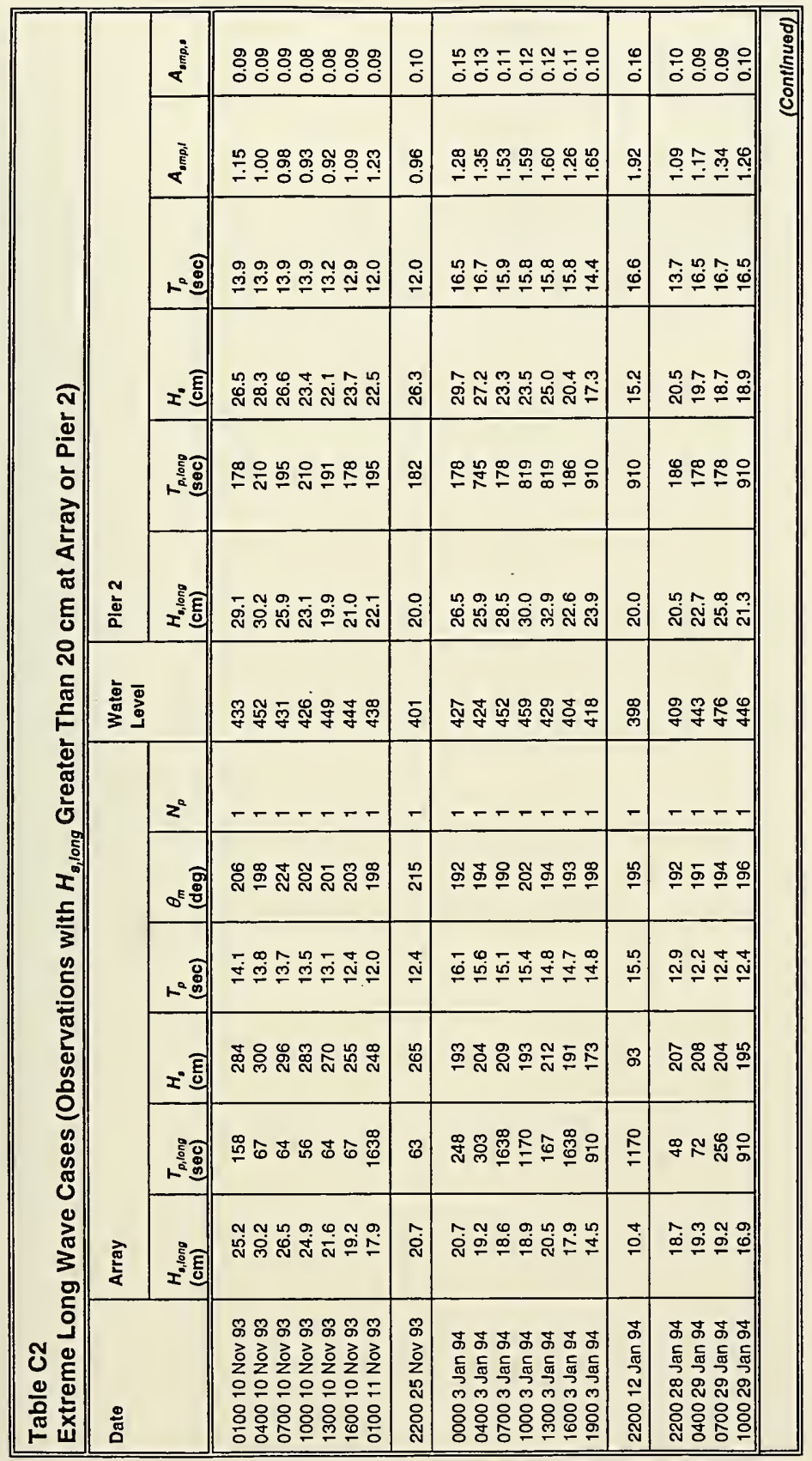




\begin{tabular}{|c|c|c|c|c|c|c|}
\hline & & 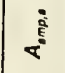 & 응 웅웅 응 & ơ & 뭉웅웅영 & $\overline{0}$ \\
\hline & & 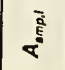 & 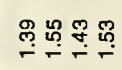 & $\stackrel{\circ}{\longleftarrow}$ & 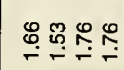 & $\stackrel{ }{+}$ \\
\hline & & ドす & 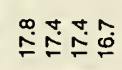 & $\stackrel{+}{=}$ & 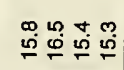 & $\begin{array}{l}\infty \\
\stackrel{\infty}{\leftrightarrow}\end{array}$ \\
\hline & & $x$ ह हㅝㅂ & 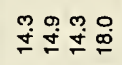 & 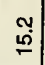 & 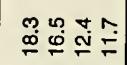 & 웅 \\
\hline & & م. & 옹읏 怘응 & \begin{tabular}{l}
$\infty$ \\
0 \\
\hdashline
\end{tabular} & 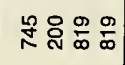 & 응 \\
\hline & $\begin{array}{l}\text { N } \\
\frac{2}{2}\end{array}$ & 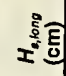 & 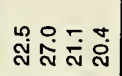 & $\stackrel{+}{\sim}$ & ลิ่ & ปั่ \\
\hline & $\begin{array}{l}\frac{5}{\omega} \\
\xi\end{array}$ & & 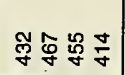 & ষ্ণ & 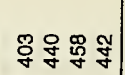 & ชิ \\
\hline & & $z^{a}$ & --- & - & $--0-$ & - \\
\hline & & $\theta^{E}$ है & ๙ธธ్ \% \% & 온 & 욤동 & ஃ \\
\hline & & ドす⿹ & 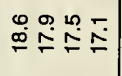 & $\hat{\circ}$ & 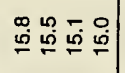 & 운 \\
\hline & & $x$ हㅔㅇ & 悉 윰 욤 & $\overline{\mathrm{N}}$ & 品 & 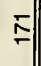 \\
\hline & & है: & 䍐罢正员 & \begin{tabular}{l}
$\infty$ \\
\hdashline \\
\hdashline
\end{tabular} & 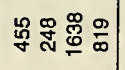 & $\stackrel{ \pm}{=}$ \\
\hline$\frac{\text { 을 }}{\mathrm{g}}$ & 产 & ₹ & 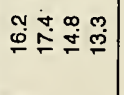 & $\underset{\infty}{\infty}$ & 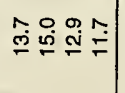 & $\stackrel{\varphi}{\square}$ \\
\hline $\begin{array}{l}\mathcal{U} \\
\mathcal{U} \\
\frac{0}{0} \\
\frac{0}{0}\end{array}$ & 总 & & 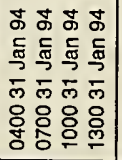 & 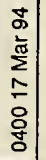 & 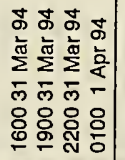 & 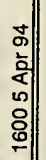 \\
\hline
\end{tabular}




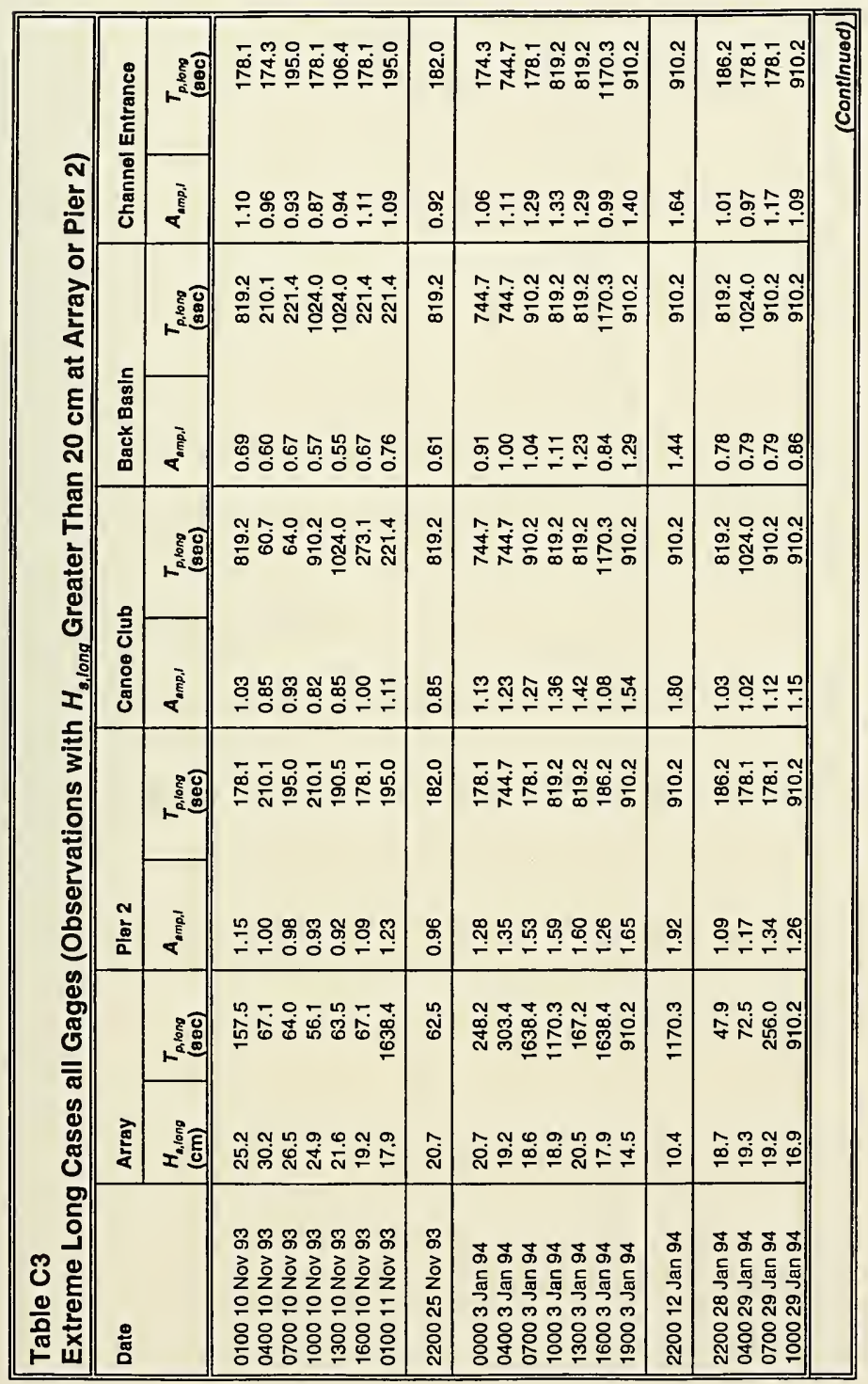




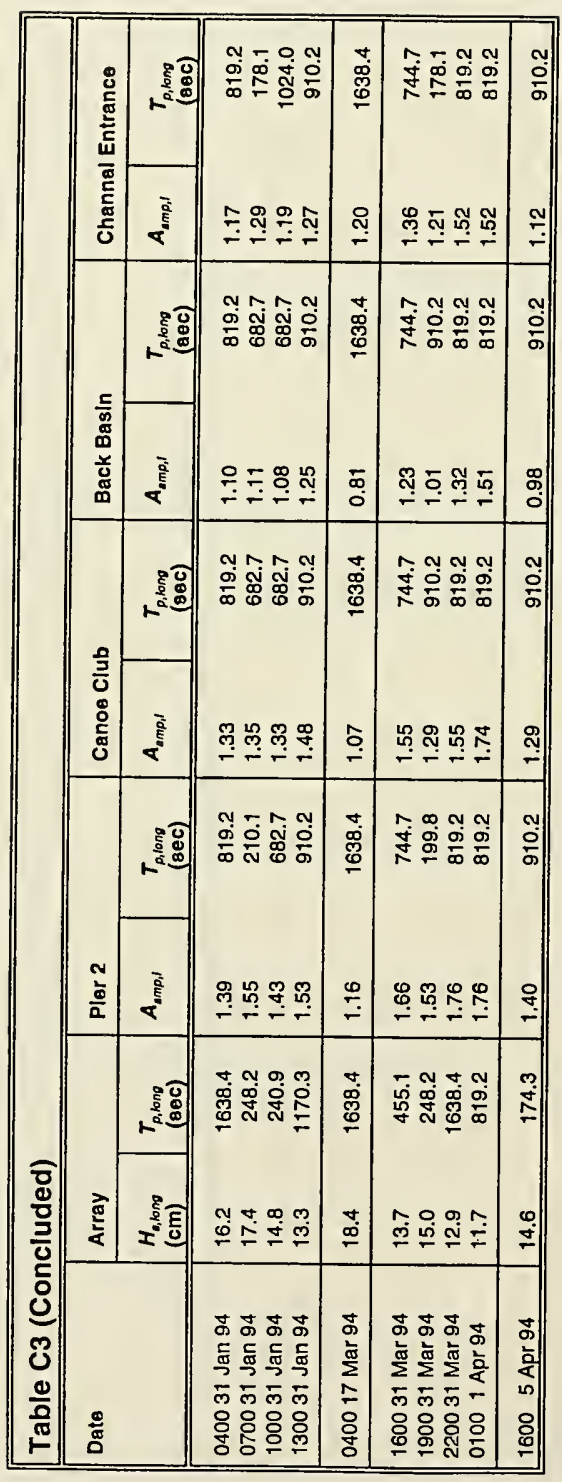




\section{Appendix D Wave Climate Summary}

\section{List of Figures}

Figure D1. Wave height time series plot for November $1994 \quad$ D2

Figure D2. Wave period time series plot for November $1994 \quad$ D2

Figure D3. Wave direction time series plot for November 1994 D3

\section{List of Tables}

Table D1. Summary Tables, NDBC Buoy 51026, N. Molokai, Oct 93-Dec 94

D4

Table D2. Summary Tables, WIS Station 5, Jan-Dec $94 \quad$ D5

Table D3. Summary Tables, WIS Station 31, Jan 56-Dec 75 D6

Table D4. Summary Tables, Array, Nov 93-Dec $94 \quad$ D7 


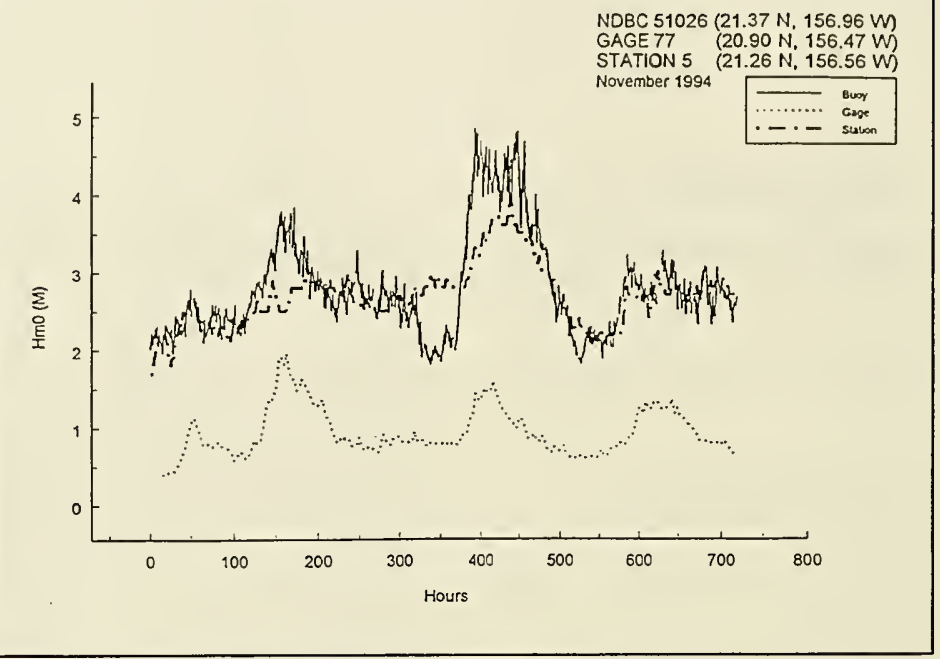

Figure D1. Wave height time series plot for November 1994

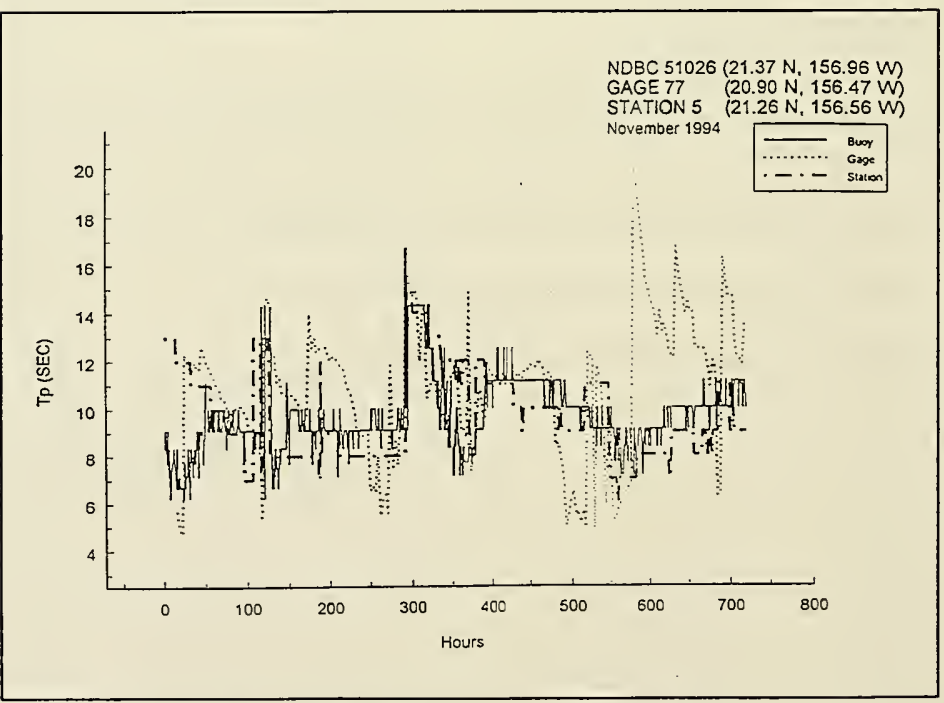

Figure D2. Wave period time series plot for November 1994 


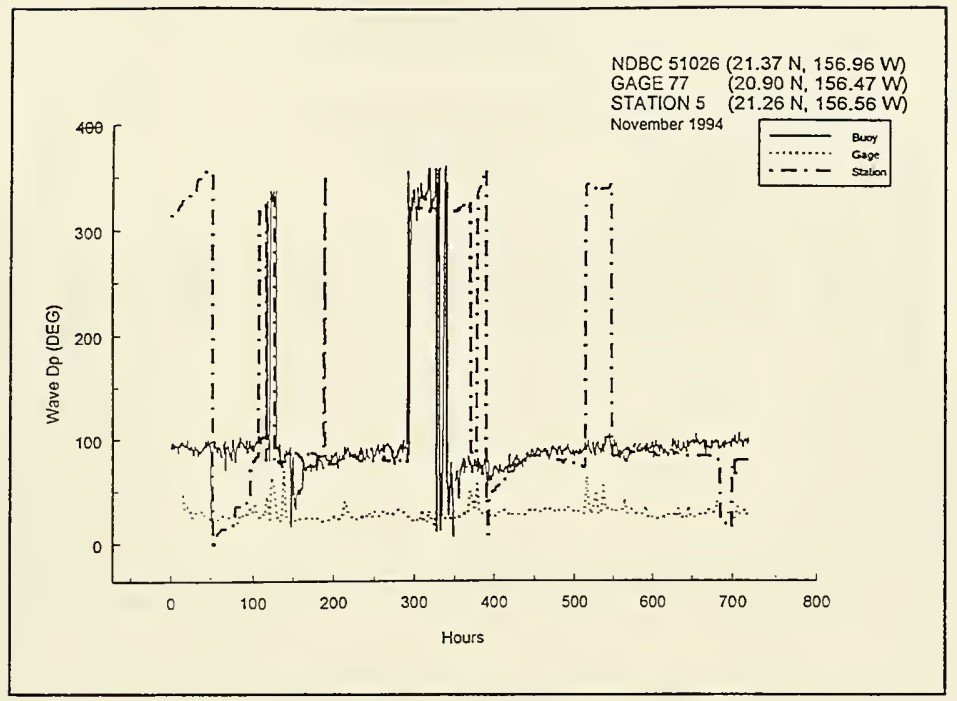

Figure D3. Wave direction time series plot for November 1994 
OCCURRENCES OF WAVE MEIGHT BY MONTH FOR ALL YEARS

$H$ mo (m)

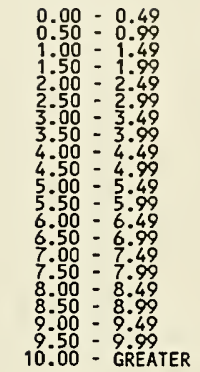

TOTAL

JAN FEB

MAR APR

HaY JUN

JUL AUG SEP OCI

HOV DEC

TOTAL

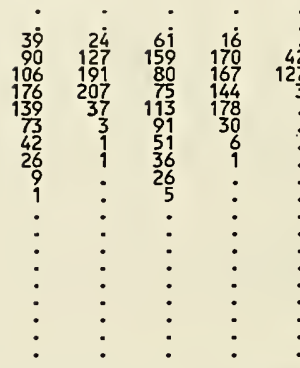

701

591

697

$712 \quad 172$

0

$\begin{array}{lllll}0 & 325 & 1435 & 1401 & 1187\end{array}$

7221

OCCURRENCES OF PEAK PERIOD BY MONTH FOR ALL YEARS

$\operatorname{Tp}(\sec )$

JAN FEB

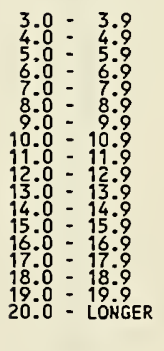

TOTAL

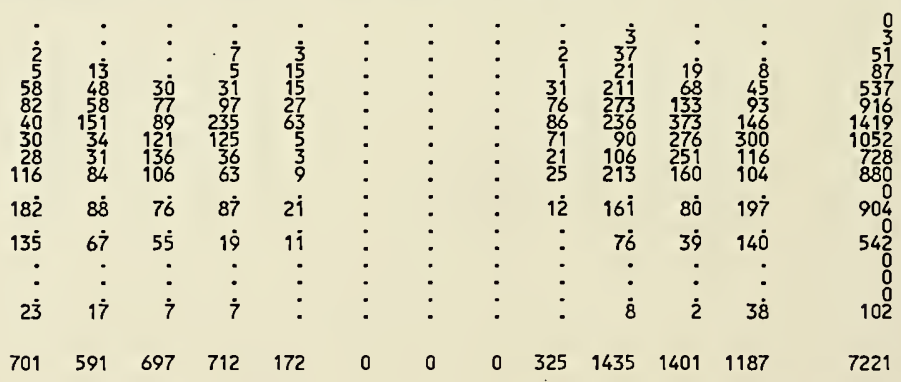

OCCURRENCES OF PEAK DIRECTIOH BY MOHTH FOR ALL YEARS

DIRECTION ${ }^{\text {OP }}{ }^{\text {(deg }}$ \&ND \& CENTER

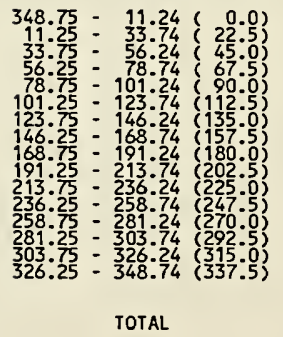

$\begin{array}{ll}59 & \\ 40 & \\ 41 & \\ 79 & 1\end{array}$
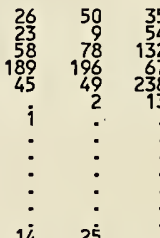

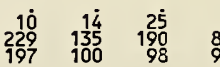

701

$$
\text { MAR APR MAY JUN JUL AUG SEP OCT HOV }
$$

HOV DEC TOTAL 


\section{KAHULUI HARBOR MAUAI 1994 \\ LAT: $21.26 \mathrm{~N}$ LONG: $1550.56 \mathrm{H}$, STATION 5 \\ SUMMARY OF WAVE INFORMATION'BY MONTH}

OCCURRENCES OF WAVE HEIGHT BY MONTH FOR ALL YEARS

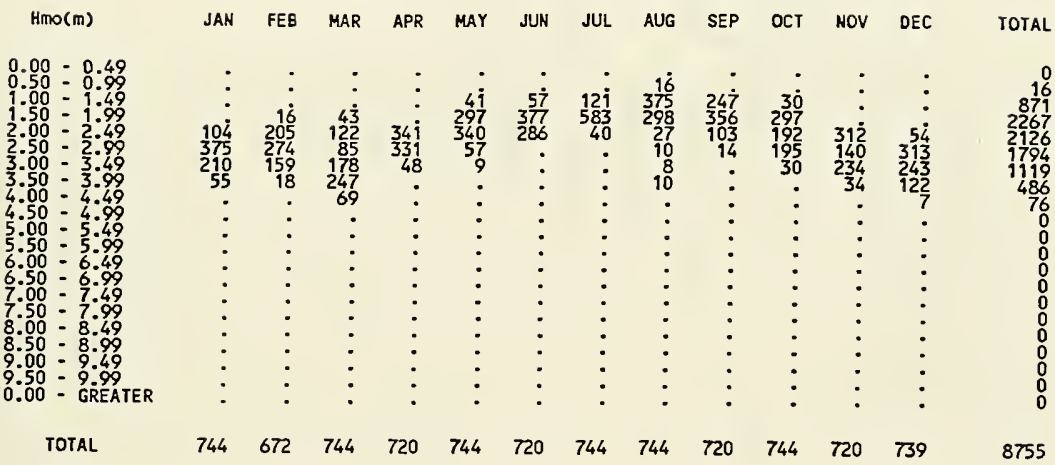

OCCURRENCES OF PEAK PERIOD BY MONTH FOR ALL YEARS

$\operatorname{Tp}(\mathrm{sec})$

JAN FEB MAR APR MAY JUN JUL AUG SEP OCT NOV DEC TOTAL

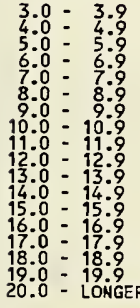

TOTAL

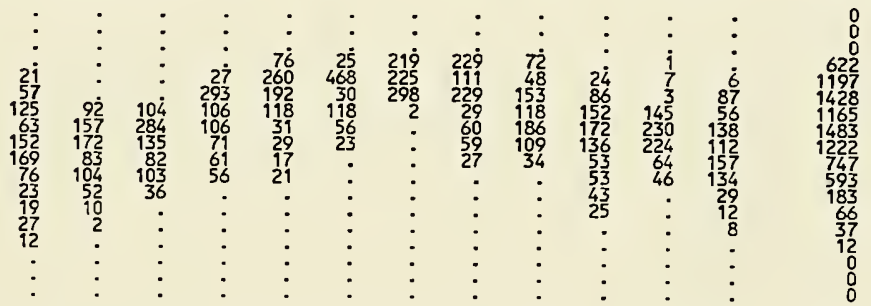

$\begin{array}{llllllllllll}744 & 672 & 744 & 720 & 744 & 720 & 744 & 744 & 720 & 744 & 720 & 739\end{array}$

8755

OCCURRENCES OF PEAK DIRECTION BY MONTH FOR ALL YEARS
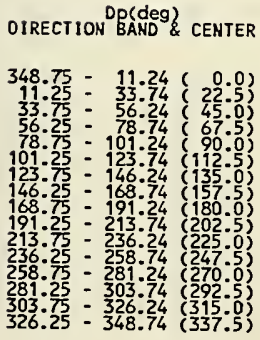

TOTAL

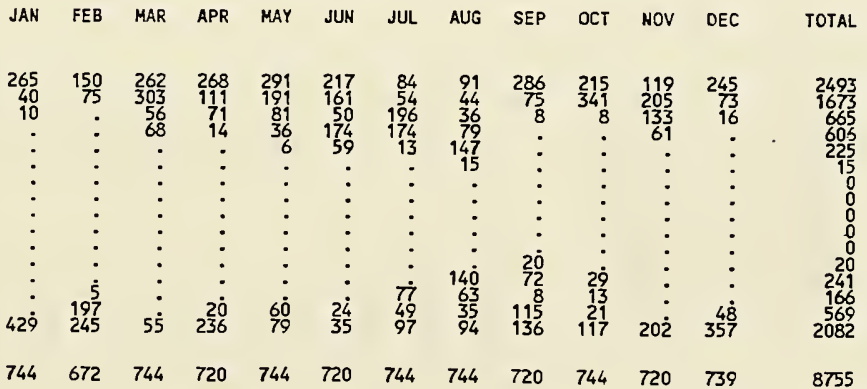




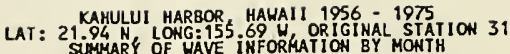

OCCURRENCES OF WAVE HEIGHT BY MONTH FOR ALL YEARS

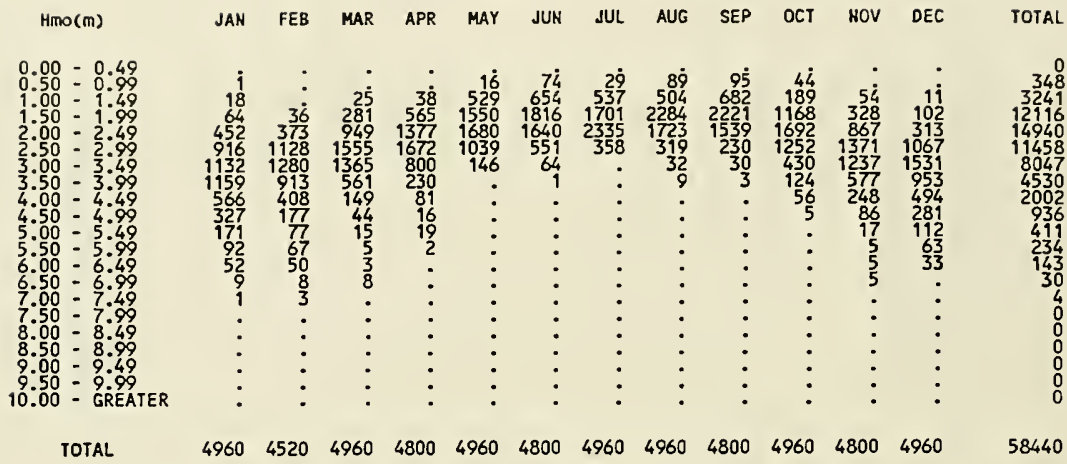

OCCURRENCES OF PEAK PERIOO BY MONTH FOR ALL YEARS

$T p(\sec )$

JAN FEB MAR APR MAY JUN JUL AUG SEP OCT NOV DEC TOTAL
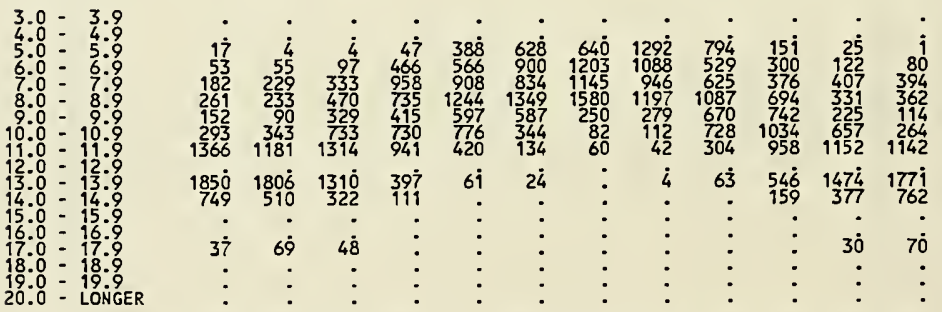

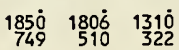

397

$6 \mathfrak{i} 2 i$

: 4 63

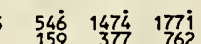

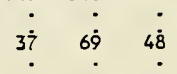

TOTAL

4960

$4960 \quad 4800$

4960

480

$4960 \quad 4960 \quad 4800 \quad 4960 \quad 4800 \quad 4960$

DIRECTION PANAND\& CENTER

OCCURRENCES OF PEAK DIRECTION BY MONTH FOR ALL YEARS
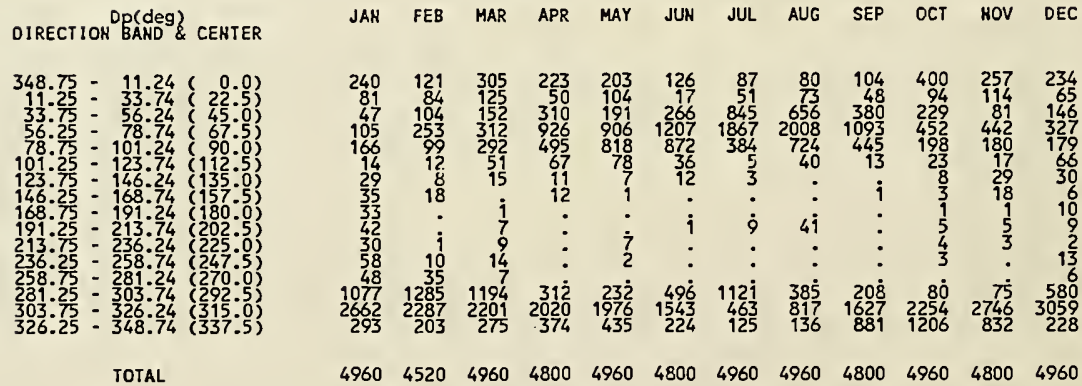

TOTAL

TOTAL

4960 


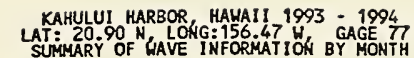

OCCURRENCES OF WAVE HEIGHT BY MONTH FOR ALL YEARS
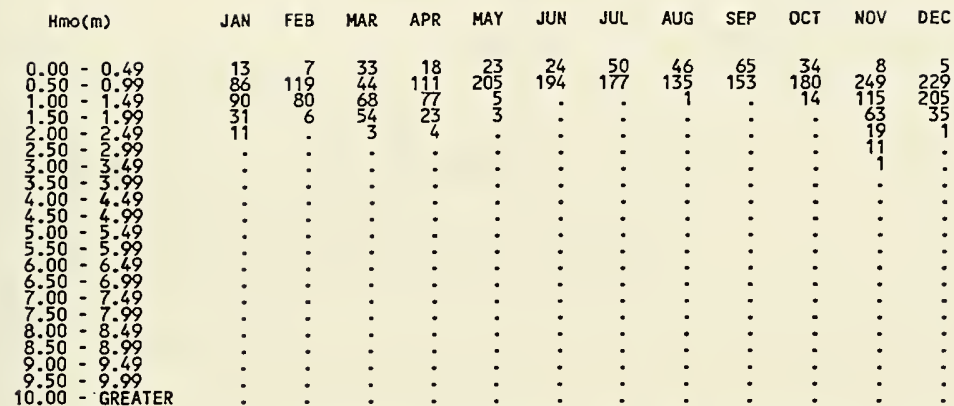

TOTAL

TOTAL

231

292202

ग2 2

26

218

27

${ }_{122}$

$218 \quad 228 \quad 466 \quad 475$

3128

OCCURRENCES OF PEAX PERIOO BY MONTH FOR ALL YEARS

$\mathrm{Tp}(\mathrm{sec})$

JAN FEB

MAR APR MAY JUN JUL AUG SEP OCT NOV DEC

IOTAL

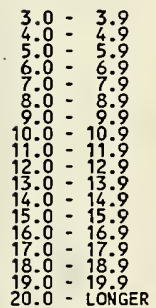

TOTAL

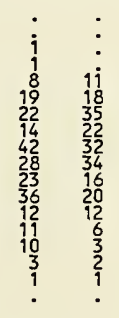

231

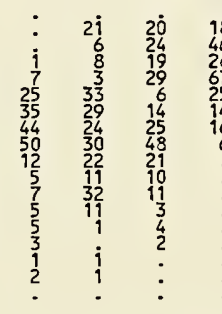

202

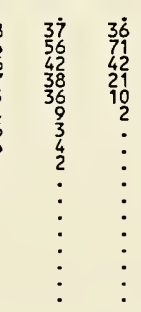

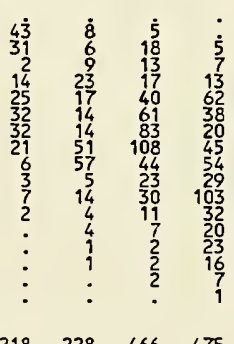

180
264
170
251
316
305
297
437
280
125
260
92
58
44
26
14

3128

OCCURRENCES OF PEAK DIRECTION BY MONTH FOR ALL YEARS

DIRECTION ${ }^{\text {DPANDE \& }}$ \&ENTER

JAN FEB MAR APR MAY JUN JUL AUG SEP OCT NOV DEC TOTAL

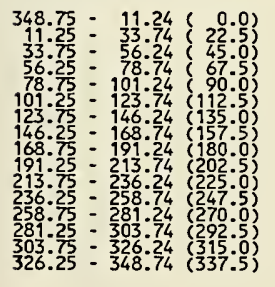

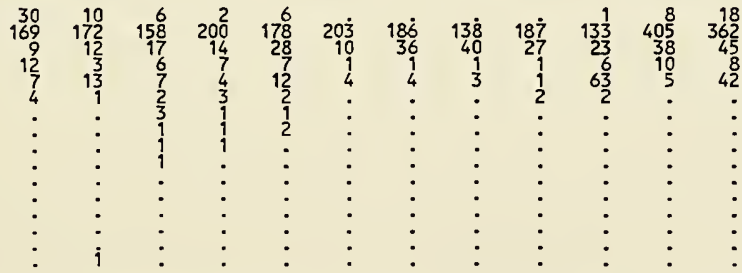

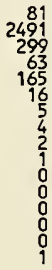

TOTAL

$23 i \quad 212$

202

233

236

218

227

182

$\begin{array}{llll}218 & 228 & 466 & 475\end{array}$

3128 



\section{Appendix E Basin Locations for Alternative Plans}




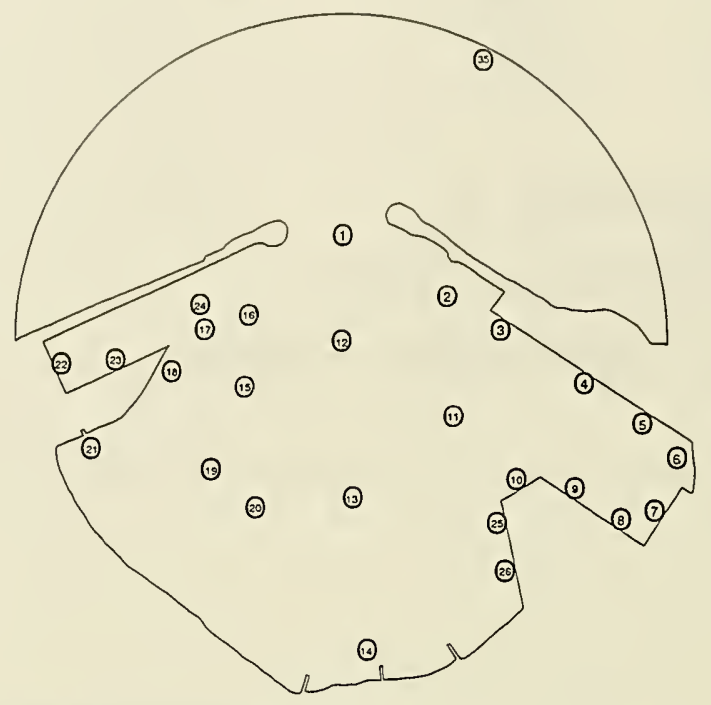

Figure E1. Basin locations, Plan 1

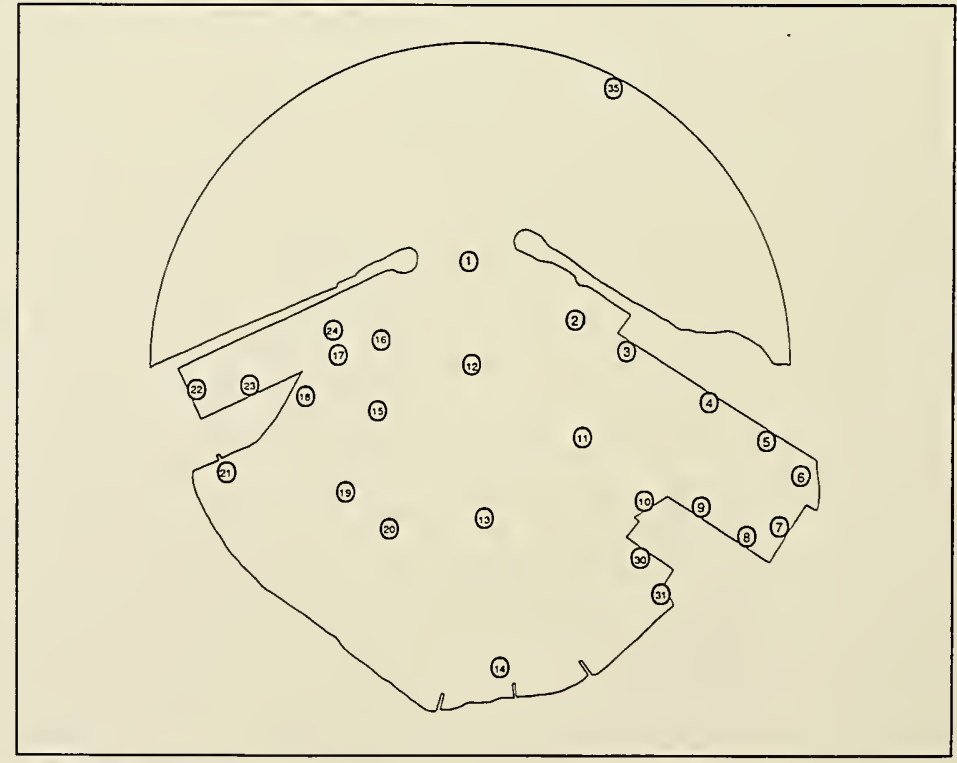

Figure E2. Basin locations, Plan 2 


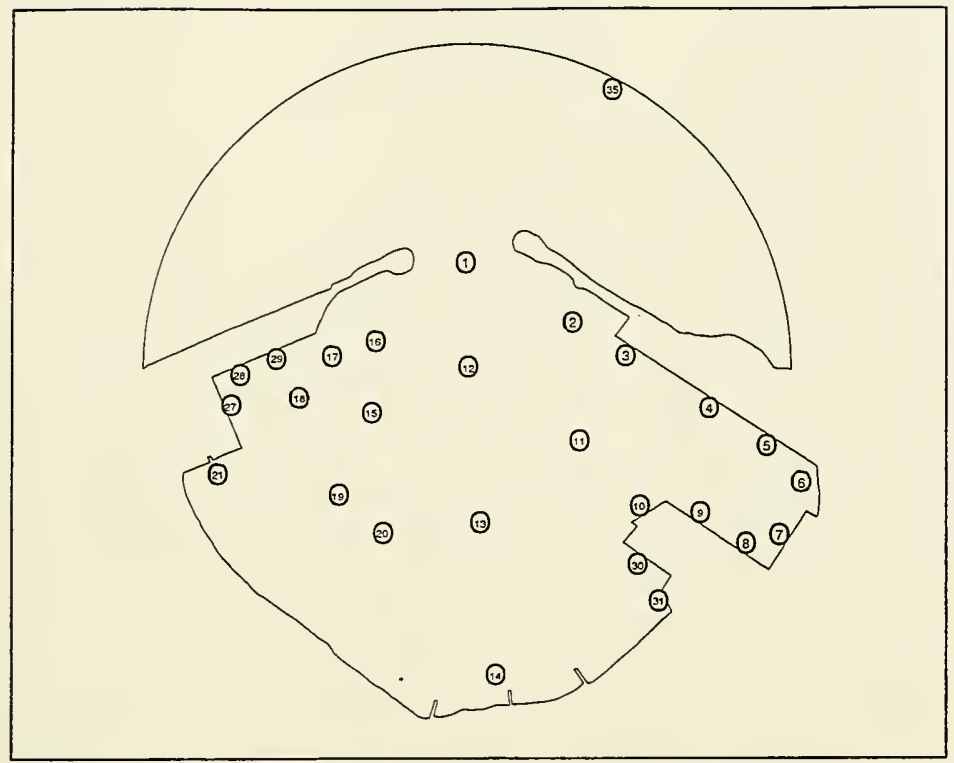

Figure E3. Basin locations, Plan 3a

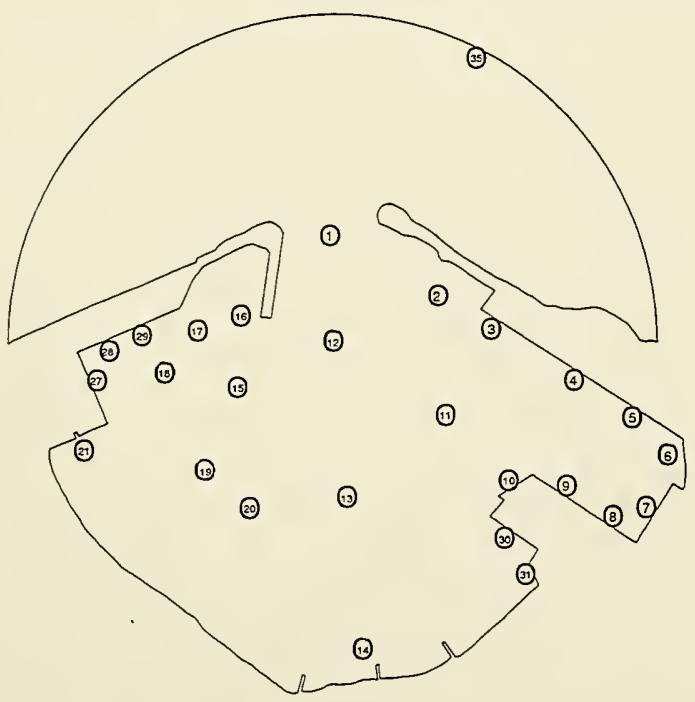

Figure E4. Basin locations, Plan 3b 


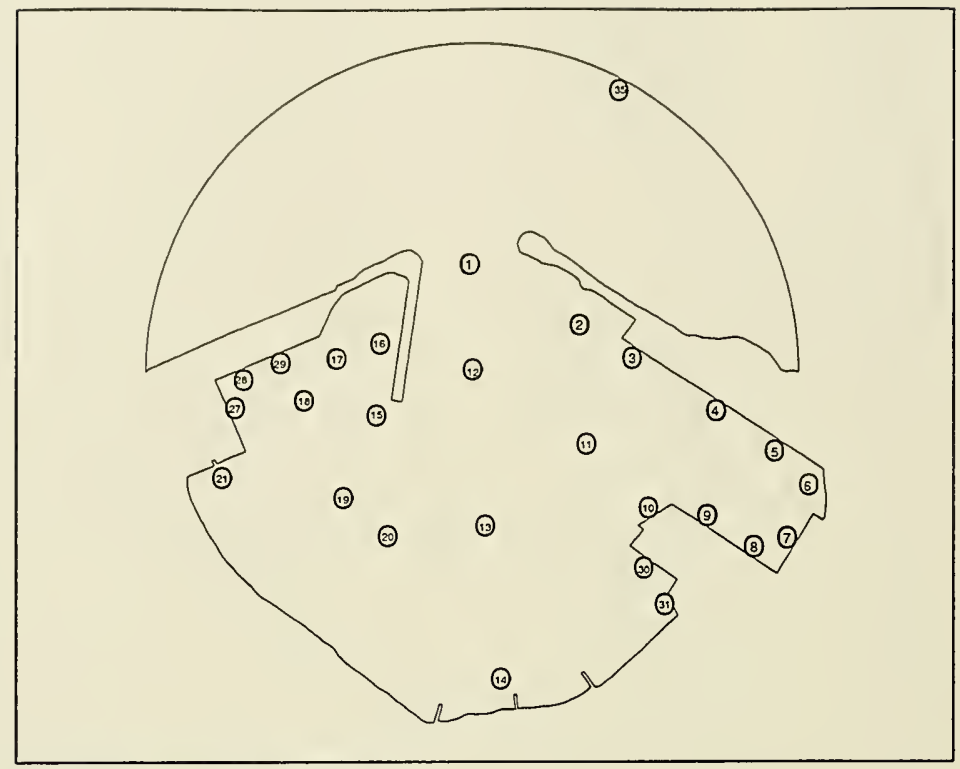

Figure E5. Basin locations, Plan 3c

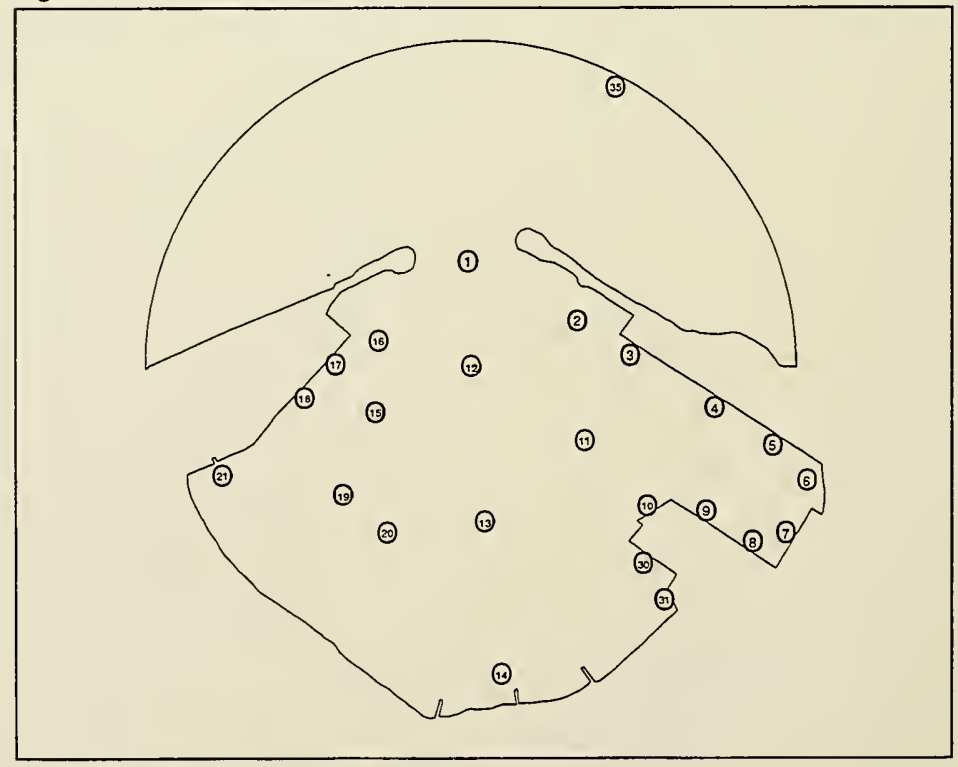

Figure E6. Basin locations, Plan 4a 


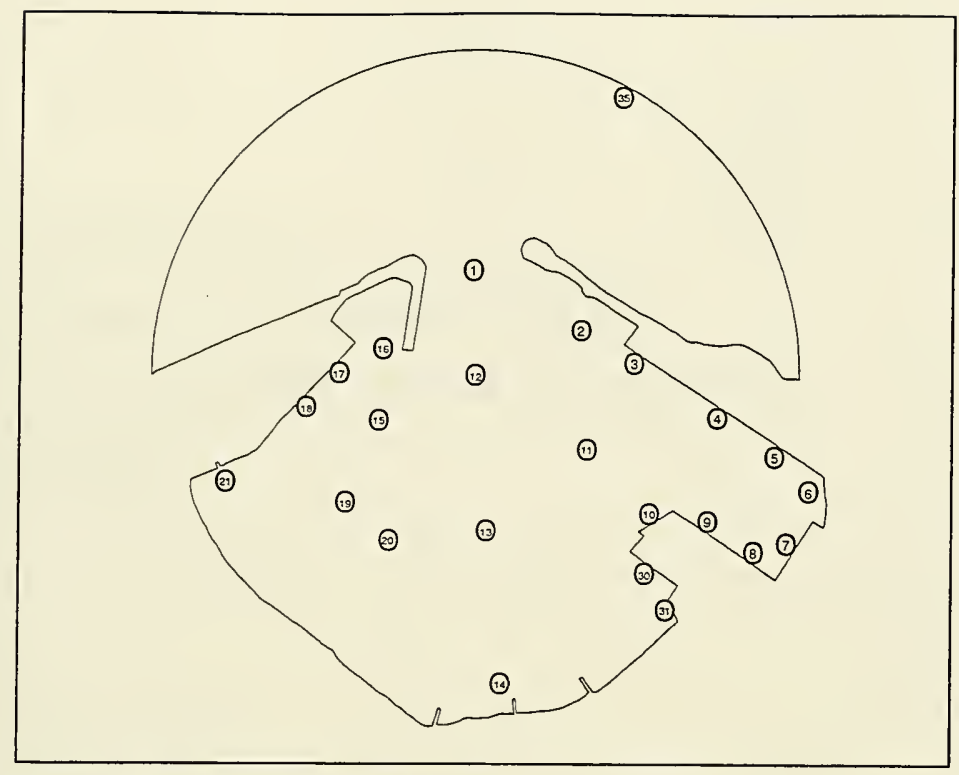

Figure E7. Basin locations, Plans $4 b$ and 6

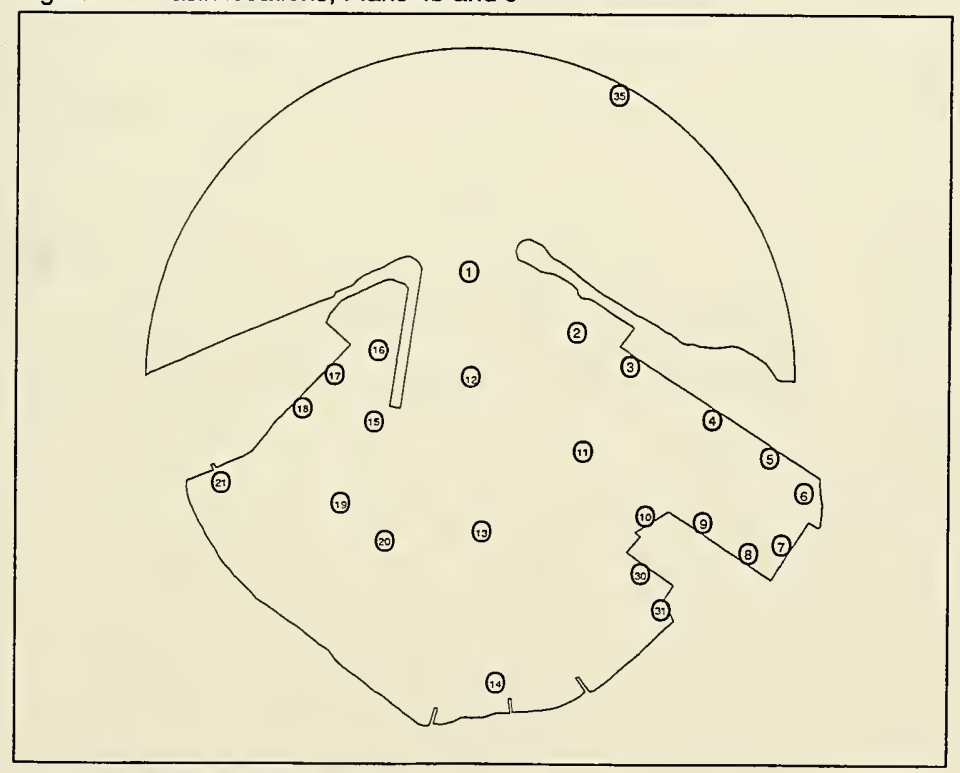

Figure E8. Basin locations, Plan 4c 


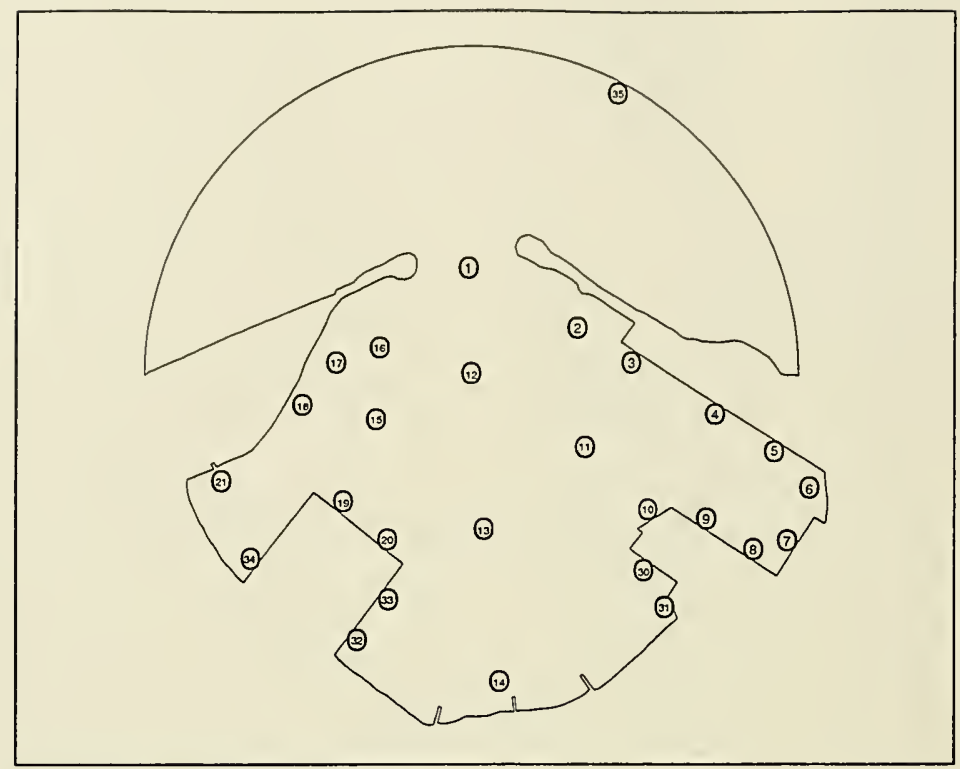

Figure E9. Basin locations, Plan 5

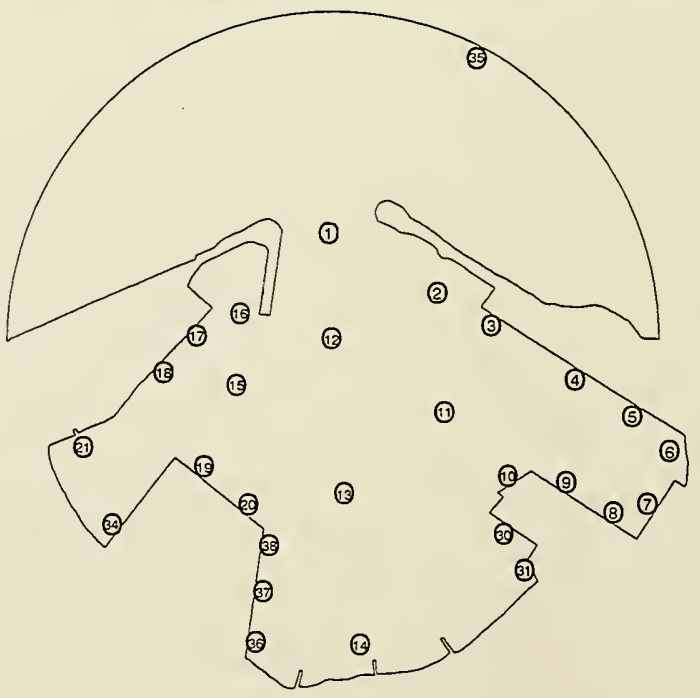

Figure E10. Basin locations, Plan 7 


\section{Appendix F Wind Wave and Swell Summaries from Numerical Model}

\section{List of Tables}

Table F1. $A_{a m p, s}$ Values for $\theta_{m}=192 \mathrm{deg}$, Existing Harbor

Table F2. $A_{\text {amp,s }}$ Values for $\theta_{m}=203 \mathrm{deg}$, Existing Harbor F4

Table F3. $A_{\text {amp,s }}$ Values for $\theta_{m}=214 \mathrm{deg}$, Existing Harbor F6

Table F4. $A_{\text {amp,s }}$ Values for $\theta_{m}=225 \mathrm{deg}$, Existing Harbor $\quad$ F8

Table F5. $A_{\text {amp,s }}$ Values for $\theta_{m}=236 \mathrm{deg}$, Existing Harbor F10

Table F6. $A_{\text {amp,s }}$ Values Weighted by Wind Wave and Swell Climate F12

Table F7. $H_{s}$ Values Exceeded 10 Percent and 1 Percent of the Time at Piers

F14 


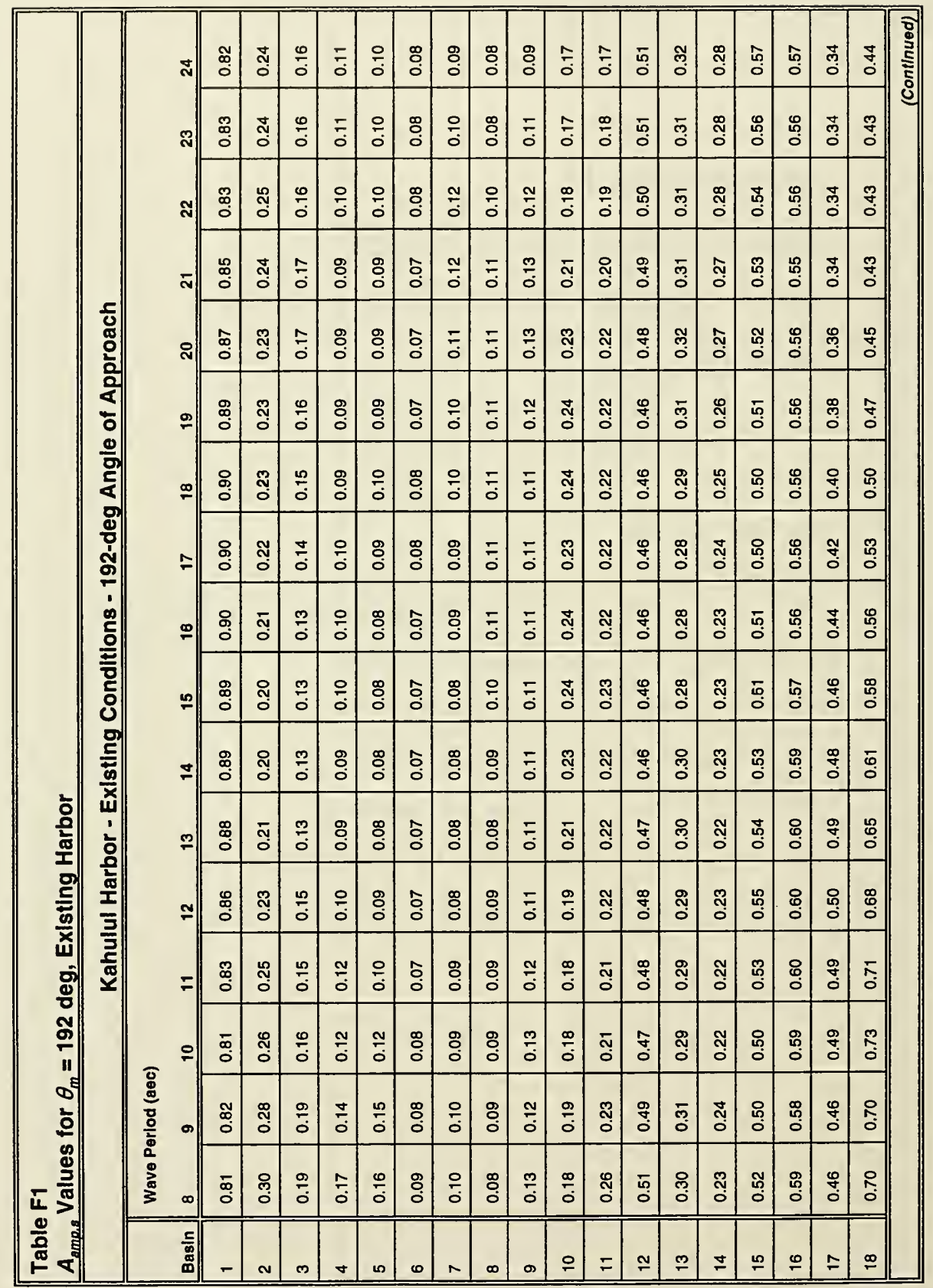




\begin{tabular}{|c|c|c|c|c|c|c|c|c|c|c|c|c|c|}
\hline & & & สี & $\stackrel{R}{0}$ & 旾 & ปั & $\stackrel{\text { ़ֻ }}{0}$ & $\stackrel{\text { ֻั }}{0}$ & ָั & ঙ্ণু & $\stackrel{N}{N}$ & $\stackrel{g}{0}$ & $\stackrel{\text { g }}{\circ}$ \\
\hline & & & జ & $\stackrel{i}{0}$ & :̊ํㅇ & કั & ָָ & ֻั & స్ & ֻু & $\stackrel{N}{\stackrel{N}{0}}$ & हִ & f̊ \\
\hline & & & ส & ז̊ & 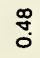 & J & શ્̣ & ্ֻণু & స్తి & 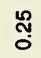 & $\stackrel{\Gamma}{0}$ & 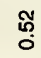 & f \\
\hline & & & N & $\stackrel{8}{\circ}$ & 音 & 导 & $\frac{\pi}{0}$ & ભ̣ & $\frac{0}{\circ}$ & ্ָডু & $\stackrel{R}{R}$ & ֶ̊: & f \\
\hline & 인 & & ి & $\underset{0}{\mathscr{0}}$ & ঙ̊ & f̊ & ণั & ঙัญ & స̃ & ָ̦ & $\underset{0}{\mathscr{8}}$ & : & 祑 \\
\hline & రิ & & 요 & $\stackrel{\hat{0}}{\circ}$ & f̊ & :̊̊? & กั & 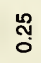 & ঙ্ণ & กิ & $\stackrel{\mathscr{O}}{0}$ & గ్రి & $\stackrel{g}{8}$ \\
\hline & है & & $\stackrel{\Phi}{0}$ & $\stackrel{\circ}{\circ}$ & f̊. & ֶึֶ & ষ্ণু & సָ & さ্ডু & ্ֻণু & 芯 & ఝ̊: & f \\
\hline & ภั่ & & F & : & 离 & 电 & ָั & 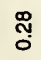 & ্ָডু & న্ণু & ஜֶ: & గ్ ชู & f \\
\hline & $\begin{array}{l}\boldsymbol{q} \\
\stackrel{0}{c} \\
\underline{0}\end{array}$ & & $\Phi$ & $\stackrel{\circ}{0}$ & f̊. & 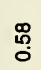 & ঙ্ণ & 忍 & さ્ડ & 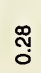 & 芯 & นึ & f \\
\hline & 임 & & $\stackrel{2}{\circ}$ & $\stackrel{\hat{\circ}}{\circ}$ & $\stackrel{0}{\stackrel{0}{0}}$ & 芯 & స్ & 忍 & ָু & 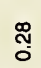 & 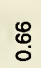 & ณิ & $\begin{array}{l}\hat{f} \\
0\end{array}$ \\
\hline & $\frac{\bar{c}}{\frac{5}{x}}$ & & $\nabla$ & R & ষ্ণ & $\stackrel{\circ}{0}$ & స్ & 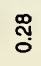 & $\underset{\substack{0 \\
0}}{ }$ & ָ̊ & $\stackrel{\Gamma}{0}$ & $\tilde{\sigma}_{0}$ & f. \\
\hline & 능 & & 9 & $\stackrel{\Re}{\stackrel{0}{0}}$ & ঙั & চீ口: & গু & $\begin{array}{l}\text { ஸ़ } \\
\text { ơ }\end{array}$ & సู่ & ญু & $\stackrel{+}{\stackrel{N}{0}}$ & एँ. & f. \\
\hline & 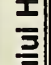 & & ฯ & $\stackrel{+}{\stackrel{0}{0}}$ & ণั & ֶֻ & సু & ঙั & ָั & ֻัญ & $\hat{\hat{O}}$ & గ్రి & f̊ \\
\hline & $\frac{\bar{\varpi}}{\tilde{\Xi}}$ & & $\mp$ & $\stackrel{?}{\stackrel{2}{0}}$ & ্ֻণ & 导 & సু & 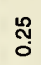 & ָָ & ্ֶָু & $\stackrel{\hat{o}}{0}$ & గ్రి & 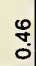 \\
\hline 0 & & & 웅 & $\stackrel{R}{0}$ & ষ্ণ & $\grave{0}$ & ָָ & స్ & స్ & ฐึ̊ & $\stackrel{\hat{N}}{0}$ & : & ț. \\
\hline 릉 & & $\stackrel{\infty}{\stackrel{\infty}{0}}$ & o) & $\stackrel{\substack{0 \\
0}}{0}$ & $\underset{0}{*}$ & $\stackrel{8}{0}$ & సָ̣ & $\stackrel{\text { ָొ }}{0}$ & กั & 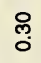 & $\begin{array}{l}\text { ه } \\
\text { O. }\end{array}$ & in & $\stackrel{\text { ? }}{0}$ \\
\hline$\frac{-}{4}$ & & $\sum_{\text {: }}^{0}$ & $\infty$ & 离 & ֻ̊? & $\underset{0}{\tilde{0}}$ & $\overline{\text { ஸ̆ }}$ & ঙ̣̊ & ָু & लू & 导 & ธ్రి & f. \\
\hline$\stackrel{\vec{\pi}}{\vec{E}}$ & & & 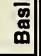 & $\stackrel{\circ}{\circ}$ & กิ & $\bar{n}$ & ฝ & $\stackrel{\mathscr{N}}{ }$ & \& & $\bar{m}$ & ले & ल & ले \\
\hline
\end{tabular}




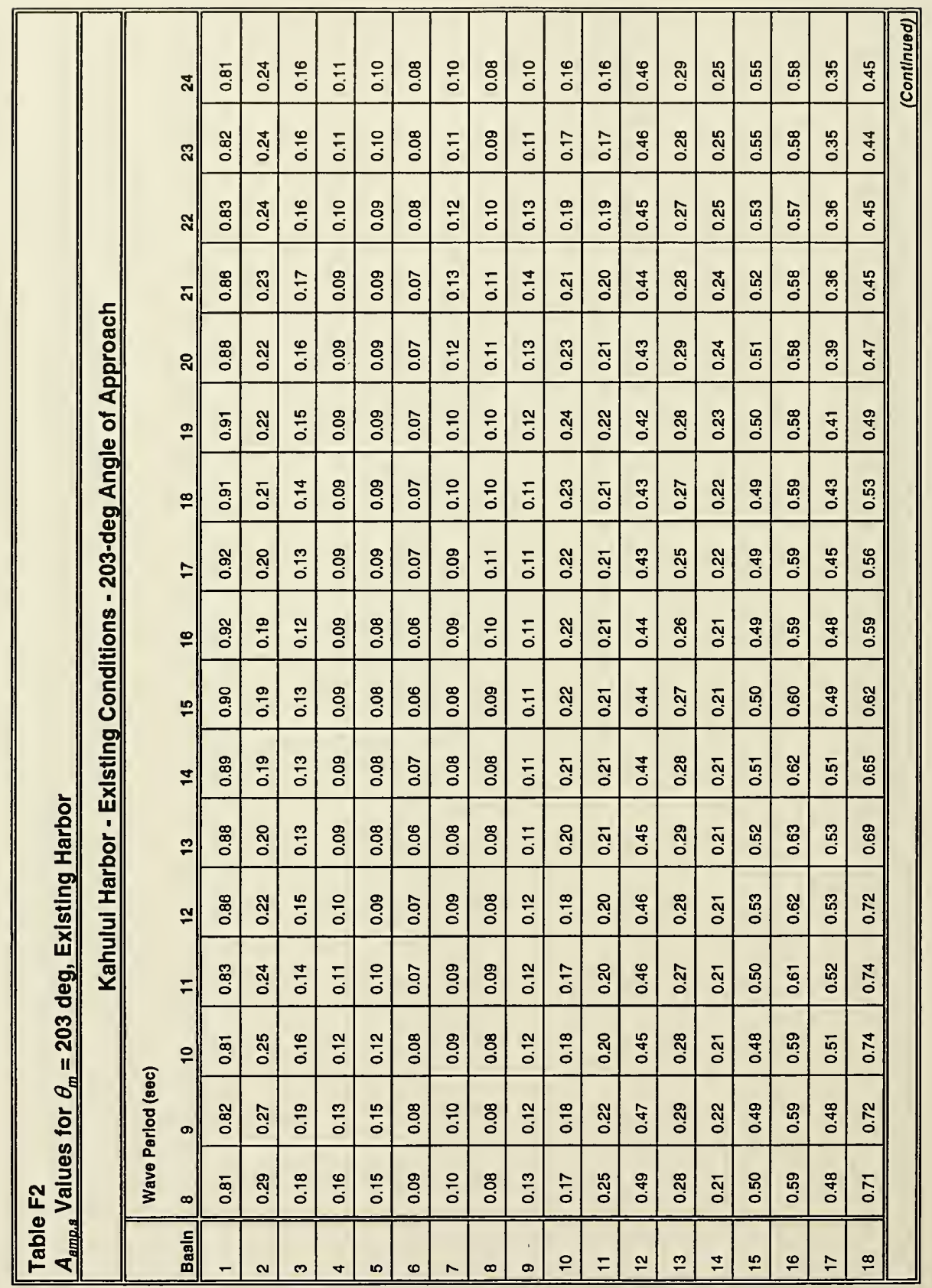




\begin{tabular}{|c|c|c|c|c|c|c|c|c|c|c|c|c|c|}
\hline & & & $\mathbb{N}$ & $\stackrel{0}{0}$ & $\stackrel{\varphi}{0}$ & ণั & 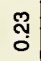 & ָָ & ָู & ঙ্ֶু & $\bar{T}_{0}$ & $\stackrel{4}{\stackrel{0}{0}}$ & ষ̀ \\
\hline & & & 刃ี & $\underset{0}{\mathscr{O}}$ & $\stackrel{0}{\stackrel{0}{0}}$ & ษั่ & ণ্ণু & ঙ্ণ & ঙ্ণ & ঙ্ֶু & $\underset{0}{R}$ & 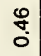 & $\stackrel{?}{0}$ \\
\hline & & & งี & $\underset{0}{\mathscr{B}}$ & $\stackrel{\mathscr{q}}{0}$ & $\stackrel{?}{0}$ & $\frac{\Phi}{0}$ & ঙ্ণ & $\frac{\infty}{0}$ & ঙ্ণু & $\begin{array}{l}R \\
0\end{array}$ & fo & ?̊? \\
\hline & & & $\bar{N}$ & $\stackrel{0}{0}$ & \&̊ & $\stackrel{0}{\circ}$ & $\frac{\infty}{0}$ & ঙ্ণু & $\frac{0}{0}$ & ণั่ & $\underset{0}{\mathscr{O}}$ & $\stackrel{\infty}{\stackrel{\infty}{0}}$ & ?్ \\
\hline & 인 & & 이 & $\stackrel{\circ}{\circ}$ & ?ִ & 趸 & ণ্ণ & 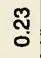 & $\bar{c}$ & 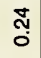 & $\hat{0}$ & $\stackrel{g}{\stackrel{g}{0}}$ & ̛̀ \\
\hline & 임 & & 요 & ¿ே. & J̛̀ & 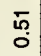 & ָָ & $\stackrel{\text { ָ̊ }}{\circ}$ & సู & 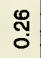 & $\stackrel{0}{0}$ & $\stackrel{9}{8}$ & ț \\
\hline & है। & & $\stackrel{\infty}{\sim}$ & : & $\stackrel{q}{0}$ & 苫 & 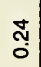 & స઼̆ & ্ָণ & :ึ̣ & : & 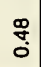 & ̛̣ \\
\hline & ช్ & & $=$ & : & 导 & t⿱⺊口灬 & đั & $\stackrel{\text { ড̆ }}{\circ}$ & $\underset{ণ}{\mathbb{O}}$ & 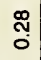 & $\bar{o}_{0}$ & f̊t & $\stackrel{9}{0}$ \\
\hline & 응 & & $\Phi$ & $\underset{0}{\mathscr{O}}$ & Ju & $\stackrel{8}{\circ}$ & ָู & స్ & ঙ্ֶ & సิ & Oֶ. & f̊ & g̣̊ \\
\hline & క్రి & & 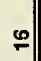 & छั & 丞 & $\stackrel{8}{0}$ & ড় & ণั & సু & ণ্ণ & \begin{tabular}{l}
\multirow{O}{*}{} \\
0
\end{tabular} & fั & ?़ \\
\hline & $\frac{\bar{g}}{\frac{\bar{g}}{x}}$ & & $\nabla$ & $\stackrel{\hat{\circ}}{\circ}$ & fó & $\stackrel{\overline{0}}{\circ}$ & ন্ডে & $\stackrel{\text { ֻ̆ }}{\circ}$ & ড় & స̃ & 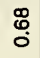 & $\hat{0}$ & $\frac{9}{0}$ \\
\hline & 능 & & $m$ & $\stackrel{8}{\circ}$ & 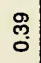 & ণัర్ర & ণ্ণ & ণ্ & ญ্ণ & సั & 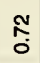 & 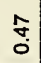 & $\stackrel{9}{0}$ \\
\hline & $\stackrel{\mathbf{I}}{\underline{\Xi}}$ & & 工 & R & శ్ల్ర & $\stackrel{\mathscr{B}}{\circ}$ & ণ্ণি & $\stackrel{\mathscr{N}}{0}$ & ণ্ণি & ঙ্ & $\stackrel{+}{\hat{0}}$ & $\stackrel{g}{\circ}$ & ?़ \\
\hline & $\underline{\underline{\Xi}}$ & & $=$ & $\stackrel{8}{\circ}$ & \& & 苛 & ָֻ̣ & ড় & సָ & స઼ & $\underset{0}{\pi}$ & 导 & ơ \\
\hline & & & 우 & $\begin{array}{l}R \\
0 \\
0\end{array}$ & Эั & $\stackrel{\circ}{\circ}$ & ণ্ণু & ঙ্ণু & ড় & స઼ & $\underset{0}{\mathbb{N}}$ & $\hat{\tilde{g}}$ & $\begin{array}{c}\bar{f} \\
0\end{array}$ \\
\hline 긍 & & $\frac{\mathscr{\infty}}{\stackrel{0}{2}}$ & o) & $\begin{array}{l}\stackrel{\mathscr{N}}{\hat{0}} \\
0\end{array}$ & $\stackrel{\text { Y }}{0}$ & $\stackrel{\hat{0}}{\circ}$ & ণ্ণ & ָั & ণু & ঙ্ণু & $\stackrel{\infty}{\stackrel{\infty}{0}}$ & 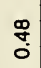 & ?ै \\
\hline 勇 & & 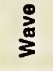 & $\infty$ & $\stackrel{\infty}{\stackrel{\infty}{0}}$ & ปั & $\underset{0}{\tilde{0}}$ & ญั & $\stackrel{\text { ֻ̊ }}{\text { ஸ̊ }}$ & ฺָָ & ల్ల్ర & 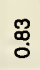 & 㞼 & $\begin{array}{l}0 \\
0 \\
0\end{array}$ \\
\hline 름 & & & 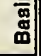 & $\stackrel{9}{\square}$ & 오 & $\overline{\boldsymbol{N}}$ & ล้ & $\stackrel{N}{N}$ & ల్ల & ले & ల్ & ભ్ల & ले \\
\hline
\end{tabular}




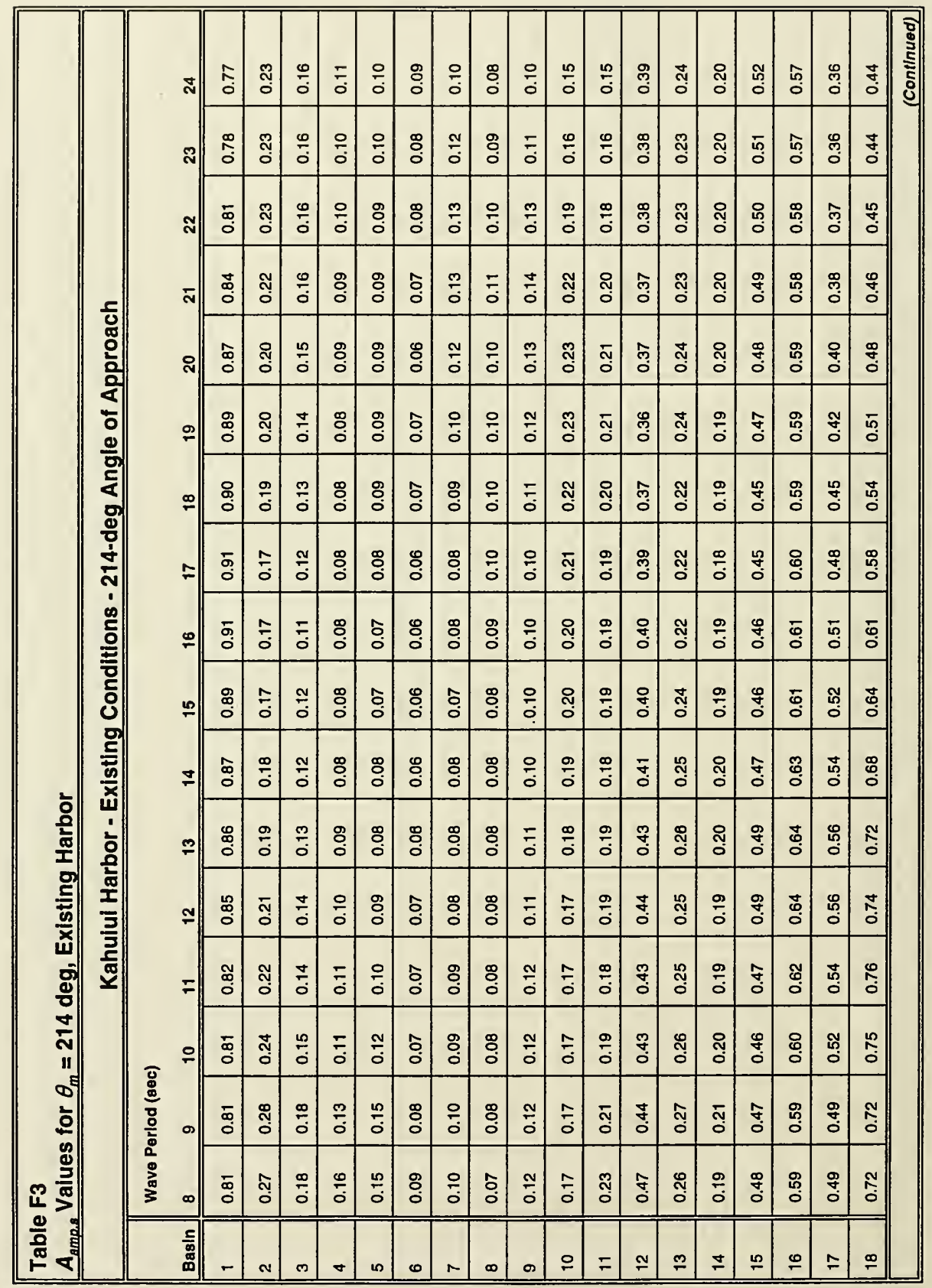




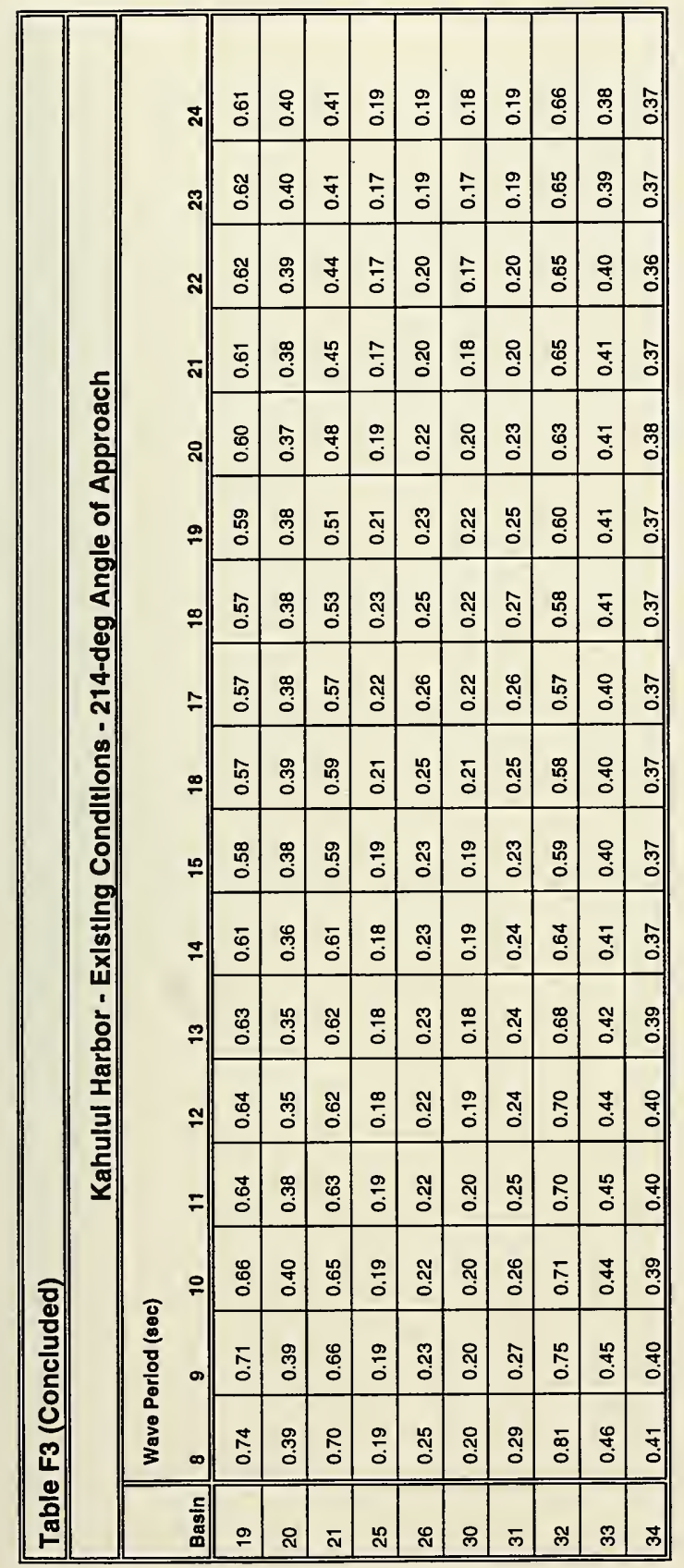




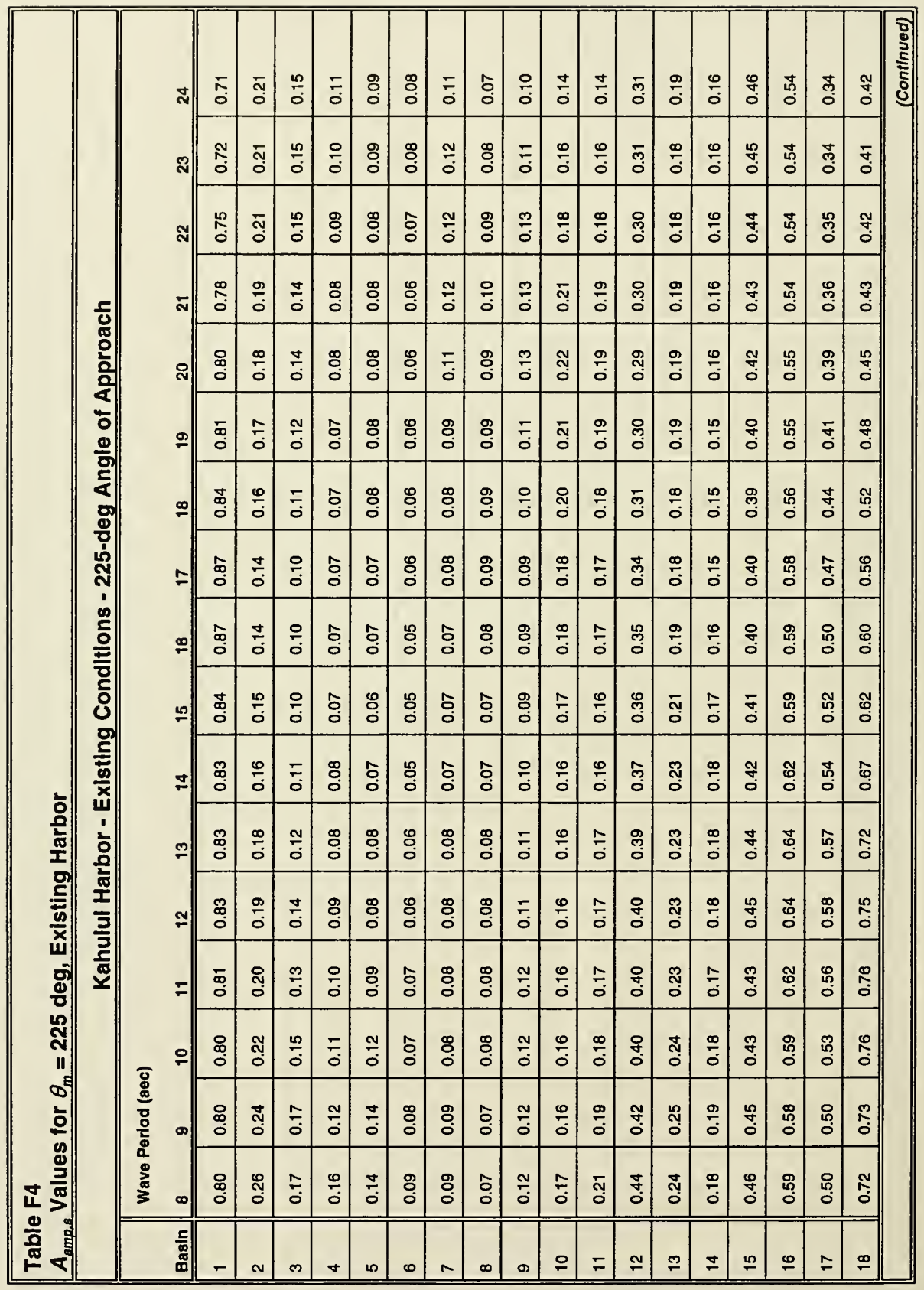




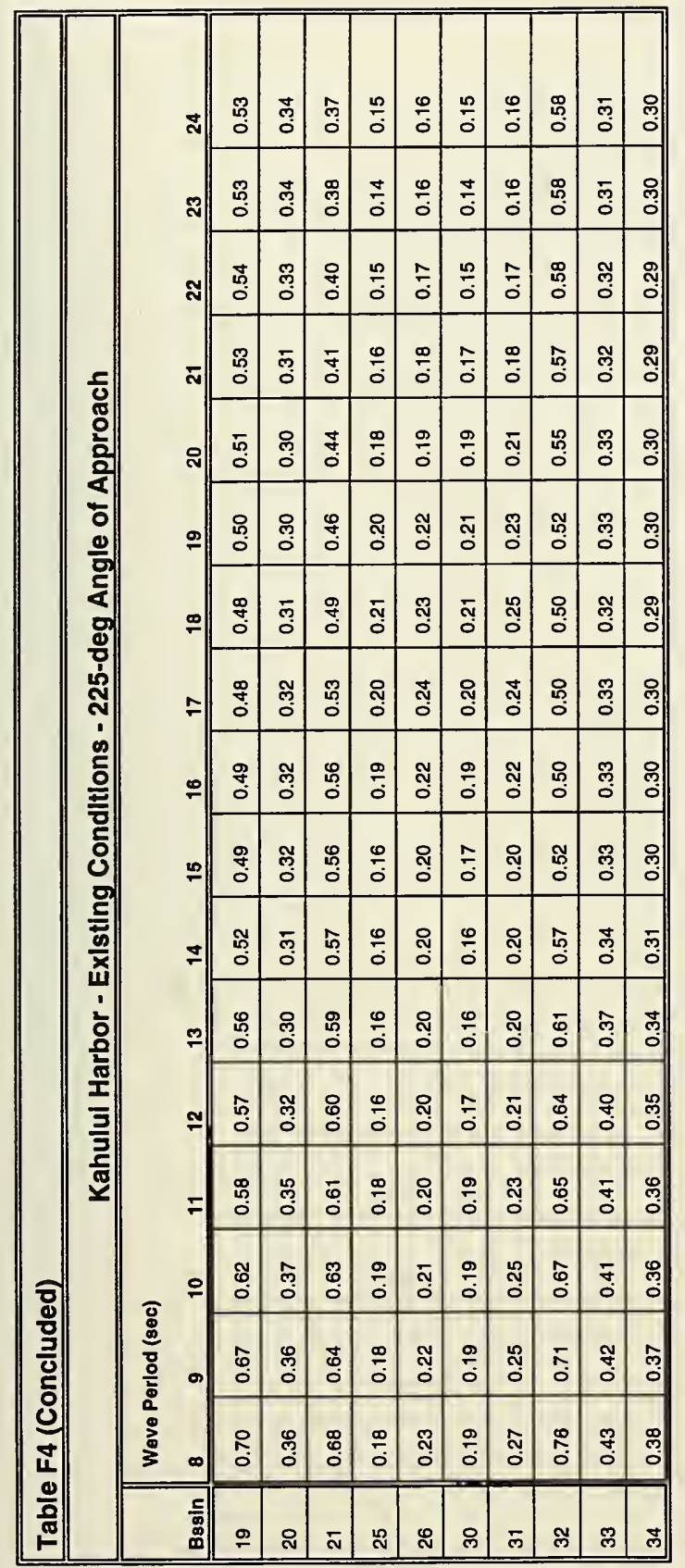




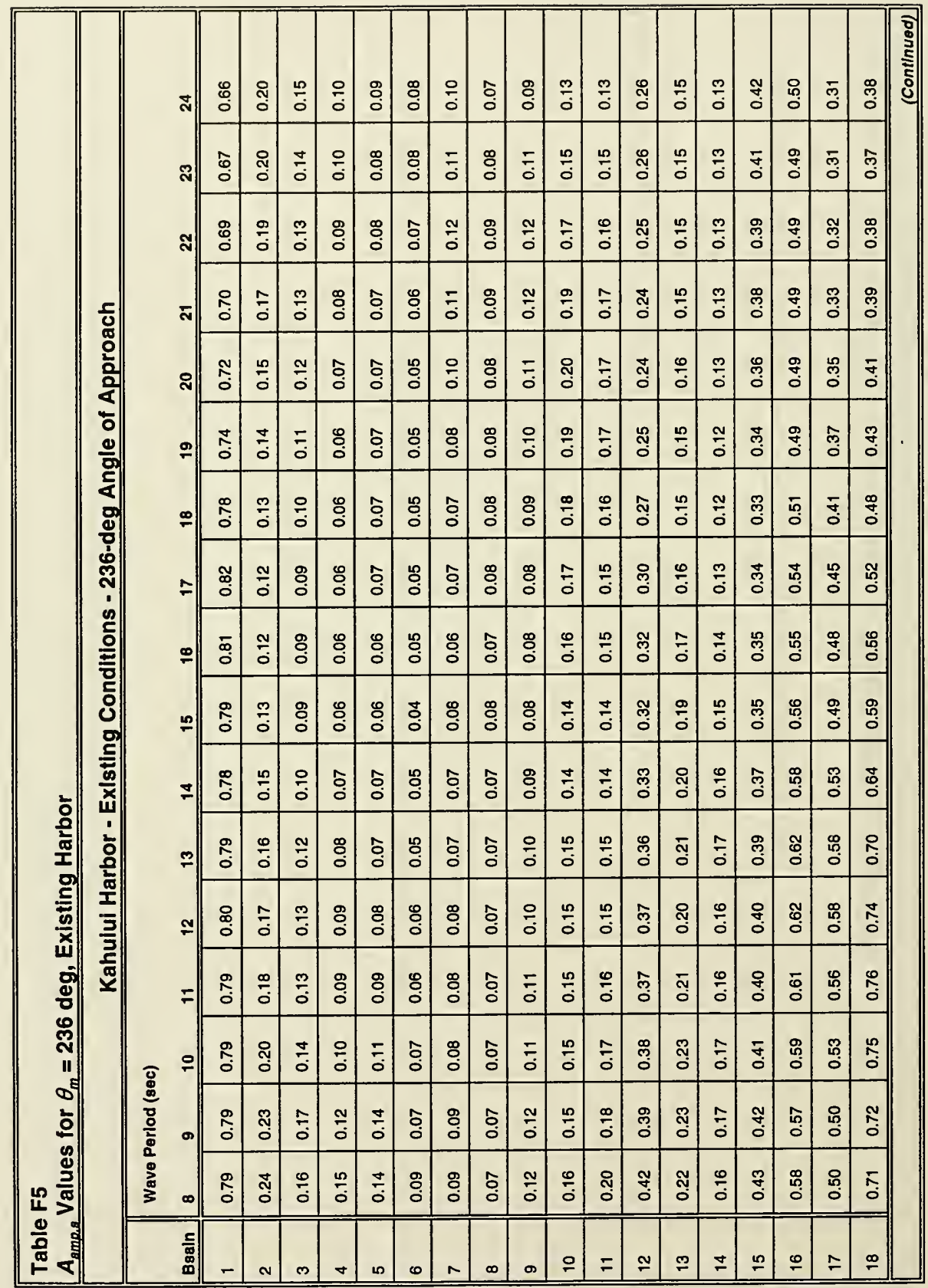




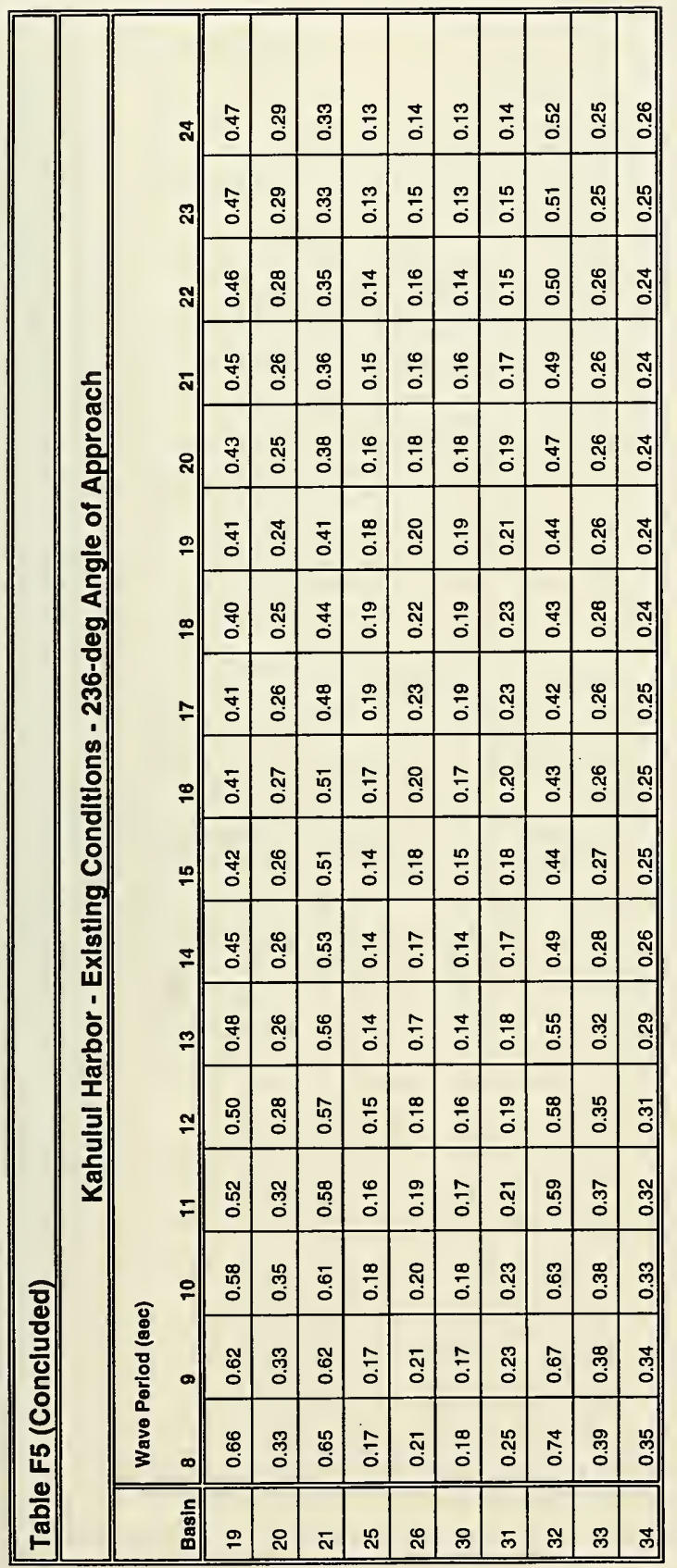




\begin{tabular}{|c|c|c|c|c|c|c|c|c|c|c|c|}
\hline \multicolumn{12}{|c|}{$\begin{array}{l}\text { Table F6 } \\
A_{\text {ames }} \text { Values Weighted by Wind Wave and Swell Climate }\end{array}$} \\
\hline \multirow{2}{*}{ Basin } & \multicolumn{10}{|c|}{ Plan } & \multirow{2}{*}{ Remarks } \\
\hline & Existing & 1 & 2 & 3a & $3 \mathrm{~b}$ & $3 c$ & $4 a$ & $4 \mathrm{~b}$ & $4 c$ & 5 & \\
\hline \multicolumn{12}{|l|}{ Pier 1} \\
\hline 2 & 0.25 & 0.15 & 0.25 & 0.17 & 0.15 & 0.15 & 0.18 & 0.17 & 0.17 & 0.20 & \\
\hline 3 & 0.16 & 0.09 & 0.17 & 0.14 & 0.12 & 0.11 & 0.19 & 0.14 & 0.11 & 0.15 & \\
\hline 4 & 0.13 & 0.06 & 0.13 & 0.08 & 0.06 & 0.07 & 0.14 & 0.08 & 0.07 & 0.10 & \\
\hline 5 & 0.12 & 0.04 & 0.14 & 0.07 & 0.05 & 0.06 & 0.11 & 0.05 & 0.05 & 0.09 & \\
\hline 6 & 0.08 & 0.04 & 0.10 & 0.05 & 0.07 & 0.04 & 0.07 & 0.05 & 0.05 & 0.07 & \\
\hline \multicolumn{12}{|c|}{ Piers $2 \& 3$} \\
\hline 7 & 0.09 & 0.06 & 0.09 & 0.08 & 0.09 & 0.07 & 0.08 & 0.07 & 0.07 & 0.08 & \\
\hline 8 & 0.08 & 0.08 & 0.09 & 0.09 & 0.09 & 0.08 & 0.10 & 0.09 & 0.09 & 0.08 & Pier 2 gage \\
\hline 9 & 0.12 & 0.09 & 0.11 & 0.12 & 0.11 & 0.11 & 0.12 & 0.11 & 0.11 & 0.10 & \\
\hline 10 & 0.18 & 0.14 & 0.17 & 0.16 & 0.17 & 0.16 & 0.17 & 0.17 & 0.17 & 0.19 & \\
\hline \multicolumn{12}{|c|}{ Barge Pier (Planned) } \\
\hline 25 & & 0.14 & & & & & & & & & Concept C \\
\hline 26 & & 0.14 & & & & & & & & & Concept C \\
\hline 30 & & & 0.12 & 0.12 & 0.12 & 0.11 & 0.12 & 0.12 & 0.11 & 0.12 & Concept 12 \\
\hline \multicolumn{12}{|c|}{ Boat Ramp } \\
\hline 21 & 0.21 & 0.19 & 0.19 & 0.16 & 0.11 & 0.06 & 0.11 & 0.08 & 0.04 & 0.20 & Adjusted for $\beta=0.032$ \\
\hline \multicolumn{12}{|c|}{ Passenger Ship Pier (Planned) } \\
\hline 17 & & & & & & & 0.35 & 0.15 & 0.07 & & Adjacent to existing fill \\
\hline 18 & & & & & & & 0.30 & 0.17 & 0.06 & & . $\quad$ " $"$ \\
\hline 23 & & 0.12 & 0.14 & & & & & & & & Slip in existing fill \\
\hline 28 & & & & 0.14 & 0.10 & 0.04 & & & & & Notch in existing fill \\
\hline 29 & & & & 0.14 & 0.11 & 0.08 & & & & & 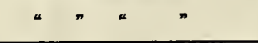 \\
\hline 32 & & & & & & & & & & 0.11 & New fill in SW harbor area \\
\hline 33 & & & & & & & & & & 0.17 & 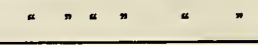 \\
\hline \multicolumn{12}{|c|}{ Other Harbor Areas } \\
\hline 1 & 0.83 & 0.81 & 0.84 & 0.85 & 0.84 & 0.84 & 0.83 & 0.83 & 0.84 & 0.84 & \\
\hline 11 & 0.22 & 0.17 & 0.22 & 0.19 & 0.19 & 0.18 & 0.24 & 0.19 & 0.18 & 0.20 & \\
\hline 12 & 0.46 & 0.42 & 0.46 & 0.46 & 0.47 & 0.46 & 0.46 & 0.47 & 0.46 & 0.44 & \\
\hline 13 & 0.27 & 0.23 & 0.26 & 0.27 & 0.29 & 0.30 & 0.26 & 0.28 & 0.30 & 0.29 & \\
\hline 14 & 0.21 & 0.17 & 0.20 & 0.21 & 0.23 & 0.24 & 0.21 & 0.28 & 0.24 & 0.23 & Back Basin gage \\
\hline
\end{tabular}




\section{Table F6 (Concluded)}

\begin{tabular}{|c|c|c|c|c|c|c|c|c|c|c|c|}
\hline \multirow{2}{*}{ Basin } & \multicolumn{10}{|c|}{ Plan } & \multirow{2}{*}{ Remarks } \\
\hline & Existing & 1 & 2 & $3 \mathbf{a}$ & 3b & $3 c$ & $4 \mathbf{a}$ & $4 \mathrm{~b}$ & $4 c$ & 5 & \\
\hline \multicolumn{12}{|c|}{ Other Harbor Areas (concluded) } \\
\hline 15 & 0.49 & 0.53 & 0.58 & 0.55 & 0.31 & 0.13 & 0.55 & 0.32 & 0.16 & 0.54 & \\
\hline 16 & 0.60 & 0.52 & 0.54 & 0.56 & 0.17 & 0.03 & 0.53 & 0.16 & 0.05 & 0.63 & Channel Entrance gage \\
\hline 17 & 0.50 & 0.34 & 0.37 & 0.40 & 0.16 & 0.05 & & & & 0.52 & \\
\hline 18 & 0.70 & 0.46 & 0.53 & 0.38 & 0.17 & 0.05 & & & & 0.72 & \\
\hline 19 & 0.71 & 0.64 & 0.85 & 0.64 & 0.41 & 0.25 & 0.85 & 0.53 & 0.34 & 0.69 & \\
\hline 20 & 0.40 & 0.36 & 0.42 & 0.46 & 0.39 & 0.33 & 0.48 & 0.39 & 0.34 & 0.41 & \\
\hline 22 & & 0.07 & 0.08 & & & & & & & & \\
\hline 24 & & 0.22 & 0.25 & & & & & & & & \\
\hline 25 & 0.20 & & & & & & & & & & \\
\hline 26 . & 0.25 & & & & & & & & & & \\
\hline 27 & & & & 0.18 & 0.11 & 0.05 & & & & & \\
\hline 30 & 0.21 & & & & & & & & & & Canoe Club gage (approx) \\
\hline 31 & 0.28 & & 0.11 & 0.14 & 0.12 & 0.09 & 0.10 & 0.10 & 0.10 & 0.10 & \\
\hline 32 & 0.75 & & & & & & & & & & \\
\hline 33 & 0.47 & & & & & & & & & & \\
\hline 34 & 0.42 & & & & & & & & & 0.30 & \\
\hline 35 & 1.09 & 1.06 & 1.09 & 1.08 & 1.08 & 1.08 & 1.08 & 1.08 & 1.08 & 1.08 & Array gage \\
\hline
\end{tabular}




\begin{tabular}{|c|c|c|c|c|c|c|c|c|}
\hline \multicolumn{9}{|c|}{$\begin{array}{l}\text { Table F7 } \\
H_{s} \text { Values E }\end{array}$} \\
\hline \multirow{3}{*}{$\begin{array}{l}\text { Basin } \\
\text { Number }\end{array}$} & \multicolumn{8}{|c|}{$H_{,}$Values Exceeded $10 \%$ and $1 \%$ of Time $(\mathrm{ft})$} \\
\hline & \multicolumn{2}{|c|}{ Existing } & \multicolumn{2}{|c|}{ Plan 1} & \multicolumn{2}{|c|}{ Plan 2} & \multicolumn{2}{|c|}{ Plan 3a } \\
\hline & $10 \%$ & $1 \%$ & $10 \%$ & $1 \%$ & $10 \%$ & $1 \%$ & $10 \%$ & $1 \%$ \\
\hline \multicolumn{9}{|l|}{ Pier 1} \\
\hline 2 & 1.19 & 1.71 & 1.18 & 1.68 & 1.19 & 1.70 & 0.87 & 1.33 \\
\hline 3 & 0.79 & 1.12 & 0.82 & 1.16 & 0.83 & 1.18 & 0.68 & 0.96 \\
\hline 4 & 0.60 & 0.85 & 0.58 & 0.83 & 0.59 & 0.83 & 0.39 & 0.63 \\
\hline 5 & 0.59 & 0.85 & 0.66 & 0.98 & 0.67 & 0.98 & 0.33 & 0.48 \\
\hline 6 & 0.37 & 0.51 & 0.47 & 0.67 & 0.47 & 0.66 & 0.25 & 0.39 \\
\hline \multicolumn{9}{|c|}{ Piers $2 \& 3$} \\
\hline 7 & 0.44 & 0.63 & 0.43 & 0.62 & 0.42 & 0.61 & 0.40 & 0.58 \\
\hline 8 & 0.42 & 0.63 & 0.46 & 0.69 & 0.46 & 0.68 & 0.47 & 0.73 \\
\hline 9 & 0.58 & 0.84 & 0.56 & 0.84 & 0.56 & 0.81 & 0.61 & 0.95 \\
\hline 10 & 0.94 & 1.43 & 0.87 & 1.31 & 0.85 & 1.26 & 0.83 & 1.21 \\
\hline \multicolumn{9}{|c|}{ Barge Pier (Planned) } \\
\hline 25 & & & 0.91 & 1.29 & & & & \\
\hline 26 & & & 0.76 & 1.13 & & & & \\
\hline 30 & & & & & 0.57 & 0.80 & 0.57 & 0.84 \\
\hline \multicolumn{9}{|c|}{ Boat Ramp } \\
\hline 21 & 1.04 & 1.52 & 1.06 & 1.50 & 1.04 & 1.47 & 0.71 & 1.04 \\
\hline \multicolumn{9}{|c|}{ Passenger Ship Pier (Planned) } \\
\hline 23 & & & 0.63 & 0.89 & 0.63 & 0.89 & & \\
\hline 28 & & & & & & & 0.69 & 1.04 \\
\hline 29 & & & & & & & 0.65 & 0.96 \\
\hline
\end{tabular}




\section{Table F7 (Continued)}

\begin{tabular}{|c|c|c|c|c|c|c|c|c|}
\hline \multirow{3}{*}{$\begin{array}{l}\text { Basin } \\
\text { Number }\end{array}$} & \multicolumn{8}{|c|}{$H_{g}$ Values Exceeded $10 \%$ and $1 \%$ of Time (tt) } \\
\hline & \multicolumn{2}{|c|}{ Plan 3b } & \multicolumn{2}{|c|}{ Plan $3 c$} & \multicolumn{2}{|c|}{ Plan 4a } & \multicolumn{2}{|c|}{ Plan $4 b$} \\
\hline & $10 \%$ & $1 \%$ & $10 \%$ & $1 \%$ & $10 \%$ & $1 \%$ & $10 \%$ & $1 \%$ \\
\hline \multicolumn{9}{|l|}{ Pier 1} \\
\hline 2 & 0.79 & 1.20 & 0.78 & 1.17 & 0.95 & 1.46 & 0.86 & 1.33 \\
\hline 3 & 0.57 & 0.88 & 0.53 & 0.80 & 0.85 & 1.24 & 0.66 & 0.93 \\
\hline 4 & 0.33 & 0.51 & 0.34 & 0.53 & 0.64 & 0.93 & 0.41 & 0.63 \\
\hline 5 & 0.26 & 0.36 & 0.27 & 0.39 & 0.49 & 0.71 & 0.26 & 0.39 \\
\hline 6 & 0.34 & 0.52 & 0.21 & 0.32 & 0.33 & 0.47 & 0.22 & 0.33 \\
\hline \multicolumn{9}{|c|}{ Piers 2 \& 3} \\
\hline 7 & 0.43 & 0.66 & 0.35 & 0.53 & 0.40 & 0.57 & 0.34 & 0.53 \\
\hline 8 & 0.43 & 0.66 & 0.43 & 0.67 & 0.48 & 0.72 & 0.44 & 0.68 \\
\hline 9 & 0.54 & 0.82 & 0.53 & 0.81 & 0.57 & 0.84 & 0.52 & 0.80 \\
\hline 10 & 0.87 & 1.30 & 0.84 & 1.26 & 0.88 & 1.29 & 0.88 & 1.37 \\
\hline \multicolumn{9}{|c|}{ Barge Pier (Planned) } \\
\hline \multicolumn{9}{|l|}{25} \\
\hline \multicolumn{9}{|l|}{26} \\
\hline 30 & 0.61 & 0.90 & 0.55 & 0.83 & 0.55 & 0.82 & 0.62 & 0.92 \\
\hline \multicolumn{9}{|c|}{ Boat Ramp } \\
\hline 21 & 0.49 & 0.72 & 0.49 & 0.69 & 0.56 & 0.84 & 0.24 & 0.37 \\
\hline \multicolumn{9}{|c|}{ Passenger Ship Pier (Planned) } \\
\hline 17 & & & & & 1.71 & 2.55 & 0.80 & 1.27 \\
\hline 18 & & & & & 1.49 & 2.22 & 0.93 & 1.48 \\
\hline 28 & 0.53 & 0.85 & 0.19 & 0.31 & & & & \\
\hline 29 & 0.55 & 0.82 & 0.41 & 0.62 & & & & \\
\hline
\end{tabular}




\begin{tabular}{|c|c|c|c|c|c|c|c|c|}
\hline \multicolumn{9}{|c|}{ Table F7 (Concluded) } \\
\hline \multirow{3}{*}{$\begin{array}{l}\text { Basin } \\
\text { Number }\end{array}$} & \multicolumn{8}{|c|}{$H$, Values Exceeded $10 \%$ and $1 \%$ of Time $(\mathrm{tt})$} \\
\hline & \multicolumn{2}{|c|}{ Plan $4 c$} & \multicolumn{2}{|c|}{ Pian 5} & \multicolumn{2}{|c|}{ Pian 6} & \multicolumn{2}{|c|}{ Pian 7} \\
\hline & $10 \%$ & $1 \%$ & $10 \%$ & $1 \%$ & $10 \%$ & $1 \%$ & $10 \%$ & $1 \%$ \\
\hline \multicolumn{9}{|l|}{ Pier 1} \\
\hline 2 & 0.83 & 1.25 & 0.96 & 1.40 & 0.83 & 1.27 & 0.90 & 1.41 \\
\hline 3 & 0.56 & 0.85 & 0.74 & 1.06 & 0.65 & 0.93 & 0.59 & 0.92 \\
\hline 4 & 0.34 & 0.54 & 0.46 & 0.71 & 0.39 & 0.58 & 0.33 & 0.51 \\
\hline 5 & 0.24 & 0.37 & 0.40 & 0.57 & 0.25 & 0.36 & 0.28 & 0.43 \\
\hline 6 & 0.23 & 0.33 & 0.34 & 0.48 & 0.22 & 0.32 & 0.20 & 0.30 \\
\hline \multicolumn{9}{|c|}{ Piers $2 \& 3$} \\
\hline 7 & 0.35 & 0.53 & 0.40 & 0.57 & 0.34 & 0.54 & 0.37 & 0.56 \\
\hline 8 & 0.46 & 0.70 & 0.43 & 0.65 & 0.45 & 0.69 & 0.45 & 0.72 \\
\hline 9 & 0.53 & 0.82 & 0.51 & 0.77 & 0.51 & 0.80 & 0.50 & 0.78 \\
\hline 10 & 0.87 & 1.32 & 0.95 & 1.39 & 0.87 & 1.30 & 0.94 & 1.44 \\
\hline \multicolumn{9}{|c|}{ Barge Pier (Planned) } \\
\hline 30 & 0.58 & 0.86 & 0.58 & 0.88 & 0.60 & 0.88 & 0.62 & 0.98 \\
\hline \multicolumn{9}{|c|}{ Boat Ramp } \\
\hline 21 & 0.21 & 0.31 & 1.22 & 1.81 & 0.29 & 0.45 & 0.37 & 0.58 \\
\hline \multicolumn{9}{|c|}{ Passenger Ship Pier (Planned) } \\
\hline 17 & 0.33 & 0.47 & & & 0.78 & 1.23 & & \\
\hline 18 & 0.29 & 0.45 & & & 0.88 & 1.39 & & \\
\hline 32 & & & 0.55 & 0.82 & & & & \\
\hline 33 & & & 0.84 & 1.25 & & & & \\
\hline 36 & & & & & & & 1.06 & 1.54 \\
\hline 37 & & & & & & & 1.22 & 1.76 \\
\hline 38 & & & & & & & 1.46 & 2.12 \\
\hline
\end{tabular}




\section{Appendix G Harbor Oscillation Summaries from Numerical Model}

\section{List of Figures}

$\begin{array}{ll}\text { Figure G1. Long wave response, Pier } 1 & \text { G2 }\end{array}$

Figure G2. Long wave response, Piers 2 and $3 \quad$ G4

Figure G3. Long wave response, barge pier $\quad$ G6

Figure G4. Long wave response, passenger pier $\quad$ G8

$\begin{array}{ll}\text { Figure G5. Long wave response, boat ramp } & \text { G10 }\end{array}$

Figure G6. Comparison to Wilson's (1967) slope criterion, 100 - to 400 -sec period

Figure G7. Comparison to Wilson's (1967) slope criterion, 30- to 100 -sec period

\section{List of Tables}

Table G1. RMS Values of $A_{\text {amp,l }}$ at Piers, $T=100-400 \mathrm{sec} \quad \mathrm{G} 14$

Table G2. Percent Occurrence of $H_{\text {s,long }} \geq 10 \mathrm{~cm}$ at Piers, $T=100-400 \mathrm{sec} \quad$ G15

Table G3. Percent Occurrence of $H_{\text {s, long }} \geq 10 \mathrm{~cm}$ at Piers, $T=30-100 \mathrm{sec} \quad$ G16

Table G4. Percent Occurrence of Cases Exceeding Wilson's (1967) Slope Criterion at Piers, $T=100-400 \mathrm{sec}$

Table G5. Percent Occurrence of Cases Exceeding Wilson's (1967)

Slope Criterion at Piers, $T=30-100 \mathrm{sec}$ 


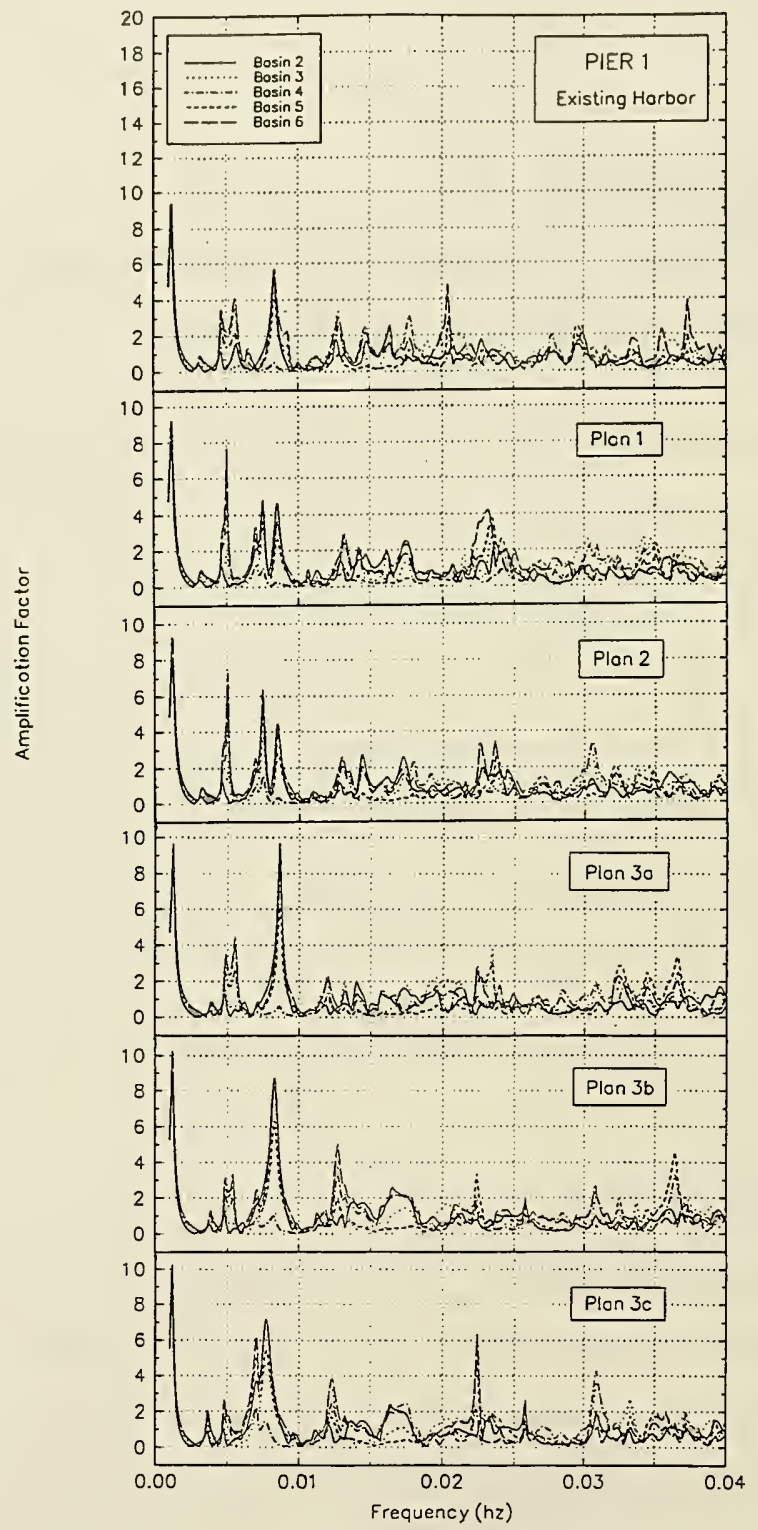

Figure G1. Long wave response, Pier 1 (Continued) 


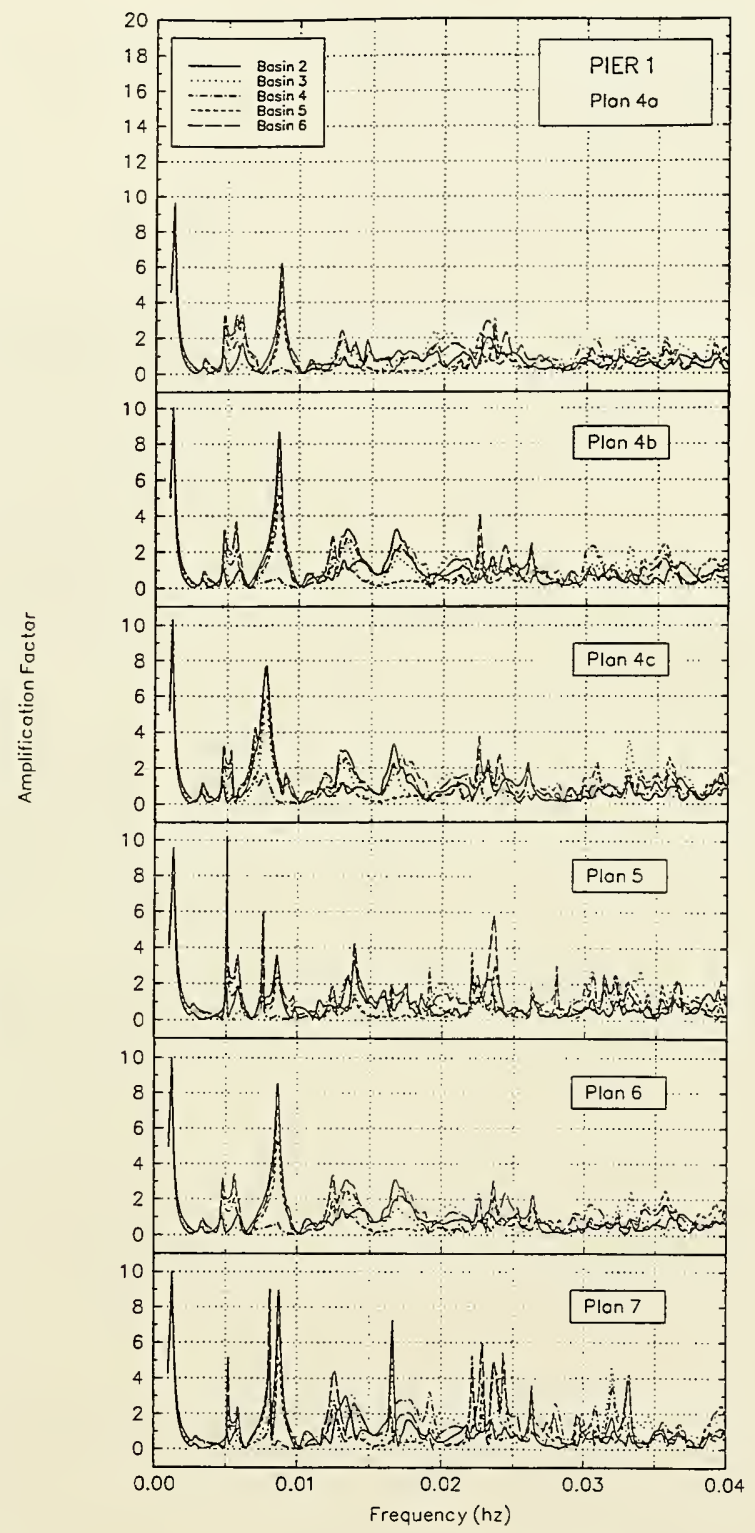

Figure G1. (Concluded) 


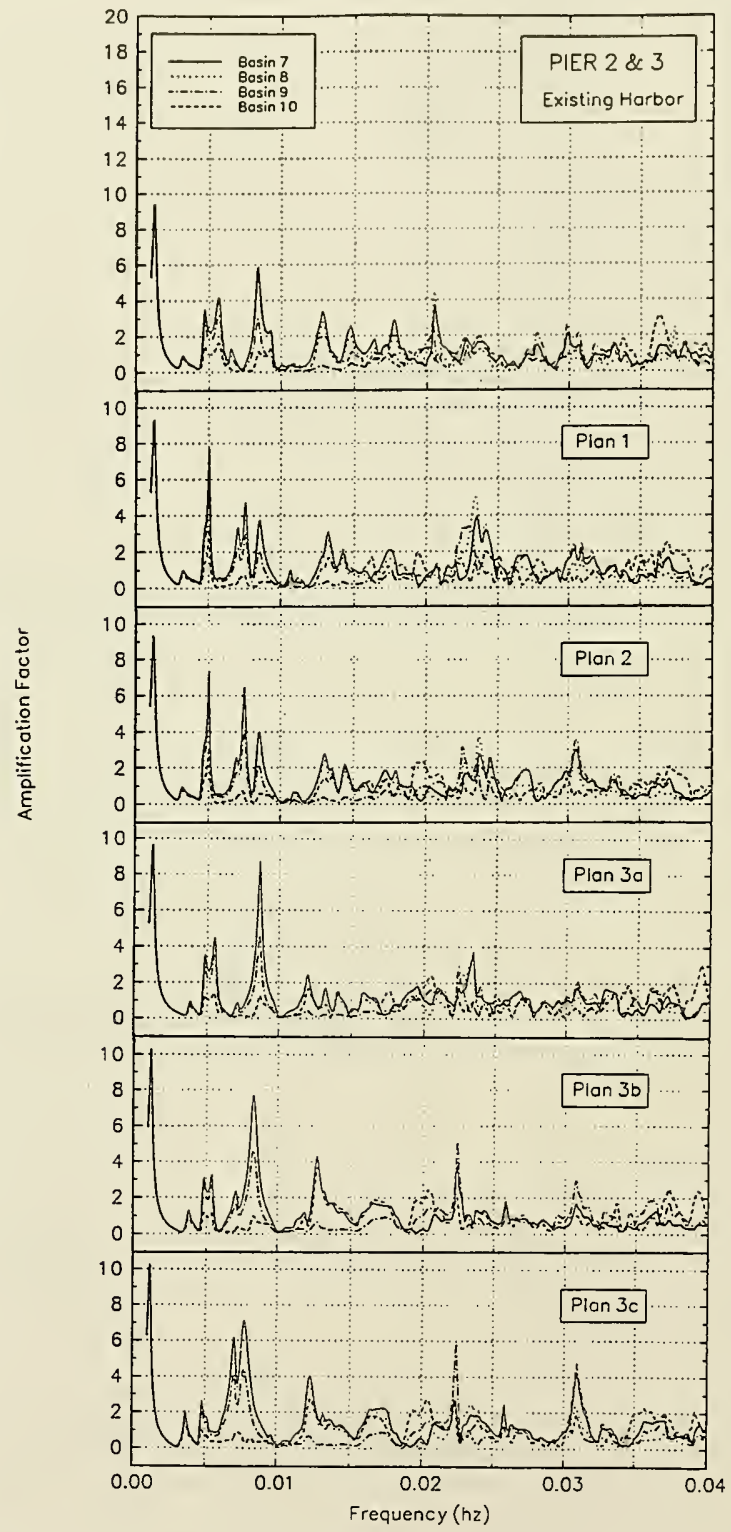

Figure G2. Long wave response, Piers 2 and 3 (Continued) 


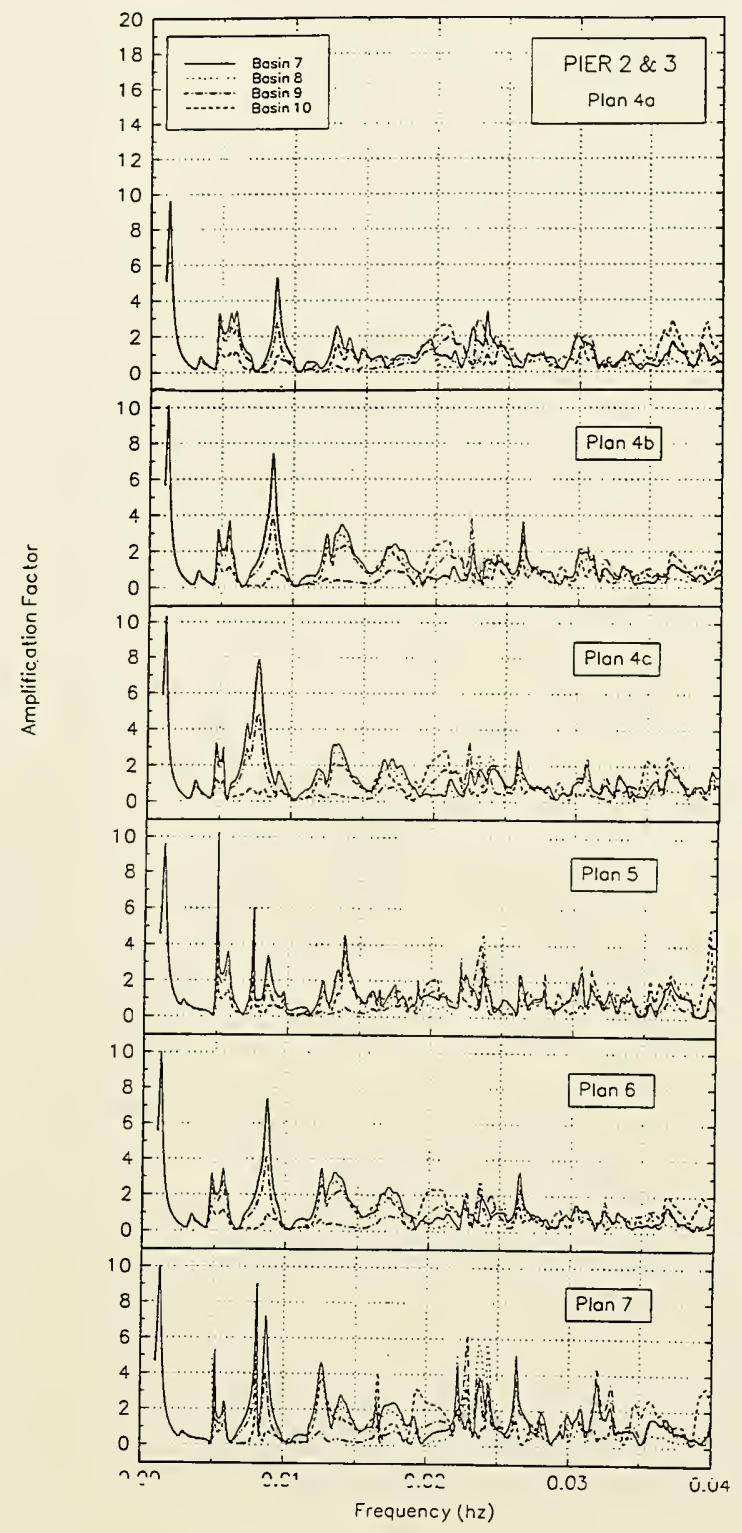

Figure G2. (Concluded) 


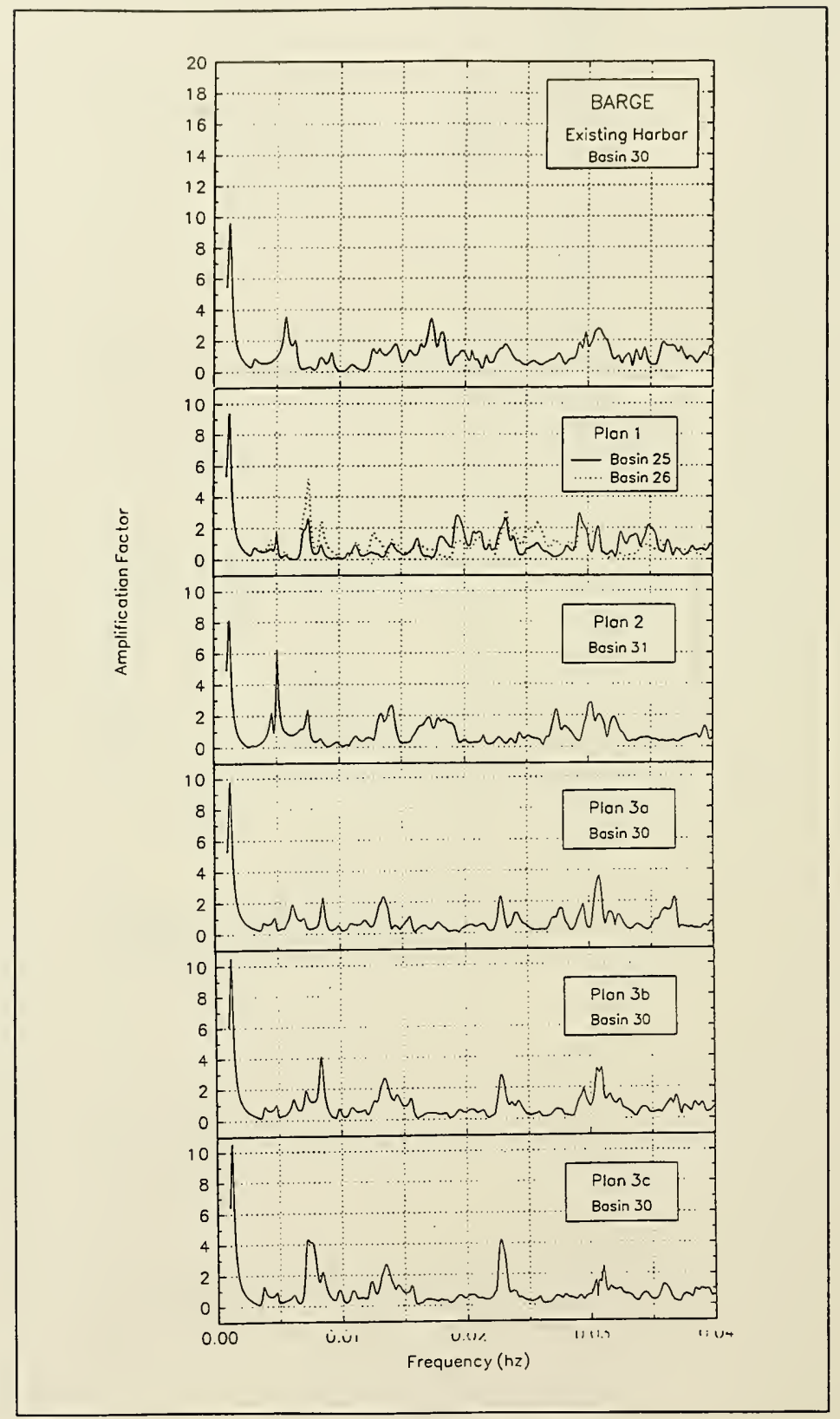

Figure G3. Long wave response, barge pier (Continued) 


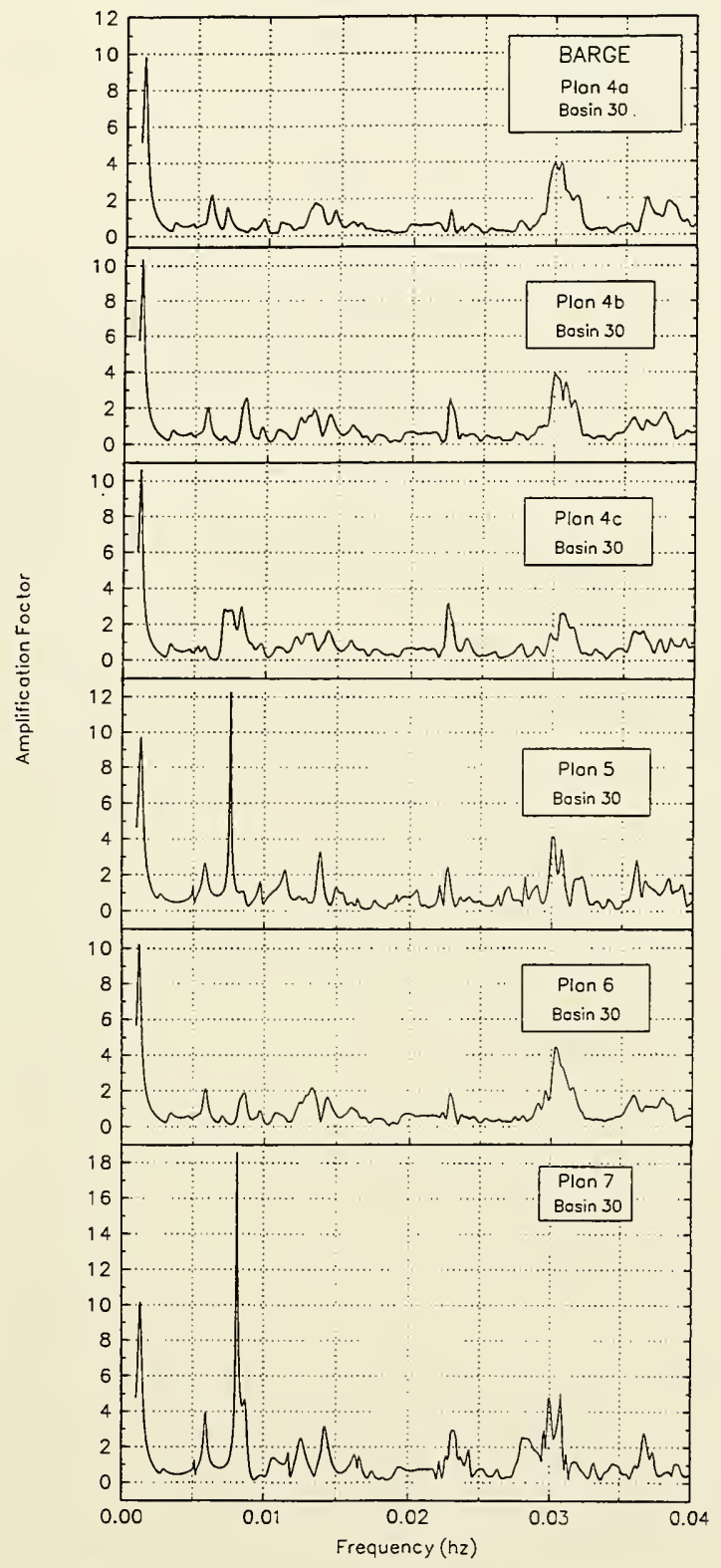

Figure G3. (Concluded) 


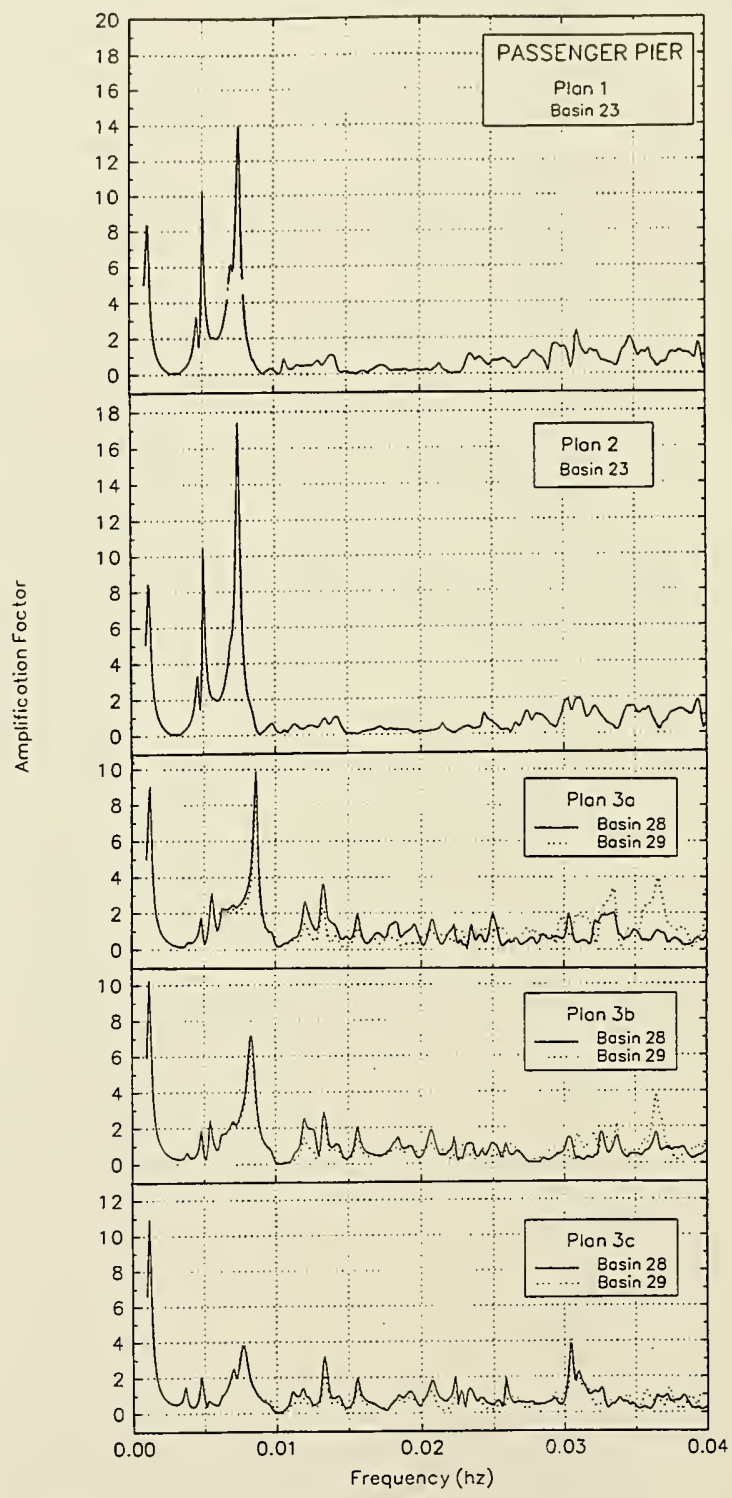

Figure G4. Long wave response, passenger pier (Continued) 


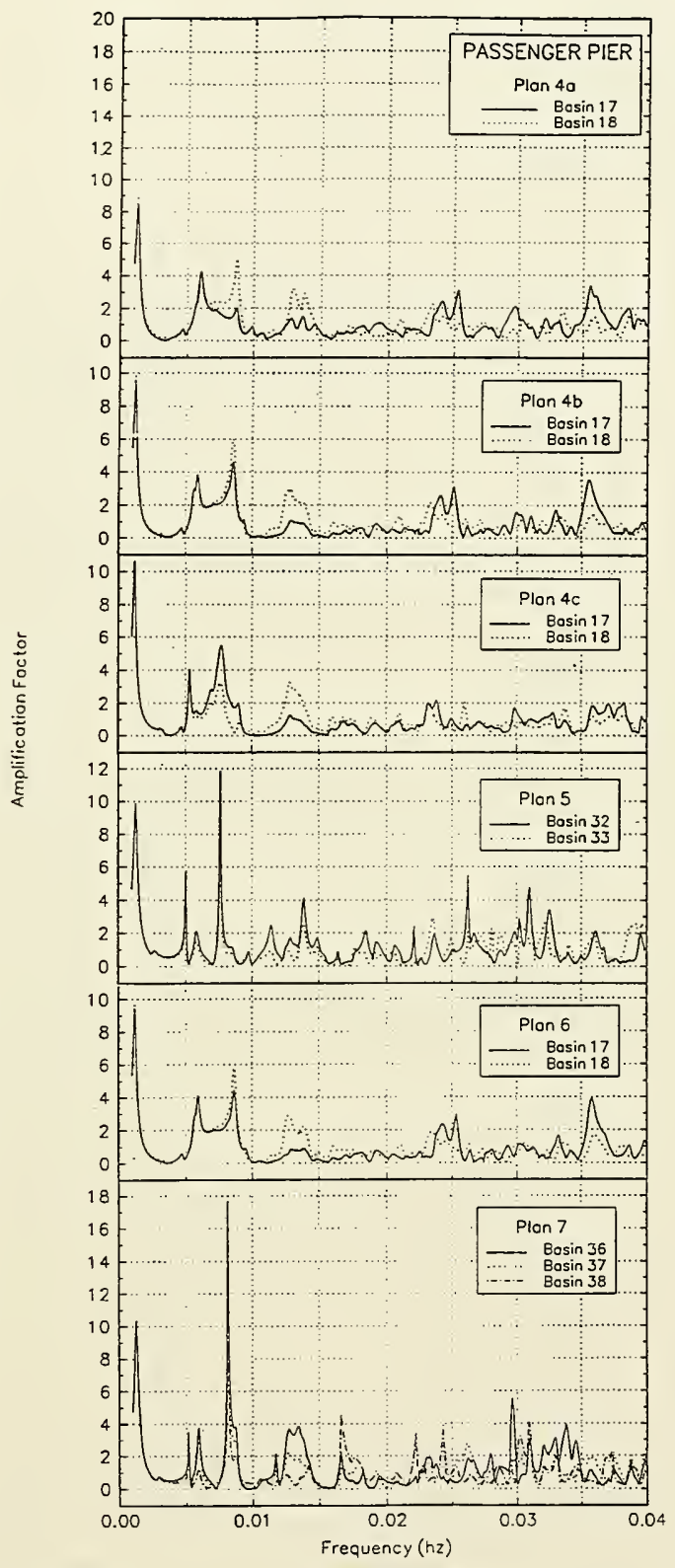

Figure G4. (Concluded) 


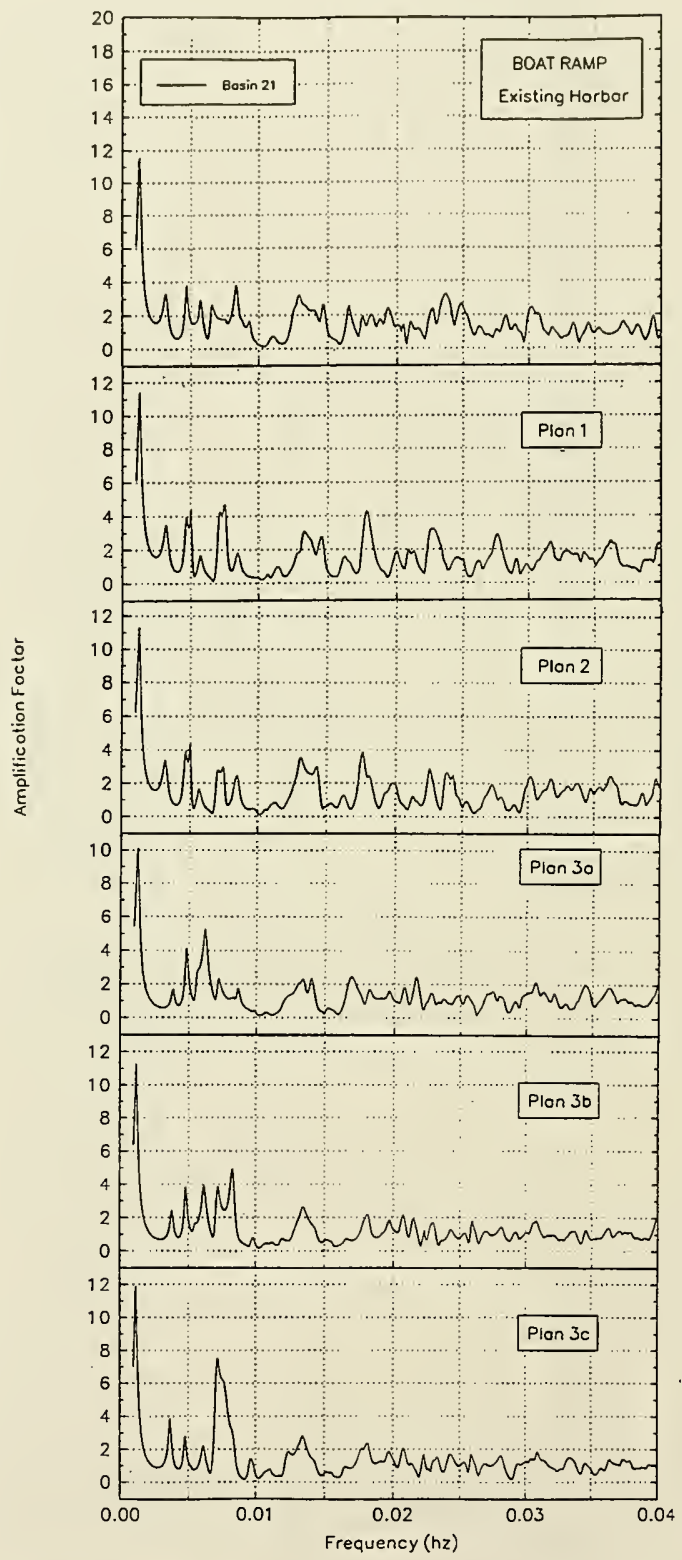

Figure G5. Long wave response, boat ramp (Continued) 


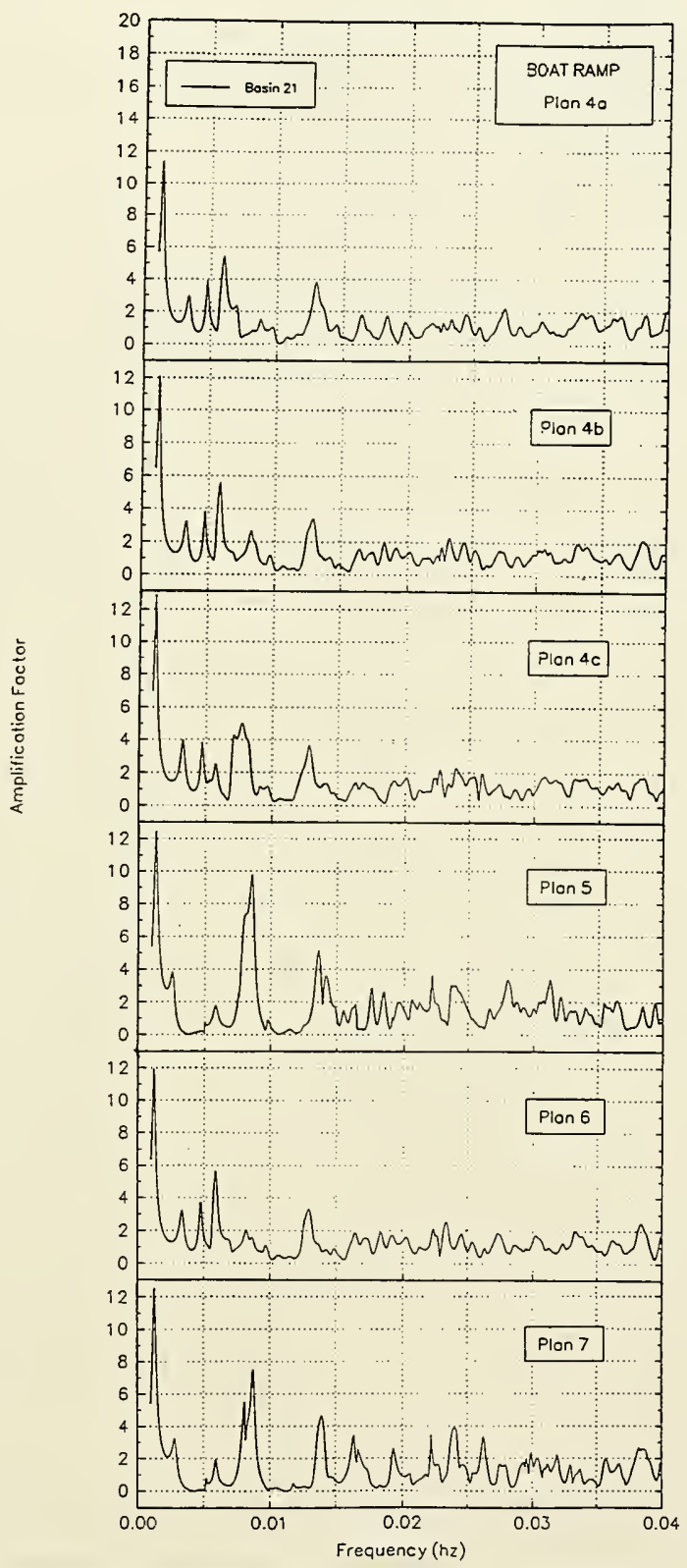

Figure G5. (Concluded) 


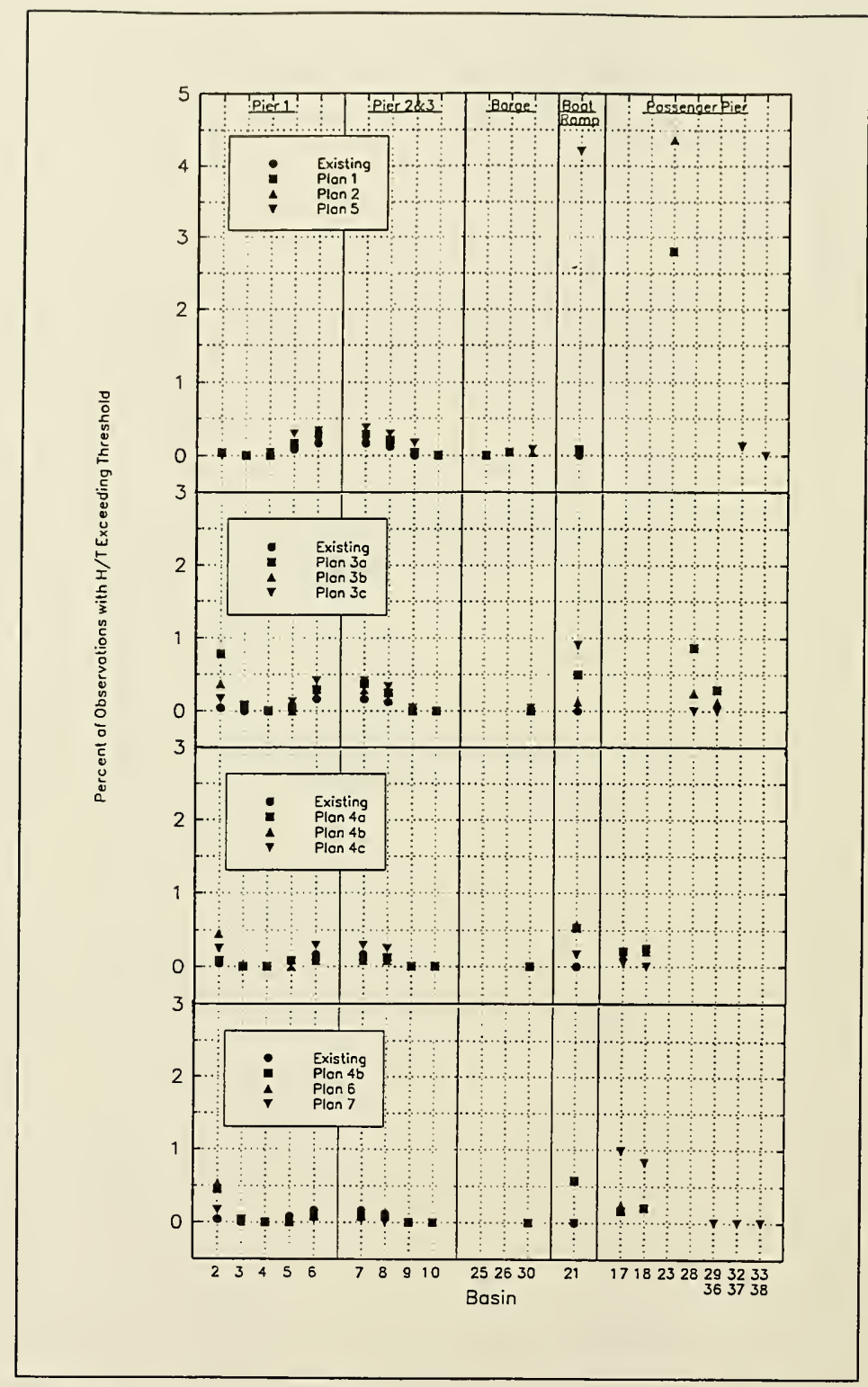

Figure G6. Comparison to Wilson's (1967) slope criterion, 100- to 400-sec period 


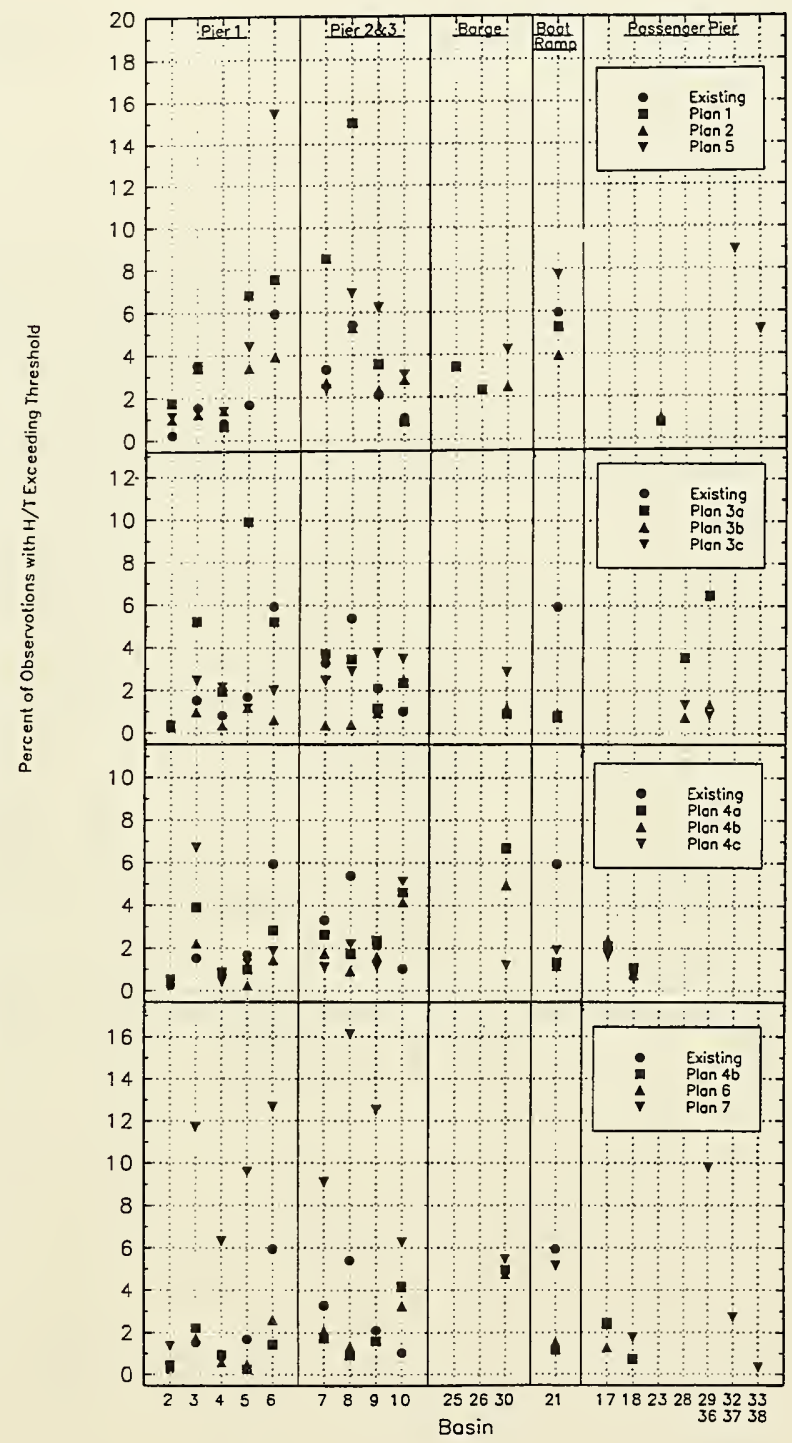

Figure G7. Comparison to Wilson's (1967) slope criterion, 30- to 100-sec period 


\begin{tabular}{|c|c|c|c|c|c|c|c|c|c|c|c|c|}
\hline \multicolumn{13}{|c|}{$\begin{array}{l}\text { Table G1 } \\
\text { RMS Values of } A_{s m p, l} \text { at Piers, } T=100-400 \mathrm{sec}\end{array}$} \\
\hline \multirow[b]{2}{*}{$\begin{array}{l}\text { Basin } \\
\text { No. }\end{array}$} & \multicolumn{12}{|c|}{ Harbor Plan } \\
\hline & Ex. & 1 & 2 & $3 a$ & 3b & $3 c$ & $4 a$ & $4 b$ & $4 c$ & 5 & 6 & 7 \\
\hline \multicolumn{13}{|c|}{ Pier 1} \\
\hline 2 & 1.40 & 1.60 & 1.64 & 2.19 & 2.53 & 2.35 & 1.58 & 2.29 & 2.35 & 1.12 & 2.27 & 2.23 \\
\hline 3 & 1.17 & 1.18 & 1.19 & 1.70 & 1.85 & 1.57 & 1.21 & 1.72 & 1.58 & 0.88 & 1.67 & 1.64 \\
\hline 4 & 0.82 & 0.98 & 0.99 & 0.81 & 0.73 & 0.88 & 0.83 & 0.75 & 0.89 & 1.01 & 0.76 & 0.71 \\
\hline 5 & 1.57 & 1.69 & 1.78 & 1.78 & 1.95 & 2.15 & 1.52 & 1.75 & 2.15 & 1.65 & 1.75 & 1.82 \\
\hline 6 & 2.01 & 2.03 & 2.15 & 2.30 & 2.58 & 2.70 & 1.89 & 2.27 & 2.71 & 1.96 & 2.23 & 2.34 \\
\hline \multicolumn{13}{|c|}{ Piers $2 \& 3$} \\
\hline 7 & 2.05 & 2.05 & 2.18 & 2.33 & 2.43 & 2.74 & 1.91 & 2.31 & 2.74 & 1.97 & 2.26 & 2.37 \\
\hline 8 & 1.92 & 1.97 & 2.08 & 2.20 & 2.44 & 2.60 & 1.82 & 2.18 & 2.61 & 1.89 & 2.14 & 2.24 \\
\hline 9 & 1.31 & 1.46 & 1.52 & 1.45 & 1.57 & 1.77 & 1.29 & 1.43 & 1.78 & 1.42 & 1.43 & 1.45 \\
\hline 10 & 0.71 & 0.64 & 0.66 & 0.58 & 0.51 & 0.51 & 0.61 & 0.57 & 0.52 & 0.75 & 0.57 & 0.71 \\
\hline \multicolumn{13}{|c|}{ Barge Pier (Planned) } \\
\hline 25 & & 0.80 & & & & & & & & & & \\
\hline 26 & & 1.43 & & & & & & & & & & \\
\hline 30 & & & 1.28 & 0.83 & 1.16 & 1.59 & 0.78 & 0.88 & 1.29 & 1.88 & 0.80 & 2.96 \\
\hline \multicolumn{13}{|c|}{ Boat Ramp } \\
\hline 21 & 1.91 & 2.00 & 1.77 & 1.87 & 2.07 & 2.72 & 1.93 & 1.95 & 2.39 & 3.13 & 1.90 & 2.26 \\
\hline \multicolumn{13}{|c|}{ Passenger Ship Pier (Planned) } \\
\hline 17 & & & & & & & 1.54 & 1.88 & 2.07 & & 1.85 & 2.32 \\
\hline 18 & & & & & & & 2.06 & 2.12 & 1.32 & & 2.07 & 2.43 \\
\hline 23 & & 3.87 & 4.27 & & & & & & & & & \\
\hline 28 & & & & 2.66 & 2.35 & 1.46 & & & & & & \\
\hline 29 & & & & 2.28 & 2.14 & 1.50 & & & & & & \\
\hline 32 & & & & & & & & & & 1.87 & & \\
\hline 33 & & & & & & & & & & 1.45 & & \\
\hline 36 & & & & & & & & & & & & 2.77 \\
\hline 37 & & & & & & & & & & & & 2.20 \\
\hline 38 & & & & & & & & & & & & 1.44 \\
\hline
\end{tabular}




\begin{tabular}{|c|c|c|c|c|c|c|c|c|c|c|c|c|}
\hline \multirow{3}{*}{$\begin{array}{l}\text { Tabl } \\
\text { Perc } \\
\text { Basin } \\
\text { No. }\end{array}$} & $\begin{array}{l}\text { G2 } \\
\text { nt Oc }\end{array}$ & urre & e o & & $0 \mathrm{cr}$ & t $P$ & rs, $T$ & $00-4$ & $\sec$ & & & \\
\hline & \multicolumn{12}{|c|}{ Harbor Plan } \\
\hline & Ex. & 1 & 2 & $3 a$ & $\mathbf{3 b}$ & $3 c$ & $4 a$ & $4 b$ & $4 c$ & 5 & 6 & 7 \\
\hline \multicolumn{13}{|c|}{ Pier 1} \\
\hline 2 & 2.1 & 2.3 & 2.4 & 5.6 & 6.2 & 5.5 & 3.5 & 6.1 & 5.4 & 1.4 & 6.6 & 4.0 \\
\hline 3 & 0.8 & 0.9 & 0.9 & 2.6 & 2.5 & 1.3 & 0.9 & 2.5 & 1.4 & 0.5 & 2.4 & 0.9 \\
\hline 4 & 1.2 & 2.2 & 2.2 & 1.2 & 0.7 & 0.8 & 1.1 & 0.7 & 0.7 & 3.0 & 0.9 & 0.1 \\
\hline 5 & 7.2 & 9.5 & 9.6 & 8.0 & 6.3 & 8.4 & 7.6 & 6.7 & 7.5 & 11.0 & 6.7 & 2.2 \\
\hline 6 & 13.1 & 13.6 & 14.3 & 14.6 & 11.7 & 13.7 & 12.9 & 13.0 & 12.5 & 15.1 & 12.3 & 5.4 \\
\hline \multicolumn{13}{|c|}{ Piers $2 \& 3$} \\
\hline 7 & 13.6 & 13.8 & 14.6 & 14.9 & 10.0 & 13.9 & 13.3 & 13.3 & 12.9 & 15.4 & 12.9 & 5.7 \\
\hline 8 & 11.8 & 12.4 & 13.4 & 12.9 & 10.0 & 12.5 & 11.7 & 11.4 & 11.7 & 14.4 & 10.8 & 4.9 \\
\hline 9 & 4.6 & 6.6 & 6.8 & 4.8 & 3.3 & 4.9 & 5.2 & 4.1 & 4.5 & 7.8 & 4.2 & 1.1 \\
\hline 10 & 0.5 & 0.4 & 0.4 & 0.1 & 0.0 & 0.1 & 0.4 & 0.1 & 0.0 & 0.6 & 0.1 & 0.1 \\
\hline \multicolumn{13}{|c|}{ Barge Pier (Planned) } \\
\hline 25 & & 0.4 & & & & & & & & & & \\
\hline 26 & & 1.9 & & & & & & & & & & \\
\hline 30 & & & 5.2 & 0.5 & 0.6 & 2.6 & 0.8 & 0.9 & 1.3 & 4.9 & 0.8 & 4.4 \\
\hline \multicolumn{13}{|c|}{ Boat Ramp } \\
\hline 21 & 10.6 & 12.6 & 11.1 & 14.1 & 12.4 & 17.5 & 15.4 & 15.6 & 14.3 & 23.8 & 15.3 & 3.7 \\
\hline \multicolumn{13}{|c|}{ Passenger Ship Pier (Planned) } \\
\hline 17 & & & & & & & 6.0 & 7.6 & 7.0 & & 7.5 & 15.5 \\
\hline 18 & & & & & & & 10.0 & 8.6 & 2.1 & & 8.7 & 15.3 \\
\hline 23 & & 35.6 & 39.2 & & & & & & & & & \\
\hline 28 & & & & 13.9 & 7.1 & 2.1 & & & & & & \\
\hline 29 & & & & 8.9 & 5.9 & 2.2 & & & & & & \\
\hline 32 & & & & & & & & & & 6.8 & & \\
\hline 33 & & & & & & & & & & 3.2 & & \\
\hline 36 & & & & & & & & & & & & 3.5 \\
\hline 37 & & & & & & & & & & & & 1.5 \\
\hline 38 & & & & & & & & & & & & 0.2 \\
\hline
\end{tabular}




\section{Table G3 \\ Percent Occurrence of $H_{s, \text { long }} \geq 10 \mathrm{~cm}$ at Piers, $T=30-100 \mathrm{sec}$}

\begin{tabular}{|c|c|c|c|c|c|c|c|c|c|c|c|c|}
\hline \multirow[b]{2}{*}{$\begin{array}{l}\text { Basin } \\
\text { No. }\end{array}$} & \multicolumn{12}{|c|}{ Harbor Plan } \\
\hline & Ex. & 1 & 2 & $\mathbf{3 a}$ & $3 b$ & $3 c$ & $4 a$ & $4 b$ & $4 c$ & 5 & 6 & 7 \\
\hline \multicolumn{13}{|c|}{ Pier 1} \\
\hline 2 & 1.4 & 2.7 & 2.6 & 0.9 & 2.1 & 2.2 & 0.9 & 2.4 & 1.8 & 2.2 & 2.2 & 5.3 \\
\hline 3 & 3.4 & 3.1 & 2.0 & 5.1 & 2.2 & 3.8 & 5.4 & 3.6 & 4.1 & 4.1 & 3.5 & 11.5 \\
\hline 4 & 3.0 & 2.2 & 2.7 & 1.8 & 2.6 & 2.8 & 1.4 & 3.7 & 3.0 & 4.1 & 3.2 & 9.2 \\
\hline 5 & 1.0 & 2.5 & 1.0 & 2.0 & 0.3 & 0.9 & 0.5 & 0.4 & 0.7 & 1.5 & 0.4 & 5.7 \\
\hline 6 & 4.8 & 5.1 & 4.0 & 3.3 & 4.6 & 4.5 & 4.4 & 6.1 & 5.6 & 9.6 & 5.9 & 16.4 \\
\hline
\end{tabular}

Piers 2 \& 3

\begin{tabular}{||l||l|l|l|l|l|l|l|l|l|l|l|l|}
\hline 7 & 5.7 & 6.3 & 4.8 & 4.6 & 2.8 & 5.5 & 3.9 & 6.6 & 5.3 & 6.2 & 6.3 & 16.2 \\
\hline 8 & 4.0 & 6.4 & 3.3 & 2.3 & 2.9 & 4.3 & 1.9 & 4.0 & 4.1 & 5.3 & 4.0 & 14.9 \\
\hline 9 & 2.1 & 2.6 & 2.4 & 1.6 & 1.2 & 2.1 & 2.7 & 2.1 & 1.8 & 3.4 & 1.5 & 8.3 \\
\hline 10 & 2.1 & 3.3 & 4.0 & 2.3 & 4.4 & 4.9 & 4.0 & 5.9 & 5.6 & 5.3 & 5.1 & 12.8 \\
\hline
\end{tabular}

Barge Pier (Planned)

\begin{tabular}{|l|l|l|l|l|l|l|l|l|l|l|l|l|}
\hline 25 & 4.1 & & & & & & & & & & \\
\hline 26 & 2.7 & & & & & & & & & & \\
\hline 30 & & & 4.0 & 1.4 & 2.7 & 2.8 & 1.9 & 2.1 & 1.6 & 3.3 & 2.2 & 6.8 \\
\hline
\end{tabular}

Boat Ramp

\begin{tabular}{||l||l|l|l|l|l|l|l|l|l|l|l|l|l||}
\hline 21 & 10.6 & 10.5 & 9.9 & 4.2 & 3.7 & 4.8 & 3.7 & 4.0 & 4.6 & 13.4 & 4.5 & 11.3 \\
\hline \multicolumn{70}{|c|}{ Passenger Ship Pier (Planned) } \\
\hline 17 & & & & & & & 2.0 & 0.8 & 0.7 & & 0.4 & 1.9 \\
\hline 18 & & & & & & 3.1 & 2.6 & 3.0 & & 1.9 & 4.5 \\
\hline 23 & & 0.3 & 0.2 & & & & & & & & & \\
\hline 28 & & & 3.6 & 2.1 & 2.4 & & & & & & \\
\hline 32 & & & & 2.0 & 0.8 & 0.7 & & & & & & \\
\hline 33 & & & & & & & & & & 3.4 & & \\
\hline 36 & & & & & & & & & & & & 11.5 \\
\hline 37 & & & & & & & & & & & & 3.5 \\
\hline
\end{tabular}




\begin{tabular}{|c|c|c|c|c|c|c|c|c|c|c|c|c|}
\hline \multirow{3}{*}{$\begin{array}{l}\text { Table } \\
\text { Perc } \\
\text { Piers } \\
\\
\text { Basin } \\
\text { No. }\end{array}$} & $\begin{array}{l}\text { G4 } \\
\text { nt Od } \\
T=10\end{array}$ & $\begin{array}{r}\text { urre } \\
-400\end{array}$ & $\begin{array}{l}\text { e of } \\
c\end{array}$ & ase & Exc & if & ilsc & (1) & ) & se & eric & \\
\hline & \multicolumn{12}{|c|}{ Harbor Plan } \\
\hline & Ex. & 1 & 2 & $3 a$ & $3 b$ & $3 c$ & $4 a$ & $4 b$ & $4 c$ & 5 & 6 & 7 \\
\hline \multicolumn{13}{|c|}{ Pier 1} \\
\hline 2 & 0.04 & 0.04 & 0.04 & 0.78 & 0.37 & 0.17 & 0.08 & 0.45 & 0.25 & 0.00 & 0.54 & 0.17 \\
\hline 3 & 0.00 & 0.00 & 0.00 & 0.08 & 0.04 & 0.00 & 0.00 & 0.04 & 0.00 & 0.00 & 0.04 & 0.00 \\
\hline 4 & 0.00 & 0.00 & 0.00 & 0.00 & 0.00 & 0.00 & 0.00 & 0.00 & 0.00 & 0.04 & 0.00 & 0.00 \\
\hline 5 & 0.08 & 0.17 & 0.17 & 0.04 & 0.00 & 0.12 & 0.08 & 0.00 & 0.04 & 0.29 & 0.00 & 0.00 \\
\hline 6 & 0.17 & 0.29 & 0.25 & 0.29 & 0.33 & 0.41 & 0.12 & 0.08 & 0.29 & 0.33 & 0.12 & 0.04 \\
\hline \multicolumn{13}{|c|}{ Piers $2 \& 3$} \\
\hline 7 & 0.17 & 0.29 & 0.25 & 0.37 & 0.29 & 0.41 & 0.12 & 0.08 & 0.29 & 0.37 & 0.12 & 0.04 \\
\hline 8 & 0.12 & 0.21 & 0.25 & 0.25 & 0.29 & 0.33 & 0.12 & 0.08 & 0.25 & 0.29 & 0.12 & 0.00 \\
\hline 9 & 0.00 & 0.04 & 0.04 & 0.00 & 0.00 & 0.04 & 0.00 & 0.00 & 0.00 & 0.17 & 0.00 & 0.00 \\
\hline 10 & 0.00 & 0.00 & 0.00 & 0.00 & 0.00 & 0.00 & 0.00 & 0.00 & 0.00 & 0.00 & 0.00 & 0.00 \\
\hline \multicolumn{13}{|c|}{ Barge Pier (Planned) } \\
\hline 25 & & 0.00 & & & & & & & & & & \\
\hline 26 & & 0.04 & & & & & & & & & & \\
\hline 30 & & & 0.04 & 0.00 & 0.00 & 0.04 & 0.00 & 0.00 & 0.00 & 0.08 & 0.00 & 0.00 \\
\hline \multicolumn{13}{|c|}{ Boat Ramp } \\
\hline 21 & 0.00 & 0.08 & 0.04 & 0.50 & 0.12 & 0.91 & 0.54 & 0.58 & 0.17 & 4.20 & 0.58 & 0.00 \\
\hline \multicolumn{13}{|c|}{ Passenger Ship Pier (Planned) } \\
\hline 17 & & & & & & & 0.21 & 0.17 & 0.04 & & 0.25 & 0.99 \\
\hline 18 & & & & & & & 0.25 & 0.21 & 0.00 & & 0.21 & 0.82 \\
\hline 23 & & 2.80 & 4.37 & & & & & & & & & \\
\hline 28 & & & & 0.87 & 0.25 & 0.00 & & & & & & \\
\hline 29 & & & & 0.29 & 0.12 & 0.00 & & & & & & \\
\hline 32 & & & & & & & & & & 0.12 & & \\
\hline 33 & & & & & & & & & & 0.00 & & \\
\hline 36 & & & & & & & & & & & & 0.00 \\
\hline 37 & & & & & & & & & & & & 0.00 \\
\hline 38 & & & & & & & & & & & & 0.00 \\
\hline
\end{tabular}




\begin{tabular}{|c|c|c|c|c|c|c|c|c|c|c|c|c|}
\hline \multirow{3}{*}{$\begin{array}{l}\text { Table } \\
\text { Perc } \\
\text { Piers } \\
\\
\text { Basin } \\
\text { No. }\end{array}$} & $\begin{array}{l}\mathrm{G5} \\
\text { it } \mathrm{O} \\
T=3\end{array}$ & $\begin{array}{l}\text { urre } \\
100\end{array}$ & $\begin{array}{l}\text { ce o } \\
\text { c }\end{array}$ & ase & & ding & Vilsc & s (1 & 7) $\mathrm{s}$ & pe $C$ & rio & \\
\hline & \multicolumn{12}{|c|}{ Harbor Plan } \\
\hline & Ex. & 1 & 2 & $\mathbf{3 a}$ & 3b & $3 c$ & $4 a$ & $4 b$ & $4 c$ & 5 & 6 & 7 \\
\hline \multicolumn{13}{|c|}{ Pier 1} \\
\hline 2 & 0.2 & 1.7 & 1.0 & 0.3 & 0.5 & 0.4 & 0.5 & 0.5 & 0.5 & 1.1 & 0.5 & 1.4 \\
\hline 3 & 1.5 & 3.4 & 1.2 & 5.2 & 1.0 & 2.5 & 3.9 & 2.2 & 6.7 & 3.5 & 1.8 & 11.7 \\
\hline 4 & 0.8 & 0.7 & 1.4 & 1.9 & 0.4 & 2.1 & 0.9 & 0.9 & 0.4 & 1.4 & 0.6 & 6.3 \\
\hline 5 & 1.7 & 6.8 & 3.4 & 9.9 & 1.2 & 1.2 & 1.0 & 0.2 & 1.3 & 4.4 & 0.5 & 9.6 \\
\hline 6 & 5.9 & 7.5 & 3.9 & 5.2 & 0.6 & 2.0 & 2.8 & 1.4 & 1.9 & 15.4 & 2.6 & 12.7 \\
\hline \multicolumn{13}{|c|}{ Piers 2 \& 3} \\
\hline 7 & 3.3 & 8.5 & 2.7 & 3.7 & 0.4 & 2.5 & 2.6 & 1.7 & 1.1 & 2.4 & 2.1 & 9.1 \\
\hline 8 & 5.4 & 15.0 & 5.3 & 3.5 & 0.4 & 2.9 & 1.7 & 0.9 & 2.2 & 6.9 & 1.4 & 16.1 \\
\hline 9 & 2.1 & 3.5 & 2.3 & 1.2 & 0.9 & 3.8 & 2.4 & 1.6 & 1.2 & 6.2 & 1.6 & 12.5 \\
\hline 10 & 1.0 & 0.9 & 2.8 & 2.4 & 2.5 & 3.5 & 4.6 & 4.2 & 5.1 & 3.1 & 3.3 & 6.3 \\
\hline \multicolumn{13}{|c|}{ Barge Pier (Planned) } \\
\hline 25 & & 3.4 & & & & & & & & & & \\
\hline 26 & & 2.3 & & & & & & & & & & \\
\hline 30 & & & 2.5 & 0.9 & 1.2 & 2.9 & 6.7 & 4.9 & 1.2 & 4.2 & 4.7 & 5.4 \\
\hline \multicolumn{13}{|c|}{ Boat Ramp } \\
\hline 21 & 5.9 & 5.3 & 3.9 & 0.7 & 0.9 & 0.8 & 1.3 & 1.2 & 1.9 & 7.7 & 1.6 & 5.2 \\
\hline \multicolumn{13}{|c|}{ Passenger Ship Pier (Planned) } \\
\hline 17 & & & & & & & 2.1 & 2.4 & 1.6 & & 1.3 & 2.5 \\
\hline 18 & & & & & & & 1.1 & 0.7 & 0.6 & & 0.7 & 1.8 \\
\hline 23 & & 0.8 & 1.0 & & & & & & & & & \\
\hline 28 & & & & 3.5 & 0.7 & 1.3 & & & & & & \\
\hline 29 & & & & 6.5 & 1.4 & 0.9 & & & & & & \\
\hline 32 & & & & & & & & & & 8.9 & & \\
\hline 33 & & & & & & & & & & 5.2 & & \\
\hline 36 & & & & & & & & & & & & 9.8 \\
\hline 37 & & & & & & & & & & & & 2.7 \\
\hline 38 & & & & & & & & & & & & 0.3 \\
\hline
\end{tabular}




\section{Appendix $\mathrm{H}$ Resonant Amplification Factor and Phase Contour Plots, All Plans}

\section{List of Figures}

Figure H1. Resonant long wave amplification factor contours, Plan 1

Figure H2. Resonant long wave phase contours, Plan 1

Figure H3. Resonant long wave amplification factor contours, Plan 2

H5

Figure H4. Resonant long wave phase contours, Plan 2

H6

Figure H5. Resonant long wave amplification factor contours, Plan 3a

Figure H6. Resonant long wave phase contours, Plan 3a

$\mathrm{H} 8$

Figure H7. Resonant long wave amplification factor contours, Plan $3 b$

Figure H8. Resonant long wave phase contours, Plan $3 b$

H10

Figure H9. Resonant long wave amplification factor contours, Plan 3c

Figure H10. Resonant long wave phase contours, Plan 3c

Figure H11. Resonant long wave amplification factor contours, Plan 4a

Figure H12. Resonant long wave phase contours, Plan 4a

Figure H13. Resonant long wave amplification factor contours, Plan 4b

Figure H14. Resonant long wave phase contours, Plan 4b 
Figure H15. Resonant long wave amplification factors, Plan 4c H17

Figure H16. Resonant long wave phase contours, Plan 4c H18

Figure H17. Resonant long wave amplification factor contours, Plan $5 \quad$ H19

$\begin{array}{ll}\text { Figure H18. Resonant long wave phase contours, Plan } 5 & \text { H20 }\end{array}$

Figure H19. Resonant long wave amplification factor contours, Plan $6 \quad$ H21

$\begin{array}{ll}\text { Figure H20. Resonant long wave phase contours, Plan } 6 & \text { H22 }\end{array}$

$\begin{array}{lll}\text { Figure } \mathrm{H} 21 \text {. Resonant long wave amplification factor contours, Plan } 7 & \text { H23 }\end{array}$

$\begin{array}{ll}\text { Figure H22. Resonant long wave phase contours, Plan } 7 & \text { H24 }\end{array}$ 


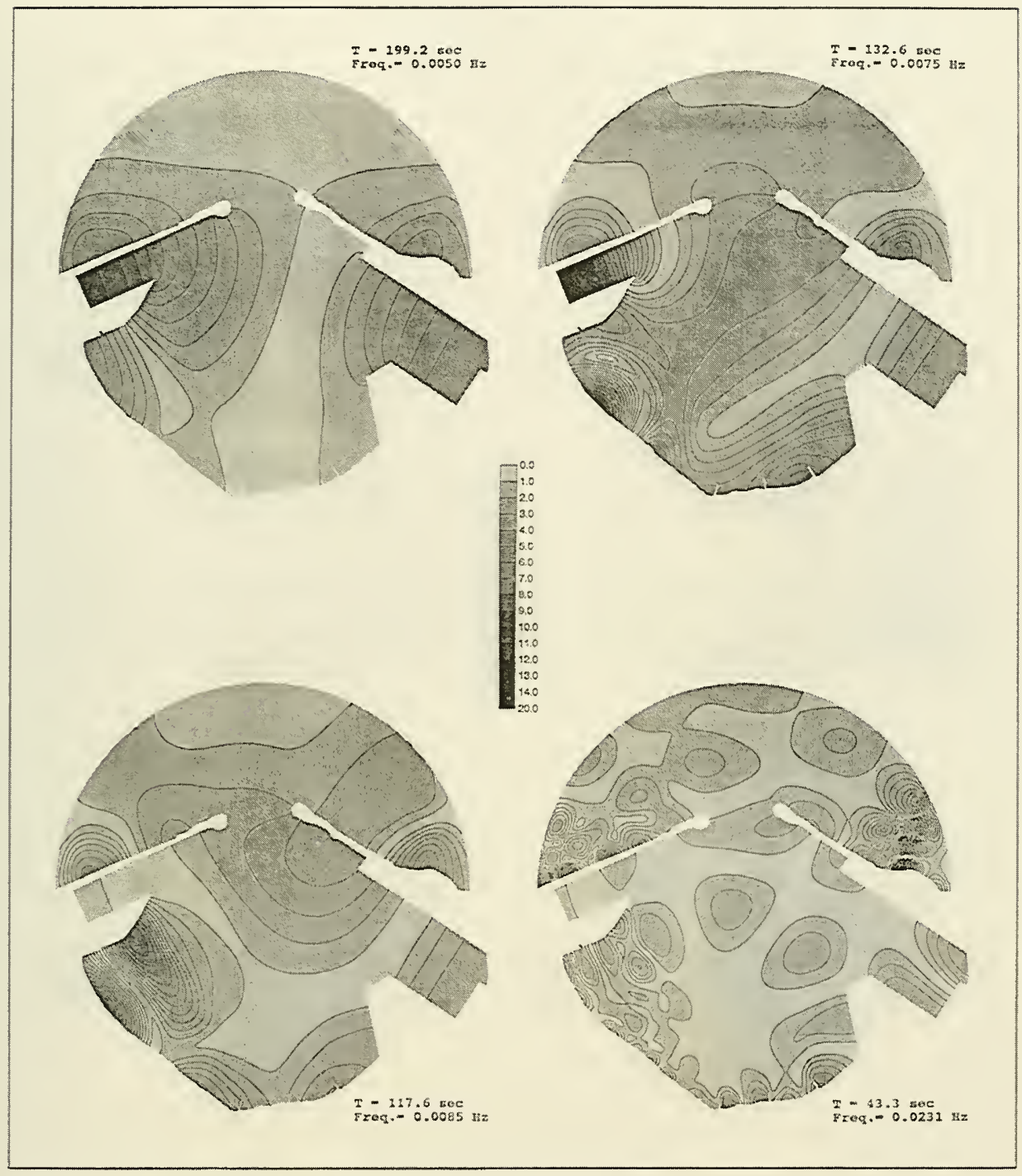

Figure H1. Resonant long wave amplification factor contours, Plan 1 


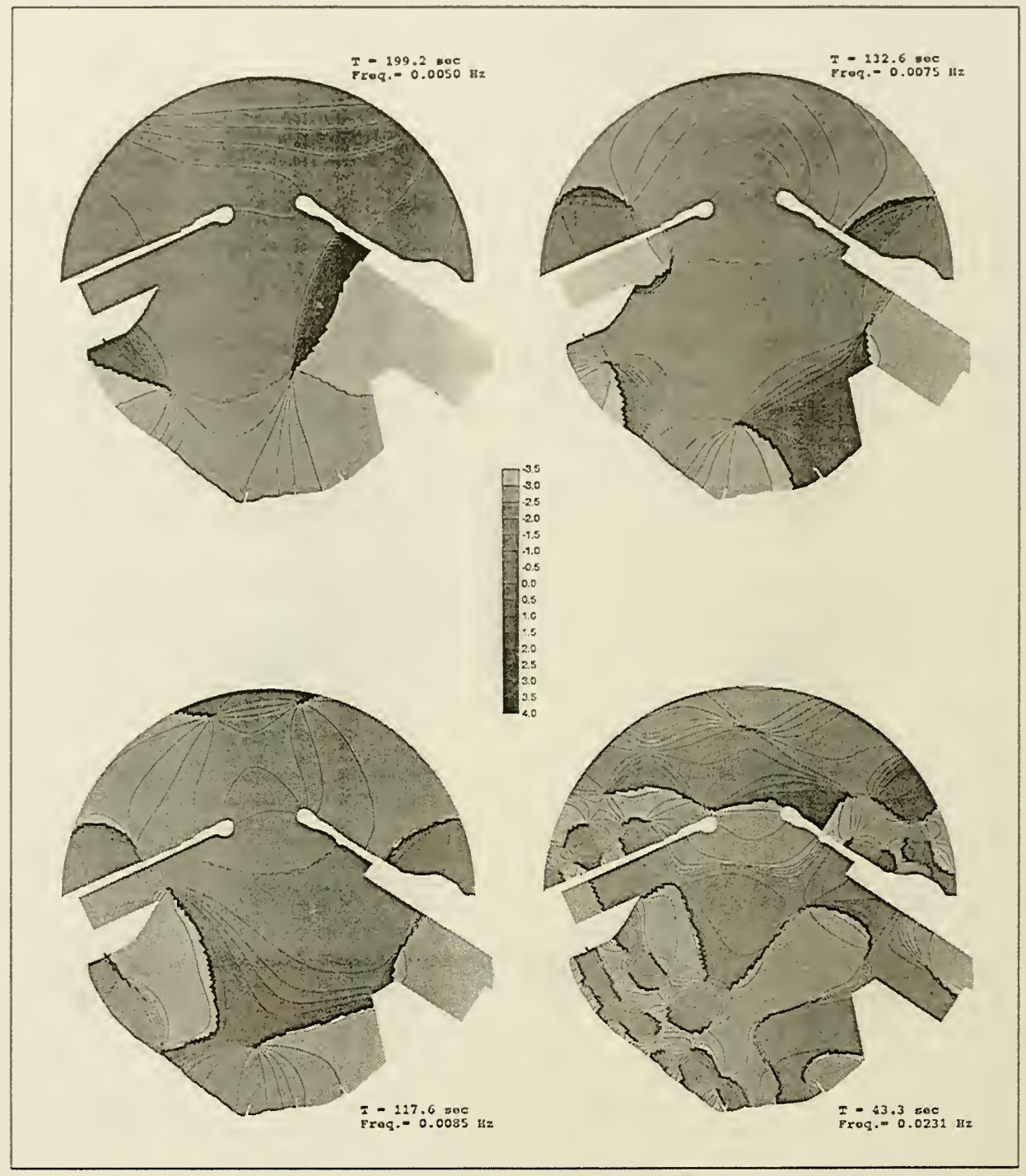

Figure H2. Resonant long wave phase contours, Plan 1 


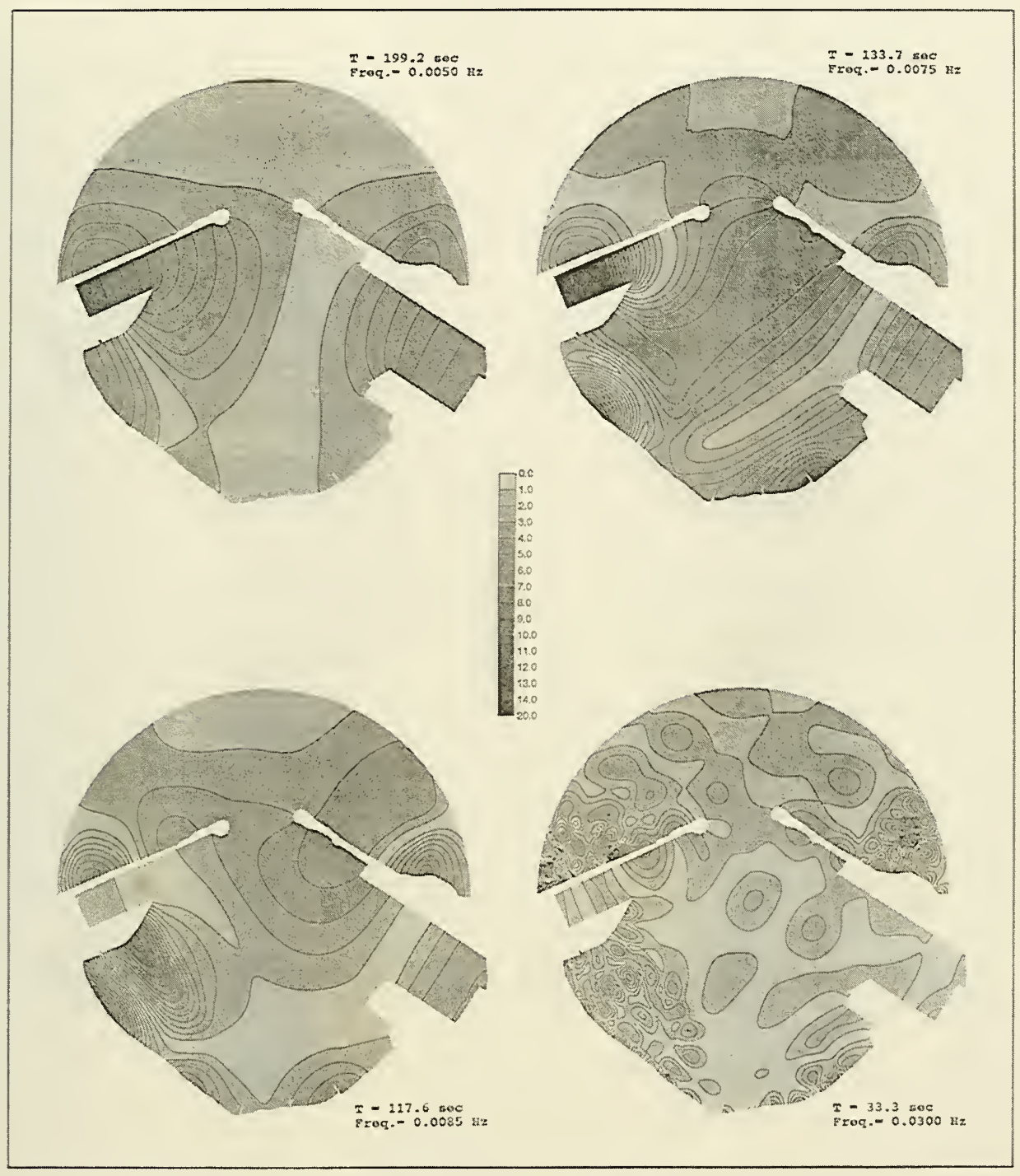

Figure H3. Resonant long wave amplification factor contours, Plan 2 


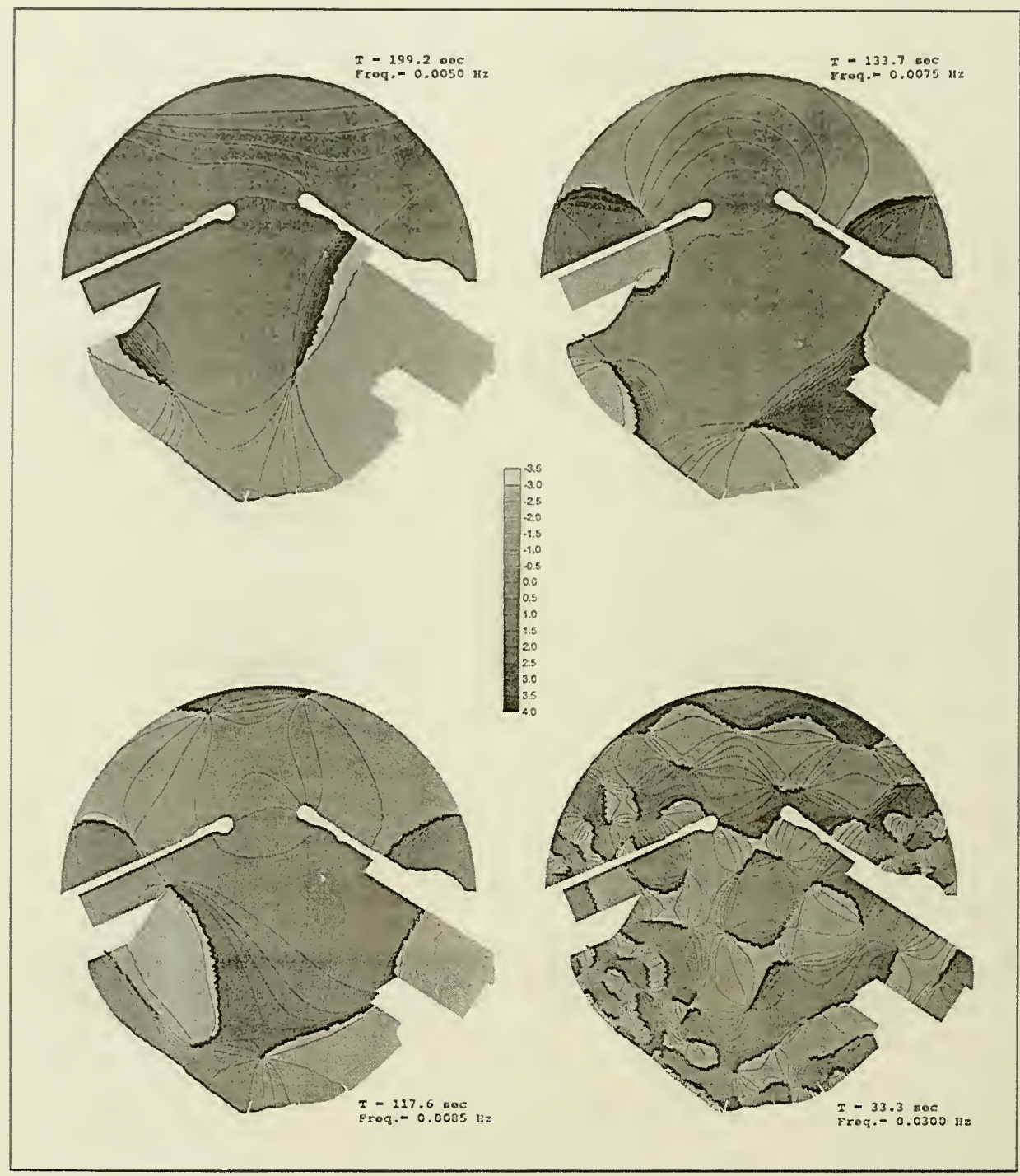

Figure H4. Resonant long wave phase contours, Plan 2 


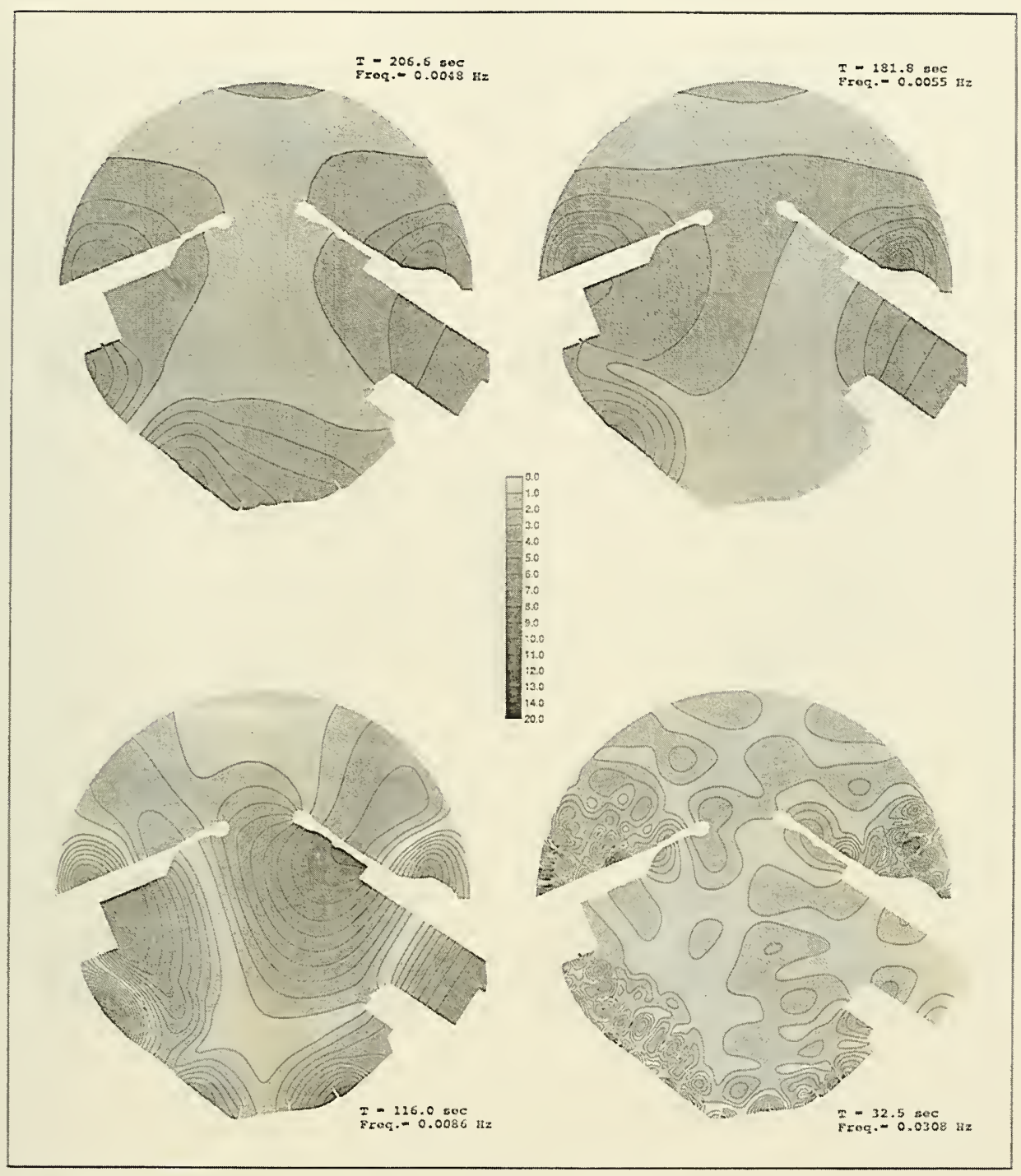

Figure H5. Resonant long wave amplification factor contours, Plan $3 a$ 


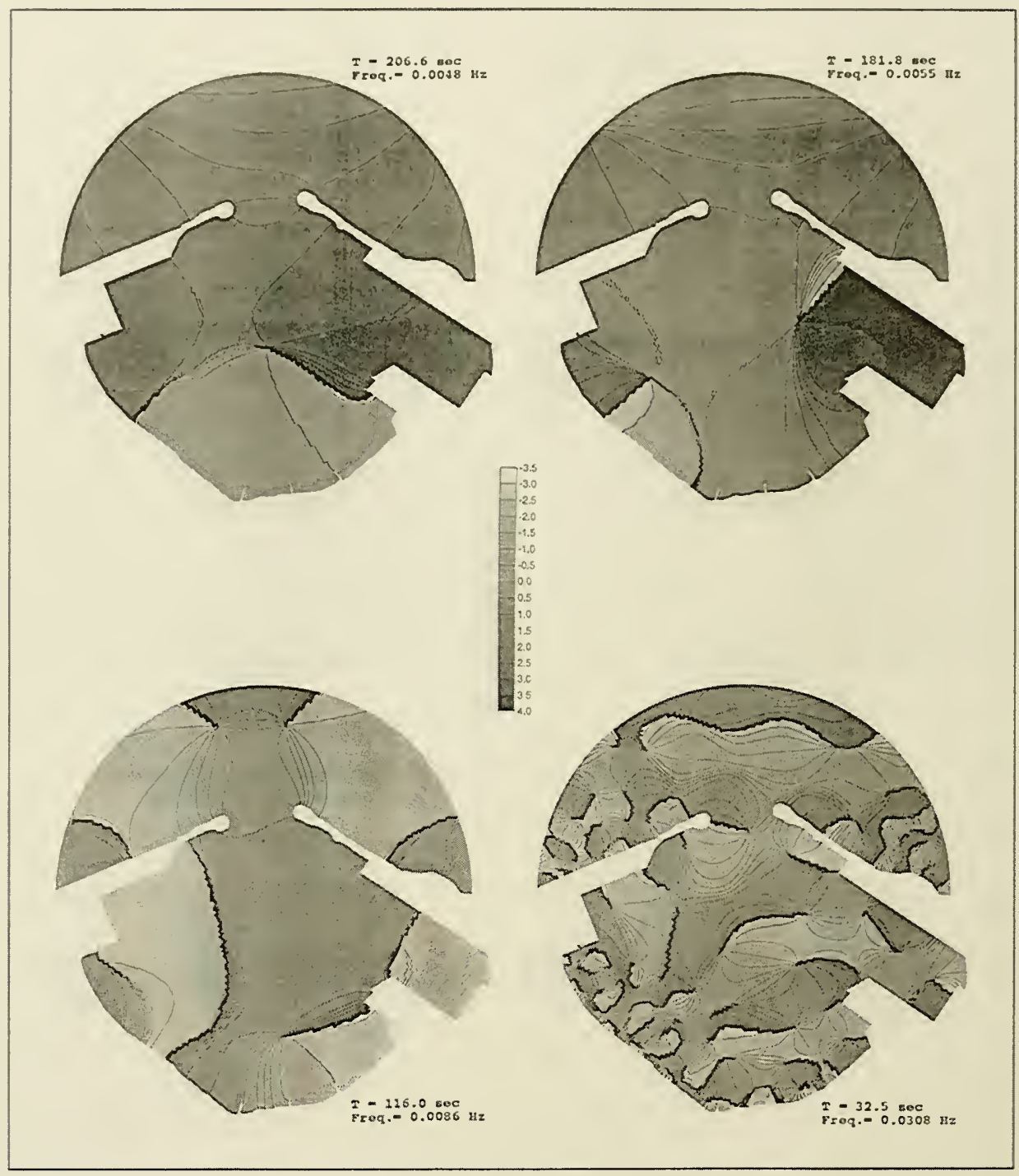

Figure H6. Resonant long wave phase contours, Plan $3 a$ 


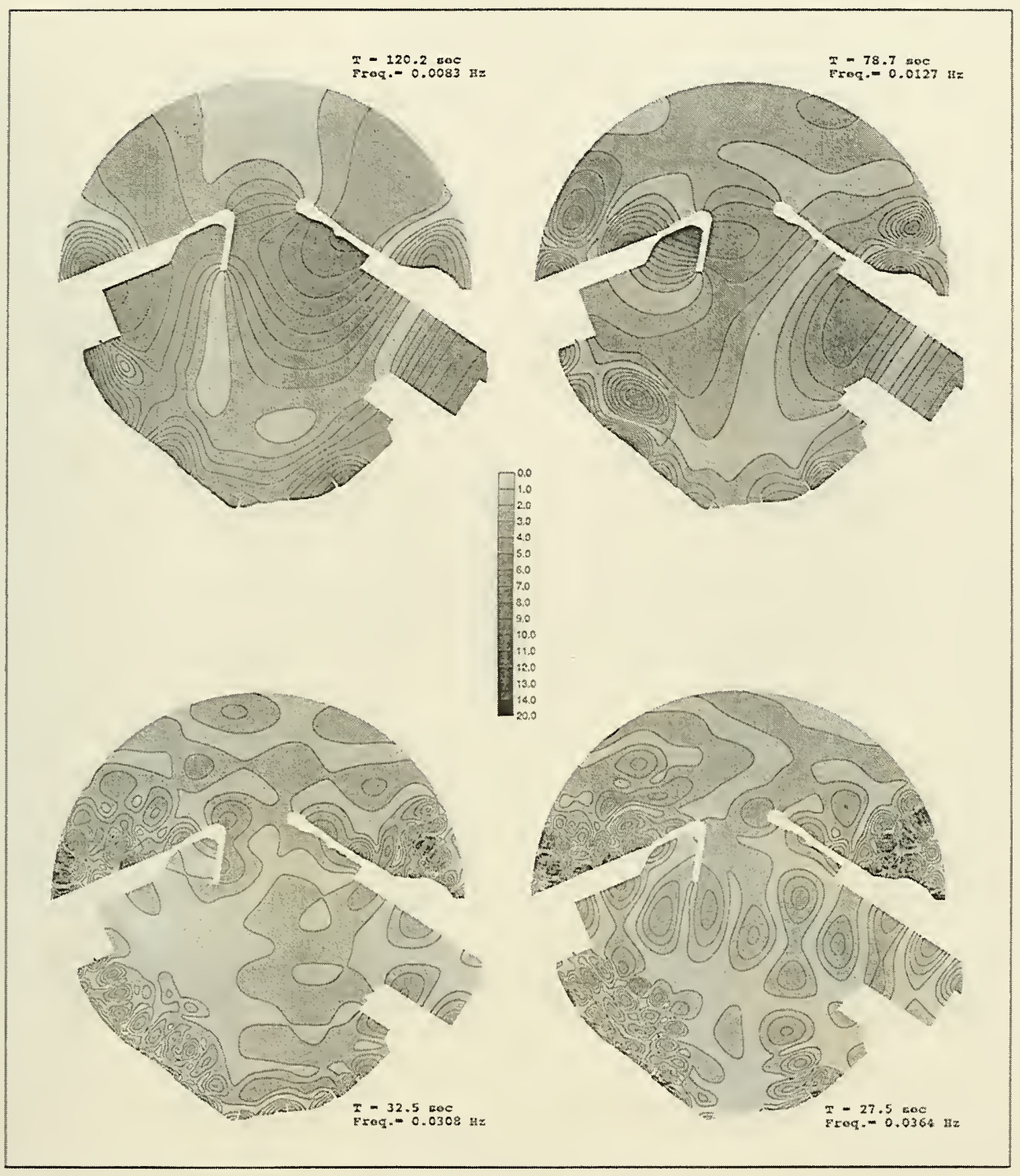

Figure H7. Resonant long wave amplification factor contours, Plan 3b 


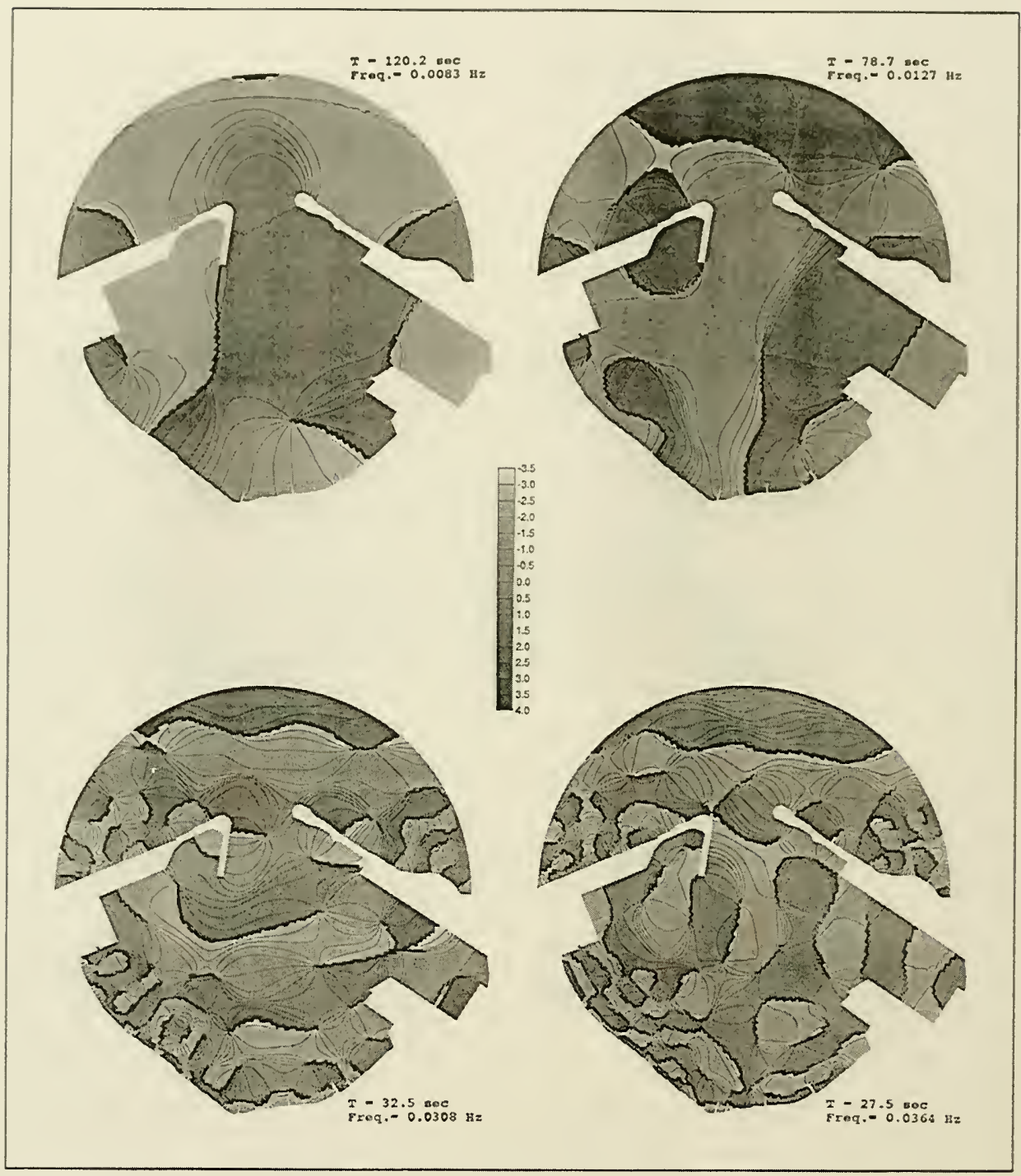

Figure H8. Resonant long wave phase contours, Plan 3b 


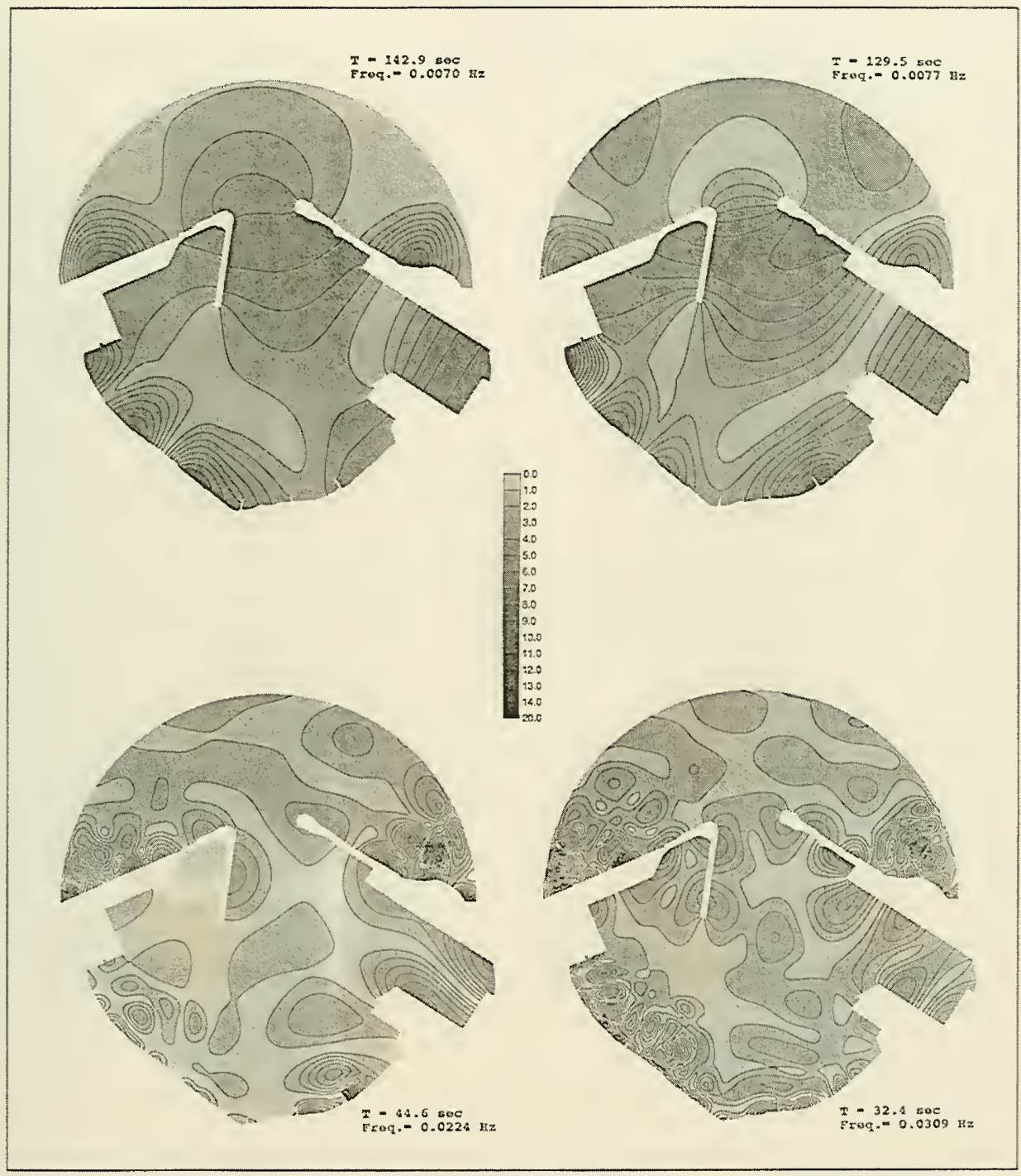

Figure H9. Resonant long wave amplification factor contours, Plan $3 c$ 


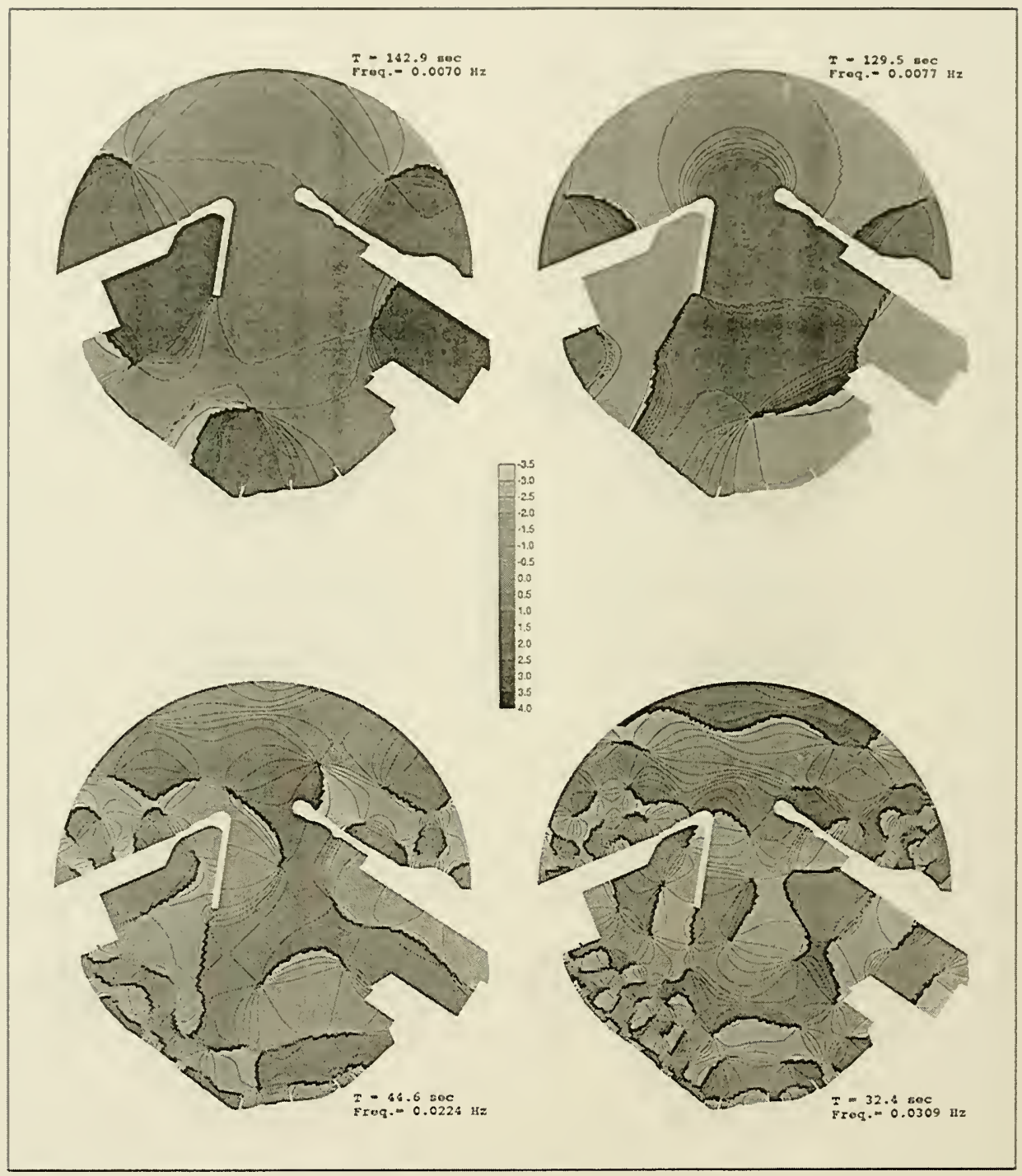

Figure H10. Resonant long wave phase contours, Plan 3c 


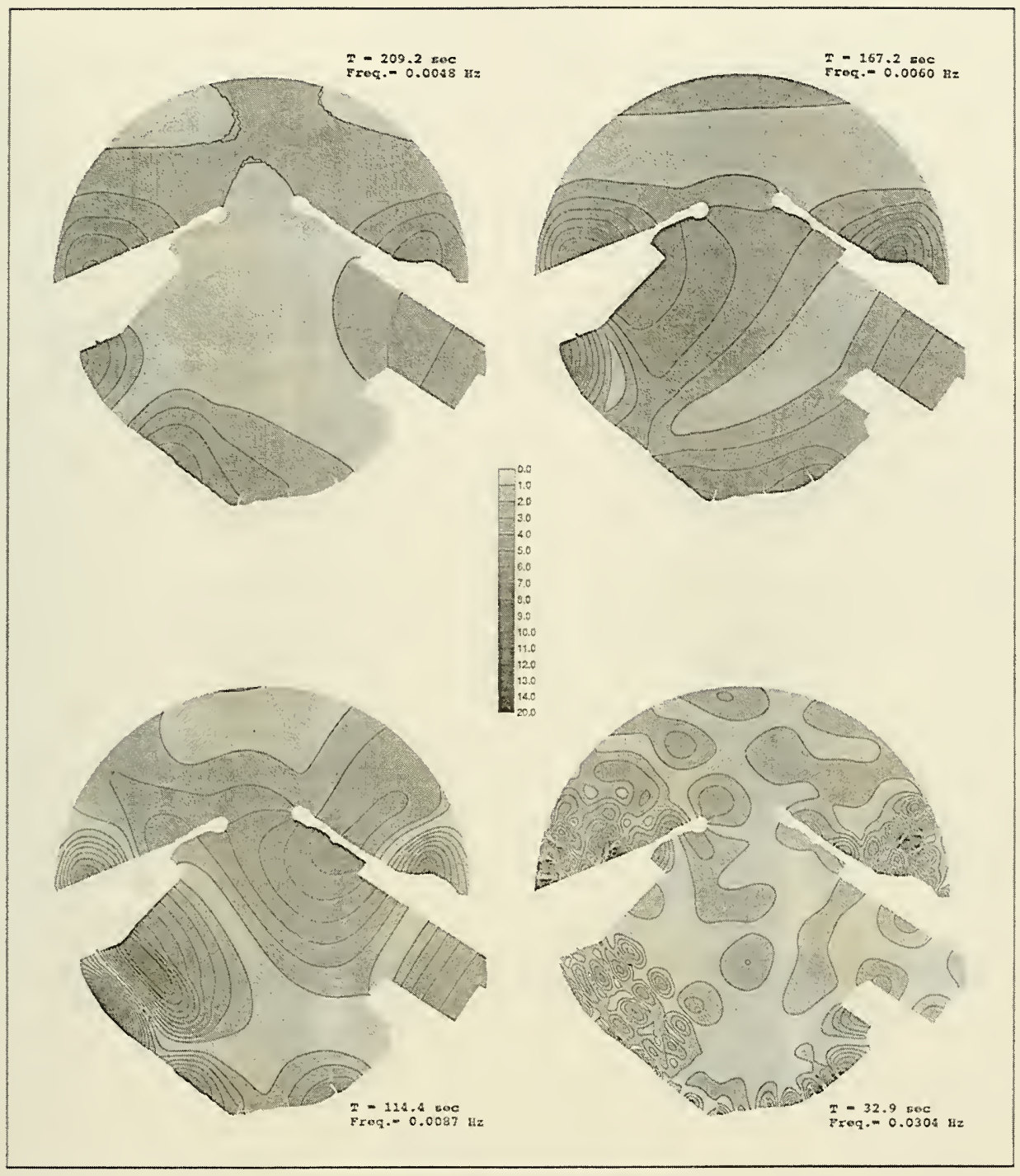

Figure H11. Resonant long wave amplification factor contours, Plan $4 a$ 


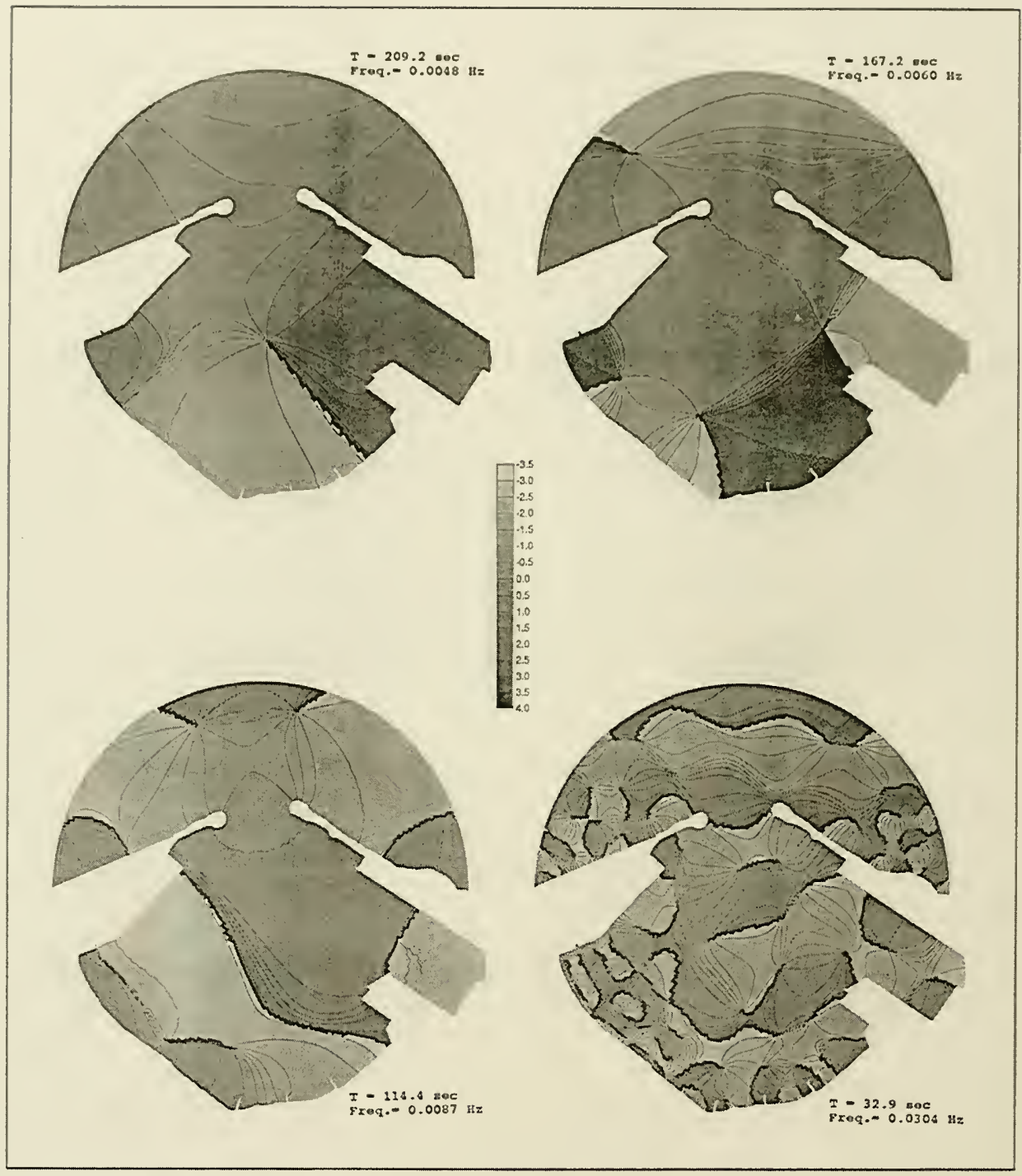

Figure H12. Resonant long wave phase contours, Plan 4a 


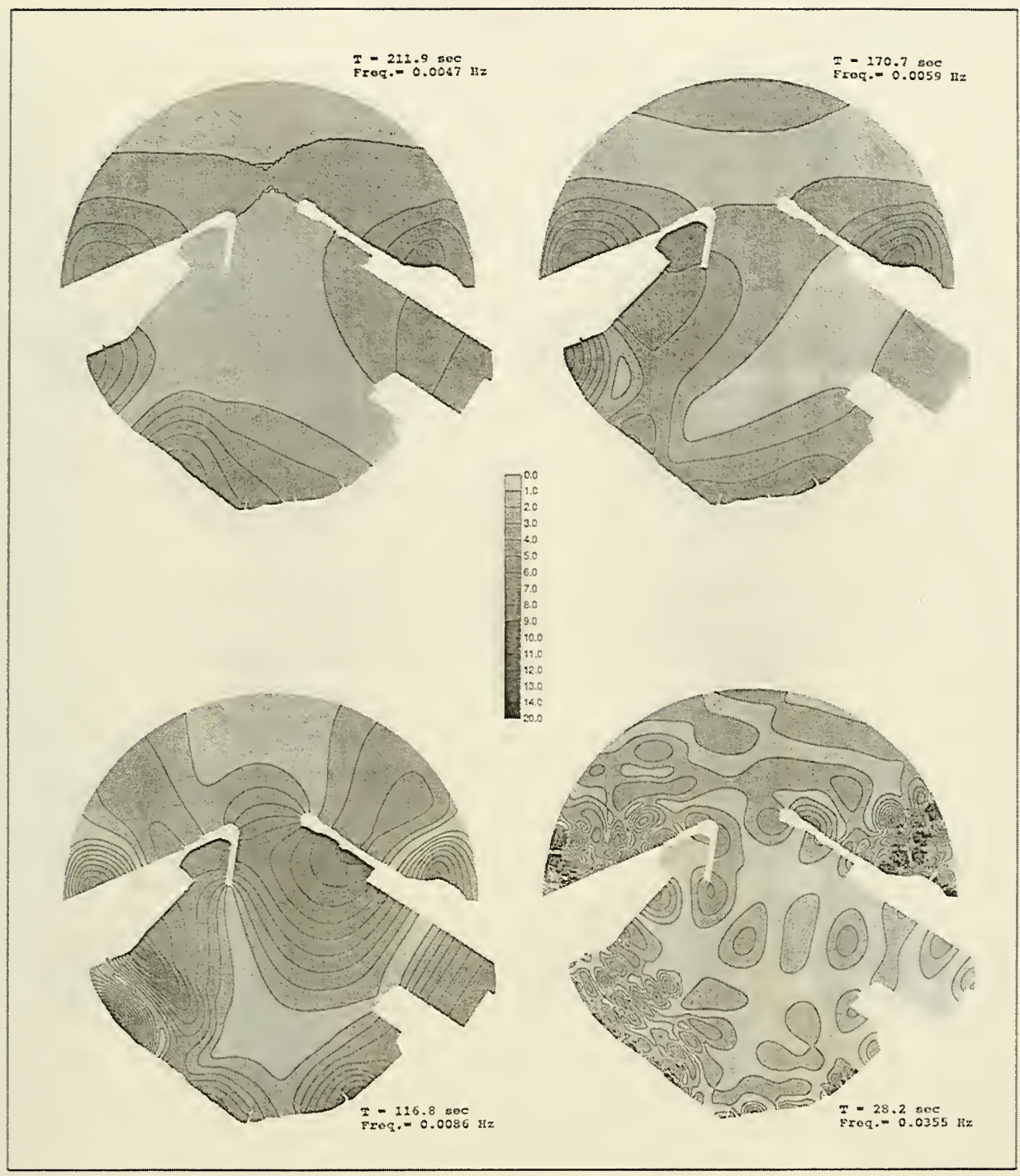

Figure H13. Resonant long wave amplification factor contours, Plan $4 b$ 


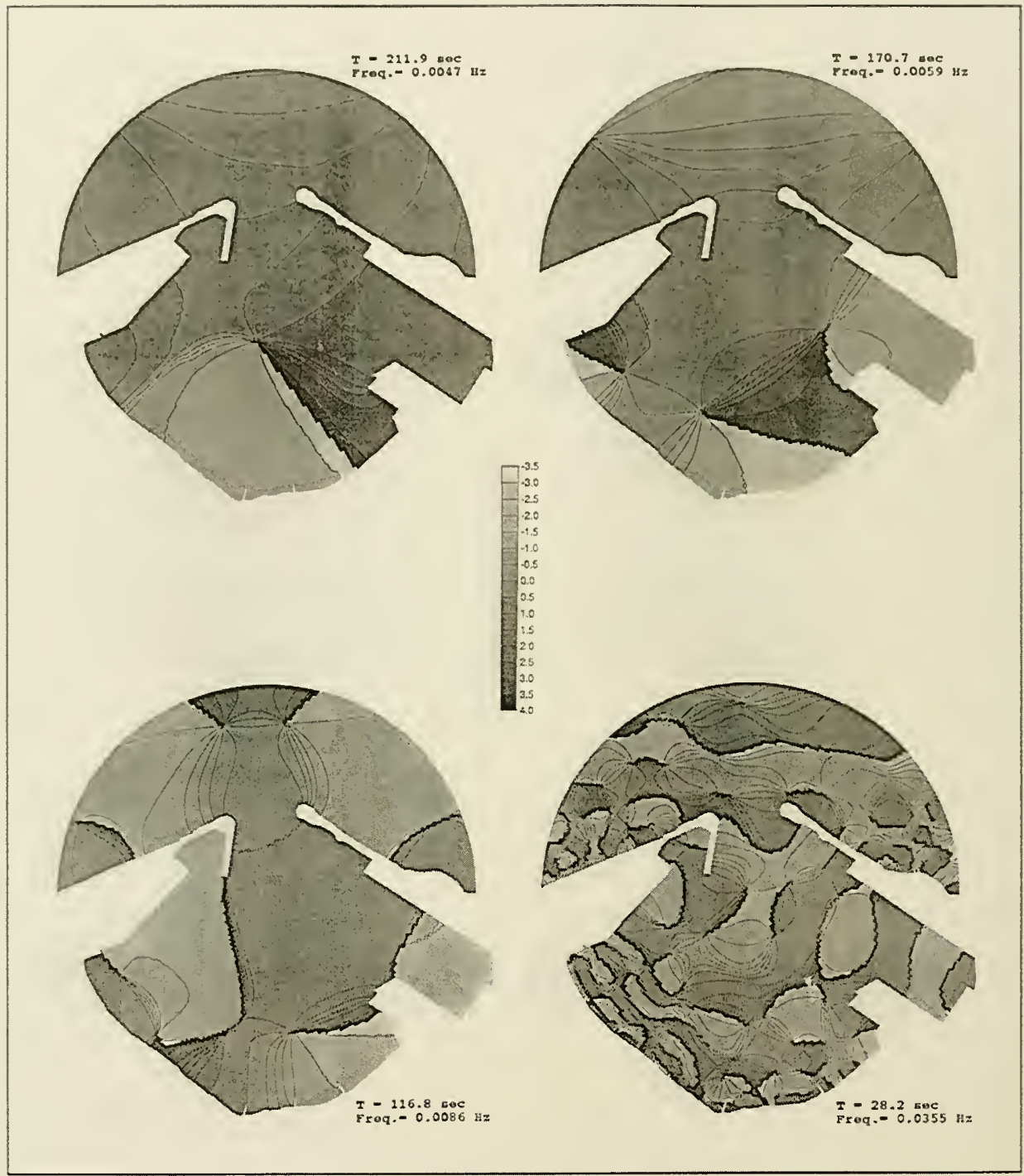

Figure H14. Resonant long wave phase contours, Plan 4b 


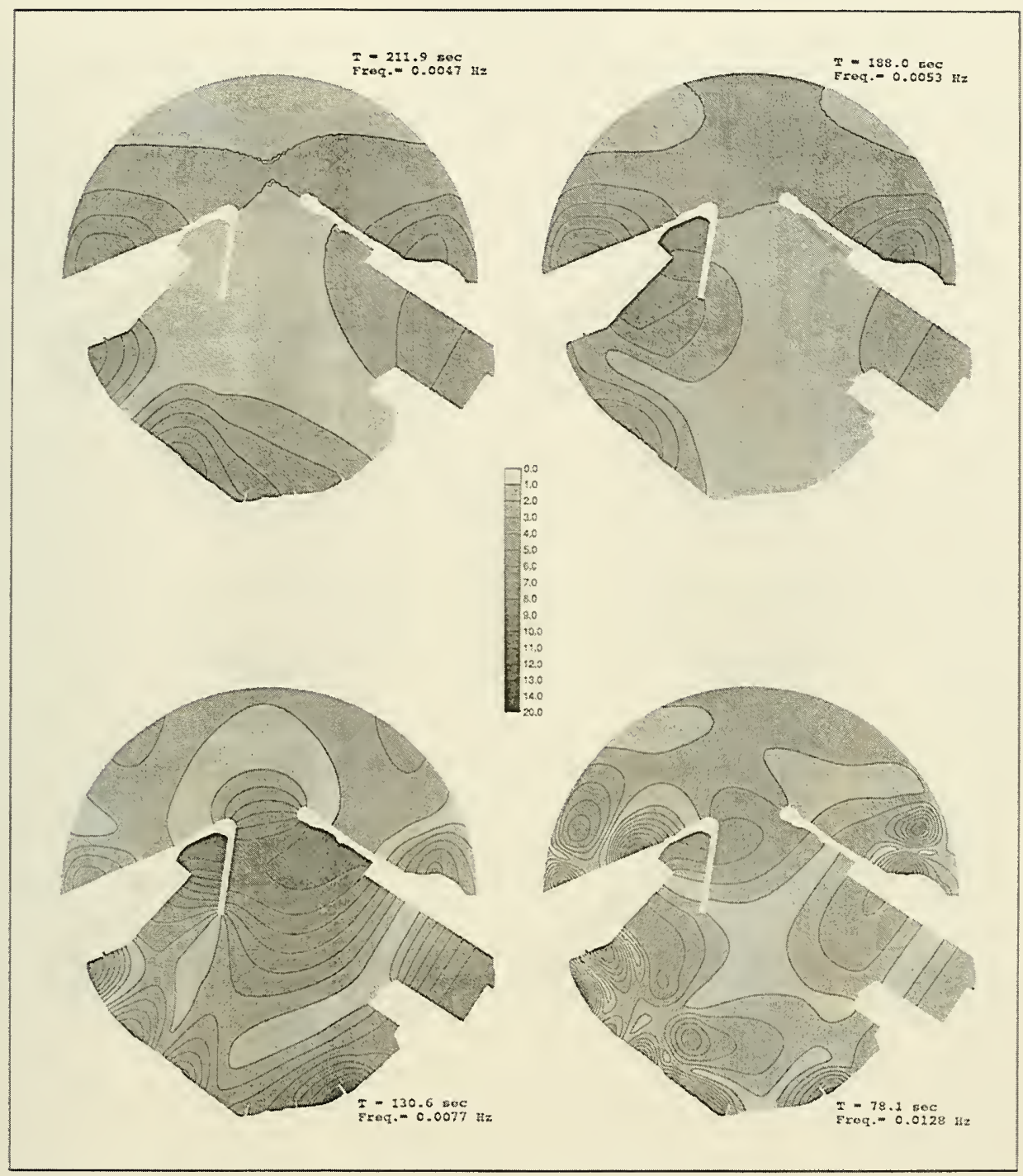

Figure H15. Resonant long wave amplification factor contours, Plan $4 \mathrm{C}$ 


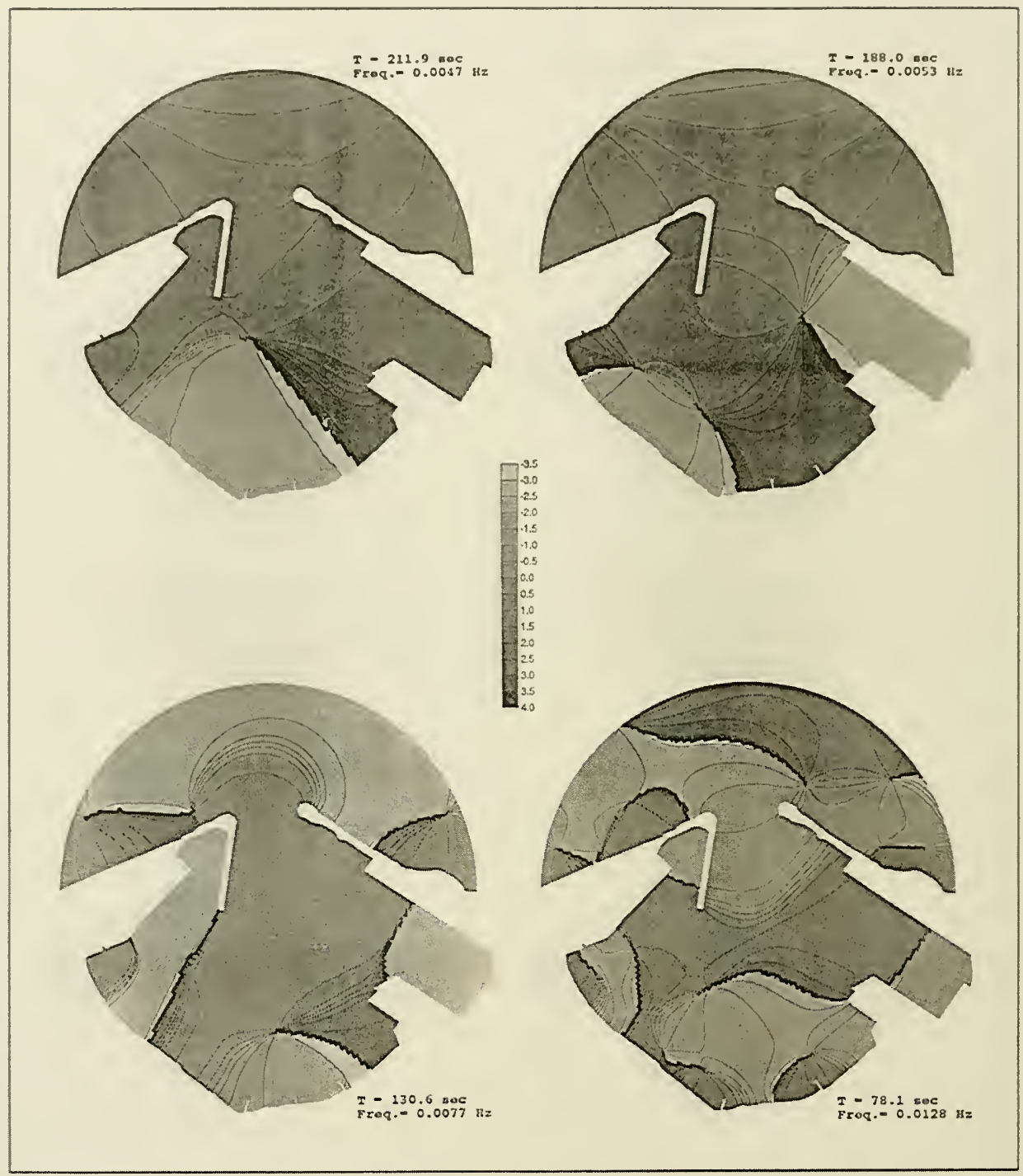

Figure H16. Resonant long wave phase contours, Plan $4 \mathrm{c}$ 


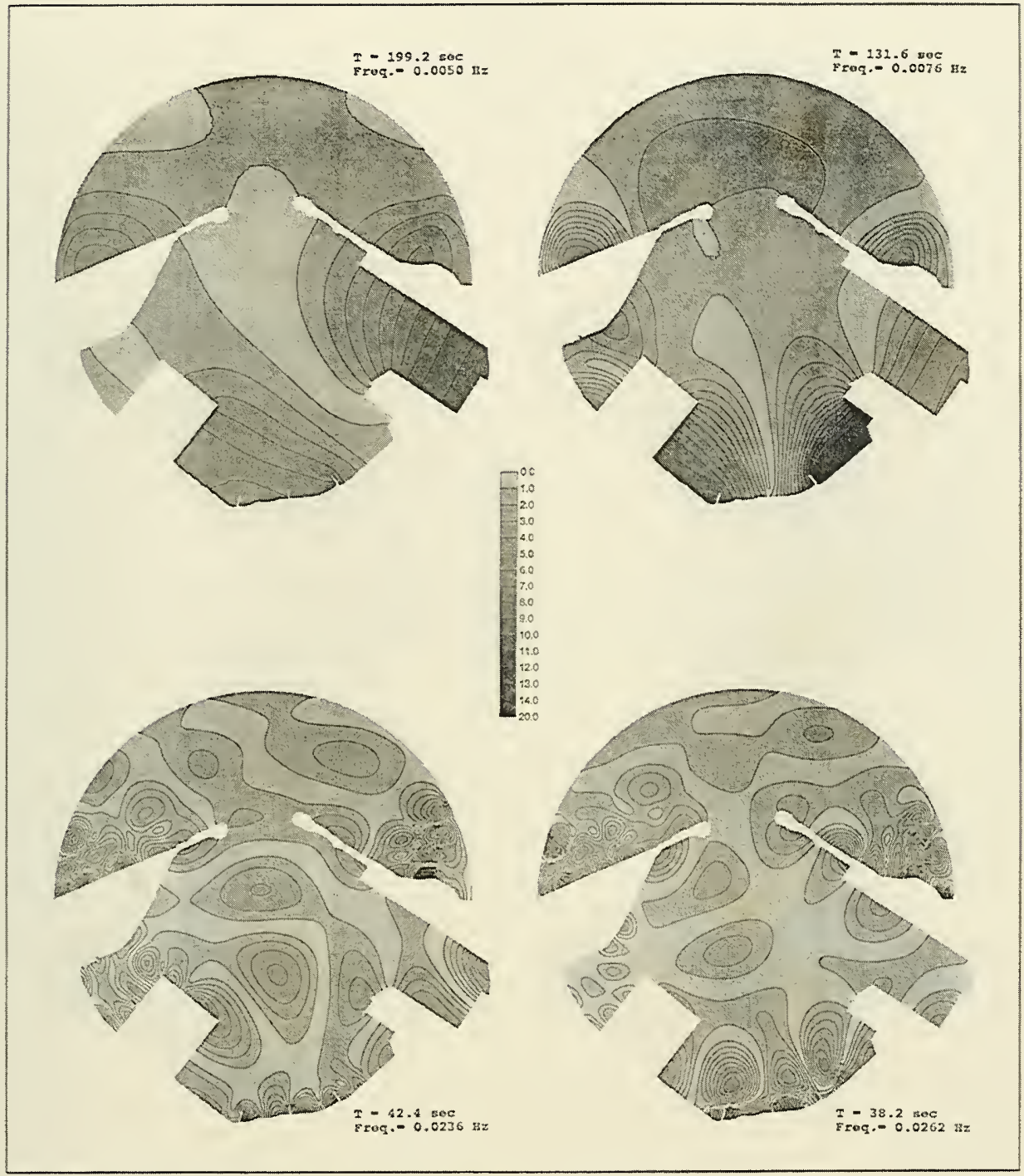

Figure H17. Resonant long wave amplification factor contours, Plan 5 


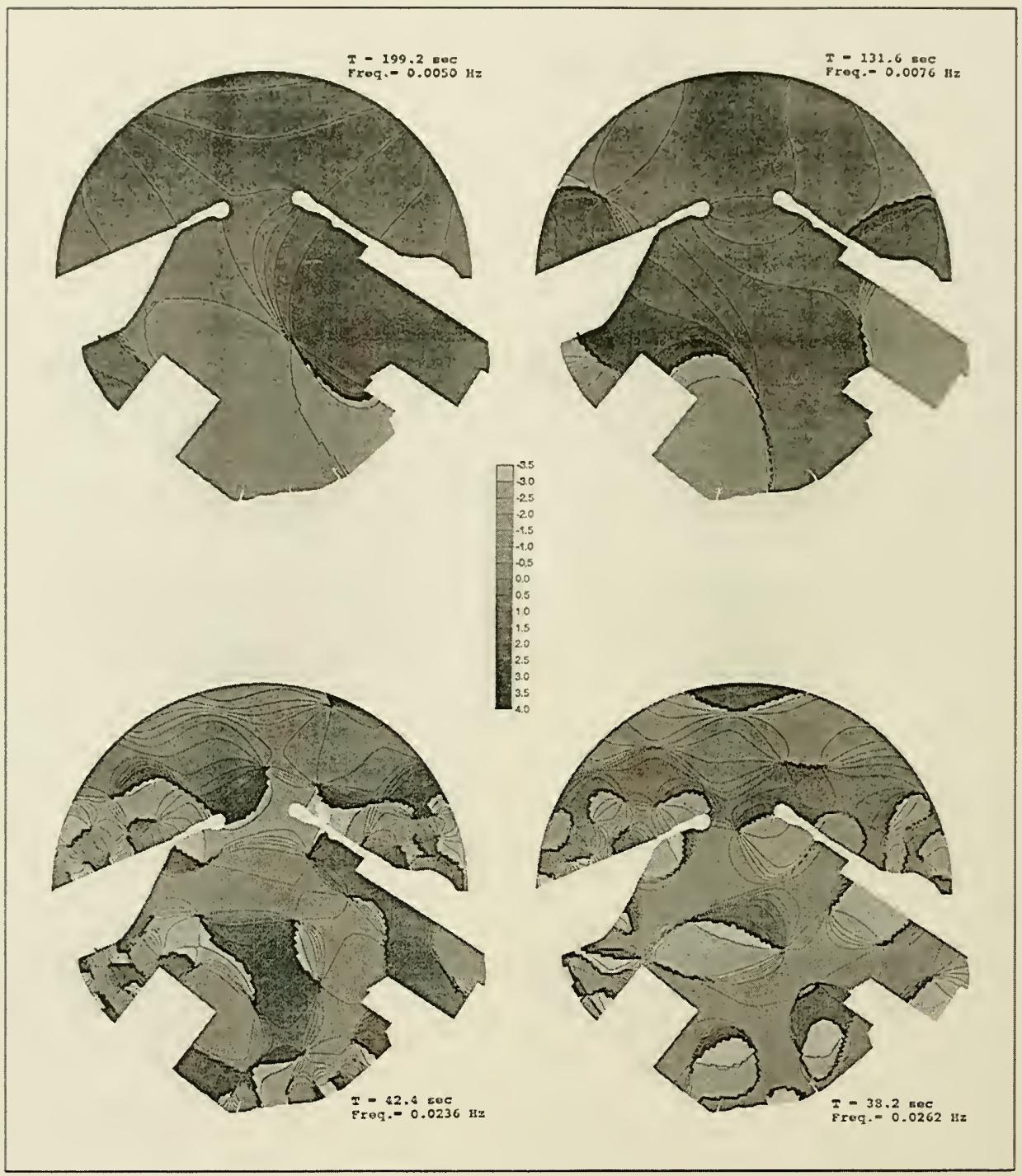

Figure H18. Resonant long wave phase contours, Plan 5 


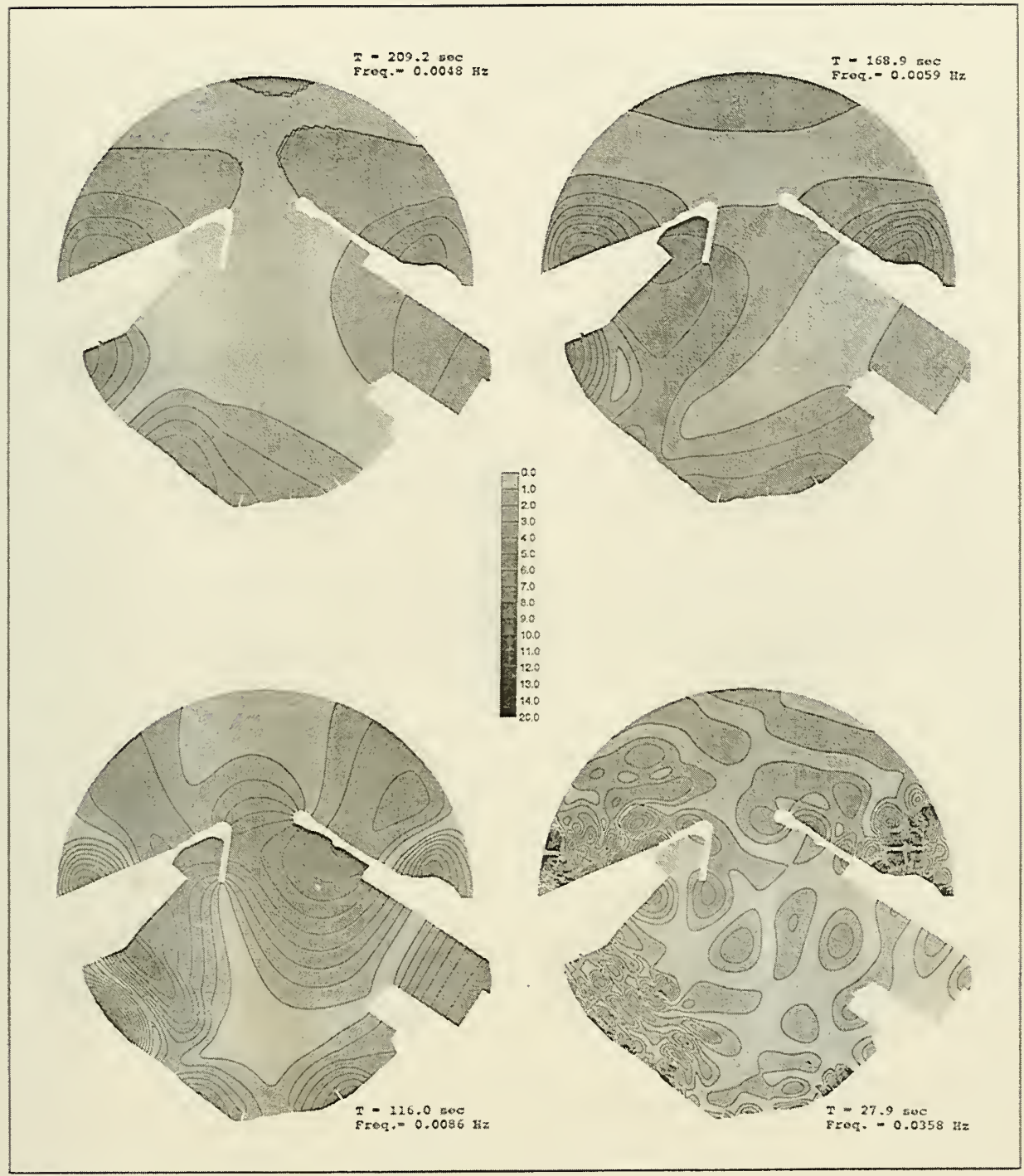

Figure H19. Resonant long wave amplification factor contours, Plan 6 


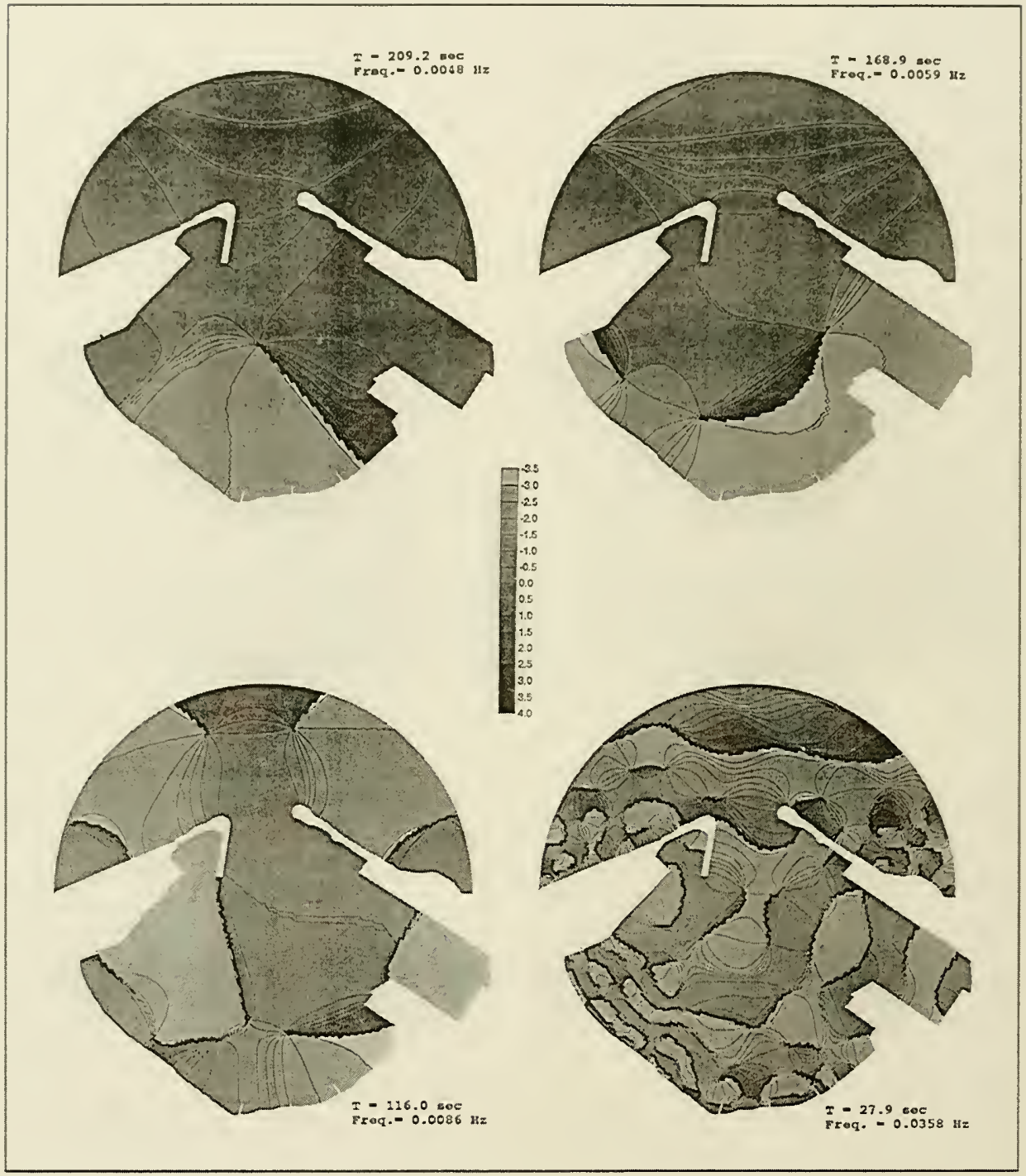

Figure H2O. Resonant long wave phase contours, Plan 6 


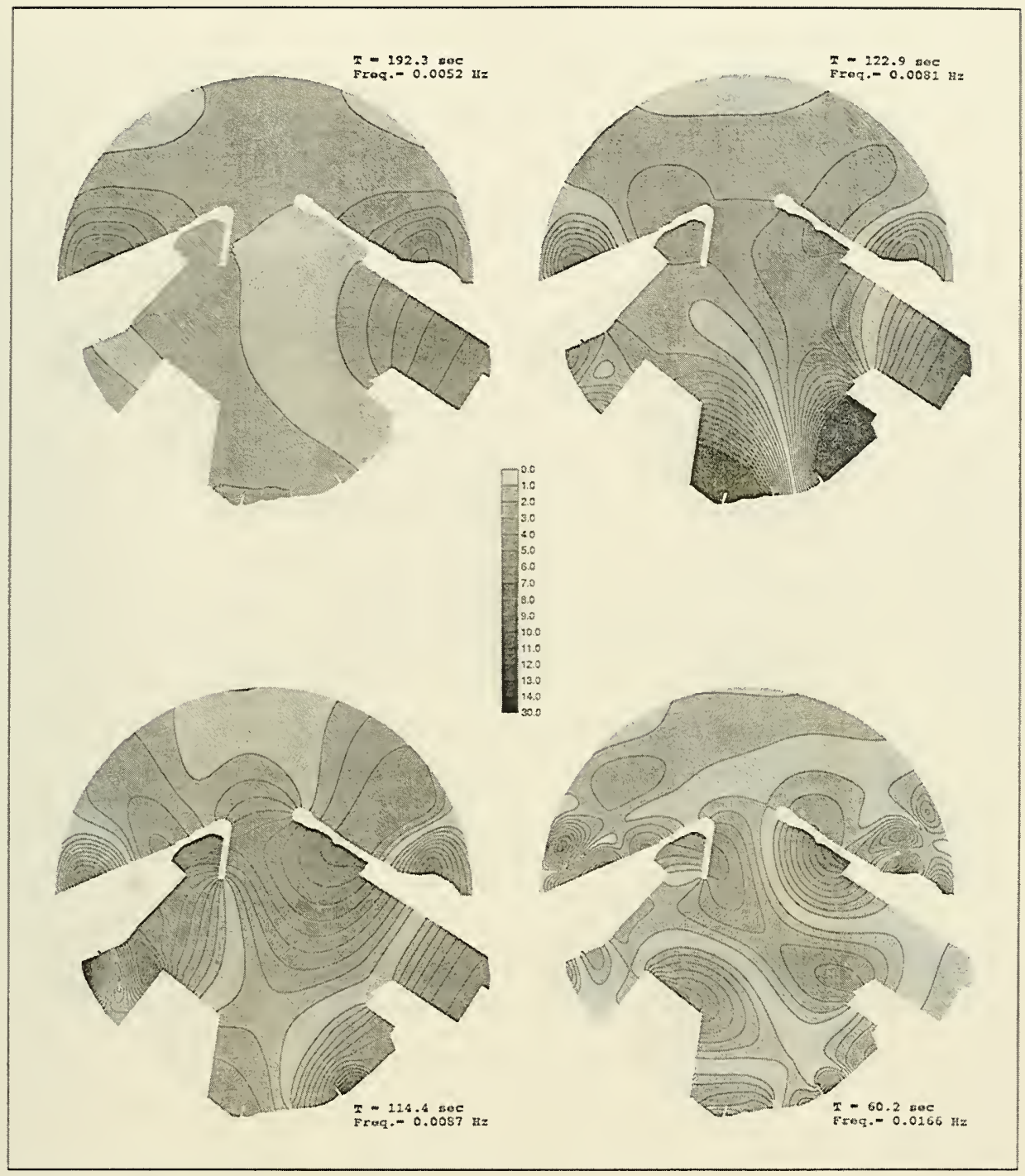

Figure H21. Resonant long wave amplification factor contours, Plan 7 


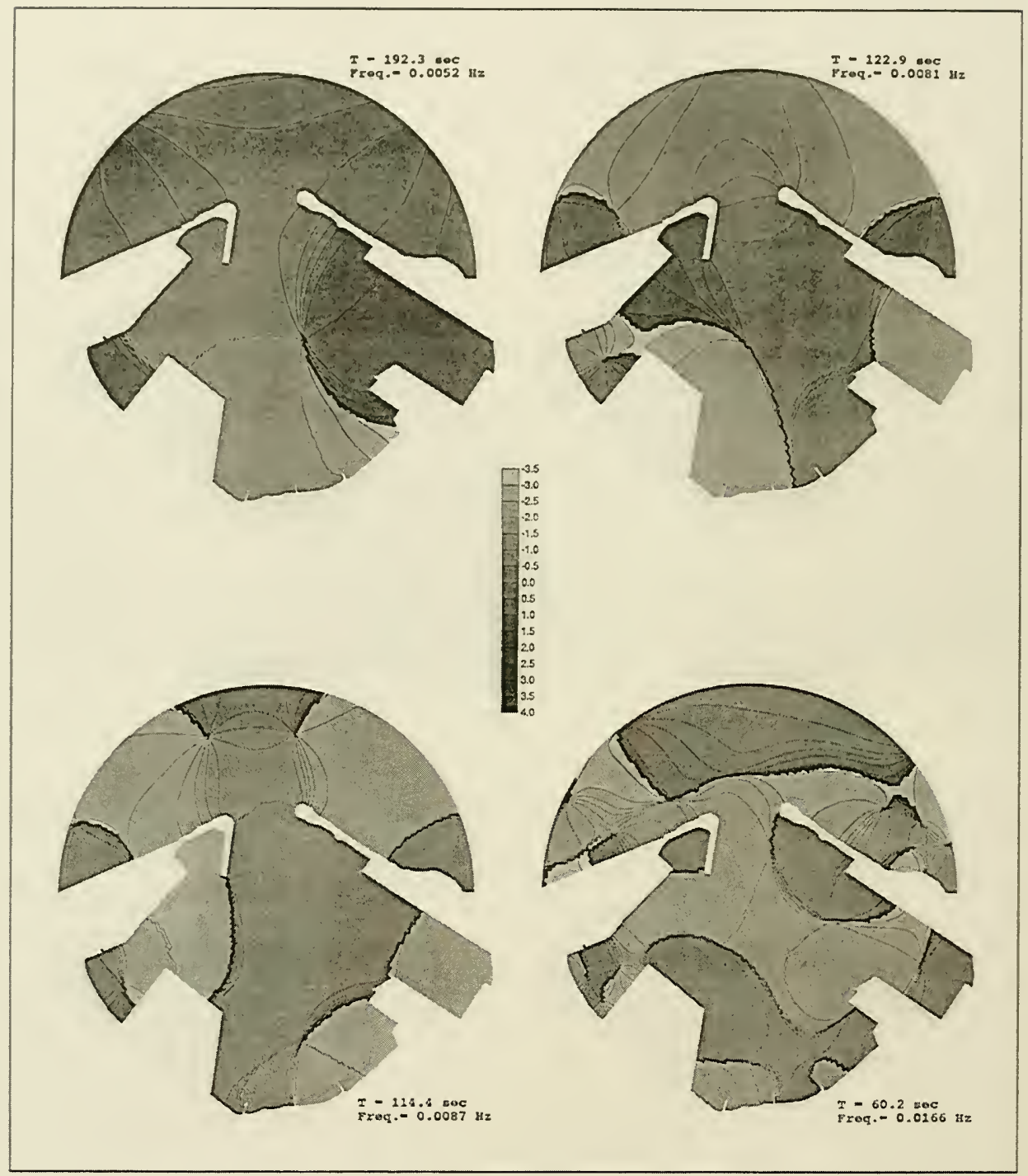

Figure H22. Resonant long wave phase contours, Plan 7 


\section{Appendix I Notation}

a Wave amplitude, $\mathrm{m}(\mathrm{ft})$

$a_{i} \quad$ Incident wave amplitude, $\mathrm{m}(\mathrm{ft})$

$A_{\text {amp }} \quad$ Wave amplification factor

$\left(A_{\text {amp }}\right)_{\text {eff }}$ Effective, or spectral, wave amplification factor

$A_{\text {amp.l }}$ Wave amplification factor for long (infragravity) waves

$A_{\text {amp,s }} \quad$ Wave amplification factor for wind waves and swell

$c \quad$ Wave phase speed, $\mathrm{m} / \mathrm{sec}(\mathrm{ft} / \mathrm{sec})$

$c_{g} \quad$ Wave group speed, $\mathrm{m} / \mathrm{sec}(\mathrm{ft} / \mathrm{sec})$

d Water depth, $\mathrm{m}(\mathrm{ft})$

$d_{\text {far }} \quad$ Water depth, m (ft)

$D(f, \theta)$ Angular spreading function dependent on wave frequency and direction

$D(\theta)$ Angular spreading function dependent only on wave direction

e Constant, 2.7183

$f, f_{i} \quad$ Wave frequency, $\sec ^{-1}$

$f_{p} \quad$ Peak spectral frequency, $\sec ^{-1}$

$g \quad$ Gravitational acceleration, $\mathrm{m} / \sec ^{2}\left(\mathrm{ft} / \mathrm{sec}^{2}\right)$

$H \quad$ Wave height, $\mathrm{m}(\mathrm{ft})$ 
$H_{i} \quad$ Incident wave height, $\mathrm{m}(\mathrm{ft})$

$H_{m 0}$ Energy-based, or zero-moment, estimate of significant wave height, $\mathrm{m}(\mathrm{ft})$

$H_{s} \quad$ Significant wave height for wind waves and swell, m (ft)

$H_{\text {s, long }}$ Significant wave height for long (infragravity) waves, m (ft)

i $\sqrt{-1}$

$K_{r} \quad$ Reflection coefficient of a solid boundary

$K_{r, \text { coest }}$ Reflection coefficient of a solid boundary

$L \quad$ Wavelength, $\mathrm{m}(\mathrm{ft})$

$L_{p} \quad$ Wavelength for waves at peak frequency, $\mathrm{m}(\mathrm{ft})$

$n \quad$ Unit normal vector directed into the solid region

$N_{D} \quad$ Number of HARBD computational wave directions for spectral approximation

$N_{p} \quad$ Number of major peaks in wind wave and swell spectrum

$N_{T} \quad$ Number of HARBD computational wave periods for spectral approximation

$r \quad$ Radial polar coordinate, $\mathrm{m}(\mathrm{ft})$

$s \quad$ Directional spreading parameter

$S(f) \quad$ Spectral energy density function dependent only on frequency

$S(f, \theta)$ Spectral energy density function dependent on frequency and direction

$S\left(f_{i}\right) \quad$ Spectral energy density at frequency, $f_{i}$

$T \quad$ Wave period, sec

$T_{p} \quad$ Peak spectral wave period for wind waves and swell, sec

$T_{p, \text { long }}$ Peak spectral wave period for long (infragravity) waves, sec

$u, v \quad$ Horizontal velocity components, $\mathrm{m} / \mathrm{sec}(\mathrm{ft} / \mathrm{sec})$

$w_{k} \quad$ Weighting factor for $k$ 'th HARBD computational frequency 
$w_{n} \quad$ Weighting factor for $n$ 'th HARBD computational direction

$x, y \quad$ Horizontal coordinates, $\mathrm{m}(\mathrm{ft})$

$\beta \quad$ Dimensionless bottom friction coefficient

$\gamma \quad$ Spectral peak enhancement factor; phase shift between stress and flow velocity

$\Delta x \quad$ Grid element dimension

$\epsilon \quad$ Significant wave steepness

$\bar{\eta} \quad$ Mean water level reading at Back Basin gage, $\mathrm{m}(\mathrm{ft})$

$\theta \quad$ Wave phase; wave direction

$\theta_{0} \quad$ Primary wave direction, deg

$\theta_{m} \quad$ Incident wave direction for wind waves and swell, deg

$\kappa \quad$ Wave number, $\mathrm{m}^{-1}\left(\mathrm{ft}^{-1}\right)$

$\lambda \quad$ Complex bottom friction factor

$\pi \quad$ Constant, 3.1416

$\phi \quad$ Velocity potential

$\phi \quad$ Velocity potential of the scattered wave

$\omega \quad$ Angular wave frequency, radians

$\nabla \quad$ Horizontal gradient operator

d Partial differentiation symbol 



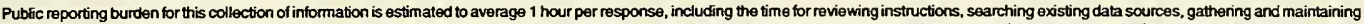

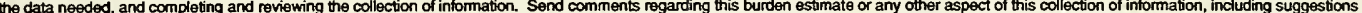

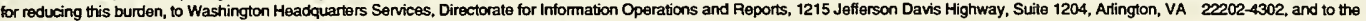
Office of Management and Budget, Paperwork Reduction Project (0704-0188), Washington, DC 20503.

\begin{tabular}{|c|c|c|}
\hline 1. AGENCY USE ONLY (Leave blank) & $\begin{array}{l}\text { 2. REPORT DATE } \\
\text { December } 1996\end{array}$ & $\begin{array}{l}\text { 3. REPORT TYPE AND DATES COVERED } \\
\text { Final report }\end{array}$ \\
\hline
\end{tabular}

4. TITLE AND SUBTTTLE

Wave Response of Kahului Harbor, Maui, Hawaii
5. FUNDING NUMBERS

8. PERFORMING ORGANIZATION REPORT NUMBER

Technical Report CERC-96-11 3909 Halls Ferry Road, Vicksburg, MS 39180-6199

10. SPONSORING/MONITORING AGENCY REPORT NUMBER

U.S. Army Engineer Division, Pacific Ocean

Building 230

Ft. Shafter, HI $96858-5440$

\section{SUPPLEMENTARY NOTES}

Available from National Technical Information Service, 5285 Port Royal Road, Springfield, VA 22161.

12a. DISTRIBUTION/AVAILABILITY STATEMENT

Approved for public release; distribution is unlimited.

12b. DISTRIBUTION CODE

13. ABSTRACT (Maximum 200 words)

Present and projected commercial activities in Kahului Harbor, Maui, Hawaii, indicate that new berths for barge and passenger ship operations will be needed. Deepening of the main harbor areas from $35 \mathrm{ft}$ to $38 \mathrm{ft}$ is also anticipated. The U.S. Army Engineer Division, Pacific Ocean, in coordination with the Harbors Division, Department of Transportation, State of Hawaii, requested field wave measurements and numerical (computer) model studies in support of long-term planning. Field measurements were collected over a period of 18 months at a deepwater directional buoy, a directional array outside the harbor, and four gages inside the harbor. The numerical model, validated with field measurements for short waves (wind waves and swell) and long waves (harbor oscillations), was used to evaluate the technical feasibility of 11 alternative modifications to the harbor. Model results were compared to experience in the existing harbor and to general criteria for operational acceptability. A physical model study is recommended as a final phase of developing harbor modification plans.

14. SUBJECT TERMS Harbor resonance Kahului Harbor Numerical modeling
Prototype wave data

Wind waves and swell
15. NUMBER OF PAGES

224

16. PRICE CODE
17. SECURITY CLASSIFICATION OF REPORT

UNCLASSIFIED
18. SECURITY CLASSIFICATION OF THIS PAGE UNCLASSIFIED
19. SECURITY CLASSIFICATION 20. LIMITATION OF ABSTRACT OF ABSTRACT 
- 
Destroy this report when no longer needed. Do not return it to the originator. 

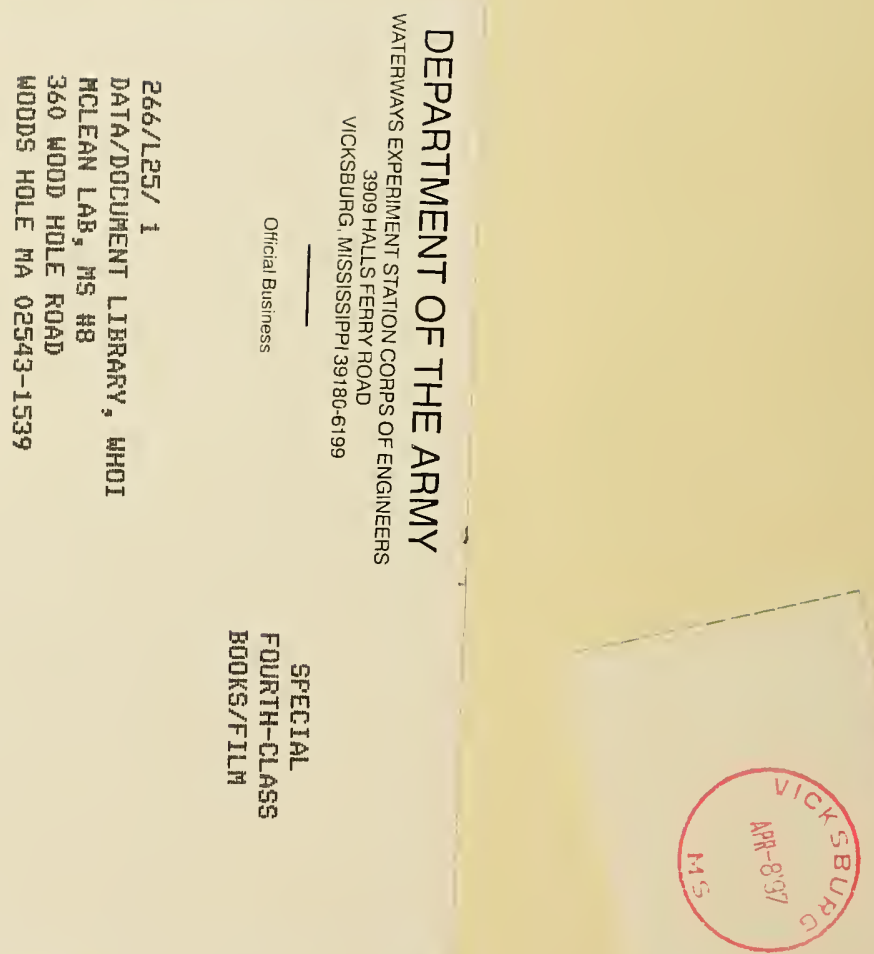